INEL/EXT-97-00123

\title{
Evaluation of Alternative Nonflame Technologies for Destruction of Hazardous Organic Waste
}

\author{
W. E. Schwinkendorf, Lockheed Martin Idaho Technologies Company \\ B. C. Musgrave, BC Musgrave, Inc. \\ R. N. Drake, Drake Engineering, Inc.
}

Published April 1997

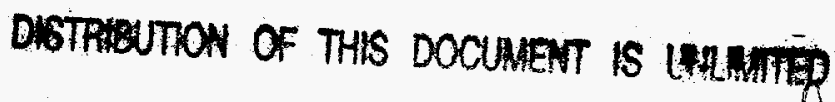

Idaho National Engineering Laboratory

Mixed Waste Focus Area

Lockheed Martin Idaho Technologies Company

Idaho Falls, Idaho 83415

Prepared for the

U.S. Department of Energy

Assistant Secretary for Environmental Management

Under DOE Idaho Operations Office

Contract DE-AC07-94ID13223 


\section{DISCLAIMER}

This report was prepared as an account of work sponsored by an agency of the United States Government. Neither the United States Government nor any agency thereof, nor any of their employees, makes any warranty, express or implied, or assumes any legal liability or responsibility for the accuracy, completeness, or usefulness of any information, apparatus, product, or process disclosed, or represents that its use would not infringe privately owned rights. Reference herein to any specific commercial product, process, or service by trade name, trademark, manufacturer, or otherwise does not necessarily constitute or imply its endorsement, recommendation, or favoring by the United States Government or any agency thereof. The views and opinions of authors expressed herein do not necessarily state or reflect those of the United States Government or any agency thereof. 


\section{DISCLAIMER}

Portions of this document may be illegible electronic image products. Images are produced from the best available original document. 


\section{ABSTRACT}

The U.S. Department of Energy's Mixed Waste Focus Area (MWFA) commissioned an evaluation of mixed waste treatment technologies that are alternatives to incineration for destruction of hazardous organic wastes. The purpose of this effort is to evaluate technologies that are alternatives to open-flame, free-oxygen combustion (as exemplified by incinerators), and recommend to the Waste Type Managers and the MWFA which technologies should be considered for further development. Alternative technologies were defined as those that have the potential to: destroy organic material without use of openflame reactions with free gas-phase oxygen as the reaction mechanism; reduce the offgas volume and associated contaminants (metals, radionuclides, and particulates) emitted under normal operating conditions; eliminate or reduce the production of dioxins and furans; and reduce the potential for excursions in the process that can lead to accidental release of harmful levels of chemical or radioactive materials. Twenty-three technologies were identified that have the potential for meeting these requirements. These technologies were rated against the categories of performance, readiness for deployment, and environment, safety, and health. The top ten technologies that resulted from this evaluation are Steam Reforming, Electron Beam, UV Photo-Oxidation, Ultrasonics, Eco Logic reduction process, Supercritical Water Oxidation, Cerium Mediated Electrochemical Oxidation, DETOXSM, Direct Chemical Oxidation (peroxydisulfate), and Neutralization/Hydrolysis. 


\section{EXECUTIVE SUMMARY}

The U.S. Department of Energy's (DOE's) Mixed Waste Focus Area (MWFA) commissioned an evaluation of mixed waste treatment technologies that are alternatives to incineration for destruction of hazardous organic wastes. The purpose of this effort is to evaluate technologies that are alternatives to open-flame, free-oxygen combustion (as exemplified by incinerators) and to recommend to the Waste Type Managers and the MWFA which technologies should be considered for further development. Alternative technologies were defined as those that have the potential to:

- Destroy organic material without use of open-flame reactions with free gas-phase oxygen as the reaction mechanism.

- Reduce the offgas volume and associated contaminants emitted under normal operating conditions per unit mass of waste fed.

- Reduce the metals, radionuclides, and particulates suspended in the offgas exiting the process.

- Eliminate, or greatly reduce, the dioxin and furan precursors in the primary treatment process, especially in the offgas streams.

- Avoid conditions which allow free chlorine production and allow dioxin and furan precursors to form and to continue to react de novo with chlorine to produce dioxins and furans.

- Reduce the potential for excursions in the process that can lead to accidental release of harmful levels of chemical or radioactive materials, and minimize the volume of gaseous emissions that are subject to release during excursions or accident conditions.

Twenty-three technologies were identified that have the potential for meeting these requirements. These technologies were rated against the categories of performance, readiness for deployment, and environment, safety, and health (ES\&H). These categories and their subcriteria were assigned weighting factors based on their importance, and the evaluation was performed using the Analytical Hierarchy Process to provide a numerical ranking or prioritization of the technologies. Performance was the major consideration in evaluating these technologies, because if a technology cannot perform well by destroying a variety of contaminants on various DOE waste matrices, then its readiness for deployment or safety is not relevant. If a technology performs well, its readiness and safety can be improved through engineering design and development. It is understood that before any process or system is implemented and operated, it will be designed and operational procedures developed to meet all ES\&H requirements. Thus, these technologies were evaluated on the difficulty in engineering or operating a system to meet these requirements. 
The top ten technologies that resulted from this evaluation are as follows:

$\begin{array}{ll}\text { 1. } & \text { Steam Reforming } \\ \text { 2. } & \text { Electron Beam } \\ \text { 3. } & \text { UV Photo-Oxidation } \\ \text { 4. Ultrasonics } \\ \text { 5. Eco Logic } \\ \text { 6. Supercritical Water Oxidation } \\ \text { 7. Cerium Mediated Electrochemical Oxidation (MEO) } \\ \text { 8. DETOXSM } \\ \text { 9. Direct Chemical Oxidation (peroxydisulfate) } \\ \text { 10. Neutralization/Hydrolysis. }\end{array}$

Several of these technologies are applicable only to aqueous waste, which is only $3.2 \%$ of the organically contaminated MLLW, and therefore have little application to the overall mixed waste problem. Aqueous waste treatment was not considered a deficiency by the Mixed Waste Focus Area, and commercial technologies are available for treatment of aqueous waste (e.g., UV photo-oxidation, activated carbon adsorption, air and steam stripping). Thus, no new development efforts are required for this waste stream.

The primary recommendation of this study is to continue to improve upon incinerator and/or other thermal systems including air pollution control systems and continuous air emission monitors. It should be noted that none of the evaluated alternative technologies alone has the capability of thermal systems to treat the large variety of MLLW in the DOE complex in a single process, and all will have particular difficulty in treating organically contaminated inorganic matrices such as soils, inorganic sludges and debris. However, the alternatives evaluated in this study may have niche applications to waste streams for which incinerators are inappropriate either due to the physical or chemical characteristics of the waste stream, tribal or stakeholder opposition, or economic considerations. Thus, the authors recommend continued research and development on alternative systems to improve effectiveness, flexibility and operability.

Regarding the decision to continue development of alternative technologies, the authors recommend developing steam reforming, DETOXSM, and/or direct chemical oxidation (DCO). These technologies are more aggressive and have the potential of treating a larger number of waste streams to the regulatory requirements than the other technologies evaluated. Because steam reforming is applicable to combustible waste and has the potential to treat organically contaminated inorganic waste matrices, this technology is recommended for further development. Aggressive, nonthermal condensed phase processes such as DETOXSM and direct chemical oxidation should be funded to determine their performance, operational issues that require resolution, and their applicability to organic and inorganic waste streams. These are low-temperature processes with low offgas and little or no volatilization of metals or radionuclides. Such technologies may be applicable to small quantities of special wastes or "problem" wastes that require treatment prior to disposal. After further testing, the "best" technology for DOE mixed wastes should be further developed. It is also recommended that, as these technologies are developed, the ancillary operations required for the technology to function properly be identified so that the technology can be developed as part of a total system leading to a conceptual system design. 


\section{ACKNOWLEDGMENTS}

This evaluation was commissioned by the U.S. Department of Energy's Mixed Waste Focus Area and the Waste Type Managers. The authors would like to acknowledge the support and direction provided by Dirk Gombert of the Mixed Waste Focus Area at the Idaho National Engineering and Environmental Laboratory, and the assistance of Lee Borduin of Los Alamos National Laboratory and John Vavruska of Equinox, Inc. in identifying conditions required for dioxin and furan production and defining the characteristics required of alternative technologies. We would also like to acknowledge the review and comments on the dioxin/furan discussion by Larry Waterland of Acurex Environmental Corporation. 


\section{CONTENTS}

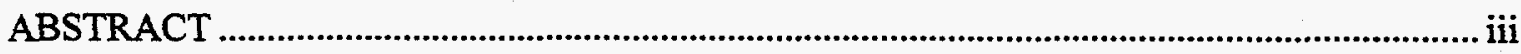

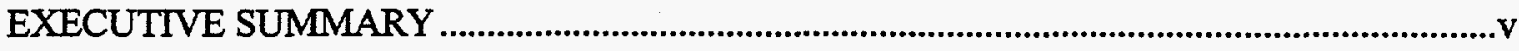

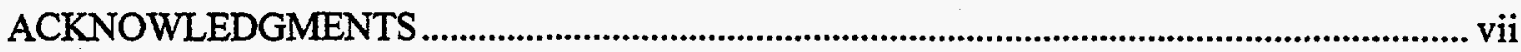

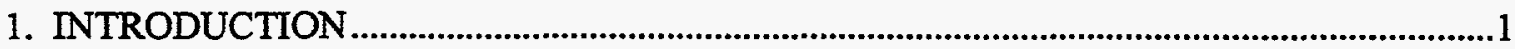

2. BACKGROUND

2.1 Public Perceptions and Basis for Concerns with Thermal Destruction Processes ..........2

2.2 Formation Conditions for Dibenzo Dioxins and Dibenzo Furans ..................................3

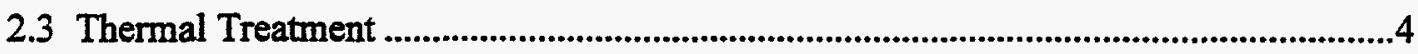

3. DEFINITION OF ALTERNATIVE ORGANIC DESTRUCTION TECHNOLOGIES..............5

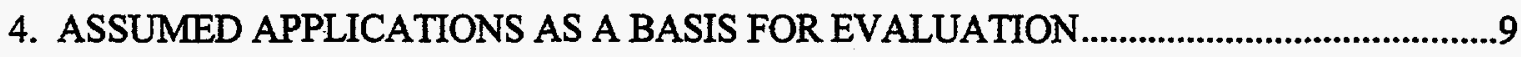

4.1 Waste Matrix Categories for DOE Mixed Low Level Wastes .........................................9

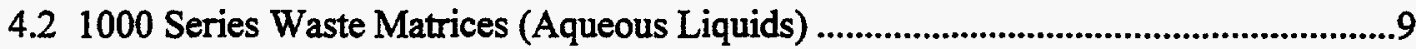

4.3 2000 Series Waste Matrices (Organic Liquids)...........................................................11

4.43000 Series Waste Matrices (Homogeneous Solids)...................................................11

4.54000 Series Waste Matrices (Soils) .............................................................................11

4.6 5000 Series Waste Matrices (Debris) …...................................................................11

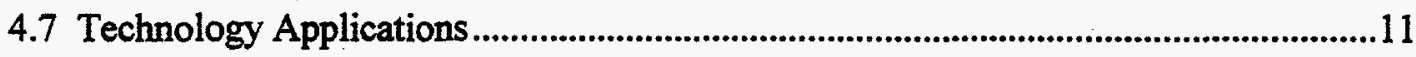

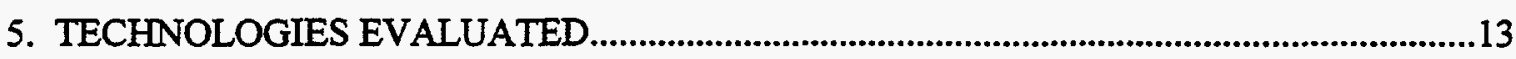

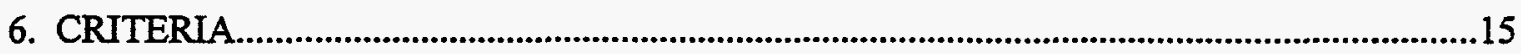

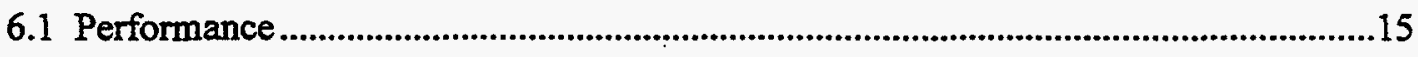

6.2 Readiness For Deployment ..........................................................................................19

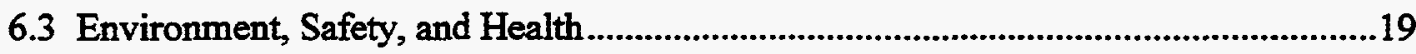

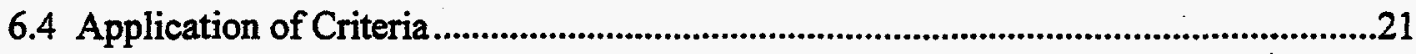

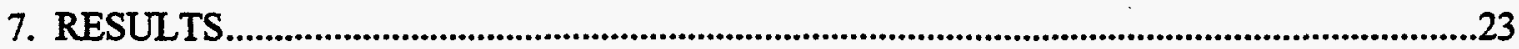

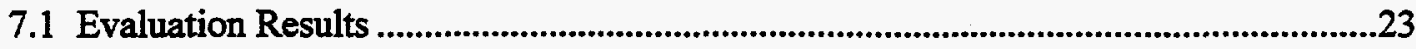

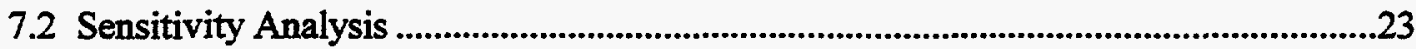

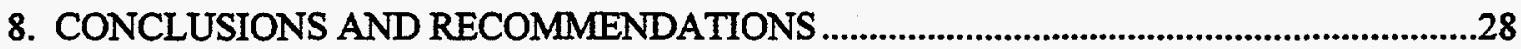

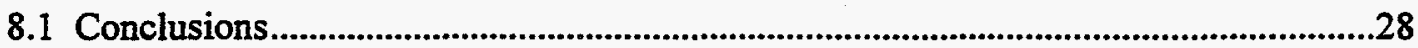

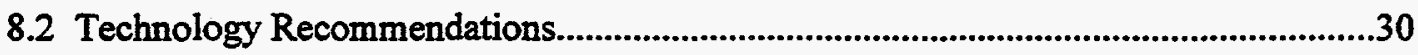

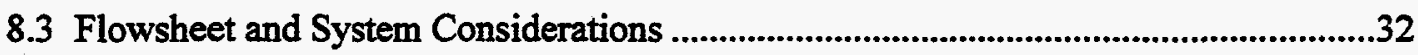

8.4 Development Issues for the Higher Ranked Technologies.........................................33 
8.5 General Recommendations for Testing and Development

Appendix A-Technology Descriptions

Appendix B-Formation of Dioxins and Furans in Waste Treatment Systems

Appendix C-Definitions of Thermal and Nonthermal Systems

\section{FIGURES}

1. Generalized waste treatment flowsheet.

\section{TABLES}

1. Distribution of current and 5-year projected mixed low-level waste streams. ..........................10

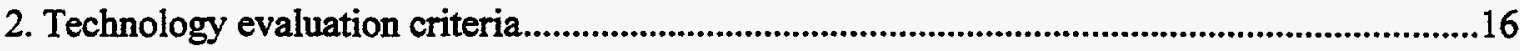

3. Weighting factors for criteria and rating factors......................................................................21

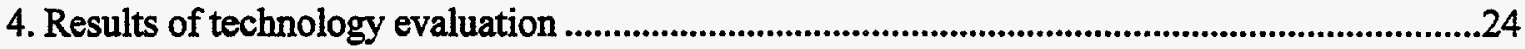

5. Results of technology evaluation with equal importance assigned to categories ......................25

6. Results of technology evaluation with elimination of "Level of Development" criterion ........27

7. Technologies and applicable aqueous and organic waste streams...........................................29

8. Conceptual Flowsheets..................................................................................................................33 
Evaluation of Alternative Nonflame Technologies for Destruction of Hazardous Organic Waste

1. INTRODUCTION

In March 1996, the U.S. Department of Energy's (DOE's) Mixed Waste Focus Area (MWFA) commissioned an evaluation of mixed waste treatment technologies that are alternatives to incineration for destruction of hazardous organic wastes. The purpose of this effort is to evaluate specified technologies and recommend to the Waste Type Managers and the MWFA which technologies should be considered for further development. This provides a path forward for the MWFA in alternative organic destruction technology development. Descriptions of these technologies are contained in Appendix A.

1 


\section{BACKGROUND}

Interest in alternatives to excess air combustion (incineration) derives from public concern for the potential stack emissions from these systems. Concerns regarding stack emissions may be addressed directly through good design and operation of the thermal treatment unit to eliminate transfer of products of incomplete combustion to the air pollution control (APC) system, good design and operation of the APC system, and use of continuous emission monitors to minimize or eliminate emission of toxic species. However, in response to the public concerns, the DOE has been investigating and developing technologies that are alternatives to incineration. In this section, we attempt to provide the background for concerns associated with incinerators and thermal organic destruction processes in general.

\subsection{Public Perceptions and Basis for Concerns with Thermal Destruction Processes}

Incinerator systems are designed to meet regulatory requirements of $99.99 \%$ destruction and removal efficiency (DRE) for Resource Conservation and Recovery Act (RCRA) organic contaminants and $99.9999 \%$ DRE for dioxins, certain dioxin precursors, and Toxic Substances Control Act contaminants (polychlorinated biphenyls). However, the public has expressed its concern about such organic destruction systems because of their potential to produce dioxins and furans and release volatile metals and radionuclides. These concerns stem from the aggressive operating conditions, including high process temperature and high volumetric air flow required to provide excess oxygen for oxidation, and turbulent gas flows that provide mixing to ensure destruction of the organic constituents. Such operating conditions are conducive to volatilizing some metals and suspending particulates in the offgas. The public is also concerned with the quantity of offgas released from waste treatment operations. Incinerators typically have high volumes of offgas, consisting primarily of nitrogen, that are discharged to the atmosphere due to their need to provide excess oxygen for proper combustion. Total offgas is perceived to be an indication of the potential quantities of contaminants emitted. The concern is that a small fraction of a large gas volume may still contain a significant total release of contaminants. Releases of special concern from incinerators are products of incomplete combustion (PICs), products of recombination of molecular fragments and chlorination (especially dioxins and furans) ${ }^{2}$, and emission of volatile toxic metals and radionuclides. Particulates, which may include nonvolatile metals and radionuclides, may also be a concern, particularly for conventional hazardous waste incinerators. However, mixed waste incinerators use high-efficiency particulate air (HEPA) filters that prevent particulate emissions and are durable enough to withstand ordinary excursions (off-normal events in operating conditions) so that particulate emissions may be of lesser concern for these systems.

Excursions in the treatment operation are also a concern due to the perceived difficulty in controlling releases to the atmosphere. Excursion conditions may occur due to an increase in the input rate of organic material or an input of organic material with unexpectedly high heating value. Either may cause rapid reactions and overloading of the process systems. If such conditions exceed the ability of the combustion chamber to oxidize the organic materials, due to insufficient residence time or lack of oxygen, the result may be an increase in emissions of contaminants if the design capacity of the APC system to remove metals and trace organics is exceeded. Such off-normal conditions have the potential for incomplete destruction of the organics and their release to the offgas from the primary thermal treatment unit. The concern for the potential release of specific hazardous materials from waste treatment processes is further amplified for processes which have a large gaseous effluent flow rate. The greater

a. In this document "dioxin" is used to mean the family of tetra through octa chlorodibenzo dioxins, and "furan" is used to mean the family of tetra through octa chlorodibenzo furans. 
the quantity of gaseous effluent released, the greater the perceived likelihood that significant quantities of hazardous materials will be released to the environment.

An additional concern is that dioxins and furans can be formed in the cooling of high-temperature process offgas (termed de novo synthesis) if the appropriate conditions and precursors are present. The temperature and conditions at which dioxins and furans are formed in offgas streams are now reasonably well understood. Although these contaminants are of primary concern in an offgas which is perceived to be uncontrolled, dioxins and furans may also be produced in condensed phase (i.e., liquid phase) processes. It is useful, therefore, to review the known conditions for production of dioxins and furans in the offgas from high-temperature processes and from condensed phase processes.

\subsection{Formation Conditions for Dibenzo Dioxins and Dibenzo Furans}

If several conditions are met, dioxins and furans are formed from thermal treatment units (TTUs) in those offgas streams that are slowly cooled through the temperature range from $350^{\circ} \mathrm{C}$ to approximately $250^{\circ} \mathrm{C}$. b This method of formation is termed de novo synthesis. Detailed mechanisms have not been established in the published literature; however, the necessary conditions are reasonably clear. ${ }^{1}$ There are certain preconditions that must occur for dioxins and furans to be formed de novo: (1) following combustion, organic precursors are left in the offgas stream; (2) a source of chlorine is available in the gas stream; (3) free oxygen is available in the gas phase; (4) significant particulate matter is present; and (5) adequate reaction time during the offgas cooldown phase is available for the appropriate sequence of reactions to occur.

Each of these are discussed briefly here. A somewhat more detailed discussion of the production of dioxins and furans in the offgas from thermal treatment units and in condensed phase processes is presented in Appendix B.

Organic Precursors: The presence of aromatic hydrocarbons or partially oxygenated aromatics is required.

Chlorine: A source of chlorine $\left(\mathrm{Cl}_{2}\right)$ must be present such as $\mathrm{HCl}$. Free chlorine can be produced by a metal-catalyzed reaction with $\mathrm{HCl}$ (copper is a known active catalyst, other metals may also catalyze this reaction), where the metal source is the particulates entrained in the offgas. The $\mathrm{Cl}_{2} \mathrm{can}$ easily chlorinate the organic precursors by hydrogen abstraction.

Oxygen: Increasing concentrations of free gas-phase oxygen $\left(\mathrm{O}_{2}\right)$ from 0 to $10 \%$ have been shown to increase the production of dioxins and furans via the Deacon reaction to produce free chlorine $\left(\mathrm{Cl}_{2}\right)$ from $\mathrm{HCl}$ (i.e., $2 \mathrm{HCl}+1 / 2 \mathrm{O}_{2} \Leftrightarrow \mathrm{Cl}_{2}+\mathrm{H}_{2} \mathrm{O}$ ).

Particulates: Particulates provide the source of metal to catalyze chlorine production, and the reaction surfaces for chlorination of organic precursors and for free radical combination reactions of organic precursors to form dioxins and furans.

Reaction Time: The most important aspect of the particulate involvement is holdup at temperatures in the $250-350^{\circ} \mathrm{C}$ range.c Reaction times for the de novo synthesis process are of the order of minutes. Slow offgas cooling or holdup of particulates in the required temperature range (e.g., waste heat boiler tubes or hot particle collection devices) allows sufficient time at the proper conditions for chlorine addition to occur. Rapid quenching from combustion temperatures $\left(870-1,200^{\circ} \mathrm{C}\right)$ at the outlet of thermal processors to $80^{\circ} \mathrm{C}$ leads to very low net production of dioxins and furans.

b. L. Waterland, personal communication with the authors, December 18, 1996.

c. L. Waterland, personal communication with the authors, December 18, 1996. 
Condensed Phase Formation: Equally important, formation of dioxins and furans has also been observed in aqueous systems under conditions of aggressive chlorination in the presence of aromatic hydrocarbons. Examples include bleaching of wood pulp with chlorine, and use of hypochlorite for disinfection of water containing phenol. Dioxins may also form under slow aqueous phase destruction of aromatic organo-chlorides where free radical recombination is probable. Therefore, characterization of effluents is equally necessary for alternative treatment processes as for open-flame destruction processes.

\subsection{Thermal Treatment}

This response to public concerns does not imply that incineration or thermal treatment should not be used where it makes good technical sense. Primary thermal treatment units have inherent advantages, including reliable acceptance of a wide variety of waste matrices. Such primary thermal treatment units, coupled with a well-designed and -operated secondary combustion chamber to complete destruction of gas-phase organics leaving the primary treatment device, can eliminate dioxin and furan precursors and other products of incomplete combustion. Also, a well-designed and -operated APC system can eliminate release of volatile metals and radionuclides and particulates. Devices that can remove particulates before cooling and prevent de novo synthesis of dioxins or furans can help overcome the concern over these substances. An example is high-temperature filtration, an emerging technology, that can be installed just downstream from a secondary combustion chamber. High-integrity HEPA filters may reduce the concern for release of particulate-borne metals and radionuclides, even during upsets. Cooled (or subcooled) wet scrubbing systems reduce the vapor pressure of mercury and other volatile metals and transfer the condensed metals to the aqueous liquid phase for subsequent containment and treatment.

Thus, this investigation of alternative treatment technologies does not imply that well-designed and -operated thermal systems, or incinerators, should not be used to treat DOE mixed low-level waste (MLLW) where appropriate. New technologies are being developed to improve performance of these thermal treatment systems, including the APC system, and that should make such systems more acceptable. 


\section{DEFINITION OF ALTERNATIVE ORGANIC DESTRUCTION TECHNOLOGIES}

For the past few years within DOE, the term "nonthermal" has been applied to organic destruction technologies that are alternatives to incineration and which operate below $350^{\circ} \mathrm{C}$. As a working definition for nonthermal or nonflame treatment technologies, this definition has served to focus discussion on nonincinerator technologies that relied primarily on condensed-phase (or liquid-phase) organic destruction processes. This definition was based on a partial understanding of the mode of formation of dioxins and furans in incinerator offgas. Early information on dioxin formation indicated that dioxins and furans were formed by combination of molecular fragments as the offgas cooled through about $350^{\circ} \mathrm{C}$; thus, by keeping the temperature less than $350^{\circ} \mathrm{C}$ it was thought that dioxins and furans would not be formed de novo. However, it has been recognized that this definition, based on operating temperature, does not address all the real issues of interest, and several technologies operating at higher temperatures may also limit the formation of dioxins and furans and production of volatile metals and radionuclides. In addition, it is known that dioxins and furans may be formed in aqueous solutions given the proper conditions.

A new way is needed for categorizing alternative technologies, including low-temperature (nonthermal) technologies and high-temperature (thermal) technologies that are operated in a mode significantly different from incinerators. An understanding of these separate categories of treatment technologies is needed to identify what is meant by "alternative" technologies. These categories include the following:

\section{Thermal Destruction}
a. Incinerators
b. Nonincinerator thermal organic destruction technologies that operate in a mode significantly different than incinerators.

2. Thermal technologies that do not destroy organics.

3. Technologies that do not use heat or high-temperatures as the primary driver for the organic destruction process.

To understand and establish the basis for the definition of "alternative" technologies, we need to first review the existing Environmental Protection Agency (EPA) definitions of thermal treatment.

Thermal treatment means the treatment of hazardous waste in a device which uses elevated temperatures as a primary means to change the chemical, physical, or biological character or composition of the hazardous waste.

Thermal treatment units for organic destruction, which change the chemical composition of the waste, include incinerators and nonincinerators. The EPA definitions are summarized as follows:

Incinerators are defined as thermal treatment units that

- Use controlled-flame combustion

- Are infrared incinerators or plasma arc incinerators. 
Nonincinerator organic destruction thermal treatment units include:

$\begin{array}{ll}\text { - } & \text { Molten salt } \\ \text { - } & \text { Pyrolysis } \\ \text { - } & \text { Wet air oxidation } \\ \text { - } & \text { Microwave discharge. }\end{array}$

Although this is EPA's list of nonincinerator organic thermal destruction units, molten glass, molten metal, and steam reforming may also be included. However, in molten glass and molten metal systems, organics are rapidly vaporized and organic destruction occurs primarily in the gas phase above the melt with free oxygen in a fully oxidizing or starved air (pyrolysis) mode.

Thermal treatment processes that do not destroy organics include those that use elevated temperatures for separation (change the physical character of the waste) of organic contaminants from an inert substrate (sludge, soil or debris); for example, thermal desorption. A more detailed presentation and discussion of the EPA definitions and development of a corresponding definition of nonthermal treatment is presented in Appendix C.

Nonthermal technologies have not been defined by EPA but may be considered the antithesis of thermal technologies. Nonthermal technologies use entirely different means for organic destruction than do thermal technologies, and for the purposes of this study are defined as follows:

Nonthermal treatment means the destruction of hazardous organic waste in a device which uses chemical or electrochemical oxidants other than oxygen or air as the primary means to change the chemical, physical, or biological character or composition of the hazardous waste. Moderate increases in temperature may be used to accelerate the rates of the organic destruction reactions, but gas-phase oxidation or pyrolytic degradation with or without combustion flames or plasma arcs is not included in these systems. Examples of nonthermal treatment processes are electrochemical oxidation, aqueous phase UV photolysis, systems of oxidation of organic materials based on the use of Fenton's reagent, and aqueous phase oxidation with strong inorganic oxidants. Examples of strong inorganic oxidants are nitric acid, permanganate, $\mathrm{Ag}^{2+}, \mathrm{Ce}^{2+}$, perchlorate, peroxy disulfate, and dichromate.

Thus, alternative technologies evaluated in this report are those that operate in such a manner as to minimize the generation of effluent and contaminants that are associated with incinerators, and that minimize the stakeholder concerns identified in the previous section. Alternative technologies include nonthermal technologies and thermal technologies that operate under significantly different physical and chemical conditions than incinerators. Our interest is in providing technologies which will change the "chemical, physical, or biological character or composition of the hazardous waste" without emitting undesirable products in the offgas regardless of temperature. This includes offgas from the primary treatment unit to the APC system, and offgas from the APC system by eliminating the conditions that lead to de novo synthesis of dioxins and furans in the APC system. In this evaluation, the focus is on alternatives to open-flame combustion with free oxygen that address the key issues of decreased volume of offgas, reduced emissions of volatiles and formation of dioxins or furans or their precursors, and that can be deployed in locations or instances where incinerators may not be suitable. This revised definition of alternative technologies should be based on the operating characteristics of the technology and how its 
operation is expected to avoid the perceived problems associated with incinerators. Technologies defined as alternatives and selected for evaluation should have the potential to:

- Destroy organic material without use of open-flame reactions with free gas-phase oxygen as the reaction mechanism.

- Reduce the offgas volume and associated contaminants emitted under normal operating conditions per unit mass of waste fed.

- Reduce the metals, radionuclides, and particulates suspended in the offgas exiting the process.

- Eliminate or greatly reduce the dioxin and furan precursors in the primary treatment process, especially in the offgas streams.

- Avoid conditions which allow free chlorine production and allow dioxin and furan precursors to form and to continue to react de novo with chlorine to produce dioxins and furans.

- Reduce the potential for excursions in the process that can lead to accidental release of harmful levels of chemical or radioactive materials, and minimize the volume of gaseous emissions that are subject to release during excursions or accident conditions

Alternative technologies have the advantages of relatively low volume gaseous emissions, potentially generate few or no dioxin compounds in the offgas, and usually operate at low enough temperature that metals (except mercury) and radionuclides are not volatilized. These technologies also operate under conditions that minimize or eliminate particulate entrainment in the offgas. In addition, lower temperatures and condensed phase media moderate the potential of emissions to the atmosphere in the event of a process excursion. Alternative technologies are also of interest for their potential to be used in installations where a thermal treatment unit is not suitable, and to treat waste streams that are not appropriate to thermal destruction either due to physical characteristics, regulatory or stakeholder concerns, or economic factors. However, they have issues that must be resolved, including performance uncertainties, destruction efficiency, corrosion, and secondary waste generation.

The primary objective in examining technology alternatives to incineration is to avoid the key concerns discussed in detail below.

Destroy Organic Material Without Use of Open-Flame Reactions with Free Oxygen: Incinerators and the nonincinerator thermal technologies all operate at elevated temperatures using thermal excitation as the initiating step in the destruction reaction sequence. Even pyrolysis, destructive distillation, and wet air oxidation, all thermally driven processes, use free oxygen as the primary source of oxidative (or partial oxidative) destruction of the waste feed material. This allows for partially oxidized free radical or molecular species to survive in the gas phase where they are available for recombination reactions or chlorination during a cooldown phase to produce undesirable compounds. However, certain of these thermal, free oxygen processes have operating conditions that tend to mitigate the production of offgas contaminants. For example, wet air oxidation takes place in a condensed media (water) at low temperature $\left(150\right.$ to $350^{\circ} \mathrm{C}$ ) with dissolved oxygen so that little cooldown of the offgas is required, no metals are volatilized (except possibly mercury), and no particulates are entrained. Reduction processes that use steam as the initial source of oxygen do not use free gas-phase oxygen in the reforming process, produce a relatively low volume of combustible offgas (syngas) from which particulates may be removed in the hot condition prior to final oxidation in a thermal oxidizer and subsequent cooling, and the chlorinated organics and ring compounds have been reformed before the syngas is oxidized, thereby decreasing the potential for de novo synthesis of dioxins and furans.

Reduce Offgas: Concern for the potential release of specific hazardous materials from waste treatment processes is aimed first at those processes that release large quantities of gas. The greater the quantity of gas released, the greater the likelihood that significant quantities of hazardous materials will be released to the environment even if only at very low concentrations. These gases, released on a 
continuous basis from an operating process, are considered released and beyond control when they leave the waste treatment units. Properly sized APC systems, taking into account an expected range of offgas flowrates, should be able to treat the offgas under normal conditions and under most excursion conditions. However, lacking the ability to divert excess or off-specification gases, public perception appears to be that excursions in operations in the thermal treatment units may lead to contaminant releases to the atmosphere even after the gas is processed through the APC system. On this basis, a preference has been expressed for technologies that produce the lowest possible offgas. Condensed phase and/or relatively low-temperature treatment processes that do not require excess air for combustion have relatively low offgas with the potential to totally contain the offgas for further treatment before it is finally released to the atmosphere.

Reduce Suspended Particulate: Particulates include nonvolatile metals and radionuclides. For turbulent conditions as occur in incinerators, especially rotary kilns or operations such as plasma arcs, a great deal of material can be entrained in the gas phase. A fraction of the ash formed during destruction of organic materials in the primary oxidation chamber is entrained in the gas stream leaving the chamber and must be removed in the APC system. This ash content is significantly higher than for systems that have a relatively quiescent operation. Low-temperature processes, especially the condensed-phase processes, have very little potential of releasing particulates, ash, and radionuclides into a gas stream. Processes that operate in the starved air or reducing mode are relatively quiescent, and have low volumes of combustible offgas that may be cleaned to remove particulate and acid gases before combustion in a thermal oxidizer.

Eliminate or Minimize Dioxin and Furan Precursors in the Gas Leaving the Primary Treatment Unit: Here again, condensed phase, low-offgas technologies will tend to hold the precursors in the reactor system rather than releasing them to the offgas. However, the complete answer to the precursor problem is more complicated than this simple conceptualization. The precursors are chlorine, oxygen, and aromatic hydrocarbons, which are characteristically present in open-flame processes at the 0.1 to $1 \mathrm{ppb}$ level. Chlorination of organics can be avoided by (1) destruction of all carbon-hydrogen bonds in the organic waste matrix, and (2) making the chlorine unavailable for reaction with hydrocarbons by separation or reaction with an alkali metal such as sodium to form a chloride salt.

Provide Conditions that Guarantee Destruction of Dioxin and Furan Precursors: In oxidizing environments, many factors contribute to the production of dioxins and furans in the offgas stream. Certain chlorinated aromatic hydrocarbons are defined by the EPA as dioxin/furan precursors and may be part of the feed stream. Dioxins and furans can also be produced when reaction sites are available and partially oxidized aromatic hydrocarbons are in the presence of chlorine at the appropriate temperature for a sufficient period of time. Processes in which reaction sites (particulates) and $\mathrm{HCl}$ can be removed from the hot offgas stream before the final offgas oxidation step, or prevention of $\mathrm{Cl}_{2}$ formation, may decrease the de novo production of dioxins and furans. Destruction of halogenated organics is difficult for some of the aqueous-based processes, and reduction of dioxin and furan precursors may be more difficult. However, retention of dioxins/furans or precursors in the condensed phase may allow more control and longer residence time for continued destruction.

Reduce The Potential for Excursions in The Process: A well-designed and -controlled thermal oxidation system can be operated at stable and constant conditions with a continuous feed. The conditions in a rotary or controlled air incinerator operated in a batch feeding mode can lead to swings in the oxidation conditions within the incinerator. However, a good secondary combustion chamber design can accommodate such fluctuations and destroy organic materials (PICs) leaving the primary chamber. Assurance of smooth reactions requires a continuous feed or a process with high inertia, such that batch feeding of highly reactive waste will not cause large swings in the emissions from the treatment process. 


\section{ASSUMED APPLICATIONS AS A BASIS FOR EVALUATION}

Potential applications of alternative technologies include the treatment of all MLLW that contain hazardous organic contaminants. To track mixed waste matrices, they have been given numerical designations as follows: 1000-aqueous liquids and slurries, 2000-organic liquids, 3000-homogeneous solids, 4000-soil, and 5000-debris. Inorganic sludges (matrix 3100), soils (matrix set 4000), and inorganic debris (matrices 5100 and parts of 5400) are much more difficult for these technologies to treat.

\subsection{Waste Matrix Categories for DOE Mixed Low Level Wastes}

Table 1 shows the total volume of the stored and 5-year projected newly generated MLLW streams based on the Site Treatment Plan database. Wastes are tabulated at the 100 s level matrix designation. This tabulation keeps the data at a fairly high level yet allows, for example, listing inorganic and organic homogeneous solids separately and inorganic and organic debris separately (Column 1). Column 2 shows the total volumes of each waste category and the totals of these at the major matrix category level. Column 4 shows the volume of these wastes that are contaminated with regulated organics and that are candidates for treatment by alternative technologies. Column 5 lists the percent each 100 s category, from column 4 , is of the total MLLW listed. The total volume of these wastes that is contaminated with organic is $67.4 \%$.

Waste waters

Organic liquids

Homogeneous solids

Soils

Debris

Unknown
$3.8 \%$

$2.5 \%$

$25.8 \%$

$10.2 \%$

$24.9 \%$

$0.2 \%$

Of the total MLLW listed inventory that is organically contaminated, $83.3 \%$ is inorganic matrix materials, $12.3 \%$ is indicated to be primarily organic matrix waste, and $3.8 \%$ is aqueous or unknown matrix. Lab packs and special wastes were not included in this analysis.

\subsection{Series Waste Matrices (Aqueous Liquids)}

Aqueous wastes includes liquids and slurries that contain less that $1 \%$ organic carbon. This category is $7.1 \%$ of the total MLLW and $3.8 \%$ of the MLLW containing organic contaminants. These waste streams are relatively easy to treat with the available technologies. Destruction technologies for some organics in aqueous streams have been in use for some period of time. There are some questions of the ability of available technologies to treat the more difficult organic compounds. 
Table 1. Distribution of current and 5-year projected mixed low-level waste streams. ${ }^{2}$

\begin{tabular}{|c|c|c|c|c|c|}
\hline Waste Matrices & $\begin{array}{c}\text { Total } \\
\text { Volume } \\
\left(\mathrm{m}^{3}\right)\end{array}$ & $\begin{array}{l}\text { Percent of } \\
\text { Total } \\
\text { MLLW }\end{array}$ & $\begin{array}{l}\text { Volume of Waste } \\
\text { Contaminated } \\
\text { with Regulated } \\
\text { Organics }\left(\mathrm{m}^{3}\right)\end{array}$ & $\begin{array}{c}\text { Percent of } \\
\text { MLLW } \\
\text { Contaminated } \\
\text { with Regulated } \\
\text { Organics }\end{array}$ & $\begin{array}{c}\text { Percent of } \\
\text { Organically } \\
\text { Contaminated } \\
\text { Waste }\end{array}$ \\
\hline \multicolumn{6}{|l|}{1000 Series Wastes } \\
\hline 1000 aqueous liquid slurries & 5,489 & $4.0 \%$ & 1,580 & $1.1 \%$ & $1.7 \%$ \\
\hline 1100 waste waters & 3,967 & $2.9 \%$ & 3,250 & $2.3 \%$ & $3.5 \%$ \\
\hline 1200 aqueous slurries & 423 & $0.3 \%$ & 401 & $0.3 \%$ & $0.4 \%$ \\
\hline Total & 9,879 & $7.1 \%$ & 5,231 & $3.8 \%$ & $5.6 \%$ \\
\hline \multicolumn{6}{|l|}{2000 Series Wastes } \\
\hline 2000 organic liquids & 791 & $0.6 \%$ & 625 & $0.5 \%$ & $0.7 \%$ \\
\hline 2100 aqueous organic liquids & 1,640 & $1.2 \%$ & 1,614 & $1.2 \%$ & $1.7 \%$ \\
\hline 2200 pure organic liquids & 880 & $0.6 \%$ & 823 & $0.6 \%$ & $0.9 \%$ \\
\hline 2900 unknown organic liquids & 363 & $0.3 \%$ & 345 & $0.2 \%$ & $0.4 \%$ \\
\hline Total & 3,674 & $2.7 \%$ & 3,407 & $2.5 \%$ & $3.7 \%$ \\
\hline \multicolumn{6}{|l|}{3000 Series Wastes } \\
\hline 3000 homogeneous solids & 0 & $0.0 \%$ & 0 & $0.0 \%$ & $0.0 \%$ \\
\hline 3100 inorganic homog. solids & 59,934 & $43.3 \%$ & 34,648 & $25.0 \%$ & $37.1 \%$ \\
\hline 3200 organic homog. solids & 1,045 & $0.8 \%$ & 1,004 & $0.7 \%$ & $1.1 \%$ \\
\hline 3900 unknown homog. solids & 70 & $0.1 \%$ & 66 & $0 \%$ & $0.1 \%$ \\
\hline Total & 61,049 & $44.1 \%$ & 35,718 & $25.8 \%$ & $38.3 \%$ \\
\hline \multicolumn{6}{|l|}{4000 Series Wastes } \\
\hline 4000 soils and gravel & 6,756 & $4.9 \%$ & 6,523 & $4.7 \%$ & $7.0 \%$ \\
\hline 4100 soils & 8,438 & $6.1 \%$ & 6,154 & $4.4 \%$ & $6.6 \%$ \\
\hline 4200 soils/debris & 1,374 & $1.0 \%$ & 1,276 & $0.9 \%$ & $1.4 \%$ \\
\hline 4300 rock/gravel & 37 & $0.0 \%$ & 0 & $0.0 \%$ & $0.0 \%$ \\
\hline 4900 unknown other soil & 194 & $0.1 \%$ & 194 & $0.1 \%$ & $0.2 \%$ \\
\hline Total & 16,799 & $12.1 \%$ & 14,147 & $10.2 \%$ & $15.2 \%$ \\
\hline \multicolumn{6}{|l|}{5000 Series Wastes } \\
\hline 5000 debris & 739 & $0.5 \%$ & 739 & $0.5 \%$ & $0.8 \%$ \\
\hline 5100 inorganic debris & 5,652 & $4.1 \%$ & 2,296 & $1.7 \%$ & $2.5 \%$ \\
\hline 5300 organic debris & 9,053 & $6.5 \%$ & 8,128 & $5.9 \%$ & $8.7 \%$ \\
\hline 5400 heterogeneous debris & 30,744 & $22.2 \%$ & 23,137 & $16.7 \%$ & $24.8 \%$ \\
\hline 5900 unknown/other debris & 239 & $0.2 \%$ & 188 & $0.1 \%$ & $0.2 \%$ \\
\hline Total & 46,427 & $33.5 \%$ & 34,488 & $24.9 \%$ & $37.0 \%$ \\
\hline \multicolumn{6}{|l|}{9000 Series Wastes } \\
\hline 9000 unknown - Total & 647 & $0.5 \%$ & 282 & $0.2 \%$ & $0.3 \%$ \\
\hline Total MLLW & 138,475 & $100 \%$ & 93,272 & $67.4 \%$ & $100 \%$ \\
\hline
\end{tabular}




\subsection{Series Waste Matrices (Organic Liquids)}

This category includes aqueous organic solutions and slurries and organic liquids containing greater than $1 \%$ total organic carbon. These comprise $2.7 \%$ of the total MLLW listed and $2.5 \%$ of the MLLW contaminated with regulated organics. These are also relatively easy to treat and have been the subject of considerable development effort. There are still some questions of the ability of some available technologies to treat the more difficult organic compounds.

\subsection{Series Waste Matrices (Homogeneous Solids)}

Homogeneous solids are solid waste materials that are not soil or classified as debris by EPA regulations. These are generally process sludges and particulates and the materials may be inorganic (43.3\% of the total and $25 \%$ of the MLLW contaminated with regulated organics) or organic matrices $(0.8 \%$ of the total and $0.7 \%$ contains regulated organic contaminants). Any of these may have been stabilized with a variety of stabilization agents. The materials may also be made up of aqueous or organic solution adsorbed on organic materials such as activated carbon or inorganic adsorbent materials such as vermiculite or clay.

\subsection{Series Waste Matrices (Soils)}

Soils are naturally occurring soil and gravel material that does not meet the EPA definition of debris, and mixtures of soil with other wastes that are greater than $50 \%$ soil. Soils constitute $12.1 \%$ of the total and $10.2 \%$ of the MLLW contaminated with regulated organics.

\subsection{Series Waste Matrices (Debris)}

Debris includes wastes that are at least $50 \%$ by volume debris according to the EPA definition:

Debris means solid material exceeding a $60-\mathrm{mm}$ particle size that is intended for disposal and that is: (1) manufactured object or (2) plant or animal matter, or (3) natural geologic material.

The regulation excludes from the debris definition materials previously subject to regulation, intact containers, waste treatment residues, and solidified sludges. Mixtures of debris with other materials that appear to be primarily debris "based on visual inspection" is also treated as debris. (Debris is $33.5 \%$ of the total and is $24.9 \%$ of the MLLW contaminated with regulated organics.)

\subsection{Technology Applications}

Many of the MLLW nonincinerator and nonthermal treatment efforts that have been carried out to date have been directed toward destruction of organics in aqueous waste or in organic waste matrices. Few of the technologies have been developed for the purpose of destroying organic contaminants in the presence of inorganic matrices. For some technologies, the presence of the inorganic matrix material largely interferes with or intercepts and deactivates the organic destruction agent before it has a chance to react with the low concentrations of organic material present in most of these wastes.

Generally, for alternative processes to be applicable to the treatment of the inorganic matrices (inorganic sludges, soils, and inorganic debris), pretreatment processes are required for separation of the organic contaminants from the matrix. The separated organic is then destroyed in the candidate organic 
destruction technology. Methods for removal of the organics include thermal desorption and washing. Neither of these processes have been demonstrated on inorganic sludges, and the removal efficiency for organics on soils or debris varies between 60 and $99.9 \%$ depending on the technology, the matrix, and the boiling point or solubility of the organic contaminant.

Separation of organics from the solid matrices is integral to the high-temperature processes such as steam reforming and the Eco Logic reduction process. In these technologies, the solid surfaces must be exposed to high-temperature steam or hydrogen and steam to vaporize the contaminant and initiate the destruction process; the destruction is then completed in the gas phase. The ability of these processes to remove organic contaminants adequately from these solid inorganic matrices has not been demonstrated at this time.

Aqueous liquids, organic liquids, organic sludges (such as ion exchange resins), and some combustible debris are the only waste streams in which organics have been shown to be destroyed by alternative technologies without separation of the contaminants from the matrix. However, some of the high-temperature and chemical oxidation alternative technologies identified below may have the potential for direct treatment of organics in the inorganic matrices.

For example, the developers of the DETOXSM and acid digestion processes have not recommended application of these technologies to soil, sludge, or inorganic debris waste matrices. These highly aggressive technologies may rapidly expend the oxidizing agent by dissolving much of the nontoxic waste matrix and rapidly increasing the solids concentration of the solution beyond the solubility limit. This result would increase the frequency at which the solution must be changed or a slip stream be regenerated and increase the operating cost for treatment of these waste categories. However, recent data on solubility of inorganic matrix material has been encouraging for the application of these low temperature chemical destruction processes for in-matrix destruction of organic contaminants in some of these inorganic matrices. These applications remain to be demonstrated and evaluated. It has been shown that the reagent used in the Direct Chemical Oxidation (DCO) process does not react with inert matrix materials; however, the potential of this technology for application to direct in-matrix organic destruction also remains to be demonstrated. 


\section{TECHNOLOGIES EVALUATED}

The technologies that were evaluated are listed below as a function of the waste streams for which they are considered applicable. Descriptions of these technologies are provided in Appendix A. There is some overlap because some technologies are applicable to more than one waste stream or waste matrix. After a review of technologies that are available or that are under development for treatment of organic contaminants, we selected these technologies for further evaluation because they appear to meet the requirements of alternative technologies discussed in Section 3.

- Wastewaters: Waste matrix categories 1100 and 1200.

- UV Photo-Oxidation (ambient temperature)

- UV Photo-Catalytic Oxidation (ambient temperature)

- Electron Beam (ambient temperature)

- Chromox (ambient temperature)

- Ultrasonics (average ambient temperature)

- Electrohydraulic Discharge (average ambient temperature)

- $\quad$ Liquid Corona (average ambient temperature)

- $\quad$ Mixed Oxidants (MIOX) process (up to $60^{\circ} \mathrm{C}$ )

- $\quad$ Electrochemical Peroxidation $\left(15-70^{\circ} \mathrm{C}\right)$

-. X-Ray/Gamma Ray Destruction (ambient temperature)

- $\quad$ Supercritical Water Oxidation (above $374^{\circ} \mathrm{C}$ ).

Although mediated electrochemical oxidation, acid digestion, and catalyzed wet oxidation (DETOXSM) can be used to treat aqueous waste, the water would need to be metered in slowly and the excess water evaporated to prevent dilution of the acid solutions. These technologies appear better suited to concentrated organic liquids and sludges.

- Organic Liquids and Organic Sludges: Waste matrix categories 2000 and 3200.

- Wet Air Oxidation $\left(150-325^{\circ} \mathrm{C}\right)$

- Wet Oxidation $\left(80-100^{\circ} \mathrm{C}\right)$

- $\quad$ Catalyzed Wet Oxidation (Delphi DETOXSM) $\left(200^{\circ} \mathrm{C}\right)$

- $\quad$ Acid Digestion (phosphoric/nitric acid) $\left(185-200^{\circ} \mathrm{C}\right)$

- Mediated Electrochemical Oxidation - three concepts based on silver, cerium, and cobalt $\left(50-60^{\circ} \mathrm{C}\right)$

- $\quad$ Peroxydisulfate (Direct Chemical Oxidation) process $\left(80-100^{\circ} \mathrm{C}\right)$

- Neutralization/Hydrolysis (ambient temperature)

- $\quad$ Supercritical Water Oxidation (above $374^{\circ} \mathrm{C}$ )

- $\quad$ Steam Reforming $\left(300-1,200^{\circ} \mathrm{C}\right)$

- ChemChar $\left(1,200^{\circ} \mathrm{C}\right)$

- Eco Logic process $\left(850-950^{\circ} \mathrm{C}\right)$.

The last four technologies are relatively high temperature (i.e., $300-1,200^{\circ} \mathrm{C}$ ), but operate in an aqueous environment or reducing mode with steam as the source of oxygen, thereby reducing the potential for dioxin or furan formation in the offgas or de novo synthesis in the APC system. The presence or absence of these contaminants needs further investigation as does the issue of volatilized metals and radionuclides in these high-temperature processes.

- Combustible Debris: Waste matrix category 5300.

- $\quad$ Catalyzed Wet Oxidation (Delphi DETOXSM) $\left(200^{\circ} \mathrm{C}\right)$

- $\quad$ Acid Digestion (phosphoric/nitric acid) $\left(185-200^{\circ} \mathrm{C}\right)$

- Steam Reforming $\left(300-1,200^{\circ} \mathrm{C}\right)$

- ChemChar $\left(1,200^{\circ} \mathrm{C}\right)$

- $\quad$ Eco Logic process $\left(850-950^{\circ} \mathrm{C}\right)$. 
Some technologies listed as applicable to organic liquids and sludges may also be applicable to combustible debris if the debris is sufficiently size reduced. However, this may be of sufficient difficulty to prevent application of technologies such as supercritical water oxidation to this type of matrix.

Steam reforming, ChemChar, and the Eco Logic processes may be applicable to in-matrix destruction of organics on soils and inorganic sludges, and ultrasonics may be used to remove organics from slurried soils and sludges and destroy the organics when they reach the aqueous phase. If it can be shown that nontoxic materials, such as silica, alumina, and carbonates in soils and sludges are not readily soluble in DETOXSM, acid digestion, or direct chemical oxidation solutions, then these processes may also be applicable to in-matrix destruction of organics on these matrices. However, a demonstrated capability of these technologies to treat these matrices is required.

Several nonthermal technologies (e.g., ultrasonics, electrohydraulic discharge, and liquid corona) have very high localized temperatures, but the average temperature of the reaction process is low. These processes generate hydroxyl radicals that oxidize organic material rather than using gaseous free oxygen as the oxidizer. The extremely short periods of time during which the high-temperature regions exist (of the order of milliseconds or less) and the lack of free oxygen make formation of dioxins and furans highly improbable. Wet air oxidation uses dissolved oxygen and the process takes place at $<325^{\circ} \mathrm{C}$, making the presence of dioxins and furans in the offgas, or de novo synthesis, highly improbable. The thermal processes (steam reforming, ChemChar, and Eco Logic) use steam as the source of oxygen so free gaseous oxygen is not available to drive the Deacon reaction and few particulates are entrained in the offgas to provide a source of catalysts or reaction sites for de novo synthesis of dioxins or furans. Secondary combustion of the syngas from these processes should occur after particulates, and possibly $\mathrm{HCl}$, have been removed. Similarly, supercritical water has little or no particulate emissions in the offgas. 


\section{CRITERIA}

Criteria used to evaluate these technologies are summarized in Table 2 together with brief guidelines for ranking technologies against each criterion. Application of these criteria to the evaluation of technologies provides a uniform and traceable basis for evaluation.

The MWFA is seeking effective and readily deployable waste treatment technologies as alternatives to incineration as the final detoxification and volume-reduction step for treatment of many DOE mixed wastes. The technologies evaluated are primarily applicable to treatment of organic contaminants and have minimal applicability to the inorganic contaminants (i.e., heavy metals or radionuclides) that may be contained in or adhere to the waste matrices. These inorganic contaminants may remain with the original waste stream in the ash, or may form soluble species such as salts in a secondary waste stream. In either case, the inorganic contaminants will subsequently be stabilized.

For this evaluation, it is assumed that any treatment technology that is implemented will be engineered and operated to comply with applicable regulations and provide adequate protection of human health and the environment. However, candidate technologies will be evaluated on the perceived difficulty in achieving adequate environmental and health protection. In addition, candidate technologies will be evaluated against criteria related to technical performance and readiness for deployment.

\subsection{Performance}

Preferred technologies will be capable of treating all or several of the major categories of DOE mixed waste matrices (e.g., aqueous solutions and slurries, organic liquids, organic or inorganic sludges and slurries, combustible and noncombustible debris, soils). For each matrix category of waste, preferred technologies will be capable of treating a wide range of organic contaminants. Treatment should be complete and effective, yielding products and residues that comply with EPA's Universal Treatment Standards (UTSs) for land disposal, and yield a minimum of secondary wastes requiring additional treatment. Finally, anticipated (routine and upset) emissions from preferred treatment technologies should be few in number and low in volume and hazard.

The following criteria were used to evaluate and rank the technical performance of the candidate treatment technologies.

Range of Feed Materials: Preferred technologies will be capable of treating more than one matrix category of mixed waste. In addition, preferred technologies will be relatively "omnivorous" in treating a variety of contaminants. For example, technologies capable of treating a range and mix of organic contaminants in a variety of waste matrices will be preferred over technologies that can effectively treat only one or a few contaminants in a limited number of matrices. Likewise, preferred technologies will be able to successfully process wastes exhibiting widely varying contaminant compositions and concentrations.

Treatment Effectiveness: Effective treatment technologies will treat waste feed to remove or destroy hazardous organic constituents to UTSs. Effective treatment technologies will not merely separate wastes into streams of higher and lower hazard and will avoid or minimize: (1) generation of regulated secondary wastes, (2) transfer of wastes between media, and (3) dilution of wastes. Treatment technologies that minimize postreatment of products and residues before stabilization for final disposal are preferred over technologies that have low destruction efficiencies and that require post treatment to meet the UTSs. 
Table 2. Technology evaluation criteria.

\section{Performance Category}

\begin{tabular}{|c|c|c|c|}
\hline Criteria & High Score & Middle Score & Low Score \\
\hline Range of Feed Material & $\begin{array}{l}\text { Effectively treats more } \\
\text { than two matrix } \\
\text { categories of mixed } \\
\text { waste. Treats all organic } \\
\text { contaminants to meet all } \\
\text { UTSs with little or no } \\
\text { pretreatment. }\end{array}$ & $\begin{array}{l}\text { Treats at least two } \\
\text { categories of mixed waste } \\
\text { and a wide variety of } \\
\text { chlorinated solvents, volatile } \\
\text { organic compounds, and } \\
\text { petroleum hydrocarbons to } \\
\text { meet all UTSs. }\end{array}$ & $\begin{array}{l}\text { Effectively treats only } \\
\text { one category of mixed } \\
\text { waste. Treats only a few } \\
\text { specific contaminants } \\
\text { and destruction } \\
\text { efficiency varies } \\
\text { substantially with the } \\
\text { contaminant. }\end{array}$ \\
\hline Treatment Effectiveness & $\begin{array}{l}\text { Treated streams are } \\
\text { suitable for discharge } \\
\text { with postreatment for } \\
\text { inorganic contaminants or } \\
\text { stabilization. Hazardous } \\
\text { organic components are } \\
\text { destroyed and no } \\
\text { regulated secondary } \\
\text { wastes are produced. }\end{array}$ & $\begin{array}{l}\text { Hazardous organic } \\
\text { constituents are destroyed } \\
\text { but some postreatment is } \\
\text { required to meet UTSs. } \\
\text { Postreatment technology is } \\
\text { demonstrated and available. } \\
\text { Only minor amounts of } \\
\text { regulated secondary waste } \\
\text { are produced. }\end{array}$ & $\begin{array}{l}\text { Treated streams contain } \\
\text { residual hazardous } \\
\text { organic components } \\
\text { requiring significant } \\
\text { postreatment or recycle. } \\
\text { Postreatment } \\
\text { technologies must be } \\
\text { developed or modified. } \\
\text { Substantial amounts of } \\
\text { regulated secondary } \\
\text { waste are produced. }\end{array}$ \\
\hline
\end{tabular}


Table 2. (continued).

Readiness for Deployment Category

\begin{tabular}{|c|c|c|c|}
\hline Criteria & High Score & Middle Score & Low Score \\
\hline $\begin{array}{l}\text { Level of Development } \\
\text { and Understanding }\end{array}$ & $\begin{array}{l}\text { Technology has been } \\
\text { demonstrated at the pilot } \\
\text { scale. Overall concept for } \\
\text { application of the } \\
\text { technology in an integrated } \\
\text { treatment system is } \\
\text { available. Development } \\
\text { and understanding will } \\
\text { support adaptation to } \\
\text { radioactive service and } \\
\text { demonstration on } \\
\text { simulated or actual } \\
\text { MLLW. }\end{array}$ & $\begin{array}{l}\text { Scientific basis of } \\
\text { technology has been } \\
\text { demonstrated at the } \\
\text { laboratory or bench scale. } \\
\text { Range of MLLW } \\
\text { applications has been } \\
\text { determined. Additional } \\
\text { development required to } \\
\text { obtain scale-up, } \\
\text { radioactive service, and } \\
\text { system conceptual design } \\
\text { data. }\end{array}$ & $\begin{array}{l}\text { Laboratory and bench-scale } \\
\text { testing have yet to be } \\
\text { completed on a range of } \\
\text { compounds of interest to } \\
\text { DOE. }\end{array}$ \\
\hline Complexity & $\begin{array}{l}\text { Process is completed in } \\
\text { one or two unit operations } \\
\text { in a single process train. } \\
\text { Normal working side- } \\
\text { streams may be recycled } \\
\text { using available technology. } \\
\text { Support systems limited to } \\
\text { normal utilities. Process } \\
\text { equipment of conventional } \\
\text { design. No unusual I\&C, } \\
\text { QAVC, inspections or } \\
\text { monitoring required. } \\
\text { Minimum pretreatment } \\
\text { requirements and } \\
\text { technology is demonstrated } \\
\text { and available. }\end{array}$ & $\begin{array}{l}\text { Technology requires } \\
\text { multiple unit operations } \\
\text { and/or multiple process } \\
\text { trains. Technology } \\
\text { required for pretreatment } \\
\text { or to recycle working side } \\
\text { streams has been defined } \\
\text { but needs to be } \\
\text { demonstrated. Process } \\
\text { uses unique equipment } \\
\text { designs, and requires } \\
\text { special (gas storage, } \\
\text { custom power supplies, } \\
\text { real time analyses, etc.) } \\
\text { auxiliary and support } \\
\text { systems. Exotic materials } \\
\text { of construction are } \\
\text { required that may increase } \\
\text { downtime and } \\
\text { maintenance } \\
\text { requirements. }\end{array}$ & $\begin{array}{l}\text { Technology is very } \\
\text { complex. Requires multiple } \\
\text { unit operations including } \\
\text { difficult or extensive } \\
\text { materials handling and } \\
\text { recycle systems. Process } \\
\text { stream splitting, metering, } \\
\text { blending, and real time } \\
\text { analyses are required. } \\
\text { Auxiliary and support } \\
\text { systems are unique, } \\
\text { sophisticated and require } \\
\text { highly trained personnel for } \\
\text { operations and maintenance. } \\
\text { Extensive pretreatment and } \\
\text { feed characterization are } \\
\text { required, and/or } \\
\text { pretreatment technology } \\
\text { must be developed and } \\
\text { demonstrated. Exotic } \\
\text { construction materials are } \\
\text { required. }\end{array}$ \\
\hline
\end{tabular}


Table 2. (continued).

\begin{tabular}{|c|c|c|c|}
\hline \multicolumn{4}{|c|}{ Environment, Safety, and Health Category } \\
\hline Criteria & High Score & Middle Score & Low Score \\
\hline Emissions & $\begin{array}{l}\text { Produces no uncontrolled } \\
\text { emissions during normal } \\
\text { operations. Minimum } \\
\text { potential to produce } \\
\text { mobile products of } \\
\text { incomplete reaction or } \\
\text { recombination such as } \\
\text { dioxins/furans. Low } \\
\text { specific volume of } \\
\text { emissions, low } \\
\text { concentrations of } \\
\text { hazardous materials, and } \\
\text { easily treated by known } \\
\text { technology. }\end{array}$ & $\begin{array}{l}\text { Some emissions may be hard } \\
\text { to control or will require } \\
\text { nonstandard or unproved } \\
\text { control technology. Specific } \\
\text { volume of emissions similar to } \\
\text { that for incinerators. } \\
\text { Postreatment processes are } \\
\text { available to treat gaseous or } \\
\text { liquid effluent containing } \\
\text { products of incomplete } \\
\text { reaction or recombination. }\end{array}$ & $\begin{array}{l}\text { Large specific volume } \\
\text { of emissions or } \\
\text { emissions containing } \\
\text { high concentrations of } \\
\text { hazardous species. } \\
\text { Real time monitoring of } \\
\text { emissions is difficult or } \\
\text { impossible. Postreat- } \\
\text { ment processes to treat } \\
\text { gaseous or liquid } \\
\text { effluent containing } \\
\text { products of incomplete } \\
\text { reaction or } \\
\text { recombination need } \\
\text { development or } \\
\text { demonstration. }\end{array}$ \\
\hline $\begin{array}{l}\text { Worker Health and } \\
\text { Safety }\end{array}$ & $\begin{array}{l}\text { Process operates near ( }<2 \\
\text { atm) or below ambient } \\
\text { pressure, and at a } \\
\text { relatively low }\left(<120^{\circ} \mathrm{C}\right) \\
\text { temperature. Pressure } \\
\text { vessel code fabrication is } \\
\text { not required. Small } \\
\text { inventories of "in- } \\
\text { process" materials. } \\
\text { Corrosion and erosion are } \\
\text { minor concerns. Mixing } \\
\text { of process streams with } \\
\text { air or water are minor } \\
\text { concerns. Control time } \\
\text { constants are long } \\
\text { (minutes to hours). } \\
\text { System is easily } \\
\text { maintained remotely. }\end{array}$ & $\begin{array}{l}\text { Pressure vessel code } \\
\text { fabrication is required for } \\
\text { major reaction vessels and } \\
\text { process equipment. Equipment } \\
\text { life is limited by thermal } \\
\text { stress, corrosion, erosion, or } \\
\text { deposition. Potential for } \\
\text { adverse reactions if process } \\
\text { streams are mixed with air or } \\
\text { water. Control time constants } \\
\text { are short (seconds to minutes). } \\
\text { Maintenance requirements are } \\
\text { standard but direct } \\
\text { involvement by personnel is } \\
\text { required. }\end{array}$ & $\begin{array}{l}\text { Processes operate near } \\
\text { application limits for } \\
\text { high-alloy steels. } \\
\text { Highly specialized } \\
\text { design and construction - } \\
\text { (exotic materials, liners, } \\
\text { power supplies, } \\
\text { dimensional tolerances, } \\
\text { etc.) are required for } \\
\text { key components. "In - } \\
\text { process" materials } \\
\text { exhibit high specific } \\
\text { energy. Mixing of } \\
\text { process streams with air } \\
\text { or water potentially } \\
\text { catastrophic. } \\
\text { Maintenance } \\
\text { requirements are } \\
\text { complex and direct } \\
\text { involvement by } \\
\text { personnel is required. }\end{array}$ \\
\hline
\end{tabular}


Figure 1 shows a generalized waste treatment flowsheet, which depicts the relationship of the evaluated primary treatment process to other elements of an integrated processing system. Stream 2 is the untreated primary waste entering the primary treatment process, and treated primary waste is Stream 3. Primary waste includes treatment residues such as waste resulting from precipitation of heavy metals or radionuclides. Waste that results from material that is added to the process (e.g., scrubber sludge, adsorbent beds, support media, or filters) will be considered as secondary waste (Streams 5 and 6 ).

Preferred primary treatment processes will not require significant pretreatment or postreatment to effectively destroy the target hazardous constituents. Similarly, preferred technologies will not require extensive auxiliary and support systems for pollution control and treatment of secondary wastes.

\subsection{Readiness For Deployment}

Preferred technologies will be based on sound and well-understood scientific and technical principles, and will be suited for application in radioactive service. Radioactive service implies stringent requirements for containment, monitoring, reliability, availability, maintainability, materials accountability, personnel protection, and remote or semi-remote materials handling and processing.

The following criteria were used to evaluate and rank the readiness for deployment of candidate waste treatment technologies.

Level of Development and Understanding: Preferred technologies will be demonstrated at the pilot scale or greater to include any ancillary processes required for recovery and recycle of working fluids. Major scale-up issues will be understood and an overall system concept for application of the technology will be available. Development and understanding of preferred technologies will be adequate to support adaptation to radioactive service, and prototype demonstration on simulated or actual MLLW.

Suitability for Radioactive Service: Key criteria for evaluating a technology's suitability for radioactive service include Operating Conditions and system Complexity. Operating conditions are evaluated under Environment, safety, and health concerns below. Preferred technologies allow the destruction process to be completed in one or two steps in process equipment of conventional design. Standard support systems and systems for reconditioning or recycle of process working fluids or side streams are used. Likewise, extensive pretreatment and postreatment are not required (See Figure 1), and needed pre- and postreatment processes are proven and available.

\subsection{Environment, Safety, and Health}

Preferred technologies are those that provide little or no additional risk to workers, the public, or the environment. Technologies will be evaluated on occupational safety and health issues, chemical and radiological hazards, pollution issues, and mechanical and electrical hazards. Environment, safety, and health (ES\&H) is a very important issue when installing and operating a waste treatment system. Safety is so important that it is assumed that any treatment technology that is implemented will be engineered and operated to provide the maximum protection of human health and the environment. Since the installation of any technology will be designed safe, this cannot be a discriminator for evaluating technologies. Rather, technologies will be evaluated on the difficulty in meeting the following ES\&H requirements, and it is this difficulty in designing and operating a process safely that can discriminate between technologies. 


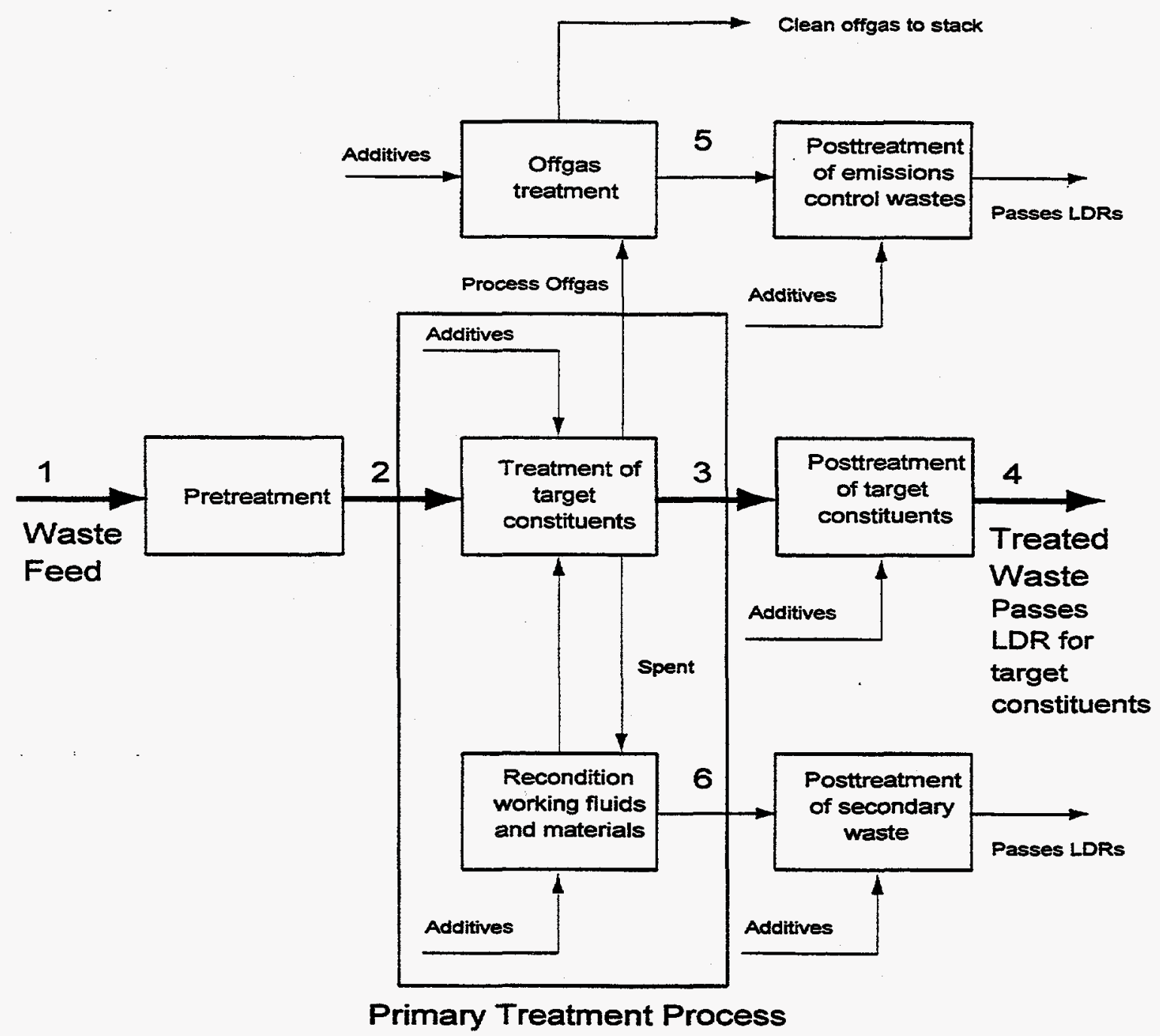

Figure 1. Generalized waste treatment flowsheet.

Emissions: Preferred technologies will not produce emissions that are difficult to control. Preferred processes will exhibit emissions having (1) low specific volume with respect to unit waste treated, (2) low concentrations and mobility of hazardous and radioactive components, and (3) secondary wastes or emissions that can be easily treated by known means. The ability to recover and recycle emissions, such as acid gases or spent reagents, into the process is also preferred. Preferred processes have minimum potential of forming mobile species of dioxins, furans, or other reaction or recombination products that are regulated or generally known or widely perceived to be toxic, carcinogenic, or otherwise hazardous. Emissions or effluent will be considered as coming from the primary operation and sent to some auxiliary cleanup process (e.g., offgas is sent to an APC system). Emissions evaluated are not those discharged to the environment. The emissions will be evaluated with respect to the volume and difficulty of treatment in the auxiliary process.

Worker Health and Safety: Preferred technologies can be easily designed and engineered for ease of scheduled and unscheduled maintenance with acceptable risk to workers. Those technologies that are complex and difficult to maintain, have excessive maintenance requirements or require long downtime, and have the potential to expose maintenance personnel to radioactive or hazardous conditions or materials receive a low score. Preferred technologies operate near ambient pressure and temperature, have small inventories of "in process" material, are easily controlled, and cause minimal concern for corrosion, erosion, 
or mixing of process streams with air or water. Complex systems which conduct chemical and physical processing at extreme conditions (temperature, pressure, flow, concentration, power density, etc.) are more difficult to contain, monitor, and control. Margins of safety are narrower and process and equipment reliability, availability, and maintainability are reduced.

\subsection{Application of Criteria}

These categories and criteria were compared against each other in a pairwise fashion using "Expert Choice" decision support software 3 to determine the importance of each and to develop weighting factors. Each technology was evaluated against each of the criteria and rated as high, medium, or low. These rating factors were also compared to each other in a pairwise fashion with respect to the preference of a high rating over a medium rating, etc. The resulting weighting factors for the criteria and the rating factors are shown in Table 3.

Table 3. Weighting factors for criteria and rating factors.

\begin{tabular}{cll}
\hline \multicolumn{3}{c}{ Criteria } \\
\hline Performance & \multicolumn{1}{c}{ Readiness } & \multicolumn{1}{c}{ ES\&H } \\
0.603 & 0.186 & 0.21 \\
\hline Range of Feed: 0.25 & Level of Development: 0.485 & Emissions: 0.447 \\
Treatment Effectiveness: 0.75 & Complexity: 0.515 & Worker Health and Safety: 0.553 \\
\hline \multicolumn{3}{c}{ Rating Factors } \\
\hline High: $0.649(1.000)$ & Medium: $0.279(0.430)$ & Low: $0.072(0.111)$ \\
\hline
\end{tabular}

The weighting factors for the categories add to unity, and the criteria under each category add to unity. The rating factors also add to unity; however, the rating factors are divided by the highest rating $(0.649)$ to obtain the numbers in parentheses in Table 3, and the criteria are multiplied by these modified rating factors. For example, if technology $A$ is rated high for range of feed, then its score for this criterion would be as follows:

$$
\text { Score }(A \text { - range })=0.25 \times 0.603 \times 1.0=0.151
$$

If this technology is rated medium for complexity, its score for this criterion would be:

$$
\text { Score }(A-\text { complexity })=0.515 \times 0.186 \times 0.43=0.041
$$

Thus, technologies rated high receive the full weighting of the criteria and categories, whereas technologies rated lower receive a fraction of the criteria weighting factors. Thus, a medium rating received $43 \%$ of the maximum score associated with the criteria, and a low rating only $11.1 \%$ of the maximum. This division of the rating factors by the highest rating (i.e., 0.649 ) is a mathematical construct of the Expert Choice software and does not change the final results or prioritization of the technologies.

As indicated in Table 3, performance is considered significantly more important that either readiness for implementation or ES\&H. If a technology cannot perform well by destroying a variety of contaminants on various DOE waste matrices, then its readiness for deployment or safety is not relevant. The readiness and safety of a technology can also be improved through engineering design and development. The criteria Level of Development and Complexity are nearly equal in importance, as are Emissions and Worker Health and Safety. However, Treatment Effectiveness is considered strongly more important than Range of Feed Material. Again, if the treatment is not effective, it doesn't matter how many waste matrices can be fed to the process. 
Each technology is given a rating (high, medium or low) for each criterion. The criterion and category weighting factors are multiplied, and then multiplied by the modified rating factor again using "Expert Choice." These scores are then added for the given technology to obtain a total score.

Technologies with the highest scores received the highest overall ratings for the various criteria as discussed in the next section. 


\section{RESULTS}

\subsection{Evaluation Results}

The methodology used to evaluate and prioritize the technologies was based on the Analytical Hierarchy Process, which is the basis for the "Expert Choice" decision support software. ${ }^{3}$ The technologies were evaluated against the criteria and given a high, medium, or low ranking. Criteria ranked between high and medium, or between medium and low, were given a numerical ranking between the rating factors shown in Table 3. The technologies were then prioritized as shown in Table 4, which provides a global ranking of all the technologies, the total score for each technology, and the ranking each technology received for each of the criteria.

The rationale for the rating factors assigned to the technologies for each of the criteria is provided in Appendix A. It is important to understand that these rating factors were applied with limited knowledge, with inadequate test data, and in most cases minimal or no reported operating experience. Thus, there is significant uncertainty associated with the rankings and, because in many cases there is little difference between the technology rankings, selection of one technology as "better" than another would be speculative. Also, further testing on a pilot scale to provide operational experience, and evolution and improvement of the process designs based on pilot-scale studies, may have a significant effect on these results.

The highest-ranked technology is steam reforming due to its ability to treat most waste matrices and decompose most organic contaminants. This is a highly effective but complex system that requires waste size reduction, a complex feed system, and offgas treatment, but is nearly ready for deployment. Three of the highly ranked technologies (electron beam, UV photooxidation, and ultrasonics) are rated low in range of feed material because they are applicable to only aqueous waste. The high ranking is due to their safety with few emissions, simplicity, and relatively high level of development. The ranking of these aqueous waste treatment technologies is nearly equal; differences are primarily in their level of development, complexity (UV photooxidation was downgraded because of the greater need for pretreatment), and range of feed.

Several condensed-phase chemical oxidation processes (Cerium Mediated Electrochemical Oxidation [MEO], DETOXSM, and Direct Chemical Oxidation) ranked near the middle to high range of the technologies evaluated. These technologies ranked medium to high for ES\&H, and medium to high with respect to performance. These technologies received lower overall rankings because they need significant development and demonstration before they are ready for deployment, and are somewhat complex due to the recycle streams required to recover reagents. Although these recycle streams may not prove to be significant, the overall processes have not been fully designed and demonstrated on a continuous basis.

\subsection{Sensitivity Analysis}

The effect of the weighting factors on the ranking of the technologies can be seen by comparing the results in Table 4 with the results in Table 5. In Table 5 the importance of the three categories were assumed to be equal so that the weighting factors were equal. The importance of the criteria for each of the categories was assumed to be the same as in Table 3. For this case, the importance of performance is suppressed, and technologies that rated high in ES\&H and readiness for deployment ranked high overall. 
Table 4. Results of technology evaluation. a $^{a}$

\begin{tabular}{|c|c|c|c|c|c|c|c|}
\hline \multirow[b]{2}{*}{ Alternatives } & \multirow[b]{2}{*}{$\begin{array}{l}\text { Total } \\
\text { Score }\end{array}$} & \multicolumn{2}{|c|}{ Performance } & \multicolumn{2}{|c|}{ Readiness } & \multicolumn{2}{|c|}{ ES\&H } \\
\hline & & Range of Feed & $\begin{array}{c}\text { Treatment } \\
\text { Effectiveness }\end{array}$ & $\begin{array}{c}\text { Level of } \\
\text { Development }\end{array}$ & Complexity & Emissions & $\begin{array}{c}\text { Worker Health \& } \\
\text { Safety }\end{array}$ \\
\hline Steam Reforming & 0.740 & High & High & Medium & 0.271 & Medium & 0.271 \\
\hline Electron Beam & 0.737 & Low & 0.715 & High & High & High & High \\
\hline UV Photo-Oxidation & 0.727 & Low & 0.715 & High & 0.9 & High & High \\
\hline Ultrasonics & 0.699 & Medium & 0.715 & 0.35 & High & 0.715 & High \\
\hline Eco Logic & 0.690 & Medium & High & High & Low & Medium & 0.271 \\
\hline Supercritical Water & 0.672 & 0.271 & High & Medium & Medium & 0.715 & 0.271 \\
\hline Cerium MEO & 0.622 & 0.271 & 0.715 & 0.9 & 0.271 & 0.715 & 0.715 \\
\hline DETOXSM & 0.593 & 0.715 & 0.715 & 0.5 & 0.271 & Medium & Medium \\
\hline Direct Chemical Oxidation & 0.515 & 0.715 & Medium & 0.2 & Low & 0.715 & 0.715 \\
\hline Neutralization/Hydrolysis & 0.515 & Low & Medium & 0.271 & 0.715 & High & High \\
\hline Electrohydraulic Discharge & 0.509 & Low & 0.715 & Low & Medium & 0.715 & Medium \\
\hline Wet Air Oxidation & 0.484 & 0.271 & Medium & High & Medium & 0.715 & Medium \\
\hline Liquid Corona & 0.482 & Low & 0.715 & Low & Medium & Medium & Medium \\
\hline X-Ray/Gamma Ray & 0.475 & Low & 0.271 & Medium & 0.9 & High & High \\
\hline Wet Oxidation & 0.473 & 0.271 & 0.271 & High & 0.715 & 0.715 & 0.715 \\
\hline Photo-Catalytic Oxidation & 0.472 & Low & Medium & 0.271 & 0.271 & High & High \\
\hline Chromox & 0.460 & Low & Medium & 0.271 & Medium & 0.715 & High \\
\hline ChemChar & 0.456 & 0.271 & 0.715 & 0.271 & Low & 0.271 & 0.271 \\
\hline Silver MEO & 0.421 & 0.271 & 0.271 & 0.9 & 0.271 & 0.715 & 0.715 \\
\hline $\begin{array}{l}\text { Electrochemical } \\
\text { Peroxidation }\end{array}$ & 0.373 & 0.271 & 0.271 & 0.2 & Medium & 0.715 & 0.715 \\
\hline Cobalt MEO & 0.350 & 0.271 & 0.271 & Low & 0.271 & 0.715 & 0.715 \\
\hline MIOX & 0.283 & Low & Low & 0.271 & Medium & 0.715 & 0.715 \\
\hline Acid Digestion & 0.217 & 0.271 & Low & Low & 0.271 & Medium & Medium \\
\hline
\end{tabular}

a. The numerical ratings in Table 4 were assigned when the authors rated a technology between high and medium or between medium and low. The numerical values of high, medium and low ratings are given in Table 3. 
Table 5. Results of technology evaluation with equal importance assigned to categories.

\begin{tabular}{|c|c|c|c|c|c|c|c|}
\hline \multirow[b]{2}{*}{ Alternatives } & \multirow[b]{2}{*}{$\begin{array}{l}\text { Total } \\
\text { Score }\end{array}$} & \multicolumn{2}{|c|}{ Performance } & \multicolumn{2}{|c|}{ Readiness } & \multicolumn{2}{|c|}{ ES\&H } \\
\hline & & Range of Feed & $\begin{array}{c}\text { Treatment } \\
\text { Effectiveness }\end{array}$ & $\begin{array}{c}\text { Level of } \\
\text { Development }\end{array}$ & Complexity & Emissions & $\begin{array}{l}\text { Worker Health } \\
\text { \& Safety }\end{array}$ \\
\hline Electron Beam & 0.855 & Low & 0.715 & High & High & High & High \\
\hline UV Photo-Oxidation & 0.837 & Low & 0.715 & High & 0.9 & High & High \\
\hline Ultrasonics & 0.734 & Medium & 0.715 & 0.35 & High & 0.715 & High \\
\hline X-Ray/Gamma Ray & 0.634 & Low & 0.271 & Medium & 0.9 & High & High \\
\hline Cerium MEO & 0.632 & 0.271 & 0.715 & 0.9 & 0.271 & 0.715 & 0.715 \\
\hline Neutralization/Hydrolysis & 0.617 & Low & Medium & 0.271 & 0.715 & High & High \\
\hline Wet Oxidation & 0.613 & 0.271 & 0.271 & High & 0.715 & 0.715 & 0.715 \\
\hline Eco Logic & 0.580 & Medium & High & High & Low & Medium & 0.271 \\
\hline Supercritical Water & 0.572 & 0.271 & High & Medium & Medium & 0.715 & 0.271 \\
\hline Steam Reforming & 0.563 & High & High & Medium & 0.271 & Medium & 0.271 \\
\hline Wet Air Oxidation & 0.551 & 0.271 & Medium & High & Medium & 0.715 & Medium \\
\hline Photo-Catalytic Oxidation & 0.540 & Low & Medium & 0.271 & 0.271 & High & High \\
\hline Chromox & 0.525 & Low & Medium & 0.271 & Medium & 0.715 & High \\
\hline Silver MEO & 0.521 & 0.271 & 0.271 & 0.9 & 0.271 & 0.715 & 0.715 \\
\hline Direct Chemical Oxidation & 0.509 & 0.715 & Medium & 0.2 & Low & 0.715 & 0.715 \\
\hline DETOXSM & 0.509 & 0.715 & 0.715 & 0.5 & 0.271 & Medium & Medium \\
\hline Electrohydraulic Discharge & 0.465 & Low & 0.715 & Low & Medium & 0.715 & Medium \\
\hline $\begin{array}{l}\text { Electrochemical } \\
\text { Peroxidation }\end{array}$ & 0.435 & 0.271 & 0.271 & 0.2 & Medium & 0.715 & 0.715 \\
\hline Liquid Corona & 0.423 & Low & 0.715 & Low & Medium & Medium & Medium \\
\hline Cobalt MEO & 0.393 & 0.271 & 0.271 & Low & 0.271 & 0.715 & 0.715 \\
\hline MIOX & 0.393 & Low & Low & 0.271 & Medium & 0.715 & 0.715 \\
\hline ChemChar & 0.354 & 0.271 & 0.715 & 0.271 & Low & 0.271 & 0.271 \\
\hline Acid Digestion & 0.258 & 0.271 & Low & Low & 0.271 & Medium & Medium \\
\hline
\end{tabular}


Technologies that have high performance are generally very aggressive and therefore may be rated relatively low with respect to ES\&H. Thus, for equal importance of the categories, technologies that are farther along in development, better characterized and tested, and that are simpler and safer receive a higher overall ranking although most are not very aggressive and suffer in their performance and applicability to the various mixed waste streams.

Another way to look at these technologies is to eliminate the criterion "Level of Development," which is related to the maturity of the technology. Once this criterion is eliminated, the category of Readiness for Deployment consists of only the criterion of Complexity, which will have a weighting factor of unity. Assuming the weighting factors for the categories and the same weighting factors for the remaining criteria as shown in Table 3, the results of the evaluation is shown in Table 6. By eliminating consideration of the maturity of a technology, some of the less mature technologies move up slightly in the ratings, but there is no significant change in prioritization. The technologies that are limited to aqueous waste treatment, and that rate high for complexity and ES\&H, are still ranked high overall although their usefulness to the mixed waste problem is limited. 
Table 6. Results of technology evaluation with elimination of "Level of Development" criterion.

\begin{tabular}{|c|c|c|c|c|c|c|}
\hline \multirow[b]{2}{*}{ Alternatives } & \multirow[b]{2}{*}{$\begin{array}{l}\text { Total } \\
\text { Score }\end{array}$} & \multicolumn{2}{|c|}{ Performance } & \multirow{2}{*}{$\begin{array}{l}\text { Readiness } \\
\text { Complexity }\end{array}$} & \multicolumn{2}{|c|}{ ES\&H } \\
\hline & & Range of Feed & $\begin{array}{c}\text { Treatment } \\
\text { Effectiveness }\end{array}$ & & Emissions & $\begin{array}{c}\text { Worker Health \& } \\
\text { Safety }\end{array}$ \\
\hline Ultrasonics & 0.758 & Medium & 0.715 & High & 0.715 & High \\
\hline Electron Beam & 0.737 & Low & 0.715 & High & High & High \\
\hline Steam Reforming & 0.726 & High & High & 0.271 & Medium & 0.271 \\
\hline UV Photo-Oxidation & 0.718 & Low & 0.715 & 0.9 & High & High \\
\hline Supercritical Water & 0.672 & 0.271 & High & Medium & 0.715 & 0.271 \\
\hline Eco Logic & 0.610 & Medium & High & Low & Medium & 0.271 \\
\hline DETOXSM & 0.572 & 0.715 & 0.715 & 0.271 & Medium & Medium \\
\hline Cerium MEO & 0.565 & 0.271 & 0.715 & 0.271 & 0.715 & 0.715 \\
\hline Neutralization/Hydrolysis & 0.555 & Low & Medium & 0.715 & High & High \\
\hline Electrohydraulic Discharge & 0.537 & Low & 0.715 & Medium & 0.715 & Medium \\
\hline X-Ray/Gamma Ray & 0.517 & Low & 0.271 & 0.9 & High & High \\
\hline Liquid Corona & 0.511 & Low & 0.715 & Medium & Medium & Medium \\
\hline Direct Chemical Oxidation & 0.507 & 0.715 & Medium & Low & 0.715 & 0.715 \\
\hline Chromox & 0.475 & Low & Medium & Medium & 0.715 & High \\
\hline Photo-Catalytic Oxidation & 0.472 & Low & Medium & 0.271 & High & High \\
\hline Wet Oxidation & 0.447 & 0.271 & 0.271 & 0.715 & 0.715 & 0.715 \\
\hline ChemChar & 0.442 & 0.271 & 0.715 & Low & 0.271 & 0.271 \\
\hline Wet Air Oxidation & 0.433 & 0.271 & Medium & Medium & 0.715 & Medium \\
\hline Electrochemical Peroxidation & 0.394 & 0.271 & 0.271 & Medium & 0.715 & 0.715 \\
\hline Silver MEO & 0.364 & 0.271 & 0.271 & 0.271 & 0.715 & 0.715 \\
\hline Cobalt MEO & 0.364 & 0.271 & 0.271 & 0.271 & 0.715 & 0.715 \\
\hline MIOX & 0.297 & Low & Low & Medium & 0.715 & 0.715 \\
\hline Acid Digestion & 0.232 & 0.271 & Low & 0.271 & Medium & Medium \\
\hline
\end{tabular}




\section{CONCLUSIONS AND RECOMMENDATIONS}

\subsection{Conclusions}

Regardless of the importance assigned to the criteria, those nonaggressive technologies with limited applicability to the mixed waste problem had a high overall ranking. This was especially true when the performance criteria were suppressed and made equal to the readiness for deployment and ES\&H criteria. These less aggressive technologies may find suitable, or niche, applications at locations with single waste streams or small quantities of a few amenable waste streams. However, to make the greatest impact on the MLLW problem, technologies chosen for further development or investigation should be those that can treat the largest percentage of organically contaminated waste. This means that, in general, the more aggressive processes that are more complex and difficult to engineer for operation and ES\&H compliance are preferred. However, this study has shown that that none of these technologies alone can replace the functions of an incinerator. It will be necessary to provide significantly more pretreatment than is necessary with an incinerator, or employ several treatment processes to treat all types of waste matrices.

The technologies evaluated in this report are listed in Table 7 in order of their overall rankings and according to the waste matrices for which they are primarily applicable. The first column lists those technologies developed primarily to treat organic compounds in aqueous wastes. Column 2 lists the technologies best suited to organic liquids and unsolidified organic sludges. These technologies have been developed and tested primarily on liquid organics with some limited testing on organic sludge type material such as ion exchange resins. Only supercritical water oxidation appears in both the first and second columns; however, this technology is applicable to organic liquids and sludges only if diluted in an aqueous solution or suspension. Column 3 lists those technologies considered most applicable to combustible debris. Of the technologies in the third column, only acid digestion is being developed specifically for the purpose of destroying combustible debris. Placing technologies into these categories is not meant to imply that technologies such as steam reforming, ChemChar, and others cannot be used to treat aqueous wastes; however, their primary application would be for the more difficult waste streams because simpler and cheaper technologies are available to treat the aqueous waste streams.

While the initial direction of this evaluation was towards the organic matrices deemed most amenable to treatment by alternative technologies, it is clear that the waste categories in Table 7 represent only a minor fraction of the DOE MLLW that is contaminated with regulated organics. From Table 1, the contribution of these waste matrices to the organically contaminated MLLW is as follows:

\begin{tabular}{lr} 
Wastewaters with organics & $5.6 \%$ \\
Organic liquids & $3.7 \%$ \\
Organic matrix sludges & $1.1 \%$ \\
Combustible debris & $\underline{8.7 \%}$ \\
\multicolumn{1}{c}{ Total } & $19.1 \%$
\end{tabular}


Table 7. Technologies and applicable aqueous and organic waste streams.

\begin{tabular}{|c|c|c|c|c|c|}
\hline $\begin{array}{c}\text { Wastewater } \\
\text { (1000 Wastes) }\end{array}$ & Rank & $\begin{array}{l}\text { Organic Liquids ( } 2000 \\
\text { Wastes) and Organic } \\
\text { Sludges ( } 3200 \text { Wastes) }\end{array}$ & Rank & $\begin{array}{c}\text { Combustible } \\
\text { Debris } \\
\text { (5300 Wastes) }\end{array}$ & Rank \\
\hline Electron Beam & 0.737 & Steam Reforming & 0.740 & Steam Reforming & 0.740 \\
\hline UV Photo-Oxidation & 0.727 & Eco Logic & 0.690 & Eco Logic & 0.690 \\
\hline Ultrasonics & 0.699 & $\begin{array}{c}\text { Supercritical Water } \\
\text { Oxidation }\end{array}$ & 0.672 & DETOXSM & 0.593 \\
\hline $\begin{array}{l}\text { Supercritical Water } \\
\text { Oxidation }\end{array}$ & 0.672 & Cerium MEO & 0.622 & $\begin{array}{l}\text { Direct Chemical } \\
\text { Oxidation }\end{array}$ & 0.515 \\
\hline $\begin{array}{l}\text { Electrohydraulic } \\
\text { Discharge }\end{array}$ & 0.509 & DETOXSM & 0.593 & ChemChar & 0.456 \\
\hline Wet Air Oxidation & 0.484 & $\begin{array}{c}\text { Neutralization/Hydrol } \\
\text { ysis }\end{array}$ & 0.515 & Acid Digestion & 0.217 \\
\hline Liquid Corona & 0.482 & $\begin{array}{c}\text { Direct Chemical } \\
\text { Oxidation }\end{array}$ & 0.515 & & \\
\hline $\begin{array}{l}\text { Photo-Catalytic } \\
\text { Oxidation }\end{array}$ & 0.472 & X-Ray/Gamma Ray & 0.475 & & \\
\hline Chromox & 0.460 & Wet Oxidation & 0.473 & & \\
\hline $\begin{array}{l}\text { Electrochemical } \\
\text { Peroxidation }\end{array}$ & 0.373 & ChemChar & 0.456 & & \\
\hline \multirow[t]{3}{*}{ MIOX } & 0.283 & Silver MEO & 0.421 & & \\
\hline & & Cobalt MEO & 0.350 & & \\
\hline & & Acid Digestion & 0.217 & & \\
\hline
\end{tabular}

This leaves nearly $80 \%$ of the organically contaminated waste unaddressed. The largest single category that is not addressed by these alternative technologies is inorganic homogeneous solids at $37.1 \%$, which may be anything from unstabilized filter cake to stabilized sludges exhibiting properties of moderately strong concrete. Another significant category is soils at $15.2 \%$ of the total of organically contaminated wastes. Inorganic and uncategorized debris make up an additional $28.3 \%$ of the total. It is clear that the technologies under consideration have not directly addressed the major MLLW problem facing DOE. However, thermal desorption can remove many of the organic contaminants from these inorganic matrices such that the organics are in a form that can be treated by these alternative technologies. It should be noted, however, that the ability to achieve the EPA's Universal Treatment Standards depends on the nature of the contaminant, the nature of the contaminated surface, and that adequate desorption of organics from sludges has not been demonstrated.

To treat these homogeneous solids and debris categories of waste, the waste must be removed from the container and size reduced by shredding and/or grinding to allow feeding to an organic separation or destruction process. Size reduction must be sufficient to expose the organic contaminants for dissolution in the working solution or direct attack by the oxidizing agent. This is a process step that requires demonstration for any alternative technology considered applicable to organically contaminated inorganic waste matrices.

Conflicting requirements arise in the treatment of these complex materials by a condensed phase process. For example, it is necessary to open the matrix to expose the organic contaminants and provide for dispersion or direct oxidation. At the same time it is desirable to limit the dissolution or suspension of 
inorganic materials into the solution. The primary constituent of many of these wastes include silica, alumina, carbonates, etc., and many of these wastes contain adsorbents such as vermiculite or clay and/or stabilizing agents ranging from calcium silicate to Portland cement. Under most conditions some of the inorganic matrix material will dissolve in the process solution, and separation of dissolved and suspended solids and recycle of the working solution will be a general requirement for an economical process and waste minimization. It is preferable that the working solution not dissolve a large portion of the inert inorganic constituents as this will rapidly deplete the oxidizing agent and increase the frequency of regeneration of the working fluid, associated downtime, and secondary waste.

Although none of these technologies have been demonstrated on the major waste streams such as organically contaminated soils, sludges, or debris, several may be applicable to treatment of these solid inorganic waste matrices. Steam reforming and Eco Logic may be applicable if the waste can be adequately size reduced to allow contact between the steam or hydrogen and the solid waste particles to volatilize and desorb the organic contaminants. With steam reforming there are issues to be resolved associated with the ability to maintain a fluidized bed with the waste feed, contamination of the bed with heavy metals and radionuclides, and the volume and rate of secondary waste generated. ChemChar may be applicable to organicaliy contaminated solids by size reducing and mixing the solids with the char. Condensed phase chemical oxidation processes such as DETOXSM, acid digestion, and direct chemical oxidation may also be applicable to inorganic solid wastes depending on the solubility of the inert matrix in these solutions. Ultrasonics may also be applicable to slurried soils and sludges; there is evidence that the ultrasonic action may remove organic contaminants from the particles and subsequently destroy the organics once in the aqueous phase. At this time, however, the applicability of these technologies to these waste matrices is conjecture, and demonstration with a significant development effort will be required.

\subsection{Technology Recommendations}

While efforts continue to improve incinerators and other thermal systems to decrease emissions, improve the ability to control the process during upset conditions, and gain public acceptance, research and development on a few alternative systems should also continue to improve effectiveness and operational reliability.

The technologies in the last column of Table 7 are being developed to treat organic liquids, organic sludges, and organic debris. These six technologies may have the potential to treat the inorganic wastes contaminated with organics. However, none of these technologies has the capability of incinerators or certain other thermal systems (e.g., plasma, DC arc, or vitrification systems) to treat the large variety of MLLW in the DOE complex in a single, relatively simple and straightforward process. Aqueous-based oxidation technologies are available commercially and limited to aqueous wastes with relatively low concentrations of organic contaminants. Other, more aggressive alternative technologies require significant size reduction of the wastes, leading to higher costs and safety issues associated with containment of dusts and powders in the comminution equipment. Application of strong acid-based systems to inorganic matrices may rapidly deplete the reagent and increase its solids content through dissolution of inert solids, thereby increasing the downtime required for removal of solids and replacement of fresh reagent. Thus, thermal technologies with improved offgas treatment, monitoring, and controls should be more cost effective.

However, some alternative technologies may have niche applications for waste streams for which open flame combustion or high temperatures may pose some risk, or which pose problems associated with transportation to an existing thermal unit. These technologies will require significant and relatively complex support subsystems. The technologies recommended discussed below have the ability to treat a relatively small volume of the DOE mixed waste consisting of organic matrices. Aqueous wastes and substantially pure organic wastes are relatively easy to address and treat, and aqueous wastes can be 
treated using available technologies. The more difficult problem, and a more significant volume of waste, is the organically contaminated inorganics matrices such as soils, inorganic sludges and debris that can be treated in several thermal systems. To our knowledge, no alternative technology has been demonstrated to treat these waste matrices directly - and this is one of their shortcomings.

The authors recommend continued development of steam reforming, DETOXSM, and/or direct chemical oxidation (DCO). These technologies are the more aggressive of the technologies evaluated and have the potential to treat a larger variety of waste streams to the regulatory requirements, including the difficult inorganic wastes. Development should address design and demonstration of these technologies as complete systems for these waste streams. As indicated previously, pretreatment by organic separation processes (thermal desorption or washing) may be applicable to some soil and debris matrices and some contaminants; however, it will be very difficult to make these separation processes work effectively and economically on the full range of DOE inorganic sludges.

The technologies recommended by this report are as follows:

Steam Reforming: Because of the higher rating of steam reforming, its greater treatment effectiveness and advanced stage of development, the recommendation is to fund development of steam reforming for treatment of organic and large volume inorganic matrix waste streams, including the offgas system and thermal oxidizer for treatment of the combustible offgas from the steam reformer.

It is important to test the steam reformer for proper operation and control and for the ability to provide environmental protection. Tests should be performed on mixtures of refractory chlorinated organic materials, including dioxin precursors, and to measure for dioxins in the offgas before and after the thermal oxidizer. Measurements for dioxins and furans, and determination of the conditions under which such compounds may or may not be found in the offgas, are important to obtain public acceptance of the technology. The ability to size reduce, feed, and treat organically contaminated inorganic waste matrices must also be demonstrated for steam reforming to be widely accepted in the DOE complex as something other than an expensive process that can only treat a small fraction of easily treatable wastes.

Nonthermal Technologies: DETOXSM or the DCO (peroxydisulfate) processes should be considered as alternative technologies for further testing. DETOXSM is more aggressive and appears to have a higher destruction efficiency and may be able to treat more wastes, but DCO may have fewer corrosion and operational problems to overcome. However, there is concern for excessive dissolution or suspension of inert inorganic materials in the working solutions. Both processes should be tested side-byside on a variety of organic contaminants, mixtures of organics, combustible debris, and organically contaminated inorganic waste matrices. Destruction efficiencies, reaction by-products (in particular dioxins and furans in the liquid and offgas phases), and the solubility of inert constituents of sludges, soils, and inorganic debris should be determined. Operational problems and potential solutions should be identified. The two technologies can then be evaluated to determine whether to proceed with further development of both, one, or neither.

Based on our evaluation of technologies summarized in this report, there is no reason to believe that nonthermal, condensed-phase processes will produce fewer products of incomplete reaction than thermal processes. However, nonthermal processes emit significantly smaller offgas volumes than traditional incinerators using excess air for combustion, and the products of incomplete reaction may be better contained and controlled in the condensed, or liquid, phase. Processing the waste in a closed loop, batch operation may provide sufficient residence time to significantly reduce reaction byproducts. In addition, aggressive processes such as DETOXSM or direct chemical oxidation (peroxydisulfate), may be capable of treating the more prevalent inorganic waste streams if the inert waste matrices are found to have limited solubility in the oxidizing solution or to have limited impact on the cost or throughput of these processes. 
Aqueous Waste Treatment: Aqueous wastes are $7.1 \%$ of the total MLLW, but only $3.8 \%$ of the organically contaminated MLLW. Although significant quantities of aqueous waste will be generated by the treatment of other waste streams, commercial technologies are available to treat aqueous wastes (e.g., UV photo-oxidation, activated carbon adsorption, air and steam stripping), and treatment of aqueous waste was not considered a deficiency by the MWFA. 4 UV photo-oxidation and electron beam technologies have been fairly well developed and demonstrated, and are applicable to only aqueous wastes. UV photo-oxidation may benefit by improving lamp designs to improve destruction of chlorinated aromatic hydrocarbons, but this work should be done by the commercial sector. Thus, no new development work is recommended for this waste stream.

\subsection{Flowsheet and System Considerations}

These technologies have been reviewed and evaluated as stand-alone unit operations. However, any technology must operate within a system that involves removal of waste from the container, sorting, size reduction to expose internal contamination and allow feeding to the organic destruction process, treatment of secondary wastes and effluents, and regeneration and recycle of oxidizing agents. Thus, development and demonstration of these ancillary functions that allow proper operation of the organic destruction technology on the selected waste stream is imperative. For the case of solidified sludges, adequate size reduction that exposes internal contaminants must be demonstrated before steam reforming or a condensed phase process can be said to be applicable to this waste stream. The ability to economically remove dissolved and suspended solids from an acid solution to regenerate and/or recover the oxidizing agent must also be demonstrated for condensed phase processes.

Treatments selected for development and application should favor a small set of technologies that can handle the inorganic waste streams (e.g., the 3000,4000 , and 5000 category wastes). Only the higher ranked technologies in Table 4, and in particular the technologies in the last column of Table 7, should be considered further as these have the greatest potential for treating the largest volume of MLLW. The availability or need for development of ancillary technologies (e.g., size reduction equipment, feeders) should also be investigated, and complimentary combinations of technologies should be considered. There is always a potential for synergistic interactions between individual processes within an overall flowsheet or treatment facility. An important consideration is the potential for any given technology to be extended to treat the more difficult waste matrices discussed previously, and to be combined with other treatment processes to provide a comprehensive treatment capability.

The system concepts shown in the proposed flowsheets in Table 8 have the potential to provide treatment to all of DOE's MLLW. These also give a reference against which to define critical test and demonstration issues for the identified technologies. A great deal of effort has already been applied to the problem of aqueous waste treatment. Using the total system perspective, potential problems can be identified that have not been already considered and that may require further testing. A detailed system study of a complete process should precede further testing or development of organic destruction processes in wastewater treatment systems. This system study may identify issues that will necessitate a significant modification or change in the technologies identified for further development. 
Two conceptual process flowsheets are proposed for treatment of the 1000 (aqueous waste) through 5000 (debris waste) categories of MLLW: first is a system using the best combination of the alternative technologies, the second is a process using only nonthermal technologies as defined in this report. Thus, steam reforming, Eco Logic hydrogen reduction, supercritical water oxidation, and ChemChar are not included in the second flowsheet because these are nonincineration thermal technologies.

Table 8. Conceptual Flowsheets.

\begin{tabular}{|c|c|c|}
\hline \multicolumn{3}{|c|}{ Conceptual Flowsheet Using Thermal and Nonthermal Alternatives } \\
\hline Waste stream & Destination & Technology \\
\hline Aqueous & $\begin{array}{l}\text { Wastewater treatment with organic } \\
\text { destruction }\end{array}$ & UV Photo-Oxidation \\
\hline Organic liquids \& sludges & Organic destruction & Steam Reforming \\
\hline $\begin{array}{l}\text { Inorganic sludges, soils \& } \\
\text { combustible debris }\end{array}$ & $\begin{array}{l}\text { Separation, size reduction, pretreatment } \\
\text { \& organic destruction }\end{array}$ & Steam Reforming \\
\hline Inorganic debris & $\begin{array}{l}\text { Separation, size reduction, pretreatment } \\
\& \text { organic destruction }\end{array}$ & Steam Reforming \\
\hline \multicolumn{3}{|c|}{ Conceptual Flowsheet Using Nonthermal Alternatives } \\
\hline Waste stream & Destination & Technology \\
\hline Aqueous & $\begin{array}{l}\text { Wastewater treatment with organic } \\
\text { destruction }\end{array}$ & UV Photo-Oxidation \\
\hline $\begin{array}{l}\text { Organic liquids, sludges, } \\
\text { some inorganic solids, \& } \\
\text { combustible debris }\end{array}$ & Organic destruction & DETOXSM \\
\hline \multicolumn{3}{|c|}{$\begin{array}{l}\text { Suspended and dissolved solids may go the DCO for } \\
\text { treatment if still contaminated with organic. }\end{array}$} \\
\hline $\begin{array}{l}\text { Inorganic sludges, soils, \& } \\
\text { debris }\end{array}$ & $\begin{array}{l}\text { Size reduction, pretreatment and organic } \\
\text { destruction }\end{array}$ & $\begin{array}{l}\text { Direct Chemical } \\
\text { Oxidation }\end{array}$ \\
\hline \multicolumn{3}{|c|}{ Bleed stream from DCO goes to UV Photo-Oxidation } \\
\hline
\end{tabular}

\subsection{Development Issues for the Higher Ranked Technologies}

Steam Reforming: This is a high-temperature, starved air process in which oxygen is provided by superheated steam. The reactions occur in a fluidized bed, and the combustible reaction products are carried off in the offgas and destroyed in a thermal oxidizer. This combination makes this a very complicated feed preparation and first-stage (fluidized bed and starved air) reactor for a second-stage oxidation process. This technology appears to have potential for extension to inorganic matrices that will require significant size reduction to provide access for volatilization of the RCRA-regulated organic contaminant and attack by the oxidant. This process needs to be carefully tested to demonstrate whether or not dioxins, furans or other products of incomplete reaction occur in the offgas, where they occur (before or after the thermal oxidizer), their concentration, and under what conditions. The key development issues include:

- Reliable and practical methods of size reduction and feeding materials to the reactor to allow extension of this technology to the more prevalent inorganic waste streams. 
- Successful destruction of organic contaminants in inorganic waste matrices, including destruction of byproducts in the offgas.

- Offgas composition under various operating conditions and with various waste matrices and contaminants.

- Ability to maintain fluidization when treating inorganic waste matrices.

- Frequency of bed regeneration or replacement, secondary waste generation associated with contaminated bed material, and associated process economics.

Eco Logic Hydrogenolysis: This is a high-temperature, oxygen depleted process in which oxygen is supplied for reaction from steam present in the reactive gas mixture. Vaporized organics are mixed with a hydrogen-rich gas at 850 to $950^{\circ} \mathrm{C}$ and circulated to the primary organic destruction chamber. Excess gas is burned in an industrial furnace to provide heat and steam for the process. This combination makes this a very complex feed preparation and first-stage (desorption and starved air) reactor for a second-stage combustion process. As with steam reforming, this process needs to be carefully tested to demonstrate whether or not dioxins, furans or other products of incomplete reaction occur in the offgas, where they occur (before or after the thermal oxidizer), their concentration, and under what conditions. The key development issues include:

- Reliable and practical methods of size reduction and feeding materials to the reactor to allow volatilization of organics and extension of this technology to the more prevalent inorganic waste streams.

- Successful volatilization and destruction of organic contaminants in inorganic waste matrices, including destruction of byproducts in the offgas.

- Offgas composition under various operating conditions and with various waste matrices and contaminants.

- Ability to maintain a safe operating environment with high-temperature hydrogen as the primary reactant.

Supercritical Water Oxidation: This process oxidizes organics with air or oxygen in a hightemperature, high-pressure supercritical fluid environment. The process cannot tolerate many suspended solids, and any solids present must be reduced to below 100 microns. This technology is not applicable to the inorganic solid matrices, and it is questionable whether this process can tolerate combustible debris even if it is adequately size reduced. The key development issues include:

- Demonstration of effective means to avoid plugging the reactor with precipitated salts, or prevention of corrosion problems.

- Effective management of wastes to avoid runaway reactions, overpressures, and destruction of process equipment. 
- Development of process equipment that demonstrates safe operation of a system large enough to have practical capacity for application to DOE waste.

Cerium MEO: MEO operates in a $70^{\circ} \mathrm{C}$, atmospheric pressure, nitric acid solution to oxidize organics with an electrochemically generated strong metal oxidant. In this case, the oxidant is cerium-IV. This process is not sufficiently aggressive to be applicable to combustible debris; however, it has been applied successfully to various organic liquids and nonstabilized organic residues (i.e., ion exchange resins). The key development issues for this process include:

- Recovery of nitric acid decomposed by the electrochemical process.

- Removal of hydrochloric acid from the recycled nitric acid when treating chlorinated hydrocarbons to minimize corrosion and destruction of electrodes.

- Recovery of cerium to minimize secondary waste.

- Reliable and practical methods of size reduction to expose internal organic contaminants and allow extension of this technology to the more prevalent inorganic waste streams. Treatment of these inorganic waste matrices without excessive solubilization of the matrix materials must also be demonstrated.

- Production of dioxins or furans in the offgas or process solution, and if so, under what conditions.

DETOXSM: This technology operates at intermediate temperatures $\left(100\right.$ to $\left.200^{\circ} \mathrm{C}\right)$ and pressures $(\sim 20 \mathrm{psig})$ in a concentrated iron chloride - hydrochloric acid solution. The active oxidant is the ferric ion. Good destruction efficiencies have been shown for most organic materials tested, and the process solution is sufficiently aggressive to be applicable to most combustible debris materials. The key development issues for this process include:

- Operability, reliability, and maintainability of equipment in the highly corrosive environment.

- Recovery of process solution and removal of dissolved and suspended solids to minimize loss of working solution and avoid generation of secondary waste.

- Reliable and practical methods of size reduction to expose internal organic contaminants and allow extension of this technology to the more prevalent inorganic waste streams.

- Treatment of these inorganic waste matrices without excessive solubilization of the matrix materials must also be demonstrated.

Production of dioxins or furans in the offgas or process solution, and if so, under what conditions. 
Direct Chemical Oxidation: Direct chemical oxidation (DCO) uses peroxydisulfate to destroy organic materials in a sulfuric acid solution. The oxidant is regenerated in an external recycle loop using an electrochemical process. This process demonstrates good destruction effectiveness for dissolved organics, but only limited success for treatment of combustible debris. Key development issues include:

- Reliable and practical methods of size reduction to expose internal organic contaminants and allow extension of this technology to the more prevalent inorganic waste streams.

- Treatment of these inorganic waste matrices without excessive solubilization of the matrix materials must also be demonstrated.

- Operability, reliability and maintainability of equipment as a fully operable system.

- Recovery of process solution, removal of dissolved and suspended solids, and regeneration of peroxydisulfate to minimize secondary waste.

- Production of dioxins or furans in the offgas or process solution, and if so, under what conditions.

Electron Beam: This process is applicable only to aqueous waste. The basic mechanism starts with generation of reactive hydrated electrons and hydrogen or hydroxyl radicals in aqueous solution by energetic electrons. These highly reactive species attack organic material in solution. Treatment of organic or inorganic homogeneous solids is impractical; however, the process can treat dissolved organics in the presence of 5-8\% suspended solids. The process could be applied to bleed streams and secondary aqueous wastes generated by other treatment processes. Destruction efficiencies are reported to be generally $<99 \%$. It is necessary to remove hydroxyl scavengers, especially carbonates and bicarbonates, from the wastewater for the process to operate efficiently. Key development issues include:

- Demonstration of adequate destruction of organic contaminants in real process recycle streams, total throughput, and identification of the resulting byproducts.

- Level of depletion of hydroxyl scavengers and turbidity required for successful operation.

- Capability to efficiently treat chlorinated aromatic hydrocarbons.

- The capital cost of this equipment is relatively high. Total life-cycle cost should be evaluated for a particular application and amortized over the total waste to be treated and then compared to other aqueous waste treatment methods.

UV Photo-Oxidation: This process is applicable only to aqueous waste. It operates by the photolytic destruction of some soluble organic contaminants, and the generation of hydroxyl radicals from $\mathrm{H}_{2} \mathrm{O}_{2}$ or $\mathrm{O}_{3}$ added to the solution. Most of the organic destruction takes place by reaction with the hydroxyl radical with some destruction by direct photolysis. The solution must be clarified (i.e., removal of turbidity) to allow penetration of the UV photons, and removal of hydroxyl scavengers is required. The process as configured has difficulty in treating chlorinated aromatics. In a complete system, methods for clarification of the waste stream must be defined; removed hydroxyl scavengers and suspended solids must be sent to other solids-tolerant treatment processes. Key development issues include: 
- Demonstration of adequate destruction of organic contaminants, total throughput, and identification of the resulting byproducts.

- Level of depletion of hydroxyl scavengers and turbidity required for successful operation.

- Methods for efficiently treating chlorinated aromatic hydrocarbons.

Ultrasonies: This process is applicable to aqueous waste, and may be applicable to slurried inorganic solids. It depends on the generation of reactive oxidant species (primarily hydroxyl radicals) by external pulses of ultrasonic energy. The technology does not have the turbidity problem of photo-oxidation and is reported capable of treating aqueous waste with up to $10 \%$ suspended solids. However, it will require the removal or control of hydroxyl scavengers. The process has been reported to decontaminate soils "by the intense shearing action produced by cavitation which causes the adsorbed molecules on the soil particles to desorb from the surface." Upon desorption and entering the aqueous phase, the contaminants are reported destroyed by reaction with the hydroxyl radicals. High destruction effectiveness of a broad range of contaminants of interest to DOE has not been demonstrated. Key development issues include:

- Demonstration of adequate destruction of organic contaminants, total throughput, and identification of the resulting byproducts.

- Level of depletion of hydroxyl scavengers and turbidity required for successful operation.

- Capability to efficiently treat chlorinated aromatic hydrocarbons.

- Ultrasonics is used regularly in special cleaning operations. This mechanism should be tested as a feed preparation step in conjunction with processes selected for treatment of inorganic homogeneous solids and soils.

\subsection{General Recommendations for Testing and Development}

Each technology should be tested with a standard set of organic compounds and waste matrices in specified concentrations to allow a side-by-side comparison of performance. Tests should be performed using organic compounds as individual contaminants and as mixtures. Refractory organic compounds should be used in these tests-if the technology can decompose difficult compounds it should be capable of treating less refractory compounds. Such a set should include compounds such as pentachlorophenol, a dioxin precursor and a compound that is difficult to destroy. Residence times, temperatures, and pressures should be specified and by-products determined, including tests for dioxins/furans in the offgas and in solution. Contaminant destruction is often monitored with little attention to complete oxidation of undesirable intermediates and products of reaction, and more emphasis must be given to determining the end product.

An example of the need for side-by-side comparison of technologies under the same consistent conditions is shown by the data reported for the silver- and cerium-based MEO technologies (Appendix $\mathrm{A}$, Sections $\mathrm{A}-13$ and $\mathrm{A}-14$ ). Although $\mathrm{Ag}^{2+}$ has a higher oxidation potential (1.98 volts) than $\mathrm{Ce}^{4+}$ (1.61 volts in $\mathrm{HNO}_{3}$ ), the reported throughput for silver MEO is $11.68 \mathrm{~kg} / \mathrm{m}^{3}-\mathrm{hr}$ and the throughput for cerium MEO is reported as 70 to $100 \mathrm{~kg} / \mathrm{m}^{3}-\mathrm{hr}$. This apparent inconsistency points out the need for a consistent set of test requirements and operating parameters to compare different technologies and evaluate the claims of vendors and developers. 
Upon demonstrating the feasibility of a technology at a bench-scale level, a continuous process operation needs to be demonstrated, including treatment of all side streams and secondary wastes. Particular attention needs to be paid to management of the recycle streams-an important cost and secondary waste generation issue. The level of destruction and associated reaction by-products generated during continuous operation of the complete process needs to be determined. A material balance flow sheet and energy balance must also be produced. This is important information for the Principal Investigator (PI) to develop to have his/her technology accepted within the DOE complex.

DOE funding of additional technology development should be contingent on having proper and complete answers to a few questions, or at a minimum, a plan to obtain the answers. Answers to the following questions will help establish the overall development program scope and objectives and will likely highlight the critical development data needs. Proposed questions are as follows:

- How can this technology address a defined DOE waste treatment need? (If another technology can address this need better, faster, cheaper, and safer, then there is not a real need.)

- What is the overall concept for application of this technology to treatment of DOE mixed wastes?

- What ancillary and support systems are likely to be required for successful application of this technology? Do these systems exist at the level of development required?

- What are the anticipated major interfaces between this technology and other DOE waste treatment systems or processes?

- What waste treatment function(s) can this technology perform better, faster, cheaper or safer than existing, proven technologies? What are the current bases for these claims?

Identification of detailed technology development needs should be based on evaluation of each funded development program with respect to the following factors:

- Principal plant factors:

- Target waste streams

- Performance (destruction of target contaminants, reaction rate data, and type and concentration of byproducts in the offgas and/or solution)

- Operational conditions required to achieve reported performance

- Throughput

- Duty cycle

- Reliability, availability, and maintainability guidelines

- $\quad$ ES\&H guidelines

- Environmental conditions

- Transportability

- Physical characteristics of the system

- Waste acceptance criteria for the technology 
- $\quad$ Process flow diagram

- Process flowsheet with key material and energy balance data

- Major equipment list and sizing data

- Major equipment arrangement drawings

- Preliminary P\&IDs and I\&C list

- Utility requirements summary

- System and unit operations interface list and descriptions

- Tribal and public stakeholder issues to be addressed by this technology and how they will be addressed

- Regulatory issues and how they will be addressed.

These issues should be addressed by the principal investigator in the TDRDs and Test Plans, and may involve several iterations with the first iteration containing many blanks and assumptions. However, test programs should be designed and executed (according to approved test plans) to provide the data needed to fill in the blanks and verify the assumptions. The primary objective of funded development programs should be to provide data needed to ensure efficient evolution of the technology into a complete conceptual design for application to treatment of MLLW.

Early testing will focus on gathering data to confirm process feasibility and range of application. Subsequent testing will be required to obtain scale-up, equipment design, and materials data. Further evolution of the technology will require testing to obtain data to support process optimization, economic analysis, and trade-off studies. Throughout the development program, iterations on data collection and associated documentation will (1) provide a record of development progress, (2) facilitate communications among program participants, (3) provide a basis for test authorization and planning, (4) provide a basis for continuing or terminating a program, and (5) provide a common focus and end objective for all program participants.

During the first quarter, a program review should be held during which the PI should present the above information or detailed test plans on how the information will be obtained. Any PI who cannot provide this information, or plans and schedule on how this information will be obtained as part of his program, should have his funding terminated. 


\section{REFERENCES}

1. P. Acharya, S. G. DeCicco and R. G. Novak, "Factors that can Influence and Control the Emissions of Dioxins and Furans from Hazardous Waste Incinerators," Journal of the Air and Waste Management Association, Vol. 41, No. 12, pp. 1605-1615, December 1991.

2. Mixed Waste Focus Area, 1997 Data Set, current as of February 20, 1997.

3. Expert Choice, Inc., Expert Choice TM, Decision Support Software, Pittsburgh, PA.

4. Mixed Waste Focus Area Integrated Technical Baseline Report, Phase I, DOE/ID-10524, Idaho National Engineering Laboratory, Idaho Falls, ID, January 1996. 
Appendix A

Technology Descriptions 


\title{
Appendix A
}

\section{Technology Descriptions}

\author{
CONTENTS
}

\section{INTRODUCTION _- 4}

A-1 ULTRAVIOLET PHOTOLYSIS AND PHOTO-OXIDATION-

A-1.1 Technology Description - 5

A-1.2 Advantages, Disadvantages and Issues -

A-1.3 Evaluation -

A-1.4 References-_-13

A-2 PHOTO-CATALYTIC OXIDATION - 14

A-2.1 Technology Description

A-2.2 Advantages, Disadvantages and Issues -

A-2.3 Evaluation -

A-2.4 References-_-1.

A-3 ELECTRON BEAM OXIDATION —_ 18

A-3.1 Technology Description -

A-3.2 Advantages, Disadvantages, and Issues -

A-3.3 Evaluation -

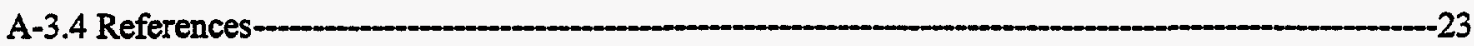

A-4 CHROMOX -

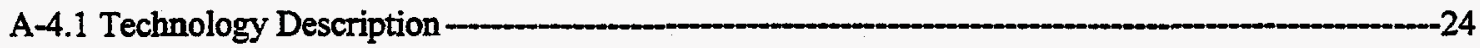

A-4.2 Advantages and Disadvantages-1..24

A-4.3 Evaluation - 24

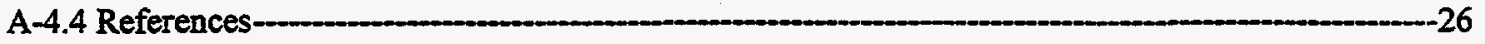

A-5 ULTRASONICS AND SONOLYSIS —_-

A-5.1 Technology Description -

A-5.2 Advantages and Disadvantages-

A-5.3 Evaluation - _._._-

A-5.4 References

A-6 ELECTROHYDRAULIC DISCHARGES AND CAVITATION - 32

A-6.1 Technology Description -

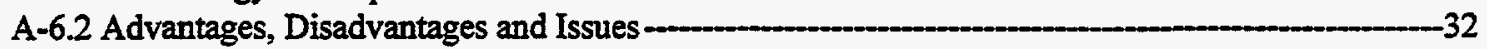

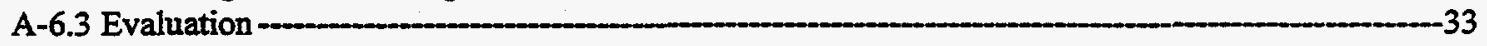

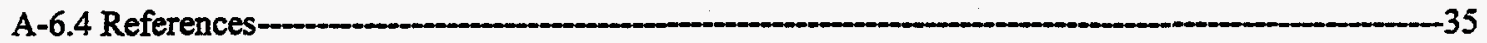

A-7 LIQUID CORONA - 36

A-7.1 Technology Description -

A-7.2 Advantages, Disadvantages and Issues

A-7.3 Evaluation -

A-7.4 References-___- 38 
A-8 MIXED OXIDANTS (MIOX)- 39

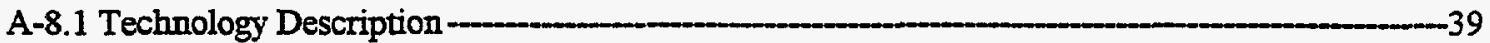

A-8.2 Advantages, Disadvantages, Issues -.______- 40

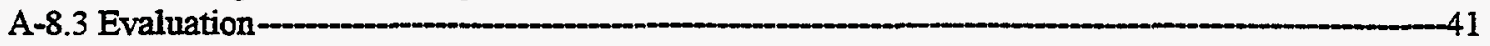

A-8.4 References-_-_._-

A-9 WET AIR OXIDATION (WAO)-

A-9.1 Technology Description -

A-9.2 Advantages, Disadvantages, and Issues -

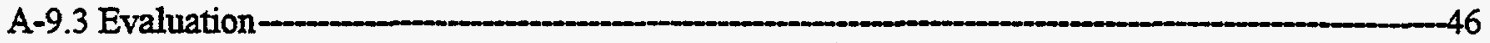

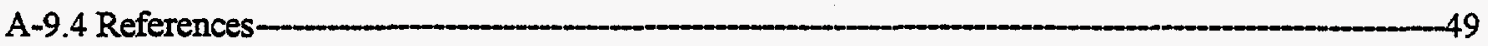

A-10 WET OXIDATION (WETOX)-

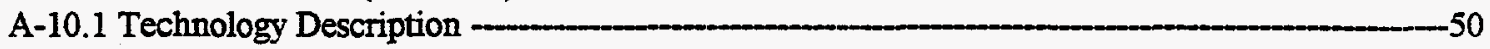

A-10.2 Advantages, Disadvantages, Issues-_- 50

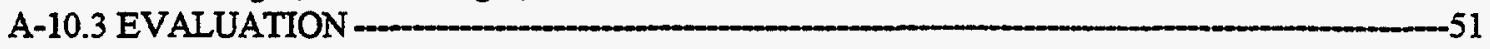

A-10.4 References - 52

A-11 CATALYZED WET OXIDATION-DETOX ${ }^{(\mathrm{SM})}$

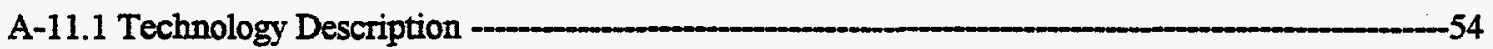

A-11.2 Advantages, Disadvantages and Issues _-_

A-11-3 Evaluation -

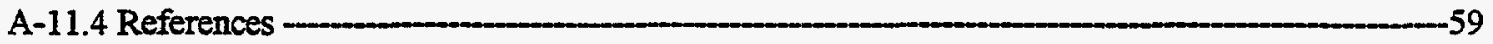

A-12 ACID DIGESTION/NITRIC-PHOSPHORIC ACID OXIDATION-

A-12.1 Technology Description --.-60

A-12.2 Advantages, Disadvantages, Issues -

A-12.3 Evaluation -

A-12.4 References -

A-13 SILVER MEDIATED ELECTROCHEMICAL OXIDATION (MEO)-

A-13.1 Technology Description - -65

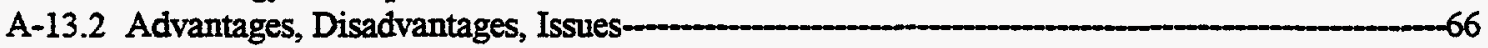

A-13.3 Evaluation -

A-13.4 References -

A-14. CERTUM MEDIATED ELECTROCHEMICAL OXIDATION (MEO) -

A-14.1 Technology Description -._-

A-14.2 Advantages, Disadvantages, Issues ___ 71

A-14.3 Evaluation- -72

A-14.4 References -

A-15 COBALT MEDIATED ELECTROCHEMICAL OXIDATION (MEO) -

A-15.1 Technology Description —_-

A-15.2 Advantages, Disadvantages, Issues ___

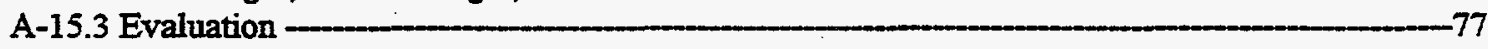

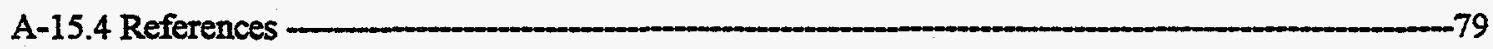

A-16 DIRECT CHEMICAL OXIDATION (DCO)

A-16.1 Technology Description ______-80

A-16.2 Advantages, Disadvantages, Issues-_____

A-16.3 Evaluation -

A-16.4 References - 
A-17 NEUTRALIZATION/HYDROLYSIS-BIODEGRADATION

A-17.1 Technology Description -._-86

A-17.2 Advantages, Disadvantages, Issues

A-17.3 Evaluation -

A-17.4 References - -

A-18 ELECTROCHEMICAL PEROXMATION (ECP) -

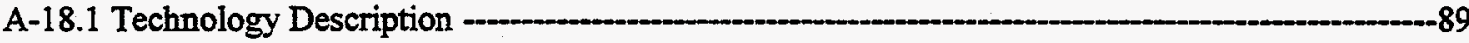

A-18.2 Advantages, Disadvantages, Issues

A-18.3 Evaluation -..._-_._-

A-18.4 References -.__-

A-19 X-RAY/GAMMAY RAY DESTRUCTION

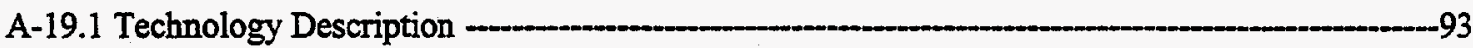

A-19.2 Advantages, Disadvantages, and Issues

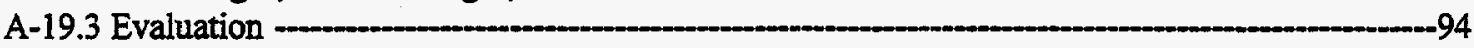

A-19.4 References

A-20 SUPERCRITICAL WATER OXIDATION (SCWO)-_-97

A-20.1 Technology Description -

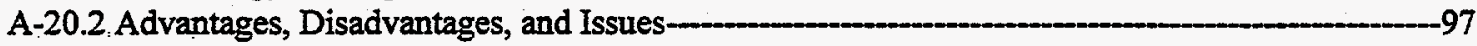

A-20.3 Evaluation -

A-20.4 References 100

A-21 STEAM REFORMING 102

A-21.1 Technology Description - 102

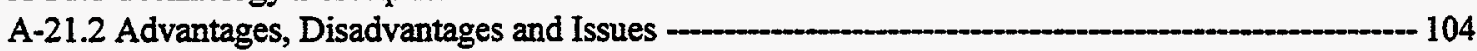

A-21.3 Evaluation - 105

A-21.4 References - 107

A-22 CHEMCHAR - 108

A-22.1 Technology Description -..._- 108

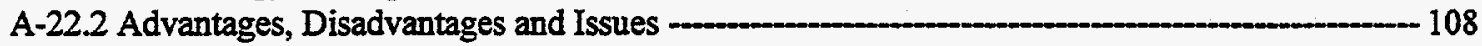

A-22.3 Evaluation - 110

A-22.4 References ___ 113

A-23 ECO LOGIC HYDROGEN REDUCTION

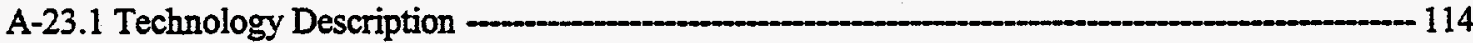

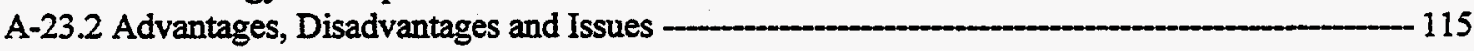

A-23.3 Evaluation - 116

A-23.4 References - 118 


\section{INTRODUCTION}

In this Appendix the various technologies are described briefly and the advantages, disadvantages and issues associated with each technology are discussed. Following the technology description and discussion, the technology is evaluated against each of the criteria discussed in Section 6 of the report. The perceived characteristics of each technology are discussed with respect to each criterion, and the rationale for ranking the technology with respect to each criterion is described. Tables that provide data on destruction efficiencies or reaction rates are taken directly from vendor or developer literature and published papers. The authors of this report have made no attempt to validate this data.

It should be noted that volume reduction of regulated waste is limited to those technologies that can convert organic wastes (e.g., organic liquids, organic sludges such as ion exchange resins, and combustible debris) to carbon dioxide and water. Volume reduction is not effected for waste matrices such as aqueous waste, soils, and inorganic sludges and debris unless the treated matrix can be delisted; however, this is unlikely without additional post-treatment since most wastes contain RCRA metals and/or radionuclides. Post-treatment technologies required to remove heavy metals or radionuclides from these matrices are not considered in this evaluation. Regarding aqueous wastes, the application of the technologies considered in this evaluation is to reduce or eliminate the presence of organic contaminants so that the water can be discharged or recycled after inorganic contaminants are removed by precipitation, filtration, and ion exchange. It is assumed that all waste streams containing RCRA metals or radionuclides will require posttreatment or stabilization prior to discharge or disposal regardless of the technology used to treat the organic constituents.

Each technology's treatment effectiveness was evaluated as to whether the primary waste effluent from treatment would require post-treatment to complete destruction of the regulated organic constituent. Further treatment of the waste stream is assumed for all wastes containing regulated metals and radionuclides for possible separation or stabilization for disposal. This was not evaluated as a potential discriminator among the technologies.

In these evaluations, technology complexity has been rated with respect to number and difficulty of unit operations, difficulty of recycling waste for further treatment, and amount and difficulty of recovering and recycling reagents. The technologies also were rated for production/generation of a RCRA regulated secondary waste from the support or recycle streams including the primary working medium.

Special consideration was given to the difficulty of off-gas treatment for each technology under the emissions category.

Much of the information and data in this appendix was obtained from the report:

W. E. Schwinkendorf, et al., "Alternatives to Incineration Technical Area Status Report," DOE/MWIP-26, U. S. Department of Energy, Office of Technology Development, Washington, D. C., April 1995.

This report contains specific references for most of the technologies discussed in this appendix; however, several new technologies are evaluated in this report and described in this appendix. Where new data was available it has been included. 


\section{A-1 ULTRAVIOLET PHOTOLYSIS AND PHOTO-OXIDATION}

\section{A-1.1 Technology Description}

Photolysis is the reaction of certain compounds with photons which leads to the destruction of chemical bonds and the disintegration of hazardous organic compounds to less hazardous reaction by-products. For destruction to occur, a light source must emit at a wavelength in the UV region that can be absorbed by the contaminant such that the molecular bonds are broken. This produces smaller molecules of organic byproducts that may continue to absorb UV light and decompose into still smaller, mostly nonhazardous, molecules. However, because of the difficulty in matching the wavelength of the light source with the absorption band of all the contaminants and reaction byproducts in an aqueous waste stream, the organic compounds are typically destroyed through an indirect photochemical process that uses UV energy to photolyze either hydrogen peroxide or ozone to generate hydroxyl radicals $(\mathrm{OH} \cdot)$ in the bulk aqueous fluid. These radicals then oxidize the organic species in the water to produce carbon dioxide, water, and some reaction byproducts.

Several processes that use UV radiation have been investigated; the differences were in the use of different wavelength light sources, different oxidants, and methods to enhance the production of hydroxyl radicals. Light sources that have been studied include medium and low pressure mercury lamps, xenon lamps, and excimer lasers. However, due to the high cost of laser systems and xenon lamps those companies that have investigated these technology have reverted to mercury lamps or have abandoned the photochemical business. In addition, catalysts and additional energy sources, such as hydrodynamic cavitation, are used to enhance the production of $\mathrm{OH} \cdot$ and the destruction of organic bonds.

Low-pressure mercury vapor UV lamps have low cost and long life $(2,000$ to $10,000 \mathrm{hrs})$ and are used by Ultrox International and Magnum Water Technologies in their CAV-OX process. Medium pressure mercury lamps are capable of higher intensity, a life of 3,000 hrs, and are used by Calgon Carbon Oxidation Systems. However, the dominant emission wavelength for mercury lamps is about $254 \mathrm{~nm}$, whereas the maximum absorptance by $\mathrm{H}_{2} \mathrm{O}_{2}$ occurs at $220 \mathrm{~nm}$. UV photolysis of $\mathrm{O}_{3}$ is not expected to have the same limitations with these lamps because the molar extinction coefficient of $\mathrm{O}_{3}$ is 170 times that of $\mathrm{H}_{2} \mathrm{O}_{2}$ at $254 \mathrm{~nm}$. However, the solubility of ozone in water is only $70 \mathrm{ppm}$ which would be the upper limit for producing hydroxyl radicals 1 . Thus, the application of ozone to streams containing high concentrations of organics is not practical, and large scale destruction of organics is better accomplished by photolysis of $\mathrm{H}_{2} \mathrm{O}_{2}$ because it is fully miscible with water. On the other hand, excess $\mathrm{H}_{2} \mathrm{O}_{2}$ scavenges hydroxyl radicals and limits the reactions with organics.

To overcome the limitations with $\mathrm{H}_{2} \mathrm{O}_{2}$ and $\mathrm{O}_{3}$, some technology developers investigated the use of pulsed xenon lamps which emit higher intensity, shorter wavelengths more readily absorbed by organic contaminants. The broad band emission of xenon lamps in the UV region $(240-300 \mathrm{~nm})$ can excite most simple organic compounds to enhance their reactivity with oxidants. In addition, the higher intensity of the Xe lamp in the region near $230 \mathrm{~nm}$ will decompose $\mathrm{H}_{2} \mathrm{O}_{2}$ into $\mathrm{OH}$ - more effectively than the $\mathrm{Hg}$ lamp. However, these lamps were not cost effective and could not compete with the mercury lamps.

Another problem with the typical UV photo-oxidation process is the difficulty to oxidize chlorinated aromatic hydrocarbons with hydroxyl radicals. Such contaminants include carbon 
tetrachloride, hexachlorobenzene, TCA, etc. However, these contaminants are amenable to direct photolysis. W.J. Schafer Associates, Inc. developed a proprietary surface discharge (SD) UV light source with enough energy below $250 \mathrm{~nm}$ for direct photolysis of these chlorinated alkanes ${ }^{2}$. A recent conversation with W.J. Schafer Associates, Inc. indicated that further development and commercialization of this lamp has been abandoned.

\section{Calgon Carbon Oxidation Systems}

Solarchem and Peroxidation Systems have been purchased by Calgon Carbon Oxidation Systems and merged into a single company. Both systems use medium pressure $30 \mathrm{~kW}$ hightemperature mercury lamps with $30 \%$ of their output between 200 and $300 \mathrm{~nm}$. A wiper is used to periodically clean the quartz sleeve over the lamp. Several lamps may be used in series depending on the application. This company markets various treatment processes based on UV oxidation chemistry with various oxidants or combinations of oxidants, and various catalysts depending on the particular contaminants to be treated and the characteristics of the water. These include a process using UV/Fenton chemistry with a reported 5-fold enhancement in treatment for aromatic and olefinic compounds.

A UV/visible/peroxide process is used for waters with a high background UV absorptance (i.e., $\mathrm{COD}>500 \mathrm{ppm}$ ) where the $\mathrm{H}_{2} \mathrm{O}_{2}$ must compete with other $\mathrm{UV}$ absorbers for photons and the production of $\mathrm{OH}$ - becomes less efficient. A proprietary catalyst was developed that strongly absorbs both UV and visible light from 200 to $500 \mathrm{~nm}$ thereby making more use of the lamps energy ${ }^{3}$. The activated catalyst then produces hydroxyl radicals in water and in the process drops back to its ground state.

Halogenated alkanes, such as carbon tetrachloride, chloroform, methyl chloride, dichloroethane (DCA), TCA, pentachloroethane (PCA), and chlorofluorocarbons (Freons) are treated slowly with UV oxidation. A patented UV/reduction process has been developed that is reported to be able to treat saturated organics with improved performance over UV oxidation 4 . This process involves the photochemical generation of hydrated electrons ( $\left.e^{-} a q\right)$ via reaction with a potassium iodide based catalyst. The hydrated electron reacts with saturated organics to treat these compounds 3 to 4 times faster than they can be treated with UV/oxidation. However, reduction of saturated organics by this process is 2 to 3 times slower than oxidation of unsaturated organics by the UV/photo-oxidation process. This reduction process is not considered to be cost effective unless the influent concentration of contaminants is above $2 \mathrm{ppm}$.

\section{Ultrox International}

A combination of UV radiation, ozone and hydrogen peroxide is used by Ultrox International to oxidize organics in water 5 . The major components of the system are the UV/oxidation reactormodule with low power mercury lamps, hydrogen peroxide feed system, and catalytic ozone_decomposition (Decompzon) unit. The unit used in an EPA SITE program had a reactor volume of 150 gallons which was divided into 6 chambers with three 65 -watt UV lamps per chamber. Each chamber had a sparger to uniformly diffuse ozone gas from the base of the reactor into the water. Hydrogen peroxide was added to and mixed with the contaminated water in the influent line. The Decompzon unit uses a nickel-based proprietary catalyst to decompose ozone to oxygen in the reactor offgas. Tests have shown that ozone stripping is a significant removal method for those compounds that are difficult to oxidize. However removal of VOCs occurred in the Decompzon unit to below detection levels. 


\section{CAV-OXProcess}

The CAV-OX process (developed and patented by Magnum Water Technology) uses the synergistic effects of hydrogen peroxide, hydrodynamic cavitation, and UV radiation to produce hydroxyl radicals and oxidize organic contaminants and cyanide in aqueous waste streams ${ }^{6}$.

\section{A-1.2 Advantages, Disadvantages and Issues}

\section{Advantages}

- Use of ambient conditions and mild solutions.

- Processes are easily controlled.

- For the intended wastewater streams (containing a few percent organics), this technology should easily satisfy most regulatory requirements.

- Systems are usually skid-mounted and portable, permitting on-site treatment.

- Only innocuous chemicals are added, none of which are solid-waste forming and no secondary waste is generated.

- They are "clean" technologies with minimum air emissions. However, an offgas system will be required to insure VOCs are not emitted with the $\mathrm{CO}_{2}$.

- The $\mathrm{H}_{2} \mathrm{O}_{2} / \mathrm{UV}$ process has the advantage that it can be modified by the addition of chemical agents that enhance the decomposition of organics and production of hydroxyl radicals, and potentially by the use of UV lamps that emit in the short UV and produce direct photolysis

\section{Disadvantages}

- When the processes involve ozone, solubility of gaseous ozone in the aqueous phase becomes the limiting factor. Although $\mathrm{H}_{2} \mathrm{O}_{2}$ can eliminate this mass transfer problem, the decomposition of $\mathrm{H}_{2} \mathrm{O}_{2}$ by $\mathrm{UV}$ light generated by inexpensive mercury lamps is relatively inefficient.

- The waste stream must be low in turbidity and solids to allow penetration by the UV light. Thus, insoluble organics and suspended solids must be removed for efficient operation. At the current state of development, most systems are useful for treatment of aqueous streams contaminated with less than $10 \%$ soluble organics.

- Some harmless organics that are generated as reaction byproducts can cause competing reactions.

- Although the reaction rate is directly proportional to light intensity, excessive light intensity could heat the water and/or the window which in turn could cause fouling of the surface in contact with the waste stream. 
- This technology works well with simple, known contaminants; however, its applicability to complex mixtures is unknown. Requirements for broad band lamps (as potentially available with the surface discharge lamp or xenon lamps) to match wavelengths to contaminant absorption spectra, matching catalysts with the contaminant, and the need for multiple processes for the mixture of contaminants needs investigation.

- These oxidation technologies cannot be used as generic destruction techniques. The choice of a particular system, and the optimum oxidant concentration, flow rate, and wavelength, will depend on the specific contaminant, or range of contaminants, and the characteristics of the water to be treated.

- Hydroxyl scavengers, such as carbonates and bicarbonates, must be removed from the waste stream for efficient application of this technology. Other inorganic contaminants that oxidize in the UV process and form insoluble species that may deposit on the lamp window may also require detection and removal from the waste stream.

- Although some organic species are easily destroyed by this process, they are rarely converted completely to carbon dioxide and water, and hazardous compounds may be produced that require subsequent treatment. However, these by-products may be biodegradable and treatable with a biofilter.

- The peroxide/ozone process is of limited utility for oxidation of some organohalides that have relatively low rate constants with $\mathrm{OH}$. such as chloroalkanes. This is due to the resistance of carbon-halogen bonds to $\mathrm{OH}$ - attack at low temperature, in contrast to carbon-hydrogen bonds which are easily broken 7 . The UV/reduction process developed by Solarchem or direct photolysis may be technical solutions to this problem but may not be cost effective and new lamps will require development.

\section{Issues}

- Work is proceeding at UV Technologies in Massachusetts to improve the output of mercury lamps in the short UV region. Further R\&D work is required to improve lamp output in the region where direct photolysis of organic contaminants occurs.

- Although UV photo-oxidation is a commercial technology, its application to mixed organic waste streams has not been demonstrated, and development is needed for the treatment of chlorinated aromatics.

- The optimum proportion of oxidants for maximum destruction or removal efficiency cannot be predetermined, but must be determined by tests on a case-by-case basis. Excess hydrogen peroxide can act as a free radical scavenger, thereby decreasing the hydroxyl radical concentration. Ozone can react directly with hydroxyl radicals consuming both ozone and radicals. 


\section{A-1.3 Evaluation}

\section{Performance}

\section{A-1.3.1 Range of Feed Materials}

Ranking - Low: Photolytic and UV oxidation systems are generally applicable to destruction of dilute organics in an aqueous phase; the process can destroy a wide variety of hazardous compounds in water. Some systems are being developed to accept influent streams with contamination levels over $10,000 \mathrm{ppm}$. Photolytic and UV Technology could treat organic liquid if diluted into an aqueous feed. Solid wastes sludges, soil and debris are impractical to treat with this technology.

The most successful applications include oxidation of chlorinated olefins (TCE, PCE, etc.) that have high rate constants with $\mathrm{OH}$ radicals. The peroxide/ozone process is of limited utility for oxidation of some organohalides that have relatively low rate constants with $\mathrm{OH} \bullet$ such as chloroalkanes 1,1,1-trichloroethane, chloroform, and carbon tetrachloride. However, the development of cost effective lamps that emit a significant portion of their energy below $250 \mathrm{~nm}$ may increase the applicability of UV processes to these compounds.

\section{A-1.3.2 Treatment Effectiveness}

Ranking - High-Medium: Most contaminants are rapidly destroyed by hydroxyl radicals, although there are some compounds that are not readily attacked by $\mathrm{OH}$ radicals and require direct photolysis or a reducing environment for efficient removal. The contaminant removal efficiencies and selection of the optimum treatment system depends on the type of contaminant to be treated.

Post-treatment may be required to remove residual organic depending on the contaminant and residence time; however, post-treatment technologies are available including activated carbon for removal of trace organics. Post-treatment may also be required if a technology is selected that cannot sufficiently degrade chlorinated hydrocarbons. Metals present in their reduced state may be oxidized to a more toxic form (e.g., trivalent chromium to hexavalent chromium), or to a less soluble form which may precipitate and cause scaling of the UV lamp or window, or produce suspended solids. However, these precipitates are easily removed with current technology.

Although no secondary waste is generated, these technologies do not directly reduce the waste volume. The application is to reduce or eliminate the presence of organic contaminants in the water such that it can be discharged or recycled.

\section{$\underline{\mathrm{UV} / \mathrm{H}_{2}} \underline{\mathrm{O}}_{2}$}

Tests with UV/peroxide on a variety of organic contaminants in water demonstrated that for most compounds the effluent levels were below detection levels, and the removal efficiencies were greater than 82 to $99 \%$. Examples are shown in Tables A-1.1 and A-1.2.

Solarchem's Rayox ${ }^{8}-\mathrm{A}$ process uses ferrioxalate as the light absorber which absorbs strongly in the $\mathrm{UV}$ and near visible region out to $500 \mathrm{~nm}$. Mixed with $\mathrm{H}_{2} \mathrm{O}_{2}$, ferrioxalate 
photolysis generates $\mathrm{OH}$. to oxidize organics as shown in Table A-1.3 for various organics treated by installed systems.

Table A-1.1: Performance Data for the Peroxidation System 8

\begin{tabular}{|l|c|c|c|}
\hline \multicolumn{1}{|c|}{ Compound } & Influent $(\mu \mathrm{g} /)$ & Effluent $(\boldsymbol{\mu g} / \mathbf{l})$ & Percent Removed \\
\hline \hline Chloroform & 41 & 1.2 & 97 \\
\hline 1,2-dichloroethane & 22 & $<1.6$ & $>92$ \\
\hline 1,2-dichloroethylene & 195 & $<1.6$ & $>99$ \\
\hline Methylene Chloride & 8 & $<1.1$ & $>86$ \\
\hline Trichloroethylene & 21 & $<1.4$ & $>93$ \\
\hline Benzene & 52 & $<2.0$ & $>96$ \\
\hline Thiodiglycol & 477 & $<10.0$ & $>97$ \\
\hline 1,4-Dithiane & 200 & $<2.2$ & $>98$ \\
\hline 1,4-Oxathiane & 82 & $<2.14$ & $>97$ \\
\hline Benzathiazole & 20 & $<3.47$ & $>82$ \\
\hline 1,3,5-Trinitrobenzene & 15 & 0.53 & 96 \\
\hline
\end{tabular}

\section{UV/Ozone/H2}

The Ultrox system was tested in a pilot-scale study to treat groundwater at a site with groundwater containing VOCs including TCE $(280$ to $920 \mu \mathrm{g} / \mathrm{l})$, vinyl chloride (51 to $146 \mu \mathrm{g} / \mathrm{l})$, and 1,2-trans-dichloroethane (42 to $68 \mu \mathrm{g} / 1)^{5}$. Results at these operating conditions were total VOC removal of $90 \%$, while removal efficiencies for TCE were about $98 \%$ and those for $1,1-$ DCA and 1,1,1-TCA were about $60 \%$ and $85 \%$, respectively. Because the Ultrox system treated groundwater by bubbling ozone through it, some VOC removal occurred due to stripping in addition to oxidation. The percentage of removal by stripping was high for compounds that are difficult to oxidize and have high Henry's law constants.

\section{CAV-OX Process}

The CAV-OX process was demonstrated at Edwards Air Force Base on groundwater containing TCE $(1,475$ to $2,000 \mathrm{ppb})$, benzene $(240$ to $500 \mathrm{ppb})$, toluene ( 8 to $11 \mathrm{ppb})$, and xylene $(0 \text { to } 100 \mathrm{ppb})^{6}$. Up to $99.9 \%$ destruction of these compounds was achieved depending on the flow rate and $\mathrm{H}_{2} \mathrm{O}_{2}$ levels.

\section{Readiness for Deployment}

\section{A-1.3.3 Level of Development and Understanding}

Ranking - High: UV light induced oxidation of organic contaminants in aqueous waste stream has been commercialized for several years by several vendors, and has been investigated by EPA and at several DOE facilities to determine its applicability to specific waste streams. The process has been approved by EPA, state, and municipal regulatory authorities. Most of the developed systems have been tested at the pilot or full-scale level as part of EPA's SITE program and are continually being improved upon. The overall concept for application of the technology in an integrated system is available.

Calgon Carbon Oxidation Systems, with their Peroxidation and Solarchem systems has fielded over 140 systems for groundwater and wastewater treatment. Several systems are 
operating at Hanford to treat mixed waste. Mixed waste is also being treated at the Naval Shipyard at Peugeot Sound and at Ontario Hydro where heavy water from a nuclear cooling facility is treated. Ultrox International has fielded several pilot and full-scale systems, and was tested as part of EPA's SITE program and at DOE's Kansas City Plant.

Table A-1.2: Destruction Data From Peroxidation Systems, Inc. Literature

\begin{tabular}{|c|c|c|c|c|}
\hline Contaminant & Influent $(\mu g /)$ & Effluent $(\mu \mathrm{g} / \mathrm{l})$ & $\begin{array}{c}\text { Oxidation Time } \\
\text { (min.) }\end{array}$ & $\begin{array}{c}\text { Percent } \\
\text { Removed }\end{array}$ \\
\hline TCE & 150 & $<1$ & 0.3 & $>99.3$ \\
\hline 1,2-DCE & 3480 & $<1$ & 0.55 & $>99.97$ \\
\hline$\overline{\mathrm{PCE}}$ & 24990 & $<1$ & 1.5 & $>99.99$ \\
\hline TCA & 940 & 89 & 4.0 & 90 \\
\hline $\begin{array}{l}\text { Methylene } \\
\text { Chloride }\end{array}$ & 2510 & $<20$ & 4.0 & $>99$ \\
\hline Phenol & 100,000 & $<100$ & 1.0 & $>99.9$ \\
\hline $\begin{array}{l}\text { Pentachloro- } \\
\text { phenol }\end{array}$ & 5600 & $<0.1$ & 1.5 & $>99.99$ \\
\hline $\begin{array}{l}2,4,6- \\
\text { Trichlorophenol }\end{array}$ & 2310 & $<0.1$ & 2.0 & $>99.99$ \\
\hline $\begin{array}{l}2,4- \\
\text { Dinitrophenol }\end{array}$ & 250 & $<0.1$ & 1.0 & $>99.96$ \\
\hline Naphthalene & 891 & $<2$ & 1.0 & $>99.7$ \\
\hline Acenapthene & 205 & $<0.1$ & 1.0 & $>99.9$ \\
\hline $1,2-\mathrm{DCA}$ & 5500 & 0.2 & 4.0 & 99.99 \\
\hline $\begin{array}{l}\text { Dichloro- } \\
\text { propane }\end{array}$ & 110 & 4 & 2 & 96.4 \\
\hline Benzene & 12900 & 2 & 1.3 & 99.98 \\
\hline Toluene & 7600 & 2 & 2 & 99.97 \\
\hline Ethyl Benzene & 3000 & 0.6 & 2 & 99.98 \\
\hline Xylenes & 18500 & 8 & 2 & 99.96 \\
\hline
\end{tabular}

Table A-1.3: Treatment Results of Installed Solarchem Rayox $(8)$ Systems $^{3}$

\begin{tabular}{|l|c|c|c|}
\hline \multicolumn{1}{|c|}{$\begin{array}{c}\text { Controlling } \\
\text { Contaminant }\end{array}$} & Flowrate (gpm) & $\begin{array}{c}\text { Influent } \\
\text { Concentration (ppb) }\end{array}$ & $\begin{array}{c}\text { Effluent } \\
\text { Concentration (ppb) }\end{array}$ \\
\hline \hline $\begin{array}{l}\text { Methylethyl Ketone } \\
\text { (MEK) }\end{array}$ & 0.5 & $35,000,000$ & $<1,000$ \\
\hline Hydrazines \& NDMA & $400 \mathrm{gpd}$ & $7,000,000$ & $<1$ \\
\hline Phenolics & 50 & 25,000 & $<100$ \\
\hline Total Organic Carbon & $2600 \mathrm{gpd}$ & 700,000 & $<15,000$ \\
\hline Trichloroethylene & 425 & 4,000 & $<5$ \\
\hline Thiodiglycol & 30 & 34,000 & $<10$ \\
\hline $\begin{array}{l}\text { Laboratory Mixed } \\
\text { Waste }\end{array}$ & $1000 \mathrm{gpd}$ & $400,000,000$ & $<10$ \\
\hline Dinoseb & $2000 \mathrm{gpd}$ & & $<00,000$ \\
\hline Pentachlorophenol & 120 & 1,000 & $<10$ \\
\hline
\end{tabular}


Although UV photo-oxidation is a commercial technology, its application to mixed organic waste streams has not been demonstrated, and development is needed for the treatment of chlorinated aromatics. Cost effective lamps that emit in wavelengths below $250 \mathrm{~nm}$ to provide direct photolysis would enhance the effectiveness of this technology.

\section{A-1.3.4 System Complexity}

Ranking - High Minus: These systems are quite simple consisting of UV lamps and hydrogen peroxide and/or ozone injection and ozone decomposition units where needed. They operate at room temperature and pressure. These systems are expected to be reliable with little maintenance and high availability, especially those technologies that use automated window cleaners or wipers. Those systems that do not have wipers as part of their systems would be expected to have increased downtime to clean or replace windows or lamps.

The only complication is pre-treatment which may be extensive depending on the quality of the wastewater; however, this would involve well known water treatment technologies. Some complexity may also be introduced into the system if a series of operations are required to treat multiple types of contaminants. These oxidation technologies cannot be used as generic destruction techniques. The choice of a particular system, and the optimum oxidant concentration, flow rate, and wavelength, will depend on the specific contaminant, or range of contaminants, and the characteristics of the water to be treated. Thus, significant characterization may be required.

Because of the pretreatment and characterization requirements compared to other advanced oxidation processes, this technology gets a slightly lower score than "high."

\section{Environmental Health and Safety}

\section{A-1.3.5 Emissions}

Ranking - High: Reaction products are primarily cover gas (air) containing carbon dioxide, water vapor and possibly some excess ozone or VOCs. Ozone or VOCs may be easily decomposed or removed by activated carbon. The gaseous effluent will contain no volatile metals or dioxins. The resulting aqueous effluent will require treatment for radionuclides and heavy metals, and possible organic by-products or residual POCs. The process has no uncontrolled emissions or discharges.

\section{A-1.3.6 Worker Health and Safety}

Ranking - High: There should be few adverse impacts on worker health and safety. The process operates near ambient temperature and pressure. Waste streams and effluent are relatively dilute and are enclosed in transfer pipelines. Failure of primary containment would likely result in a simple spill or discharge of untreated liquid waste. Specific energy of process fluids is low and reaction of process fluids with air or water is not a concern. Corrosion and erosion of key process equipment is not a major concern. Deposition of waste and treatment process products on windows or lamps may require more frequent maintenance, but routine window cleaning or lamp replacement should be easily accomplished remotely. There is little potential for accidents or process excursions. 


\section{A-1.4 References}

1. L. W. Gray, et al., "Aqueous Phase Oxidation Techniques as an Alternative to Incineration," Proceedings of the 1992 Incineration Conference, Albuquerque, NM, pp. 157-165, May 11-15, 19922.

2. W. J. Schafer Associates and Vulcan Peroxidation Systems, Inc., "Demonstration Test and Evaluation of Ultraviolet/Ultraviolet Catalyzed Peroxide Oxidation for Groundwater Remediation at Oak Ridge K-25 Site," DOE/OR2002, Oak Ridge National Laboratory, Oak Ridge, TN, March 1994.

3. Solarchem Environmental Systems, The UV/Oxidation Handbook, Markham, Ontario, 1994.

4. Personnel communication with Solarchem Environmental Systems.

5. EPA/540/AR-89/012, "Ultrox International Ultraviolet Radiation/Oxidation Technology," Applications Analysis Report. U. S. Environmental Protection Agency, Office of Research and Development, Washington, DC, September 1990.

6. EPA/540/MR-93/520, SITE Demonstration Bulletin, "CAV-OX Ultraviolet Oxidation Process," U. S. Environmental Protection Agency, Office of Research and Development, Washington, DC, August 1993.

7. C. S. Turchi, J. F. Klausner and E. Marchand, "Field Test Results for the Solar Photovoltaic Detoxification of Fuel-Contaminated Groundwater," Chemical Oxidation: Technologies for the Nineties, Third International Symposium, Nashville, TN, February 17019, 1993.

8. K. V. Topudurti, et al., "The Applicability of UV/Oxidation Technologies to Treat Contaminated Groundwater," Environmental Progress, Vol. 12, No. 1, pp. 54-60, 1993. 


\section{A-2 PHOTO-CATALYTIC OXIDATION}

\section{A-2.1 Technology Description}

Steady-state $\mathrm{OH}$. concentrations approximately 3 orders of magnitude greater than that produced with $\mathrm{UV} / \mathrm{H}_{2} \mathrm{O}_{2}$ can be generated in aqueous solutions over immobilized particles of UV-irradiated titanium dioxide. The illumination of $\mathrm{TiO}_{2}$ in water with light of wavelength $<385$ $\mathrm{nm}$ generates excess electrons in the conduction band $\left(\mathrm{e}^{-} \mathrm{cb}\right)$ and positive holes in the valence band $\left(h^{+} v b\right)$. At the surface the holes react with either adsorbed $\mathrm{H}_{2} \mathrm{O}$ or surface $\mathrm{OH}^{-}$groups to form $\mathrm{OH}$ radicals ${ }^{1}$. Excess electrons in the conduction band react with molecular oxygen to form superoxide ions which further disproportionate in water to form more $\mathrm{OH}$ radicals.

The OH. adsorbed on the surface of the $\mathrm{TiO}_{2}$ particles reacts with adsorbed pollutant molecules to initiate the degradation process. Studies have demonstrated that the addition of titanium dioxide can improve the efficiency and loading capacity of UV/oxidation systems and increase the range of application of the system. In some cases efficient organic destruction within 30 seconds to 2 minutes is achieved depending on the contaminant 2 .

\section{A-2.2 Advantages, Disadvantages and Issues}

One practical problem in using $\mathrm{TiO}_{2}$ as a photocatalyst is the "electron-hole" recombination process. In the absence of efficient electron acceptors, this process is very efficient. For high concentrations of organics or more refractory contaminants, additives which are electron acceptors such as hydrogen peroxide, ozone, ammonium persulfate, and potassium bromate may be added in small quantities $(0.003 \mathrm{M})$ to inhibit the "electron-hole" recombination process and accelerate reactions. The use of these additives may increase the processing rate within this system by 3 to 6 times. However, the destruction efficiency achieved for each of these additives depends on the organic contaminant ${ }^{2}$. For 1,1,2-TCA the degradation rate was increased over that with no additive with the addition of ozone, but decreased with the addition of $\mathrm{H}_{2} \mathrm{O}_{2}$.

The rate of photocatalytic disappearance of organic compounds depends on various parameters such as initial concentration, $\mathrm{pH}$, radiant flux, wavelength, mass and type of photocatalyst, type of photoreactor, and other material (such as metal ions) in the waste stream. The rate of disappearance of pollutants increases with increasing amounts of $\mathrm{TiO}_{2}$ up to a limit corresponding to complete absorption of photons.

Since this method of treatment involves a surface, its efficiency decreases for low concentrations of pollutant, and the rate of degradation of a given pollutant can be modified by competition for the surface sites. This competition may be due to intermediate compounds, and other organic or inorganic material in the waste stream.

Investigations at SNLA on $\mathrm{TiO}_{2}$ photocatalysis for treating water contaminated with dissolved metals and a variety of organics demonstrate a synergism between the oxidation and reduction processes, and efficient design must consider both processes ${ }^{3}$. Thus, a dissolved metal may be reduced and plate out onto the photocatalyst while simultaneous oxidation occurs to retain electroneutrality. Consequently, organics may be destroyed by photocatalytic oxidation while metals are removed by reduction. The rate at which the organic reductant disappears depends on the nature of the organic compound, and the oxidant (metal) in solution. 
These results point out the need to characterize the waste stream, and the need to tailor the process characteristics for the contaminants present in order to achieve optimum destruction and minimize generation of toxic end-products.

\section{A-2.3 Evaluation}

\section{Performance}

\section{A-2.3.1 Range of Feed Material}

Ranking - Low: As with UV photo-oxidation, photocatalysis can treat a variety of dilute organic contaminants in an aqueous solution. The efficiency of organic destruction and process parameters required for efficient operation depends on many factors including type of contaminant and metals present. To optimize the process detailed characterization appears necessary. This technology could treat organic liquid if diluted into an aqueous feed. Solid wastes sludges, soil and debris are impractical to treat with this technology.

\section{A-2.3.2 Treatment Effectiveness}

Ranking - Medium: In tests on the photodegradation of $40 \mathrm{ppm}$ of 2,4-dichlorophenol (2,4DCP), $60 \%$ degradation and $40 \%$ mineralization was achieved in 10 minutes using a UV lamp emitting in the $300-400 \mathrm{~nm}$ range 2 . The destruction rate was $2.9 \mathrm{ppm} / \mathrm{min}$ and when ozone was added the destruction rate increased to $40 \mathrm{ppm} / \mathrm{min}$; destruction of 2,4-DCP was complete in 2.5 minutes, and mineralization was complete in 10 minutes. Destruction efficiencies depend on a variety of parameters, as defined previously, including the design of the photoreactor. Consequently, they have little absolute meaning and each case of waste stream and treatment system must be tested to determine applicability.

Tests on TNT and RDX explosives indicated between $70 \%$ and $80 \%$ mineralization in about 300 minutes using a $100 \mathrm{Watt}_{\mathrm{Hg} \mathrm{lamp}}{ }^{4}$. Although the catalyst accelerated the mineralization of TNT and decreased concentrations of light absorbing reaction intermediates, other non lightabsorbing intermediates were formed that were intractable to further degradation. However, if the reactor was purged with nitrogen during the photocatalytic reaction to produce anaerobic conditions, no light-absorbing or intractable intermediates were formed, and greater mineralization of TNT was achieved. Aerobic photocatalytic degradation of RDX was achieved with little by-product formation.

The end-products tend to be other organic compounds which may, or may not, be hazardous depending on the original contaminants and the details of the destruction process (i.e., light intensity and wavelength, residence time, presence of oxidizing agents, solution $\mathrm{pH}$, etc.). Although most simple small hydrocarbons are easily oxidized completely to $\mathrm{CO}_{2}$ and $\mathrm{H}_{2} \mathrm{O}$, the reaction of larger, more complex compounds involve many intermediates and require a much longer time for complete mineralization versus simple removal of the original compound.

These technologies do not directly reduce the waste volume. The application is to reduce or eliminate the presence of organic contaminants in the water such that it can be discharged or recycled. Some post-treatment may be required depending on the contaminant and residence time; however, post-treatment technologies are available including activated carbon. 
During the reduction of heavy metals, the metals plate out onto the $\mathrm{TiO}_{2}$ catalyst thereby consuming the catalyst surface. These metals may be removed in a post-treatment step to allow recycling of the catalyst; however, methods for regenerating the catalyst are undefined and if the catalyst is not recoverable it may become a secondary waste containing heavy metals and radionuclides. If a method for regenerating the photocatalyst is not available, then spent $\mathrm{TiO}_{2}$ must be stabilized and disposed as a low-level radioactive secondary waste. Thus, some posttreatment may be required to destroy or remove remaining organics or organic byproducts, or regeneration and recycling or stabilization and disposal of the catalyst.

\section{Readiness for Deployment}

\section{A-2.3.3 Level of Development and Understanding}

Ranking - Medium-Low: There is a significant amount of research being performed by university, EPA, and DOE researchers into photocatalytic treatment of wastewaters. Most of this is at the laboratory or bench scale to evaluate the process parameters and characterize the destruction process. Although there is some effort to commercialize this process, and there have been several pilot or field scale tests performed, system components have not been demonstrated on a commercial basis. The particles can be fouled by substances that inhibit the production of $\mathrm{OH} \cdot$ at the surface and since the process is heterogeneous there is a mass transfer limitation. The range of MLLW that can be treated, lifetime of the catalyst, and catalyst recovery and regeneration have not been demonstrated.

\section{A-2.3.4 System Complexity}

Ranking - Medium-Low: This process is somewhat more complex than the UV/photooxidation process in that the $\mathrm{TiO}_{2}$ must be added to the waste stream and subsequently recovered. Spent particles will require regeneration and recycling, or disposal as a secondary waste; however, these processes have not been developed.

Pre-treatment is required which may be extensive depending on the quality of the wastewater; however, standard technologies exist. As with non-catalyzed UV photo-oxidation, the input stream must be filtered to remove suspended particulates and other material that may hinder the transmission of UV radiation, and radical scavengers must be eliminated. Because the oxidation of organics and the reduction of metals are intrinsically related, detailed characterization of the waste stream is required to select the process parameters and tailor the process for the contaminants present.

A moderate amount of post-treatment may be required to remove trace levels of organic byproducts and inorganic contaminants. The major issue is recovery of the catalyst. Post-treatment is required to either regenerate and recycle the $\mathrm{TiO}_{2}$ or stabilize and dispose of the catalyst.

\section{Environmental Health and Safety}

\section{A-2.3.5 Emissions}

Ranking - High: Emissions are the same $\left(\mathrm{CO}_{2}\right.$, water vapor, ozone, VOCs) as for photooxidation except for the addition of spent catalyst. A moderate amount of post-treatment (filtration, activated carbon) may be required to remove trace levels of organic by-products and 
inorganic contaminants. The major issue is recovery of the catalyst. Post-treatment is required to either regenerate and recycle the $\mathrm{TiO}_{2}$ or stabilize and dispose of the catalyst.

\section{A-2.3.6 Worker Health and Safety}

Ranking - High: There should be few adverse impacts on worker health and safety. The process operates near ambient temperature and pressure. Waste streams and effluent are relatively dilute and are enclosed in transfer pipelines. Failure of primary containment would likely result in a simple spill or discharge of untreated liquid waste. Specific energy of process fluids is low and reaction of process fluids with air or water is not a concern. Corrosion and erosion of key process equipment is not a major concern. Deposition of waste and treatment process products on windows or lamps may require more frequent maintenance, but routine window cleaning or lamp replacement should be easily accomplished remotely. There is little potential for accidents or process excursions. Potential for personnel exposure might be slightly greater than for UV/photo-oxidation in that spent catalyst particles may require handling for regeneration or disposal.

\section{A-2.4 References}

1. 'J. C. Ireland, et al., "Inactivation of Escherichia coli by Titanium Dioxide Photocatalytic Oxidation," Applied and Environmental Microbiology, Vol. 59, pp. 1668-1670, May 1993.

2. H. Al-Ekabi, et al., "TiO 2 Advance Photo-Oxidation Technology: Effect of Electron Acceptors," Photocatalytic Purification and Treatment of Water and Air, D. F. Ollis and H. Al-Ekabi (Editors), Elsevier Science Publishers, New York, NY, 1993.

3. M. R. Prairie, et al., "An Investigation of $\mathrm{TiO}_{2}$ Photocatalysis for the Treatment Water Contaminated with Metals and Organic Chemicals," Environmental Science and Technology, Vol. 27, No. 9, pp. 1778-1782, 1993.

4. M. R. Prairie, et al., Heterogeneous Photocatalysis for the Treatment of Synthetic and Actual Pinkwater," International Symposium on Energetic Materials Technology, Orlando, FL, March 21-24, 1994. 


\section{A-3 ELECTRON BEAM OXWATION}

\section{A-3.1 Technology Description}

Electron-beam processing involves exposing material to high-speed electrons produced by electron accelerators. A single high energy electron is capable of initiating several thousand reactions as it dissipates its energy as compared to a single reaction induced by a photon. The process of irradiation in aqueous solutions produces sizable quantities of the reducing free radicals $\mathrm{e}_{\mathrm{aq}}{ }^{-}$and $\mathrm{H}$., the oxidizing radical $\mathrm{OH}$. in approximately equal concentrations, and the more stable oxidant $\mathrm{H}_{2} \mathrm{O}_{2}$. As with $\mathrm{UV} /$ photo-oxidation, these radicals react with organic contaminants to break the chemical bonds and produce $\mathrm{CO}_{2}, \mathrm{H}_{2} \mathrm{O}$, non-hazardous salts, and intermediate organic reaction products. In this process the $\mathrm{e}_{\mathrm{aq}}{ }^{-}$and $\mathrm{OH}$ radicals account for over $90 \%$ of the reactive species. Most of the organic species investigated are primarily oxidized by the $\mathrm{OH}$ radical; however, with some species the reaction is predominantly reduction with the $e_{a q}{ }^{-}$radical. For example, reactions involving the $e_{a q^{-}}$radical may result in dechlorination of organohalogen compounds or destruction of chlorinated aromatics, and further reaction of the resulting organic radical may completely destroy the compound $l$.

High Voltage Environmental Applications, Inc. (HVEA) uses a $1.5 \mathrm{Mev}, 50$ milliamp fixed system for test and development that produces doses in water that vary from 645 to 900 kilorads at full power 2 . The system developed by HVEA for commercial applications to hazardous waste streams is a $500 \mathrm{kev}, 20$ to $25 \mathrm{~kW}$, continuous duty profile, mobile accelerator ${ }^{3}$. The accelerating voltage determines the energy of the electron and therefore the penetration of the electron into the material. The current determines the flux of electrons and therefore the amount of material that can be treated within the field of electrons.

The beam current can be adjusted to alter the number of electrons generated which affects the dose absorbed by the water. In the fixed $1.5 \mathrm{Mev}$ system the horizontal electron beam passes through magnetic coils that spread the beam into a rectangular pattern 4 feet wide by 2 inches tall. The beam passes through two 1-mil thick titanium windows, and then into the water which cascades in a thin sheet over a weir. The beam current and wastewater flow rate can be varied to vary the dose. However, in this configuration there is a potential for loss of volatile organic contaminants (e.g., benzene, toluene and xylenes) due to volatilization as the waste stream passes over the weir. In the mobile system the beam is vertical and the water stream is enclosed preventing escape of VOCs.

The HVEA process can either be permanently installed at a treatment facility, or mounted in a trailer for mobile treatment ${ }^{4}$. The waste stream flow rates can be adjusted from 2 to 5000 gpm depending on the system design, and the concentration of contaminants that can be treated ranges from the ppb level to saturation. The current mobile system is capable of treating flows up to $50 \mathrm{gpm}$.

\section{A-3.2 Advantages, Disadvantages, and Issues}

\section{Advantages}

- E-beam treatment is effective for destruction of a broad range of hazardous wastes, particularly chlorinated hydrocarbons. This technology is not sensitive to the 
treatability of the contaminant or the particular target species, and treats waste streams of varied composition.

- The aqueous systems are closed loop with a short (fraction of a second) residence time. Recycling of the waste stream can provide the required destruction efficiency for compounds difficult to destroy.

- It is a low temperature process so that VOCs and volatile metals or metal compounds are not vented or produced during treatment of aqueous wastes. However, some offgasing of VOCs may occur as the aqueous waste flows over the weir of the high power system. Plugging, scaling, and corrosion issues characteristic of other processes are avoided.

- High power e-beams can treat pumpable slurried waste directly (i.e., without chemical addition), and has been effective in treating wastes with $5 \%$ to $10 \%$ solid content.

- This technology has an established engineering base in that electron accelerators are an established technology.

- The waste treatment unit stands off from the waste stream preventing large scale contamination and generation of secondary waste, and making the system easy to maintain. This stand-off characteristic makes this technology applicable to mixed waste since only the plumbing will become contaminated with radionuclides.

\section{Disadvantages}

- The high initial capital cost for high power e-beam systems applicable to aqueous wastes (over \$1 million) which needs to be amortized over a large volume of waste. Thus, large volumes of waste may be required to justify the initial expense.

o The need for skilled operators and maintenance personnel for the accelerators.

- As with all wastewater treatment processes discussed here, this process will not destroy solids.

- There is a potential need for post-processing to achieve the required destruction efficiency, depending on contaminants and local discharge requirements.

- Some harmiess organics that are generated as reaction byproducts can cause competing reactions.

- This technology works well with simple, known contaminants; however, the byproducts produced from complex mixtures is unknown.

- Hydroxyl scavengers, such as carbonates and bicarbonates, must be removed from the waste stream for efficient oxidation. However, If saturated or perhalogenated hydrocarbons are to be treated OH. scavengers will remove the hydroxyl radical thereby preventing recombination of $\mathrm{OH}$. and hydrated electrons. This allows the reducing agent $\left(\mathrm{e}_{\mathrm{aq}}{ }^{-}\right)$to attack and destroy these compounds that are resistant to oxidation. 


\section{A-3.3 Evaluation}

\section{Performance}

\section{A-3.3.1 Range of Feed Material}

Ranking - Low: HVEA reports the applicable range of contaminants from the ppb level to saturation in aqueous systems. Treatment has also been accomplished on hazardous waste containing 1\% DNAPL (dense non aqueous phase liquids). The process will destroy liquid organics, such as solvents, in aqueous solution or slurry and may destroy nitrates and nitrites. $E$ beam technology could treat organic liquid if diluted into an aqueous feed. Tests have been performed with up to $10 \mathrm{wt}$. \% clay added to the waste stream with no adverse effect on the contaminant removal rate. Sludges and soils suspended or emulsified in solution may be treated. However, this process is not feasible for destruction of organic solids in any form, except possibly for biological materials. Solid wastes sludges, soil, and debris are impractical to treat with this technology.

\section{A-3.3.2 Treatment Effectiveness}

Ranking - High-Medium: Although the percentage removal increases with increasing dose, the efficiency decreases at high dose rates due to the recombination of excess radicals. Thus, it is more efficient to operate the system at low dose rates (e.g., $100 \mathrm{krad} / \mathrm{pass}$ ) and flow the fluid past the e-beam several times to achieve a high cumulative dose. The removal efficiency also increases with solute concentration due to decreased radical-radical recombination in the presence of contaminants. Factors that affect removal efficiency include water quality (i.e., the presence of radical scavengers), dose, and contaminant type and concentration. Table A-3.1 provides a summary of the average dose required to remove $99 \%$ of various contaminants.

Table A-3.1: Summary of the Average Dose Required to Remove $99 \%$ of Organic Species from an Aqueous Solution Using E-Beam Treatment 5

\begin{tabular}{|l|c|c|}
\hline \multicolumn{1}{|c|}{ Compound } & $\begin{array}{c}\text { Initial Concentration } \\
\text { (mg/liter) }\end{array}$ & Average Dose (krad) \\
\hline \hline TCE & $5.2-7.6$ & 107 \\
\hline PCE & $0.93-4.8$ & 442 \\
\hline Chloroform & $5.2-7.0$ & 1004 \\
\hline Benzene & $1.8-6.8$ & 200 \\
\hline Toluene & $3.7-6.1$ & 169 \\
\hline Phenol & $56.4-61.5$ & 1110 \\
\hline
\end{tabular}

The application is to reduce or eliminate the presence of organic contaminants so that the water can be discharged or recycled after inorganic contaminants are removed by precipitation, filtration, and ion exchange. No secondary waste is generated from support or recycle streams.

Metals present in their reduced state may be oxidized to a more toxic form (e.g., trivalent chromium to hexavalent chromium) and oxidized metals may form precipitates. Some posttreatment may be required depending on the contaminant and residence time; however, partially oxidized reaction by-products may be treated by subsequent passes through the electron beam, or by available post-treatment processes. Reaction by-products include phenols and various carbonyl compounds that were significantly decreased in the effluent by the addition of $\mathrm{H}_{2} \mathrm{O}_{2}$ to 
the influent (i.e., more efficient destruction) or by increasing the dose to the waste stream. Formaldehyde and formic acid, at micro-molar $(\mu \mathrm{M})$ concentrations, were the only reaction byproducts identified for TCE, PCE, and chloroform. The remainder of the parent compound was completely mineralized to $\mathrm{CO}_{2}, \mathrm{H}_{2} \mathrm{O}$ and $\mathrm{HCl}$.

A summary of the removal percentages for most organic compounds that have been investigated to date by HVEA is presented in Table A-3.2 for a single pass through the e-beam. Only insignificant quantities of reaction by-products (e.g., sub-micro-Molar concentrations) have been identified when destruction of the parent compound is near completion. When complete destruction does occur the compounds are reduced to $\mathrm{CO} 2, \mathrm{H} 2 \mathrm{O}$ and salts. Tests with the mobile system showed $99.1 \%$ destruction of phenol with 4 passes through the beam, $99.95 \%$ destruction of aromatics with 4 passes, and $97.3 \%$ destruction of absorbable organic halogen in a landfill leachate with 5 passes7. Although these removal efficiencies are less than desirable, they are based on a single pass through the system. Since this is a flow through system, there is essentially no retention time - once the electrons enter the water, treatment occurs in a fraction of a second. Therefore, it may be economical to recycle the waste stream several times to achieve the required removal efficiency.

\section{Readiness for Deployment}

\section{A-3.3.3 Level of Development and Understanding}

Ranking - High: Significant test and development has been performed in DOE and the commercial sector. Industrial based accelerators are available and a system has been commercialized and thoroughly tested. HVEA was accepted into EPA's Emerging Technology SITE program in 1993. They built a mobile treatment system that has been demonstrated at several EPA sites and at the Savannah River Site in September 1994. Rate constants have been developed by HVEA for the reactive species with scavenging species in natural waters, and for reactive species with various contaminants.

Computer-based chemical kinetic models were developed at LANL to understand the waste removal process, to predict the expected removal efficiency, to develop scale-up parameters, and to compare standard electrostatic accelerators to pulsed accelerators in terms of free radical production. The models produced excellent correlation's with experimental results. Thus, the scientific basis of the technology is well understood.

Several factors are restricting the use of this technology: its size, perceived cost, and lack of understanding by the environmental community. Although a major initial investment is required, and additional costs to house the machine will be incurred, over 20 years the life cycle cost may be low. The initial capital cost of the accelerator for a fixed, large-scale facility is high; for DC machines below about $2.5 \mathrm{Mev}$ the facility costs ranges from $\$ 1$ million to $\$ 1.5$ million. However, such direct current accelerators have been used in industry for years and are considered reliable. To be accepted by the environmental community, this group needs to receive training about the technology to establish a higher level of comfort, and the equipment must be shown to be robust and reliable with life times of at least 20 years. 
Table A-3.2: Summary of Electron-Beam Removals of Various Organic Compounds 8

\begin{tabular}{|l|c|c|}
\hline \multicolumn{1}{|c|}{ Compound } & Percent Removal & Required Dose (krad) \\
\hline \hline Benzene & $>99$ & $49-650$ \\
\hline Chloroform & $83-99$ & $586-650$ \\
\hline Bromodichloromethane & $>99$ & 80 \\
\hline Dibromochloromethane & $>99$ & 80 \\
\hline Bromoform & $>99$ & 80 \\
\hline Carbon Tetrachloride & $>99$ & 80 \\
\hline Chlorobenzene & 97 & 650 \\
\hline 1,2-Dichlorobenzene & 88 & 650 \\
\hline 1,3-Dichlorobenzene & 86 & 650 \\
\hline $1,4-$ Dichlorobenzene & 84 & 650 \\
\hline trans-1,2-Dichloroethylene & 93 & 800 \\
\hline $1,1-$ Dichloroethylene & $>99$ & 800 \\
\hline $1,2-$ Dichloroethylene & 60 & 800 \\
\hline Dieldrin & $>99$ & 800 \\
\hline Ethylbenzene & 92 & 650 \\
\hline Hexảchloroethane & $>99$ & 800 \\
\hline Methyl Chloride & 77 & 800 \\
\hline Phenol (total) & 88 & $37-800$ \\
\hline Toluene & 97 & $45-650$ \\
\hline $1,1,2,2-$ Tetrachloroethane & 88 & 650 \\
\hline Tetrachloroethylene (PCE) & $>99$ & $241-500$ \\
\hline $1,1,1-$ Trichloroethane & 89 & 650 \\
\hline Trichloroethylene (TCE) & $>99$ & $57-500$ \\
\hline$m$-Xylene & 91 & 650 \\
\hline $0-X y l e n e$ & 92 & 650 \\
\hline
\end{tabular}

\section{A-3.3.4 System Complexity}

Ranking - High: The application of the technology is simple; however, the accelerator may be considered somewhat complex requiring highly trained personnel for maintenance. However, accelerators are considered reliable and downtime should not be an issue. The ionizing radiation generated in the process will require commercial units to have the same license that hospitals receive for X-ray machines. Little pretreatment is required and if it is required the technology exists. The process can treat somewhat turbid water with up to $8 \%$ suspended solids content. Scavengers that lower the concentration of the reactive species may be present in the aqueous waste stream and pretreatment may be required to remove these scavengers. Recirculating the waste stream back through the electron beam can effect destruction of organic by-products thereby eliminating the need for some other technology.

\section{Environmental Health and Safety}

\section{A-3.3.5 Emissions}

Ranking - High: Emissions will be negligible and easily controlled or treated.. Emissions will consist of carbon dioxide and treated water, similar to the emissions from UV/photo- 
oxidation. However, VOCs may be emitted as the water flows over the weir so that an offgas system (e.g. carbon adsorption) will be required for a large, fixed system. In the mobile system the water is contained and no VOCs produced. Post-treatment is similar to that required for UV/photo-oxidation: destruction of organic by-products, and removal of heavy metals and radionuclides to allow water discharge. Destruction of by-products may be by recirculating the waste stream back through the electron beam, or by some other technology such as a biofilter

\section{A-3.3.6 Worker Health and Safety}

Ranking - High: There should be few adverse impacts on worker health and safety. The process operates near ambient temperature and pressure. Waste streams and effluent are relatively dilute and are enclosed in transfer pipelines. Failure of primary containment would likely result in a simple spill or discharge of untreated liquid waste. Specific energy of process fluids is low and reaction of process fluids with air or water is not a concern. Corrosion, erosion, and deposition in key process equipment is not a major concern. There is little potential for accidents or process excursions. There exists a slight additional hazard from the high voltage accelerator and the potential for personnel exposure to secondary $\mathrm{X}$-rays generated during waste processing.

\section{A-3.4 References}

1. C. N. Kuruzc, et al., "High Energy Electron Beam Irradiation of Water, Wastewater and Sludge," Advances in Nuclear Science and Technology, Vol. 22, Edited by J. Lewins and M. Becker, Plenum Press, New York, NY, 1991.

2. C. N. Kuruzc, et al., "Full-Scale Electron Beam Treatment of Hazardous WastesEffectiveness and Costs," Proceedings of the 45th Industrial Waste Conference, Purdue University, West Lafayette, IN, May 8-10, 1990.

3. M. Nickelsen, High Voltage Environmental Applications, Inc., personal communication.

4. EPA/540/R-93/526, Superfund Innovative Technology Evaluation Program. Technology Profiles, Sixth Edition, U. S. Environmental Protection Agency, Washington DC, pp. 308309, November 1993.

5. W. J. Cooper, "An Overview of the Use of High Energy Electron Beam Irradiation for the Destruction of Toxic Organic Chemicals from Water, Wastewater and Waters Containing Solids," Submitted for consideration in Emerging Technologies for Hazardous Waste Management October 1992.

6. W. J. Cooper, et al., "The Removal of Tri- (TCE) and Tetrachloroethylene (PCE) from Aqueous Solution Using High Energy Electrons," Journal of the Air and Waste Management Association, Vol. 43, pp. 1358-1366, October 1993.

7. W. J. Cooper, et al., "Field Demonstration of the Electron Beam Process on Contaminated Waters and Industrial Wastes Using a $20 \mathrm{KW}$ Mobile System," to be published, 1996.

8. C. N. Kuruzc et al., "Contaminated Groundwater Control Using Electron Beam Treatment Systems," High Voltage Applications, Inc., Unpublished Report. 


\section{A-4 CHROMOX}

\section{A-4.1 Technology Description}

This process uses hydrogen peroxide and a chromium catalyst to destroy organic pollutants in aqueous waste streams. In the process, a chromium salt, $\mathrm{Cr}(\mathrm{VI})$, is added to the waste stream followed by an $80 \%$ solution of $\mathrm{H}_{2} \mathrm{O}_{2}$. The $\mathrm{H}_{2} \mathrm{O}_{2}$ reacts with the $\mathrm{Cr}(\mathrm{VI})$ to form hydroxyl radicals which then oxidize the organic material to $\mathrm{CO}_{2}$, water and inorganic salts or acids ${ }^{1}$.

\section{A-4.2 Advantages and Disadvantages}

Unlike UV photo-oxidation, this process requires no glass window and the solution does not need to be optically transparent. The $\mathrm{Cr}$ is a true catalyst in that it does not need to be replenished or regenerated. However, it does need to be recovered from the wastewater prior to discharge.

\section{A-4.3 Evaluation}

Performance

\section{A-4.3.1 Range of Feed Material}

Ranking - Low: This process appears to be able to treat "dirty" water and slurries containing soils and sludges. The amount of solids that can be tolerated is undefined. The range and types of organics that can be effectively treated is undefined.

Chromox process detail is not available. The process appears to be similar to WETOX operating with chromium catalyst rather than redox with iron.

From the WETOX evaluation: "Wet Oxidation is developed primarily for treatment of aqueous-organic waste water streams. The process will also treat organic liquids diluted or dispersed into aqueous solutions.

Process also might handle some organic sludges if the organic can be suspended or dissolved into the working fluid.

While this process (WETOX ) is optimized for aqueous streams; some (95\%) destruction of ion exchange resins has been reported.

It would be difficult to apply this process to inorganic sludge, soils, and debris."

\section{A-4.3.2 Treatment Effectiveness}

Ranking - Medium: Effectiveness on more difficult compounds is unknown. As with all hydroxyl radical based treatment processes, destruction of some organic materials will be incomplete. Ability to treat chlorinated aromatics is doubtful. It has achieved $90 \%$ removal efficiency in pilot trials on solutions containing glycols, while solutions of ethers are completely degraded. 
This technology does not directly reduce the waste volume. The application is to reduce or eliminate the presence of organic contaminants in the water such that it can be discharged or recycled.

Post treatment may be required to complete the destruction of some organics. There is a potential for $\mathrm{Cr}(\mathrm{VI})$ being in the water leaving the process. The $\mathrm{Cr}$ needs to be removed prior to discharge and recovered for recycle back to the incoming waste stream. Chromium bearing secondary wastes could be generated from $\mathrm{Cr}$ recovery and recycle streams. It is unknown whether a recovery process has been developed. This process has been developed in the UK where $\mathrm{Cr}$ is not a regulated contaminant.

\section{Readiness for Deployment}

\section{A-4.3.3 Level of Development and Understanding}

Ranking - Medium-Low: This is a new process being developed by BNFL in the UK and apparently commercialized for hazardous waste. Testing has not been performed, or data has not been made available, on the range of compounds of interest to DOE. Information from BNFL in the US or the UK has not been made available. Processes from recovery of chromium from the wastewater, and regeneration to minimize secondary waste, have not been developed to our knowledge.

\section{A-4.3.4 System Complexity}

Ranking - Medium: Pre-treatment is minimized because the process can treat dirty water, slurries and sludges; however, hydroxyl scavengers such as carbonate and bicarbonate ions need to be removed from the water. This process may be more complex than other advanced oxidation systems due to the need to recover and recycle $\mathrm{Cr}$ from the wastewater prior to discharge. The chromium then needs to be converted to the form required for the process to continue and recycled back to the incoming waste stream. Methods for recovering $\mathrm{Cr}$ from the wastewater are undefined.

\section{Environmental Health and Safety}

\section{A-4.3.5 Emissions}

Ranking - High-Medium: Gaseous emissions will include only carbon dioxide, water vapor, and perhaps some VOCs. These should be easily managed by carbon adsorption. Chromium needs to be removed and recovered from the wastewater prior to discharge. The chromium then needs to be converted to the form required for the process to continue and recycled. Chromium recycle technology has yet to be demonstrated.

\section{A-4.3.6 Worker Health and Safety}

Ranking - High: There should be few adverse impacts on worker health and safety. The process operates near ambient temperature and pressure. Waste streams and effluent are relatively dilute and are enclosed in transfer pipelines. Failure of primary containment would likely result in a simple spill or discharge of untreated liquid waste. Specific energy of process fluids is low and reaction of process fluids with air or water is not a concern. Corrosion, erosion, and deposition in key process equipment is not a major concern. There is little potential for 
accidents or process excursions. Some increased risk is posed by the need to handle $80 \%$ hydrogen peroxide.

\section{A-4.4 References}

1. Anon, "Chromium Catalyzes $\mathrm{H}_{2} \mathrm{O}_{2}$ Destruction of Organic Wastes," Chemical Engineering, pp. 19, March 1996. 


\section{A-5 ULTRASONICS AND SONOLYSIS}

\section{A-5.1 Technology Description}

This process uses ultrasonic energy (high-frequency sound) waves to produce an alternating adiabatic compression and rarefaction of the liquid media being irradiated. During the expansion cycle, a sound wave of sufficient intensity can generate cavities, which grow gradually with each cycle. Upon reaching a critical size, the final compression part of the wave violently collapses the cavities, creating extremely high local temperatures of up to $5,000^{\circ} \mathrm{C}$ and high local pressures up to 500 bars and a region containing supercritical water. In this environment, water is decomposed into extremely reactive hydroxyl radicals and hydrogen atoms which propagate outward into the surrounding fluid to react with organic material. During the subsequent cooling phase, these can recombine to form hydrogen peroxide and molecular hydrogen. Organic vapors within the collapsing bubbles are destroyed by direct pyrolysis or supercritical water oxidation. Inorganic compounds can be either oxidized or reduced.

Destruction is strongly affected by the intensity of the ultrasonic energy applied, with the destruction rate increasing proportional to the intensity. In general, destruction begins when the applied intensity is above a critical level, and any increase in intensity will increase the sonochemical effect. However, the intensity cannot be increased indefinitely because with increasing power density the cavities may grow so large during rarefaction that the time available for their collapse is insufficient for effective coupling of the ultrasonic energy to the system. It may also be possible to optimize the frequency for organic destruction, but this has not been investigated as yet.

Decontamination of soils is accomplished by the intense shearing action produced by cavitation which causes the adsorbed molecules on the soil particles to desorb from the surface. In addition, the repeated rarefaction/compression cycles enhance diffusion of the organic molecules from the surface of the particles thereby enhancing desorption rates. The desorbed organics are then destroyed in the aqueous phase by the mechanisms described above for groundwater contaminants $1,2,3$.

A simple ultrasonic process can be used to treat contaminated water. The water is directed into the ultrasonic chamber, which is sized to provide an adequate residence time to obtain the desired destruction efficiency for the contaminants. The ultrasonic probe is immersed in the water and the process initiated. After treatment, the cleaned water may be discharged after inorganic contaminants are removed. If catalysts such as Fenton's reagent are required to increase the reaction rate, these catalysts may need to be removed prior to discharge.

\section{A-5.2 Advantages and Disadvantages}

\section{Advantages}

- The process takes place under ambient conditions

- It can be used to treat a wide variety of organics, including chlorinated compounds, due to the non-specific nature of the process. 
- The process can handle aqueous streams with moderate amounts of suspended solids, and solutions with low light transmissivity. It is applicable to removal of organic and inorganic contaminants from soils, sludges and debris with subsequent destruction in the aqueous phase.

- This seems to be one of the few low temperature processes that can treat sludges and immiscible organics..

- Because this is a direct treatment, few by-products or secondary wastes should be generated; however, work has not been done to determine the nature of the endproducts of this process.

\section{Disadvantages}

- It is a new and emerging technology, and will require extensive development and testing before it can be applied with confidence in the field.

- Some pre-treatment will be required to remove hydroxyl scavengers.

- Post-process characterization will be required to determine the presence of reaction by-products and the need for further treatment.

\section{A-5.3 Evaluation}

\section{Performance}

\section{A-5.3.1 Range of Feed Material}

Ranking - Medium: Ultrasonic detoxification is a non-specific process for treating aqueous streams, solutions, and slurries containing low concentrations of various chlorinated organics and other RCRA components; it is also applicable to immiscible organics. The process can be used for decontaminating soils and sludges with contained organic material being suspended in solution and subject to degradation. Total removal of organic from slurries of soil and sludge will be difficult. Further treatment of some of these solids may be required. It is not applicable to treatment of combustible solids except for decontamination and would not be useful for treatment of non-combustible debris.

\section{A-5.3.2 Treatment Effectiveness}

Ranking - High-Medium: Work at ANL used a small sonication cell with an ultrasonic probe capable of reaching $500 \mathrm{~W} / \mathrm{cm}^{2}$ power intensity and $20 \mathrm{kHz}$ frequency to decontaminate $\mathrm{CCl}_{4}$ spiked water 1 . The results of these tests show an exponential decrease in $\mathrm{CCl}_{4}$ concentration with time. Greater than $99 \%$ removal efficiency of the $\mathrm{CCl}_{4}$ was achieved in these experiments in times on the order of 10 minutes. For an initial $\mathrm{CCl}_{4}$ concentration of $130 \mathrm{ppm}$, the residual concentration decreased to about $5 \mathrm{ppm}$ after 5 minutes of irradiation, while for an initial concentration of $1.6 \mathrm{ppm}$, the residual concentration decreased to about $0.05 \mathrm{ppm}$ within the same irradiation period. At higher initial concentrations of $\mathrm{CCl}_{4}$, and within the same sonication period, greater amounts of contaminant were destroyed; however, the destruction efficiency was about the same. 
These experiments at ANL indicate that the addition of oxidizing agents or catalysts had little or no effect on the destruction of $\mathrm{CCl}_{4}$. Batch tests on TCE showed a removal efficiency of $31.5 \%$ in 15 minutes with sonication only, and a $94.4 \%$ removal efficiency with sonication plus Fenton's reagent. A TCE reduction of $80 \%$ was achieved in 2 minutes with Fenton's reagent alone, and a reduction of over $90 \%$ was achieved in the same time period when ultrasonic radiation was simultaneously applied. Other studies have demonstrated over $90 \%$ dechlorination of chlorobenzene and m-dichlorobenzene in 60 and 100 minutes, respectively. Over $90 \%$ destruction of TCA has been achieved.

In treating contaminated solids such as soils and sludges, two parameters are of primary importance in soil/water detoxification; these are the energy intensity or power density as described earlier, and the dilution factor expressed as grams of water/gram of soil ${ }^{3}$. For a given energy intensity and specified treatment level, there appears to be an optimum dilution factor that minimizes the time required for destruction of the contaminant. However, at high power levels and low dilution factors, a point is reached where soils can be crushed by the ultrasonic energy producing very fine particles and changing the characteristics of the mixture into a high viscosity slurry. In such a case, the mixing capability of the system is decreased, thereby decreasing the detoxification efficiency.

Early experiments on sludges from a hazardous waste site containing an average concentration of $2.6 \%$ Aroclor 1242 and $3.3 \%$ Aroclor 1260 indicated that about $98 \%$ of the former and $63 \%$ of the latter were destroyed ${ }^{4}$. Other test results from soil samples spiked with PCB (1260) oils indicated the a destruction efficiency of $99 \%$ had been achieved. An initial amount of $\mathrm{CCl}_{4}$ spiked soil of $55 \mathrm{mg} / 1$ decreased to about $0.5 \mathrm{mg} / 1$ or $1 \mathrm{ppm}$ by weight of soil with 25 minutes of ultrasonic irradiation.

This technology does not directly produce a volume reduction. The application is to reduce or eliminate the presence of organic contaminants so that the water can be discharged or recycled after inorganic contaminants are removed. Some post-treatment of organics in solution may be required depending on the contaminant and residence time; however, post-treatment technologies are available including recirculating the waste stream back through the ultrasonic process, or removal on activated carbon. Further treatment of solids, soils and sludges may be required to achieve adequate removal of organic contaminants. Inorganics and radionuclides may be oxidized or reduced so they may remain in solution or precipitate out depending on the species. No secondary waste is generated.

\section{Readiness for Deployment}

\section{A-5.3.3 Level of Development and Understanding}

Ranking - Medium Minus: The use of ultrasonic energy has been studied for many years for the promotion of chemical reactions so the scientific principles are known. The application of ultrasonic radiation to the treatment of hazardous chlorinated organic wastes started in the early 1980s. However, ultrasonics has not been commercialized for organic destruction of waste in wastewater or soils, and very little development work is being performed to move this technology from the laboratory to the field.

The technical feasibility of this process has been demonstrated in small bench-scale batch units at Argonne National Laboratory for the destruction of $\mathrm{CCl}_{4}, \mathrm{TCE}$, and triethylamine in 
water and/or soil, and for destruction of PCBs in soil and sludge's. Work is also proceeding at the University of Akron where the efficacy of the ultrasonic process has been demonstrated for the destruction of aqueous chloromethanes, chloroethanes, chloroethylenes, benzene, and toluene. Westinghouse Hanford has contracted with The University of Akron to perform proof-ofprinciple experiments on simulated Hanford waste and wastewater.

Further development and scale-up is required and tests need to be performed on additional compounds of interest to DOE. Development of engineering data is needed for the design of a commercial-scale continuous-flow facility. Determination of the optimum operating conditions for various organic materials and mixtures is required, as well as determination of any toxic byproducts in the effluent. Mass balance of VOCs is needed to confirm destruction versus possible evaporation. This method of destruction also needs to be compared with alternatives in terms of efficiency of destruction, reliability, and cost to determine its applicability to mixed wastes.

\section{A-5.3.4 System Complexity}

Ranking - High: This is a very simple process in which liquid waste is pumped to a vessel and subjected to ultrasonic radiation through an ultrasonic probe. This may be a flow-through or batch operation. Little pretreatment is required and if it is required the technology exists. The process can treat aqueous wastes with up to $10 \%$ suspended solids. Characterization of the waste to detect and remove hydroxyl scavengers may be required. Destruction of by-products may be achieved by recirculating the waste stream back through the ultrasonic process thereby eliminating the need for some other technology.

\section{Environmental Health and Safety}

\section{A-5.3.5 Emissions}

Ranking - High-Medium: The output streams consist of $\mathrm{CO} 2$ in the offgas, and treated water and soils which may contain RCRA metals and radionuclides. Since the process takes place at ambient temperature, little or no VOCs will be present in the offgas; however, this remains to be validated. At this time intermediate products of organic decomposition have not been determined. A moderate amount of post-treatment may be required to remove trace levels of organic by-products and inorganic contaminants. Post-treatment is similar to that required for UV/photo-oxidation and e-beam treatment: destruction of organic by-products, and removal of heavy metals and radionuclides to allow water discharge. Destruction of by-products may be by recirculating the waste stream back through the ultrasonic process, or by some other technology such as a biofilter.

\section{A-5.3.6 Worker Health and Safety}

Ranking - High: There should be few adverse impacts on worker health and safety. The process operates near ambient temperature and pressure. Waste streams and effluent are relatively dilute and are enclosed in transfer pipelines. Failure of primary containment would likely result in a simple spill or discharge of untreated liquid waste. Specific energy of process fluids is low and reaction of process fluids with air or water is not a concern. Corrosion, erosion, and deposition in key process equipment is not a major concern. There is little potential for accidents or process excursions. 


\section{A-5.4 References}

1. J. M. Wu, H. S. Huang and C. D. Livengood, "Development of an Ultrasonic Process for Detoxifying Groundwater and Soil: Laboratory Research," ANL/ESD/TM-32, Argonne National Laboratory, Argonne, IL, January 1992.

2. H. S. Huang, "Ultrasonic Process for Detoxification of Groundwater and Soil," Technical Information Exchange Meeting with Industry on Environmental Restoration Needs in the Northwest United States, Seattle, WA, January 25-27, 1994.

3. J. M. Wu, H. S. Huang and C. D. Livengood, "Development of an Ultrasonic Process for Soil Remediation," 24th Annual Meeting of the Fine Particle Society, Chicago, IL, August 24-28, 1993.

4. H. S. Huang, "Ultrasonic Process for Treating Aqueous Waste Streams," Technical Task Plan No. CH-166, Argonne National Laboratory, March 15, 1993. 


\section{A-6 ELECTROHYDRAULIC DISCHARGES AND CAVTTATION}

\section{A-6.1 Technology Description}

This technology involves injection of energy directly into an aqueous solution through a plasma channel formed by a high-current/high-voltage electrical discharge between two submerged electrodes. A typical electrohydraulic discharge (EHD) process consists of a pulsedpower electrical discharge circuit and a reaction chamber. Electrical energy is stored in a large capacitance $(135 \mu \mathrm{F})$ pulsed-power circuit. Each pulse can have energies from 5 to $25 \mathrm{~kJ}$ with a duration of 20 to $100 \mu \mathrm{s}$. The reactor is designed to withstand intense shock waves generated by the discharges and to accommodate the high electrical current and voltages required by the process 1 .

The plasma channel formed during the discharge reaches temperatures of $20,000^{\circ} \mathrm{K}$ to $50,000^{\circ} \mathrm{K}$ and functions as a blackbody radiation source with a maximum emittance in the 200 to $300 \mathrm{~nm}$ region of the spectrum. The radiation emitted from the hot plasma is absorbed by the water layer immediately surrounding the plasma channel, and UV light with $\lambda>185 \mathrm{~nm}$ penetrates into the bulk of the aqueous liquid. The 5 to $20 \mathrm{kbar}$ shockwave can induce pyrolytic and free radical reactions indirectly by cavitation as described for ultrasonic treatment. As the plasma cools in 1-3 ms, thermal energy is transferred to the surrounding water resulting in a steam bubble with sufficiently high temperatures and pressures to form transient supercritical water.

Three processes have the potential to induce significant oxidation chemistry in the bulk solution: UV photolysis, electrohydraulic cavitation, and supercritical water oxidation. The principal oxidation pathways are direct UV photolysis and localized oxidation in the plasma channel region.

\section{A-6.2 Advantages, Disadvantages and Issues}

\section{Advantages}

- Several methods of organic destruction (UV photolysis, cavitation, and supercritical water) combined into one process.

- The process takes place under average ambient conditions

- It can be used to treat a wide variety of organics, including chlorinated compounds, due to the non-specific nature of the process.

- The process can handle aqueous streams with moderate amounts of suspended solids, and solutions with low light transmissivity.

- Because this is a direct treatment, few by-products or secondary wastes should be generated; however, work has not been done to determine the nature of the endproducts of this process. 


\section{Disadvantages}

- It is a new and emerging technology, and will require extensive development and testing before it can be applied with confidence in the field.

- Some pre-treatment may be required to remove hydroxyl scavengers.

- Highly skilled technicians will be required to maintain the pulse power circuitry.

- As with all wastewater treatment processes discussed here, this process will not destroy solids.

- There is a potential need for post-processing to achieve the required destruction efficiency, depending on contaminants and local discharge requirements.

- Applicability to complex mixtures and the resulting by-products are unknown.

- High pressure transients.

\section{A-6.3 Evaluation}

\section{Performance}

\section{A-6.3.1 Range of Feed Material}

Ranking - Low: Ability to treat a variety of aqueous based wastes (e.g., sludges and soils suspended and slurries) is unknown. This is a non-specific process for treating aqueous streams containing a variety of chlorinated organics and other RCRA components. Its applicability to insoluble organic liquids, the range of contaminant concentrations that it can treat, and the amount of solids that can be tolerated in the system are unknown. Organic liquids might be treated if suspended in aqueous solutions

\section{A-6.3.2 Treatment Effectiveness}

Ranking - High-Medium: Experimental results indicate that over $80 \%$ of 3,4 dichloroanaline can be degraded over $2 \mathrm{msec}$ of power utilization. TNT is $100 \%$ degraded in 260 pulse discharges (i.e., $10.4 \mathrm{msec}$ ). In the case of 4-chlorophenol, $40 \%$ degradation is achieved in $2.4 \mathrm{msec}$ with a series of 120 pulses at $5-\mathrm{kJ}$ per discharge 1 . The EHD process has the advantage of extremely fast degradation rates for hazardous waste where the macroscopic rate of degradation is controlled primarily by the repetition rate of the pulse electronic circuit. At higher repetition rates, residence times in an optimized reactor could be on the order of seconds.

Degradation of compounds such as chlorinated aromatics, which are difficult to destroy with hydroxyl radicals, is unknown with this technology. It is possible that destruction efficiencies of these compounds with this technology are improved because SCWO is one of the destruction mechanisms - but this is only speculation. 
As with the previous advanced oxidation technologies, this technology does not directly produce a volume reduction. The application is to reduce or eliminate the presence of organic contaminants so that the water can be discharged or recycled. Post-treatment is similar to that required for other advanced oxidation technologies: completion of destruction of organic partial degradation products.

Inorganics and radionuclides may be oxidized or reduced so they may remain in solution or precipitate out depending on the species. Metals present in their reduced state may be oxidized to a more toxic form (e.g., trivalent chromium to hexavalent chromium) that must be removed from the waste stream by subsequent wastewater treatment processes. No secondary waste is generated by this process during recycle or support processes.

\section{Readiness for Deployment}

\section{A-6.3.3 Level of Development and Understanding}

Ranking - Low: This is an emerging, highly immature, technology that is being investigated at the bench-scale at universities and R\&D laboratories. No commercial applications are known, and no known work is being performed in DOE laboratories. Little is known about the effectiveness of this technology on various contaminants and matrices of interest to DOE.

\section{A-6.3.4 System Complexity}

Ranking - Medium: More complex than other advanced oxidation technologies. The process uses unique equipment designs and requires specialized power supplies. Electrodes are in contact with the aqueous waste and will require replacement, and trained technicians will be required to maintain the high voltage equipment and switching gear. Little pretreatment is expected and if it is required the technology exists. The required removal of solids or hydroxyl scavengers is unknown. Destruction of by-products may be achieved by recirculating the waste stream back through the process. High pressure pulses in the system may induce leaks and excessive maintenance.

\section{Environmental Health and Safety}

\section{A-6.3.5 Emissions}

Ranking - High-Medium: Emissions are expected to be similar to those from UV/photooxidation and ultrasonic technologies with the exception that hydrogen will be produced from electrolysis of water. Post-treatment is similar to that required for other advanced oxidation technologies: destruction of organic by-products, and removal of heavy metals and radionuclides to allow water discharge. Destruction of by-products may be by recirculating the waste stream back through the process, or by some other technology such as a biofilter.

\section{A-6.3.6 Worker Health and Safety}

Ranking - Medium: Similar to UV/photo-oxidation in that submerged electrodes will require replacement or polishing to maintain the required voltage build-up and spark strength. There is the potential for electric shock to maintenance workers from the pulse power system. The reaction vessel needs to be designed to withstand hydraulic shock, but there are penetrations 
for instrumentation and electrodes that may fail. There is also an explosion potential with the production of hydrogen. However, there is little potential for process upsets or excursions.

\section{A-6.4 References}

1. D. M. Willberg, et al., "Electrohydraulic Discharge Treatment of Hazardous Waste," Second International Symposium on Advanced Oxidation Technologies, San Francisco, CA, February 28-March 1, 1996. 


\section{A-7 LIQUID CORONA}

\section{A-7.1 Technology Description}

Liquid corona uses an electric field to accelerate electrons sufficiently to create ions and radicals in a gas contacting a liquid. When the liquid corona is applied to water, the energetic electrons create a non-thermal plasma directly on the surface of the liquid which generates highly reactive species that react with contaminants in the water. The liquid surface may be a thin flowing film, or the surface of well stirred liquid contained in a vessel. Strong oxidizers such as hydroxyl radical may be formed if the cover gas is oxygen or air; however, if a reducing environment is required for the destruction of chlorinated aromatics, hydrogen may be used as the cover gas ${ }^{1,2}$.

\section{A-7.2 Advantages, Disadvantages and Issues}

\section{Advantages}

- Highly reactive species, either oxidizing or reducing, are created directly from the water and in the vapor space.

- No reactive chemicals are required.

- Can treat contaminants not effectively treated by other advanced or radiation based oxidation technologies.

\section{Disadvantages}

- Very new proprietary technology with little information made available.

- Reduction requires a hydrogen atmosphere.

- As with all wastewater treatment processes discussed here, this process will not destroy solids.

- There is a potential need for post-processing to achieve the required destruction efficiency, depending on contaminants and local discharge requirements.

- Applicability to complex mixtures and the resulting by-products are unknown.

\section{A-7.3 Evaluation}

\section{Performance}

\section{A-7.3.1 Range of Feed Material}

Ranking - Low: Appears able to treat dilute aqueous wastes. Ability to treat a variety of aqueous based wastes (e.g., sludges, slurries or wastes with immiscible organics) is unknown. This technology does not appear to be applicable to any of the solid waste streams. 


\section{A-7.3.2 Treatment Effectiveness}

Ranking - High-Medium: Effectiveness should be similar to other radiation based oxidation technologies. May be somewhat more effective on compounds that are difficult to oxidize with hydroxyl radicals. Liquid corona was used to treat water contaminated with $40 \mathrm{ppm}$ pentachlorophenol (PCP) and achieved over $90 \%$ destruction ${ }^{2}$. The time required was not specified. A hydrogen atmosphere above the waste surface should allow destruction of chlorinated compounds that are difficult to oxidize with hydroxyl radicals.

As with the previous advanced oxidation technologies, this technology does not directly produce a volume reduction. The application is to reduce or eliminate the presence of organic contaminants so that the water can be discharged or recycled. Post-treatment is similar to that required for other advanced oxidation technologies: completion of destruction of organic partial degradation products.

Inorganics and radionuclides may be oxidized or reduced so they may remain in solution or precipitate out depending on the species. Metals present in their reduced state may be oxidized to a more toxic form (e.g., trivalent chromium to hexavalent chromium) that must be removed from the waste stream by subsequent wastewater treatment processes. No secondary waste is generated that was not already in the waste.

\section{Readiness for Deployment}

\section{A-7.3.3 Level of Development and Understanding}

Ranking - Low: This is a highly immature technology that is being investigated at the bench-scale at PNNL. Its effectiveness, kinetics, and power requirements have been demonstrated at the laboratory scale and scale-up parameters for a demonstration pilot plant are being developed. Test data and further descriptions are said to be proprietary and not available for 2-3 months after a patent application is submitted. Little is known about the effectiveness of this technology on various contaminants and matrices.

\section{A-7.3.4 System Complexity}

Ranking-Medium: More complex than other advanced oxidation technologies. The process uses unique equipment designs and requires specialized power supplies. Electrodes are in contact with a reactive vapor and will require replacement, and trained specialists will be required to maintain the high voltage equipment and switching gear. Little pretreatment is expected and if it is required the technology exists. The required removal of solids or hydroxyl scavengers is unknown. Destruction of by-products may be achieved by recirculating the waste stream back through the process.

\section{Environmental Health and Safety}

\section{A-7.3.5 Emissions}

Ranking - Medium: Emissions from the process have yet to be characterized. With air used as the cover gas, gaseous emissions will likely include carbon dioxide, water vapor, ozone, $\mathrm{NO}_{\mathrm{X}}$, hydrogen, and some VOCs. If hydrogen is used as the cover gas, a much more sophisticated offgas treatment system will be required to separate and recycle hydrogen or to safely recombine or 
afterburn the offgas stream. Post-treatment is similar to that required for other advanced oxidation technologies: destruction of organic by-products, and removal of heavy metals and radionuclides to allow water discharge. Destruction of by-products may be by recirculating the waste stream back through the process, or by some other technology such as a biofilter.

\section{A-7.3.6 Worker Health and Safety}

Ranking - Medium: Electrodes operating in a contaminated atmosphere will likely require frequent replacement. There is the potential for electric shock to maintenance workers from the high voltage system. Reactions of the organic contaminants with the corona and cover gas have yet to be characterized. If hydrogen is used for the cover gas, special precautions and equipment will be required for hydrogen handling.

\section{A-7.4 References}

1. G. B. Josephson, Pacific Northwest National Laboratory, personal communication.

2. "Emerging Technology Profile: Liquid Corona," Pacific Northwest National Laboratory, 1996. 


\section{A-8 MIXED OXIDANTS (MIOX)}

\section{A-8.1 Technology Description}

This process has been developed and commercialized as treatment for drinking water $1,2,3,4$. Initial efforts were directed towards destruction of infectious bacteria in drinking water supplies. The process was therefore aimed at aqueous streams with low to very low concentrations of contaminants. Testing has been done on low concentrations of some VOCs.

The process uses a proprietary technology that generates a solution containing mixed oxidants (MIOX) in a flow-through electrolytic cell. The mixed oxidant solution has the potential for application to environmental remediation and RCRA waste water treatment. The unique feature of the proprietary cell is the membraneless flow separation of the anode solution from the cathode solution. The catholyte contains sodium hydroxide $(\mathrm{NaOH})$ and entrained hydrogen gas $\left(\mathrm{H}_{2}\right)$ produced from the electrolysis of water.

The MIOX electrolytic cell produces oxidants from sodium chloride brine. Reported oxidants and their concentrations include ozone $\left(\mathrm{O}_{3}=2\right.$ to $\left.10 \mathrm{mg} / \mathrm{L}\right)$, chlorine/hypochlorite $\left(\mathrm{Cl}_{2} / \mathrm{HOCl}>300 \mathrm{mg} / \mathrm{L}\right)$, chlorine dioxide $\left(\mathrm{ClO}_{2}=3\right.$ to $\left.6 \mathrm{mg} / \mathrm{L}\right)$, and hydrogen peroxide $\left(\mathrm{H}_{2} \mathrm{O}_{2}\right.$ $>100 \mathrm{mg} / \mathrm{L}$ ), either as a directly generated product or as the product of $\mathrm{O}_{3}$ reaction with water. Short-lived, strong oxidizing, free radicals are also believed to be produced such as $\mathrm{OH} \cdot \mathrm{Cl}_{2}{ }^{+}$, and $\mathrm{Cl}$. The observed oxidation potential of the mixed oxidant solution is about 1.4 volts. The oxidation reduction potential of solutions containing equivalent concentrations of peroxide and hypochlorite are at 0.52 and 1.02 volts respectively. The higher oxidation potential is believed to be due to the presence of the free radical species. By injecting the solution directly into the water to be treated, these strong oxidizing free radicals, which are typically short-lived, contribute to the effectiveness of oxidation. It should be expected that the solution will oxidize organic compounds that are not readily treated by peroxide or hypochlorite alone.

The process operates satisfactorily $35^{\circ} \mathrm{F}$ to $140^{\circ} \mathrm{F}$ or $1.7^{\circ} \mathrm{C}$ to $60^{\circ} \mathrm{C}$.

Application of UV light after injection of the oxidant has demonstrated a significant increase in treatment effectiveness.

The highest concentration of VOCs reported tested was about $0.2 \%$. Application of the process to treatment of waste waters with higher concentrations of regulated organic constituents will require generation of higher concentrations of oxidants, a correspondingly higher concentration of sodium hydroxide, and evolution of greater quantities of hydrogen gas in the catholyte.

Preliminary testing has shown that treatment with the mixed oxidants and ultraviolet light provides some destruction of most materials tested at concentration above the $\mathrm{mg} / \mathrm{L}$ levels. There seems to be a limit to the extent of destruction or minimum concentration achievable somewhere in the microgram per liter range for some constituents. The process does not attack carbon tetrachloride. 
Disposal or Recycle

Catholyte $\mathrm{NaOH}$ and $\mathrm{H}_{2(\mathrm{~g})}$

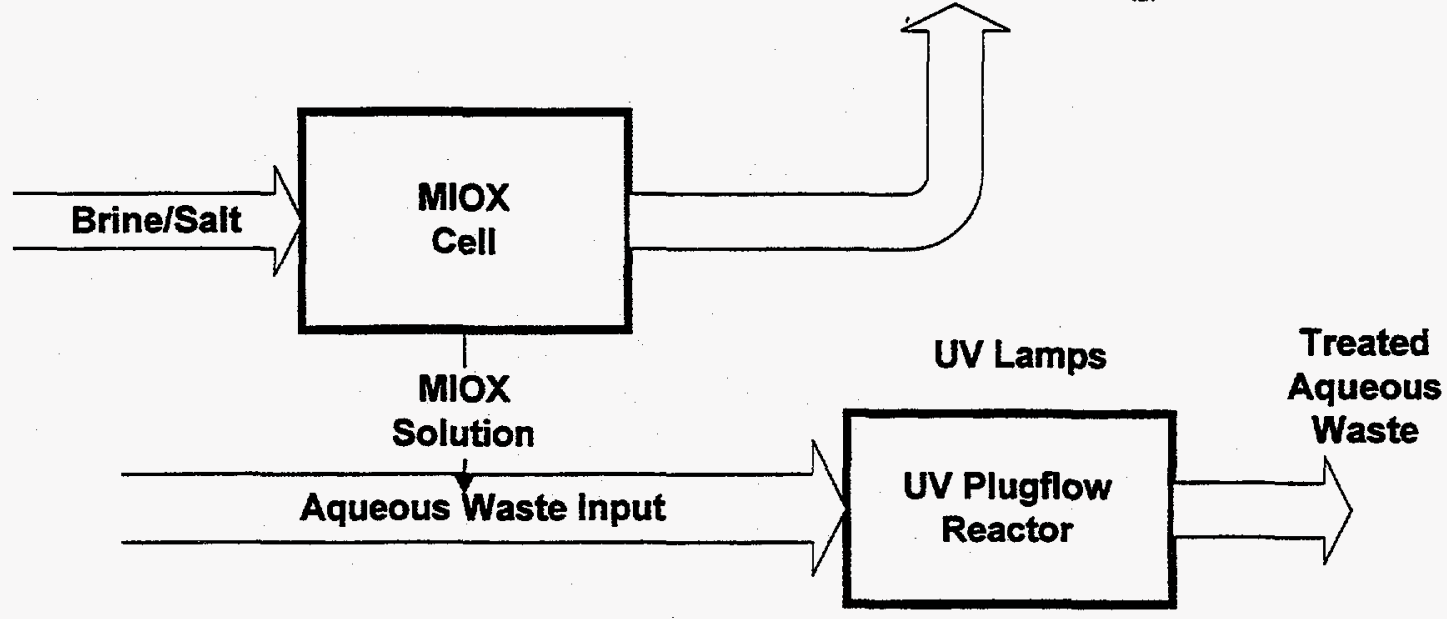

Figure A-8.1 Process Flow for the MIOX Process 1

\section{A-8.2 Advantages, Disadvantages, Issues}

\section{Advantages}

- The process produces the oxidants in solution from the electrolysis of sodium chloride solutions; these are injected directly into the treatment stream. There are no hazardous process chemicals to be handled by operators.

- Chlorine $\left(\mathrm{Cl}_{2}\right)$ is generated by direct electrochemical reactions at the anode. Chlorine reacts chemically with water to produce hypochlorite ( $\mathrm{HOCl}$ ). Chemical equilibrium established for this reaction provides the residual (continuing) concentration of $\mathrm{Cl}_{2}$ desired in treatment of drinking water.

\section{Disadvantages}

- The catholyte solution contains dilute sodium hydroxide and entrained hydrogen gas. The hydrogen gas potentially is a serious concern for installations in a radioactive materials environment.

- Process has been tested on a very limited number or organic compounds.

- Does not destroy carbon tetrachloride.

- Treatment involves several chlorine species. The treated waste stream will always contain chloride species in the ppm to percent range. This complicates the selection of materials of construction and formation of final waste forms if stabilization of residuals is required.

- A full scale process concept has not been presented. 
- Treatment with the MIOX reagent will leave chloride concentration in the treated stream in proportion (electron stoichiometry) to the organic materials removed.

Issues

- While the MIOX system for disinfection applications is fully commercialized, applications for environmental remediation and RCRA waste treatment are still in the early stages of development.

- It may require the development of a recycle process for application to hazardous waste treatment.

- Active oxidant species have not been identified with certainty.

- Safe management of the hydrogen generated in the mixed oxidant production operation. By simple electron count stoichiometry, destroying a mole of toluene would produce 18 moles or 14.24 cubic feet of hydrogen. This problem is shared with the peroxydisulfate process and the electrochemical peroxidation process.

- Potential for action as reductant for $\mathrm{Cr}^{+6}$ is to be tested. The combined oxidantreductant potential of the mixed oxidants could act to retain $\mathrm{Cr}$ in the +6 state.

\section{A-8.3 Evaluation}

\section{Performance}

\section{A-8.3.1 Range of Feed Material}

Ranking - Low: MIOX can readily treat some dilute aqueous-organic streams. The process is developed for treatment of contaminated ground waters and dilute aqueous waste water. Success has not been demonstrated with high concentration levels of organics nor with refractory organic compounds. Liquid organic may be treated by dilution into aqueous streams. This process should not be expected to handle sludges, or high concentration suspended solids in slurries. This process also is not adaptable debris treatment.

\section{A-8.3.2 Treatment Effectiveness}

Ranking - Low: Process has very little versatility. It is useful for dissolved or suspended organics in relatively dilute aqueous solution. The technology may have a potential for treatment of dilute concentrations of organic remaining after treatment processes such as catalyzed wet oxidation, DCO, or MEO. Test results for dilute organics in groundwater are shown in Table A8.1. Preliminary work has been done on ground water treatment using up to $4 \mathrm{UV}$ lamps plus injection of the MIOX solution. It is potentially applicable to cyanide and sulfide destruction/oxidation and reduction of $\mathrm{Cr}^{+6}$.

As with the other alternative oxidation technologies, this technology does not directly produce a volume reduction. The application is to reduce or eliminate the presence of organic contaminants so that the water can be discharged or recycled. 
Table A-8.1 Results Reported for Organics in Ground Water ${ }^{2}$.

\begin{tabular}{|c|c|c|c|c|}
\hline $\begin{array}{c}\text { Contaminant } \\
\text { Compound }\end{array}$ & $\begin{array}{c}\text { Raw Water } \\
\text { Concentration } \\
(\mu \mathrm{g} / \mathrm{L}) \\
\end{array}$ & $\begin{array}{l}\text { Effect of UV } \\
\text { Irradiation }\end{array}$ & $\begin{array}{l}\text { Effect of MUOX } \\
\text { Solution Alone }\end{array}$ & $\begin{array}{c}\text { Effect of MIOX }+\mathrm{UV} \\
\text { Compared to UV } \\
\text { Alone } \\
\end{array}$ \\
\hline Freon 113 & $15-108$ & $\begin{array}{l}\text { Reduced to } \\
10 \mu \mathrm{g} / \mathrm{L} \text { after one } \\
\text { UV lamp. No } \\
\text { further reduction }\end{array}$ & $\begin{array}{l}\text { Reduced to } \\
<10 \mu \mathrm{g} / \mathrm{L} \text { (as low as } \\
1.9 \mu \mathrm{g} / \mathrm{L} \text { observed) } \\
\text { at all injection } \\
\text { ratios. }\end{array}$ & $\begin{array}{l}\text { Minimal further } \\
\text { reduction below } \\
10 \mu \mathrm{g} / \mathrm{L} \text { by UV } \\
\text { irradiation. Practical } \\
\text { lower limit may be } \\
\text { about } 4 \mu \mathrm{g} / \mathrm{L} .\end{array}$ \\
\hline $1,1-\mathrm{DCE}$ & $6.4-7.3$ & $\begin{array}{l}\text { Reduced regularly } \\
\text { by UV to } 2.9 \mu \mathrm{g} / \mathrm{L} \\
\text { after lamp } 4\end{array}$ & $\begin{array}{l}\text { Reduced } \\
\text { significantly } \\
(-20 \%)\end{array}$ & $\begin{array}{l}\text { Reduced regularly by } \\
\text { UV to }<1.6 \mu \mathrm{g} / \mathrm{L} \text { after } \\
\text { UV lamp } 4 \text {. }\end{array}$ \\
\hline $\mathrm{CHCl}_{3}$ & $12-17$ & No effect. & $\begin{array}{l}\text { No effect at any } \\
\text { injection ratio. }\end{array}$ & $\begin{array}{l}\text { No effect. Perhaps a } \\
\text { slight increase after UV } \\
\text { lamp } 3 \text { or } 4 \text { with MOXX } \\
\text { by catholyte recycling. }\end{array}$ \\
\hline $\mathrm{CHCl}_{4}$ & 0.7 & No effect. & $\begin{array}{l}\text { No effect at any } \\
\text { injection ratio. }\end{array}$ & No effect. \\
\hline $1,2 \mathrm{DCA}$ & 1.0 & No effect. & $\begin{array}{l}\text { No effect at any } \\
\text { injection ratio. }\end{array}$ & $\begin{array}{l}\text { No effect. The practical } \\
\text { lower limit of } \\
\text { destruction appears to } \\
\text { be about } 10 \mu \mathrm{g} / \mathrm{L} \text {. }\end{array}$ \\
\hline TCE & $155-185$ & $\begin{array}{l}\text { Reduced regularly } \\
\text { by UV to } 11 \mu \mathrm{g} / \mathrm{L} \\
\text { after lamp } 4 .\end{array}$ & $\begin{array}{l}\text { Reduced slightly } \\
(\sim 5 \%)\end{array}$ & $\begin{array}{l}\text { Dramatic reduction in } \\
\text { concentrations with less } \\
\text { UV irradiation required. } \\
\text { Lowest concentration } \\
\text { achieved } 0.8 \mu \mathrm{g} / \mathrm{L} \text { after } \\
\text { lamp } 4\end{array}$ \\
\hline PCE & $11-15$ & $\begin{array}{l}\text { Reduced readily by } \\
\text { one lamp to } 2.3 \\
\mu \mathrm{g} / \mathrm{L} \text { and to below } \\
\text { detection by two } \\
\text { lamps. }\end{array}$ & No effect. & $\begin{array}{l}\text { Dramatic reduction in } \\
\text { concentrations to } \\
<1.2 \mu \mathrm{g} / \mathrm{L} \text { after one } \\
\text { lamp and to below } \\
\text { detection by two lamps }\end{array}$ \\
\hline
\end{tabular}

Secondary waste from this process is the cathode solution containing sodium hydroxide and hydrogen. The caustic will require neutralization which can be integrated directly into the process. This stream does not contain any of the primary waste; there should not be any issue of metals or other inorganic contaminant. Hydrogen will be generated on an electron for electron equivalent basis from the oxidation process. Use with high concentrations or large inventories of organics would mean generating large amounts of hydrogen.

Preliminary testing of the process produced drinking water levels for uncontrolled release for many of the organic contaminants tested. However, some RCRA organics are not treated by this technology. There will be a requirement for treatment of organics in the effluent from this technology. May generate high enough chloride species to require removal of chloride before the residues can be solidified. Inorganics and radionuclides may be oxidized or reduced so they may remain in solution or precipitate out depending on the species. Metals present in their reduced 
state may be oxidized to a more toxic form (e.g., trivalent chromium to hexavalent chromium) that must be removed from the waste stream by subsequent wastewater treatment processes.

\section{Readiness for Deployment}

\section{A-8.3.3 Level of Development and Understanding}

Ranking - Medium-Low: The treatment process is at early development stages and tests on compounds of interest to DOE have not been completed so that a mixed waste treatment process is not yet ready. The basic chemistry seems to be generally understood; however, the detailed process chemistry is very complex, not fully defined with many competing reactions, and will not be defined without a great deal of careful study. That level of understanding probably is not necessary for successful application of this process. Los Alamos Technical Associates ((LATA) has plans for further testing and development of a full scale process for aqueous streams containing RCRA hazardous constituents.

\section{A-8.3.4 System Complexity}

Ranking-Medium: No pretreatment is indicated at this stage of the process development, however, filtration would probably be beneficial if the solution carried high suspended solids. There will be a requirement for treatment of organics in the effluent from this technology and removal of chloride may be required before the residues can be solidified. Although this technology is based on a very simple electrolysis cell followed by aqueous chemical mixing, several process units are required to produce the oxidants, treat the waste, and treat the effluent $\left(\mathrm{NaOH}, \mathrm{H}_{2}\right.$, and chlorides). Implementation should be relatively simple when the electrolysis cell is available and sized for the process.

\section{Environmental Health and Safety}

\section{A-8.3.5 Emission}

Ranking - High-Medium: There should be no significant toxic constituents in the offgas. Potentially the most hazardous concern would be the management of the hydrogen gas in the electrolysis cell. The cathode solution will contain dilute sodium hydroxide. Preliminary testing of the process produced drinking water for uncontrolled release for many of the organic contaminants tested. However, some RCRA organics are not treated by this technology. There will be a requirement for treatment of organics in the effluent from this technology. May generate high enough chloride species to require removal of chloride before the residues can be solidified.

\section{A-8.3.6 Worker Health and Safety}

Ranking - High-Medium: The major hazards are likely to be management of elemental hydrogen and handling of chemicals to neutralize the dilute sodium hydroxide in the catholyte. Otherwise, there should be few adverse impacts on worker health and safety. The process operates near ambient temperature and pressure. Waste streams and effluent are relatively dilute and are enclosed in transfer pipelines. Failure of primary containment would likely result in a simple spill or discharge of untreated liquid waste. Specific energy of process fluids is low and reaction of process fluids with air or water is not a concern. Corrosion, erosion, and deposition 
in key process equipment is not a major concern. There is little potential for accidents or process excursions.

\section{A-8.4 References}

1. MIOX Corporation literature.

2. R. E. Harrington, F. A. Baker and W. L. Bradford, "Treatment of TCE Contaminated Groundwater with Mixed Oxidant Technology at Lawrence Livermore National Laboratory," unpublished report, August 1994.

3. L. L. Barton, "Evaluation of MIOX System for Killing Coliform Bacteria in Sewage Water," unp8ublished report, July 25, 1993.

4. L. V. Venczel, et al., "Inactivation Kinetics of Waterborn Pathogens Using a Mixed Oxidant Disinfectant," to be published, November 9, 1995. 


\section{A-9 WET AIR OXIDATION (WAO)}

\section{A-9.1 Technology Description}

Wet air oxidation (WAO) is often considered for treating organic contaminated aqueous wastes having a chemical oxygen demand (COD) in the range of about 2 to $200 \mathrm{~g} / \mathrm{l}$ which are too dilute to incinerate and too toxic to biologically treat 1 . The process is thermally self-sustaining when waste $C O D$ is above about $15 \mathrm{~g} / \mathrm{l}^{2}$. Historically, WAO's role has been as a pretreatment process to reduce waste strength and toxicity and render it suitable for final treatment and disposal by other means.

Waste materials in dilute aqueous solution or suspension are contacted with dissolved oxygen at elevated temperatures $\left(150^{\circ} \mathrm{C}\right.$ to $\left.325^{\circ} \mathrm{C}\right)$ and pressures $(2000 \mathrm{kPa}$ to $21,000 \mathrm{kPa})$ but below the critical point of water. Organic materials are partially carbonized. Dissolved oxygen reacts catalytically at the carbon sites to produce hydrogen peroxide which then decomposes to generate highly reactive oxygen and hydroxyl free radicals. These radicals then react with the carbon to form carbon dioxide 1 .

Most organic compounds are stoichiometrically oxidized, the carbon going to carbon dioxide, the hydrogen to water, any halogens to halides, sulfur to sulfate, phosphorous to phosphate, and nitrogen to ammonia or nitrogen gas. However, single-pass conversion of waste compounds is often limited by the solubility of oxygen in water. Incomplete oxidation may result in production of low-molecular weight compounds such as acetaldehyde, acetone, acetic acid, methanol, etc. These compounds are sufficiently volatile that they will distribute between the offgas and oxidized aqueous streams. The liquid effluent also will contain carboxylic acids, other carbonyl compounds, suspended solids and other insoluble (sulfates, phosphates, silicates, etc.) salts. Soluble metal salts will also usually remain with the liquid effluent.

Acids formed by the oxidation of halogen, sulfur, and phosphorous containing compounds are very aggressive at the required process conditions. Commercial WAO units for hazardous waste treatment are constructed with titanium clad steel.

Wet air oxidation is a commercial process. Systems are available from Zimpro Passavant Environmental Systems, Inc., Rothschild, $\mathrm{WI}^{3}$. Commercial system designs are based on extensive Bench- and pilot-scale experiments usually targeting a specific waste or relatively narrow range of waste types.

\section{A-9.2 Advantages, Disadvantages, and Issues}

\section{Advantages}

1. Organic waste compounds are oxidized and mineralized without formation of $\mathrm{NO}_{\mathrm{x}}$, $\mathrm{SO}_{\mathrm{X}}, \mathrm{PICs}$ and particulate.

\section{Disadvantages}

1. WAO is not a "stand-alone" treatment for DOE mixed wastes. Without substantial pre- and post-treatment WAO is limited to processing a relatively narrow range of wastes. WAO processing does not produce a final waste form. 
2. WAO requires processing in relatively large, high-alloy, pressure vessels.

3. WAO requires relatively large inventories of material-in-process to achieve moderate throughput.

4. Single-step DREs are limited by solubility of oxygen in process media.

5. WAO processing will require substantial sampling, analyses, and characterization of both feed and product materials.

\section{Issues}

WAO cannot predictably and reliably destroy a wide range of contaminants found in DOE mixed wastes. Destruction efficiencies for most waste constituents are below $99.9 \%$ and are very dependent on waste composition (physical and chemical) and waste strength. Individual commercial facilities are designed to treat a relatively narrow range of waste streams, and designs are based on extensive laboratory and pilot plant tests.

Use of WAO technology for other than pretreatment purposes implies extensive effluent storage, analysis, and recycle.

WAO reaction rates are relatively slow, and long residence times (15 to 60 minutes) are required for reasonable conversion of most wastes. As a result, systems using very large and/or multiple high-alloy pressure vessels will be required to achieve even modest throughput. See Figure 1.

\section{A-9.3 Evaluation}

\section{Performance}

\section{A-9.3.1 Range of Feed Material}

Ranking - Medium-Low: WAO is best suited to treatment of relatively dilute organics in aqueous media which do not contain refractory halogenated aromatic species. The technology cannot be applied directly to organic fluids; the limited solubility of oxygen in water requires dilution of concentrated organic species prior to WAO processing or requires recycle of partially treated process fluid. Unless operated in a batch mode, only solids which can pass through a high pressure pump may be treated by WAO. Even finely divided solids, however, may cause erosion, deposition, corrosion, and material transport problems in WAO systems. The application of this process to soils and debris would be difficult. 


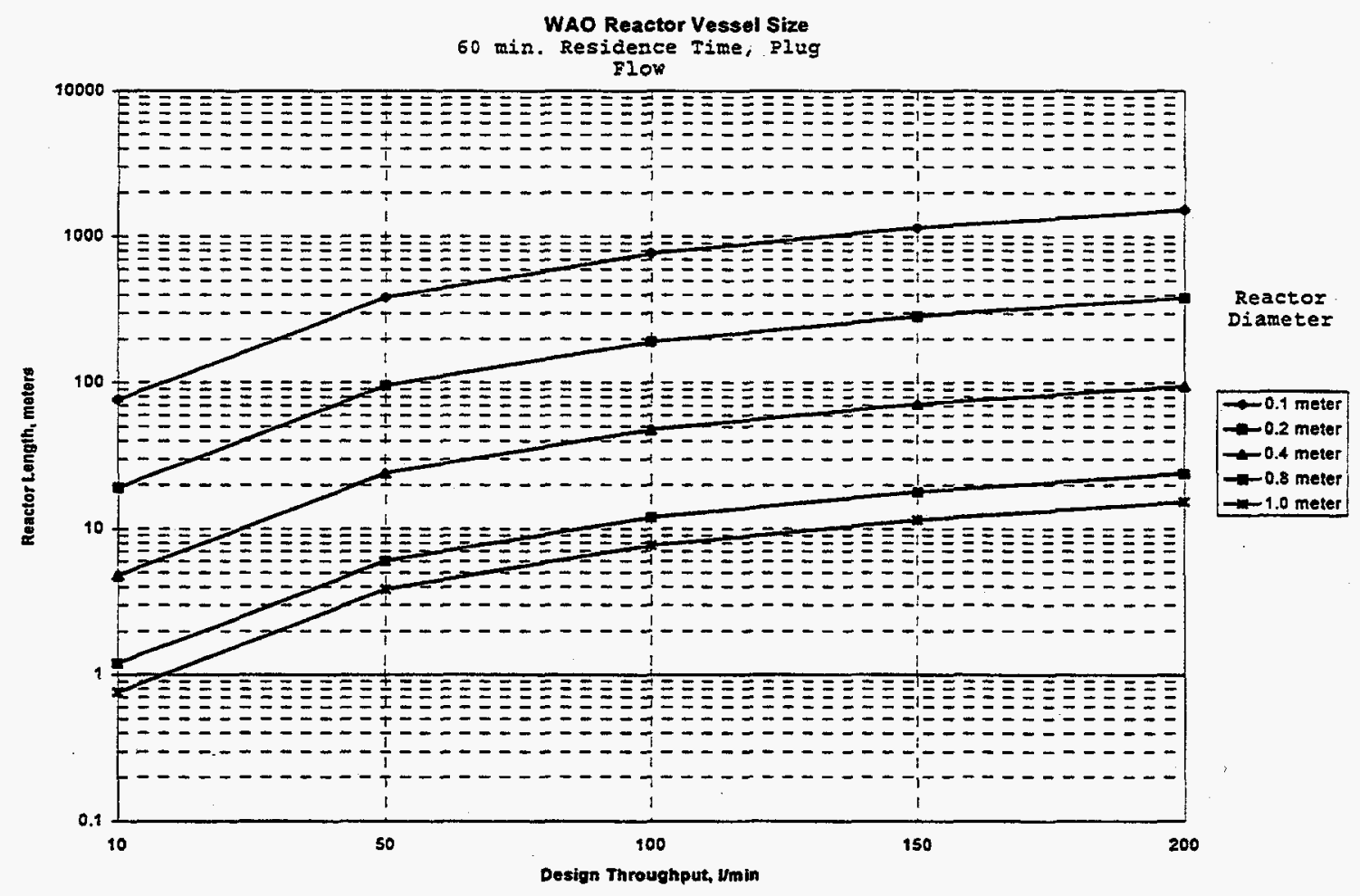

Figure A-9.1. Plug Flow Reactor Size for Wet Air Oxidation.

\section{A-9.3.2 Treatment Effectiveness}

Ranking - Medium: Treatment effectiveness has not been established for the majority of mixed wastes. Process performance so far is not predictable. Bench- and pilot-scale tests together with data from commercial operations show that most organic compounds are destroyed with a destruction efficiency better than $99 \%$ in 15 to 60 minutes at temperatures in the range from $200^{\circ} \mathrm{C}$ to $280^{\circ} \mathrm{C}^{4}$. Some compounds which are difficult to carbonize, such as acetic acid, may require longer residence times and higher temperatures to be substantially degraded. Halogenated aromatic compounds (PCBs, chlorobenzenes, etc.) are very refractory and resistant to treatment by WAO. These compounds degrade slowly ( $70 \%$ destruction in 60 minutes) unless at least one electron-donating functional group (hydroxyl, amino, methyl, etc.) is present on the ring.

As with previous advanced oxidation technologies, this technology does not directly produce a volume reduction. The application is to reduce or eliminate the presence of organic contaminants so that the water may be discharged or recycled after treatment for inorganic contaminants. Volume reduction of regulated wastes will be limited and some hazardous organics present in the waste matrix will remain.

Waste streams and residues from WAO processing are derived from constituents of the original waste. No regulated secondary or recycle wastes are generated by support systems. Some organic residuals will remain with the original waste matrix (dilute slurry or water) as will most of the inorganic oxides. 


\section{Readiness for Deployment}

\section{A-9.3.3 Level of Development and Understanding}

Ranking - High: WAO is a commercial technology applied to a number of diverse but individually well characterized waste streams. Commercial applications tend to be waste specific and are supported by extensive laboratory and pilot plant process feasibility and demonstration tests. WAO treatment performance for new or unusual waste types and compositions cannot be predicted without extensive laboratory and pilot testing.

All major elements of WAO technology have been demonstrated in non-radioactive service. Anticipated extensive ancillary (containment, HVAC, pre-treatment, post-treatment, sampling and analyses, etc.) systems required for implementation in radioactive service have yet to be demonstrated.

\section{A-9.3.4 System Complexity}

Ranking - Medium: Together with required ancillary and support systems the WAO process train will be a moderately complex system. In most cases substantial waste feed characterization and some pretreatment will be required. Concentrated wastes will require dilution, and solid wastes will require intensive comminution. Conversely, some wastes may require solids removal prior to processing.

This is a high pressure process that requires high pressure pumps that tend to leak. The process is completed in one step but provisions must be made for recycle or post-treatment of inadequately treated waste. Anticipated systems required for implementation in radioactive service are expected to add to the process complexity. Secondary containment, ventilation, and offgas treatment systems must be furnished to contain potential emissions from a sudden loss of primary (process equipment) containment. Containment and treatment of these emissions comprised primarily of steam, radioactive and hazardous aerosols and waste liquids, plus condensable and non-condensable gasses - will substantially increase the complexity and cost of support facilities. Presence of insulation will hinder decontamination and slow repair and maintenance operations. Pressure vessels and heat exchangers operating at high pressure and exposed to corrosive and erosive process solutions will likely require periodic "heel-out" and inspection.

\section{Environmental Health and Safety}

\section{A-9.3.5 Emissions}

Ranking - High-Medium: Routine emissions from WAO treatment systems will include process offgas containing $\mathrm{CO}_{2}, \mathrm{H}_{2} \mathrm{O}$, and minor quantities of volatile products (acetic acid, acetone, methanol, etc.) of incomplete oxidation of the waste POCs. Simple treatment with activated carbon should be sufficient to render WAO off gas suitable for discharge. During process excursions, some volatile waste POCs may distribute to the offgas. As with all highpressure processes, equipment failure may lead to rapid and energetic release of large quantities of contaminated material. 


\section{A-9.3.6 Worker Health and Safety}

Ranking - Medium: Non-routine maintenance in contaminated areas is expected to be somewhat greater than average due to the relative complexity of the system, and its operation at elevated temperatures and pressures with corrosive and erosive materials.

Process conditions will likely require secondary containment and other provisions to protect operating personnel. Key process equipment must be built to pressure vessel code, and sudden loss of primary containment would likely lead to rapid and large loss of process fluids accompanied by exposure of personnel to physical, chemical, and radiological hazards. The major consequence of most process excursions is likely to be inadequate treatment of the waste material. Process excursions, not involving accidents or major equipment failures, do not pose significant environmental health and safety concerns. Since the process operates at elevated temperature and pressure, active control measures will be required to maintain process conditions within permitted equipment limitations. Wastes having COD above about $15 \mathrm{~g} / \mathrm{l}$ will require removal of excess process heat. However, control functions are simple and based on reliable pressure and temperature measurements. Control time constants are relatively long (seconds to minutes), and factors of safety (operating point vs. equipment failure) are large. Safe shutdown may be easily accomplished by simply shutting off feed and reducing reactor pressure.

\section{A-9.4 References}

1. W. M. Copa and W. B. Gitchel, "Wet Oxidation," in Standard Handbook of Hazardous Waste Treatment and Disposal, H. M. Freeman, ed., McGraw-Hill Book Co., New York, NY, 1989.

2. J. L. McArdle, et al., Treatment of Hazardous Waste Leachate Noyes Data Corporation, 1988.

3. Zimpro Passavant, "Even the Toughest Wastewaters Break Under Pressure," Bulletin \#WAO-100, 1991.

4. M. J. Dietrich, et al., "Wet Air Oxidation of Hazardous Organics in Wastewater," Environmental Progress, Vol. 4, No. 3, pp. 171-177, August 1985. 


\section{A-10 WET OXIDATION (WETOX)}

\section{A-10.1 Technology Description}

Wet oxidation is a redox chain reaction process for oxidation of organic materials using Fenton's Reagent 1,2 . The oxidant solution is (typically) made up of a ferrous sulfate catalyst (FeSO 4$)$, sulfuric acid, and hydrogen peroxide $\left(\mathrm{H}_{2} \mathrm{O}_{2}\right)$ The key oxidant is the hydroxyl radical which is produced in solution by the reaction of $\left(\mathrm{Fe}^{2+}\right)$ ions with peroxide. The hydroxyl radical is understood to be the primary oxidant in these Fenton-like systems.

$$
\mathrm{Fe}^{+2}+\mathrm{H}_{2} \mathrm{O}_{2}=\mathrm{Fe}^{+3}+\mathrm{OH}^{-}+\mathrm{OH}^{-}
$$

The resultant $\mathrm{OH}^{-}$anions combine with $\mathrm{H}^{+}$ions to produce water. $\mathrm{Cu}(\mathrm{II})$ may be added as a catalyst providing another variation on this chemistry system. The ferric ion is reduced back to ferrous through further reactions in the oxidation of the organic species, for example:

$$
\mathrm{Fe}^{+3}+\mathrm{R} \cdot=\mathrm{Fe}^{+2}+\mathrm{R}^{+}
$$

The ferrous ion is then available to generate another hydroxyl radical through the first reaction above.

Wet oxidation operates in a batch mode at ambient pressure, and at temperatures between 80 to $100^{\circ} \mathrm{C}$. The $\mathrm{pH}$ of the solution is adjusted to $\sim 3$ with addition of sulfuric acid. After the ferric sulfate catalyst has been added to the waste solution, $50 \% \mathrm{H}_{2} \mathrm{O}_{2}$, is added continuously until reaction with organic material has gone to completion.

This process will treat waste liquids, sludges, and solids that are suspendable (IX resins) or dispersable in water. The process is typically operated in a batch mode. Some inorganics may also be oxidized in this process (e.g., sulfite, $\mathrm{CN}, \mathrm{S}^{=}$, etc.). Residuals from treatment are transferred to aqueous waste treatment for recovery and stabilization of inorganic residues.

The process is reported to be slow to treat alkanes, haloalkanes, polyvinyl chloride, rubber, and polyethylene.

\section{A-10.2 Advantages, Disadvantages, Issues}

\section{Advantages}

- The process is fully contained and operates at moderate conditions.

- The process does not lead to oxidation of nitrogen to NOx, or decomposition of sulfuric acid leading to release of SOx.

- Reaction mixture is less corrosive than some other aqueous based organic destruction processes.

- There is no reported production of dioxins and furans. 


\section{Disadvantages}

- Uses sulfuric acid; produces mixed acids on oxidation of chloride containing wastes.

- The process does not readily provide high destruction efficiencies; the treated solution may require further "polishing" to complete the removal or destruction of regulated organic compounds.

- The process is slow to react with alkanes, haloalkanes, polyvinyl chloride, rubber, and polyethylene.

Issues

- Rate of reaction is not determinable from the available information.

- The process is slow for destruction of halogenated materials.

- Except for materials such as ion exchange resins the process does not readily destroy solid materials.

- A detailed evaluation of all of the wet oxidation and Fenton' reagent based technologies should be performed to get an equivalent understanding and determine the usefulness of each.

\section{A-10.3 EVALUATION}

\section{Performance}

\section{A-10.3.1 Range of Feed Material}

Ranking - Medium-Low: Wet Oxidation is developed primarily for treatment of aqueousorganic waste water streams. The process will also treat organic liquids diluted or dispersed into aqueous solutions. This process also might handle some organic sludges if the organic can be suspended or dissolves into the working fluid. While Wet Oxidation is optimized for aqueous streams; some (95\%) destruction of ion exchange resins has been reported 2 . It would be difficult to apply this process to inorganic sludge, soils, and debris.

\section{A-10.3.2 Treatment Effectiveness}

Ranking - Medium-Low: WETOX can destroy only a limited number of RCRA organics in aqueous solution. The reported extent of destruction may not be adequate. Based on data available, it is difficult to tell whether the basic process can be optimized to achieve the high level of destruction required by RCRA regulations. Treatment of inorganic oxidants, or materials such as $\mathrm{H}_{2} \mathrm{~S}$ or cyanide is probable but not demonstrated.

Eventually the iron dissolved in the process probably will be removed by precipitation. If regulated metals are present, and/or the destruction of organic has been incomplete, this secondary waste will be RCRA regulated. This residue/precipitate may require delisting for organics. Some wastes will require further treatment for destruction of some RCRA organics because of the limited destruction in primary treatment. 


\section{Readiness for Deployment}

\section{A-10.3.3 Level of Development and Understanding}

Ranking - High: Commercial systems are available with at least two commercial suppliers offering the process at present. There is a good understanding in industry of the application of Fenton's Reagent to the destruction of organic compounds. To have a definite application to aqueous phase organic destruction, the process should demonstrate the ability to operate at a high throughput and high destruction efficiency without production of unwanted refractory compounds.

\section{A-10.3.4 System Complexity}

Ranking - High-Medium: This is strictly aqueous chemistry with no oxidant or acid recycle streams. The system will require only handling of standard industrial chemicals, neutralization of sulfuric acid, and removal of metal sulfate salt. Process is used for treatment of aqueous miscible wastes that require minimum preparation for introduction into the wet oxidation process. However, separation of organics from the offgas and condensate is required, and some wastes may require further treatment for destruction of some RCRA organics. Iron salts produce a secondary waste unless an iron recovery process is included.

\section{Environmental Health and Safety}

\section{A-10.3.5 Emissions}

Ranking - High-Medium: Routine emissions from WETOX treatment systems will include process offgas containing $\mathrm{CO}_{2}, \mathrm{H}_{2} \mathrm{O}$, and minor quantities of volatile products (acetic acid, acetone, methanol, etc.) of incomplete oxidation of the waste POCs. Simple treatment with activated carbon should be sufficient to render WAO off gas suitable for discharge. During process excursions, some volatile waste POCs may distribute to the offgas Some wastes may require further treatment for destruction of some RCRA organics. Residue from organic destruction will require separation and disposal. If regulated metals are present, this residue/precipitate will also require stabilization and disposal.

\section{A-10.3.6 Worker Health and Safety}

Ranking - High-Medium: This is a rather mild industrial chemical process. Waste streams and effluent are relatively dilute and are enclosed in vessels and transfer pipelines. Failure of primary containment would likely result in a simple spill or discharge of untreated or in-process liquid waste. Specific energy of process fluids is low and reaction of process fluids with air or water is not a concern. Corrosion, erosion, and deposition in key process equipment is not a major concern. There is little potential for accidents or process excursions. There should be no residual hazards to the maintenance worker.

\section{A-10.4 References}

1. D. W. Camp, et al., "Mixed Waste Management Facility Draft Conceptual Design," UCRL-PROP-116761 (L-17293-1), April 1994. 
2. M. A. Twissel, N. S. Holt and D. J. Hebditch, "Design and Testing of a Mobile Pilot Plant for Organic Radwaste Treatment by Wet Oxidation." Proceedings of the 1995 IChEME Research Event/First European Conference, pp. 237-239. 


\section{A-11 CATALYZED WET OXIDATION-DETOX(SM)}

\section{A-11.1 Technology Description}

DETOX(SM) process is a means of oxidizing organic materials with an internal regeneration of the oxidant 1 . The DETOX $(\mathrm{SM})$ process is described as a co-catalyzed wet oxidation process in which the catalysts include a high concentration of iron ions, (typically as $\mathrm{FeCl}_{3}$ ) in the presence of small amounts of platinum and ruthenium ions. Typical composition is $60 \mathrm{wt} \%$ ferric chloride and $3.6 \mathrm{wt} \% \mathrm{HCl}$ (presumably the balance, $36.4 \%$, is water). Organic compounds are oxidized completely to carbon dioxide, water, and (if chlorinated) hydrogen chloride. This composition of working fluid is far from the range of any other process considered to be "wet oxidation", catalyzed or non catalyzed.

Organic liquid waste is fed directly to the reactor; solids and sludges are size reduced then fed to the reactor. For suspended or dispersed organics, oxidation appears to occur primarily at the surface of contact between the organic (droplet or globule) and the reagent solution. Therefore particle or droplet sizing in the ball mill or by emulsification, respectively, is important. A partial pressure of oxygen is maintained above the solution to provide oxygen for reoxidation of the reduced ferrous $\left(\mathrm{Fe}^{2+}\right)$ ions back to ferric.

$$
\mathrm{Fe}(\mathrm{II})+1 / 2 \mathrm{O}_{2}+\mathrm{H}_{2} \mathrm{O}+\mathrm{e}^{-}=\mathrm{Fe}(\mathrm{III})+2 \mathrm{OH}^{-}
$$

The resultant $\mathrm{OH}^{-}$anions recombine with $\mathrm{H}^{+}$ions to produce water. A group of "homogeneous co-catalysts", metals ions, $\mathrm{Cu}(\mathrm{II}), \mathrm{Pt}(\mathrm{IV}), \mathrm{Pd}(\mathrm{II}), \mathrm{RU}(\mathrm{III})$, may influence the rate of these reactions. Catalyst concentration is approximately 0.001 molar.

Carbon dioxide produced by the oxidation of organic compounds is removed from the vessel with head space gases which also includes water vapor, oxygen, and hydrogen chloride. Off-gas is passed through a condenser to remove most of the water vapor and $\mathrm{HCl}$. A portion of the condensed acid is recycled to the reagent storage and feed system. The rest of the acid is neutralized and sent to the aqueous waste treatment system.

The process handles aqueous and liquid organic wastes, organic sludges, and combustible debris but may not handle soils or inorganic sludges and debris as readily. Delphi Research has put informal limits on waste feed to the process 2 :

- No more than $10 \%$ by weight basicity average in the feed

- No more than $10 \%$ by weight average reactive metals in the feed.

- No more than $5 \%$ by weight average fluoride in the feed. Not including the fluoride content of polymers.

- No more than $5 \%$ by weight average sulfur in the feed.

- No more than $5 \%$ by weight average phosphorus in the feed.

- No more than $5 \%$ by weight average calcium in the feed. 
- No more than $5 \%$ by weight average cyanide in the feed.

Inorganic buildup in the process solution is limited to about $20 \%$. As inorganic residues build up in the vessel, a side stream of reactor solution is removed and filtered to separate suspended solids. The acid filtrate is returned to the reaction vessel. Solids from the filter are rinsed with mild hydrochloric acid solution to extract soluble chlorides then sent to polymer stabilization.

Periodically the concentration of dissolved metals and radionuclides builds up in the solution to a level that affects the oxidation reactions. The organic feed to the reactor is stopped, organic destruction is allowed to continue until organics are destroyed. The reactor solution is cooled, neutralized, and dissolved metals are precipitated. The neutralized filtrate salt solution is transferred to the aqueous waste treatment system. The filtered metal precipitates after washing in dilute hydrochloric are stabilized in polymer.

Uncondensed organic compounds in the offgas may be oxidized by passing the gas stream through a bubble tower containing $\operatorname{DETOX}(\mathrm{SM})$ solution.

\section{A-11.2 Advantages, Disadvantages and Issues}

\section{Advantages}

- The chemical system is much more aggressive than most aqueous based processes and can treat more chemical compounds than wet oxidation at ambient conditions.

- The oxidant is continuously generated in solution. The reduced species form of the oxidant is an $\mathrm{OH}^{-}$ion or water after neutralization in the acid solution The heat input rate from oxidation of the organic materials is controlled by blending wastes to a fairly constant heating value.

- The process appears to have a potential application to leaching of organic and inorganic contaminants from inert matrix materials which will not dissolve in the working solution and are not oxidized by ferric ion.

- Has been shown to destroy highly chlorinated compounds.

\section{Disadvantages}

- Temperature control from heat of oxidation of the organic materials is controlled by blending wastes to a fairly constant heating value. This may take considerable interim storage, sorting, and blending of organics as well as a significant amount of costly characterization. Dilution to control BTU input may also reduce the net throughput of waste.

- Feeding any inorganic solids, sludges, or debris that will react with or dissolve in the acid chloride solution will quickly expend the process solution and require rework of the entire solution. 
- The DETOX $(\mathrm{SM})$ system operates with a far more aggressive solution than do the wet oxidation variations of Fenton-like reagents, and may have material compatibility and corrosion problems.

\section{Issues}

- Separation of hydrochloric acid and recycle needs to be established.

- Side stream handling needs to be demonstrated.

- Separation, washing, and precipitation of regulated inorganics from the iron chloride solution requires demonstration.

- The separation and recycle of the iron chlorides needs to be demonstrated to reduce the potential for increasing the amount of waste generated from discharge of insoluble and soluble salts.

- Reaction rates and extent of organic destruction at full scale ( $1 \mathrm{M}^{3}$ reaction solution) need to be demonstrated.

- Will the VOC oxidizing scrubber in the offgas really work? IF IT WORKS DO WE WANT TO TEST IT SEPARATELY ELSEWHERE AS A VOC SCRUBBER?

- Can treatment of inorganic sludges and debris be done adequately with a rinse/wash of the waste with the acid solution recovered from process recycle, and then blend the rinse acid back into DETOX(SM) solution?

\section{A-11.3 Evaluation}

\section{Performance}

\section{A-11.3.1 Range of Feed Material}

Ranking - High-Medium: DETOX $(\mathrm{SM})$ will handle some of the DOE waste matrices well, some may be treated with considerably more recycle of the working solution and other matrices may not be handled at all. The process is not developed for aqueous waste, excess water will dilute the working solution and will require evaporation. DETOX(SM) is developed primarily for treatment of organic liquids and some solids. Based on test experience, the process should handle some sludges and particulate reasonably well if they are finely divided and suspended, slurried, or emulsified in the working fluid.

The application to process residues is limited by the potential solubility of the inert matrix material in the working fluid. Correspondingly, the process may handle some soils, especially soils that are high in organic contaminants, but solubility of the soil inert components may limit this application. Initial work reported has shown successful destruction of organic combustible debris. The process is probably not practical for application to inorganic debris. 


\section{A-11.3.2 Treatment Effectiveness}

Ranking - High-Medium: DETOX $(\mathrm{SM})$ is reported to achieve greater than $98.5 \%$ destruction efficiency for some organic compounds; most are reported to exceed $99.5 \%$. Destruction efficiencies for various organic contaminants are shown in Table A-11.1 for unstirred reactor tests. Hexachlorobenzene, initially reported to require very long times (up to $10 \mathrm{X}$ ) at higher temperatures, has been shown to react as fast as trichloroethylene. "...average reaction rate for

organic material will be...0.05 $\mathrm{Kg} / \mathrm{L}-\mathrm{hr}$ at $5-10 \%$ organic loading...a theoretical maximum oxidation rate of almost $0.2 \mathrm{Kg} / \mathrm{L}-\mathrm{hr}$ at $10 \%$ organic loading and $200^{\circ} \mathrm{C}$ reaction temperature $2 . "$ The maximum oxidation rate of $0.2 \mathrm{Kg} / \mathrm{L}-\mathrm{hr}$ is equivalent to a rate of $200 \mathrm{Kg} / \mathrm{M}^{3}-\mathrm{hr}$. However, operation of a fluid, or condensed phase, system to oxidize organic materials at rates of 200 $\mathrm{Kg} / \mathrm{M}^{3}-\mathrm{hr}$ would create significant mass and heat transfer problems.

Oxygen (or air) would need to be introduced and reacted at a rate equivalent to several reactor volumes per minute. Carbon dioxide would be produced and released from the fluid at a corresponding rate depending on the stoichiometry of the oxidation reaction. There would also be a high rate of heat generation that must be removed, although a significant amount of heat may be removed with the released hot carbon dioxide. In any case the practical throughput rates may not correspond to the measured reaction rates, and scale-up to an operating system will be limited by sound engineering design and the ability to achieve the required heat and mass transfer across the interfaces.

Net volume reduction is expected to be high for the primary organics treated by this process. For several organic compounds of interest, the technology has difficulty achieving complete destruction. For TSCA organic waste, for which adequate destruction may not be achieved, a secondary treatment process may be required.

Secondary waste acid and salt side streams are also produced which are evaporated to recover the $\mathrm{HCl}$ and convert the solids to oxides which are filtered out as the acidity decreases.

Table A-11.1 Destruction Results from Unstirred Reactor Tests 3

\begin{tabular}{|l|c|c|}
\hline \multicolumn{1}{|c|}{ Organic Material } & $\begin{array}{c}\text { \% Absolute Destruction } \\
\text { Efficiency }\end{array}$ & $\begin{array}{c}\text { \% Absolute Destruction } \\
\text { Efficiency on vermiculite }\end{array}$ \\
\hline \hline 0-xylene & 99.9997 & 99.98 \\
\hline 1,2,4 tri methyl-benzene & 99.9997 & 99.55 \\
\hline trichloroethylene & 99.995 & \\
\hline hexachlorobenzene & 99.995 & \\
\hline polychlorinated biphenyl & 98.9 & \\
\hline carbon tetrachloride & "complete" & \\
\hline trichloroethane & "complete" & \\
\hline
\end{tabular}




\section{Readiness for Deployment}

\section{A-11.3.3 Level of Development and Understanding}

Ranking - Medium Plus: The system design is still evolving with a demonstration pilot plant expected to be completed in 1997. Pilot scale demonstration work will be completed and an operable system design available based on demonstration tests.

\section{A-11.3.4 System Complexity}

Ranking - Medium-Low: Size reduction of combustible solids is required to provide good contact with working solution. Separation of soluble inert solids may be required to prevent rapid saturation of the solution. Waste characterization and blending to control the BTU value of organic wastes may also be required. The process is somewhat complex due to the recycle and secondary streams to be handled. Extensive handling of offgas and reactor solution, separation of insoluble materials, and precipitation and separation of dissolved metals is required. Secondary waste treatment may consist of the following processes: condense and recover $\mathrm{HCl}$, neutralize, filter and rinse precipitate, evaporate, dispose of waste solution, dispose of waste condensates, adsorb unreacted VOCs, treat unreacted VOCs, stabilize solid wastes, etc. Recovery of iron may also be necessary to minimize secondary waste. Although several steps are required to process the acids and secondary wastes, it is believed that technology is available and little or no posttreatment is required to complete the destruction of the primary organic wastes or organic contaminants. Operation under elevated pressure and temperature with corrosive and erosive process solutions will likely result in leaks requiring monitoring and potentially frequent shutdowns for maintenance. Presence of insulation will hinder decontamination and slow repair and maintenance operations.

\section{Environmental Health and Safety}

\section{A-11.3.5 Emissions}

Ranking - Medium: Extensive handling of offgas and reactor solution, separation of insoluble materials, and precipitation and separation of dissolved metals is required. Although several steps are required to process the acids and secondary wastes, little or no post-treatment is required to complete the destruction of the primary organic wastes or organic contaminants. Secondary waste treatment may consist of the following processes: condense, neutralize, filter rinse precipitate, evaporate, dispose of waste solution, dispose of waste condensates, adsorb unreacted VOCs, treat unreacted VOCs, stabilize solid wastes, etc. Secondary waste acid and salt side streams are produced which will be neutralized and stabilized for disposal depending on content of regulated metals and radionuclides. Treatment of the process solution will lead to generation of secondary waste due to the complex separation processes required. For several organic compounds of interest the technology has difficulty achieving complete destruction but has as high or higher destruction efficiency as other aqueous based organic treatment processes. Net volume change may be an increase due to secondary waste. 


\section{A-11.3.6 Worker Health and Safety}

Ranking - Medium: Low availability will indicate extra maintenance requirements. Maintenance required on a rather complex system increases exposure of maintenance personnel to radiation and chemical hazards. Industrial process chemical conditions are not exceptionally hazardous for operating personnel. Process is operated at a positive pressure and moderate temperatures. Thermal excursions may occur if feed waste blending for BTU control fails. Inadvertent accumulation of oxygen and VOCs may occur, and reaction rate excursion may occur if a mistake in blending could produce high BTU waste mixtures. DETOX(SM) operates at about 20 pounds per square inch gauge (psig) and at temperatures between $300^{\circ} \mathrm{F}$ to $400^{\circ} \mathrm{F}$ $\left(150^{\circ} \mathrm{C}\right.$ to $\left.200^{\circ} \mathrm{C}\right)$. Oxygen pressure above the reactant solution will be approximately 5 psi. System has received considerable examination, and the process at planned conditions appears to be stable.

\section{A-11.4 References}

1. W. E. Schwinkendorf, "Alternatives to Incineration Technical Area Status Report," DOE/MWIP-26, U. S. Department of Energy, Office of Technology Development, Washington DC, April 1995

2. Delphi Research, Inc. 95-PMD-L212, Letter P. M. Dhooge to W.J. Quapp, page 4, October 3, 1995

3. Delphi Research, Inc. 95-PMD-L212, Letter P. M. Dhooge to W.J. Quapp, page 1, October 3, 1995 


\section{A-12 ACID DIGESTION/NITRIC-PHOSPHORIC ACID OXIDATION}

\section{A-12.1 Technology Description}

Nitric-phosphoric acid oxidation is a non-incineration process capable of destroying organic liquid and solid organic materials including paper, plastics, resins, and munitions at moderate temperature. This technology was initially tested for destruction of Savannah River (job control/glove box trash) wastes contaminated with $\mathrm{Pu}$. The target wastes are "...a wide range of solid Pu-contaminated waste of which $60 \%$ is combustible. The process will oxidize the combustibles (a mixture of $14 \%$ cellulose, $3 \%$ rubber, $64 \%$ plastics, $9 \%$ absorbed oil, $4 \%$ resins and sludges, and $6 \%$ miscellaneous organics) without requiring separation from the noncombustible portion". The technology uses a mixture of $0.1 \mathrm{M}$ nitric acid as the oxidant in a carrier acid of $14.8 \mathrm{M}$ phosphoric, and is being developed to operate below $200^{\circ} \mathrm{C}$. This mixture is relatively non-corrosive to 304-L stainless steel near room temperature. The phosphoric "carrier acid" acts to allow retention of the nitric acid in solution at temperatures at which the acid would normally have escaped into the gas phase. After destruction of the organic materials, any metals and most radionuclides are retained in solution. These may be recovered by precipitation or through use of ion exchange resins that work in phosphate solutions 1 .

Process testing has been simple batch operations; to accomplish complete oxidation, the solution temperature must be maintained above $130^{\circ} \mathrm{C}$ to $150^{\circ} \mathrm{C}$. The oxidation of simple materials is complete in a few minutes. For more stable compounds such as plastics and aliphatic, oxidation will require different and more extreme conditions (i.e., pressurization, increased temperature, and higher nitric acid concentrations). Experiments have been run up to $185^{\circ} \mathrm{C}$ and to $205^{\circ} \mathrm{C}$ in one case; however there is a significant decrease in the solubility of nitric acid at these higher temperatures.

Trace amounts of palladium $(0.001 \mathrm{M})$ are used to control the carbon monoxide concentration to near $1 \%$ of the released carbon gases. Use of palladium also should work to minimize the production of $\mathrm{N}_{2} \mathrm{O}$ which cannot easily be reoxidized to $\mathrm{HNO}_{3}$. Any $\mathrm{NO}$, and $\mathrm{NO}_{2}$ released can be captured and reoxidized to nitric acid, combined with recovered $\mathrm{HNO}_{3}$, and returned to the reaction system.

There is no reported efforts on the destruction of common multi-halogenated chemicals occurring in DOE wastes although Trimsol has been treated.

The destruction of PVC is also claimed. The only information provided is a "moderate" destruction rate for PVC at $200-205^{\circ} \mathrm{C}$ and pressure $10-15$ psig. Polyethylene was reported to react "fast" also at $200-205^{\circ} \mathrm{C}$ and pressure $10-15$ psig.

Mechanisms of reaction and identification of specific active agents have not been completed. General arguments based on bond energies provide an interesting picture. "Direct oxidation of most organic compounds by $\mathrm{HNO}_{3}$ is energetically favorable (thermodynamics) but very slow (kinetics) due to its inability to break (mechanism) the carbon-hydrogen bond." The assumed active agents are $\mathrm{NO}_{2}$ and $\mathrm{NO}$ produced from decomposition of nitric acid. 


\section{A-12.2 Advantages, Disadvantages, Issues}

\section{Advantages}

- This is a moderate temperature, strong acid mixture that requires pressure to achieve oxidation of even moderately resistant materials. Because of the low concentration of oxidant, it is necessary to reconstitute the oxidant externally, sparge with air to reoxidize nitric acid reduction products in solution, or continue addition of fresh oxidant. The complete process has not been detailed. Some of the required acid reconstitution and recycle technology can probably be adapted from other processes which are a bit more advanced at least conceptually.

- Phosphate waste can be converted to phosphate bonded ceramic; work is continuing in this area.

- Process has been shown to remove plutonium oxide from debris materials.

\section{Disadvantages}

- Process operates at higher temperature and pressure than most competitive aqueous based organic destruction processes.

- Process has not been shown to destroy the more resistant chemicals of interest to DOE. Medium to low oxidation potential of the most-probable active-species suggest the process will not see success in this area.

- Presence of $\mathrm{CO}$ in the uncatalyzed oxidation product is another indication of weak oxidant.

Issues

- The process and the active agents need to be established, understood, and explained. One paper refers to air sparging. Others do not. Pressurized oxygen dissolved in this acid solution should be a stronger oxidant than the nitrate ion, $\mathrm{NO}_{2}$, or $\mathrm{NO}$.

- Air is indicated for use in regeneration and recycle of the nitric acid.

- According to the authors, foaming of the working solution occurs as soluble metals concentration builds up.

- Separation of hydrochloric acid from nitric acid in the offgas stream needs to be established.

- Scrubbing of $\mathrm{HCl}$ or $\mathrm{HNO}_{3}$ out of a mixture in the offgas stream to prevent a solution saturated with a mixture of the two acids.

- What is the equilibrium level of $\mathrm{HCl}$ in the process working solution at various nitric acid concentrations, temperatures, and pressures? 
- Important to the management of secondary waste streams is the type and quality of final waste forms. Will phosphate based forms be adequate for all residuals including high chloride and high metals?

- Working with chloride, nitrate, and phosphate in the process will provide an interesting materials of construction issue.

\section{A-12.3 Evaluation}

\section{Performance}

\section{A-12.3.1 Range of Feed Material}

Ranking - Medium-Low: The process is developed for destruction of solid organic wastes (job control and glove box trash). This process should work for the combustible fraction of debris type wastes. Initial work reported has shown fairly successful destruction of the candidate solid wastes. Some organic liquids will also be destroyed, however, some oils have reacted very slowly. Acid Digestion is not designed for aqueous waste. The process has not been tested on any of the sludges, stabilized solids or particulate wastes.

\section{A-12.3.2 Treatment Effectiveness}

Ranking - Low: Destruction of regulated organics has not been demonstrated or has not been reported. Most work has been directed at destruction of bulk organic solid materials not regulated constituents. Estimated destruction rates are provided in Table A-12.1. Destruction of high chain hydrocarbons is difficult; it can be implied that some if not many of the RCRA regulated organics will be difficult to treat also. Destruction of refractory organics remains to be demonstrated.

This process has not been demonstrated to destroy all RCRA organics. Treated wastes may still contain organics and will probably require post-treatment for destruction of halogenated hazardous organic compounds. There is no indication of what the process does with inorganic reactive species.

Table A-12.1 Estimated Destruction Rates 2

\begin{tabular}{|l|c|c|c|c|}
\hline $\begin{array}{c}\text { Chemical } \\
\text { Material }\end{array}$ & $\begin{array}{c}\text { Temperature } \\
\text { (degrees C) }\end{array}$ & $\begin{array}{c}\text { Pressure } \\
\text { (psig) }\end{array}$ & $\begin{array}{c}\text { Rate } \\
(\mathbf{g} / \mathbf{L}-\mathbf{h r})\end{array}$ & $\begin{array}{c}\text { Rate } \\
(\mathbf{k g} / \mathbf{M} \text { - } \mathbf{h r})\end{array}$ \\
\hline EDTA & 140 & $0-5$ & 142 & 142 \\
\hline cellulose & 150 & $0-5$ & 95 & 95 \\
\hline neoprene & 165 & $0-5$ & 50 & 50 \\
\hline Polystyrene resin & 170 & $5-10$ & 65 & 65 \\
\hline polypropylene & 180 & $10-15$ & 35 & 35 \\
\hline Nitromethane & 155 & $0-5$ & "fast" & $\begin{array}{c}\text { Similar to EDTA } \\
\text { \& cellulose }\end{array}$ \\
\hline
\end{tabular}

Process solutions require extensive recycle. Phosphoric acid will be an advantage if the final form selected is a phosphate and all residues can be incorporated in phosphate waste form. 


\section{Readiness for Deployment}

\section{A-12.3.3 Level of Development and Understanding}

Ranking - Low: Still preliminary and tests have not been completed on a range of wastes of interest to DOE. The level of understanding presented in the available papers does not establish a basis for expecting successful application of this process for general RCRA organic destruction. Pilot plant, 10 gallon size, to be designed by the end of the year. Not clear how complete the flowsheet will be in that pilot plant. The process equipment design and materials of construction are largely unknown at this time. Ability to adequately separate $\mathrm{HCl}$ from nitric acid has not been demonstrated.

\section{A-12.3.4 System Complexity}

Ranking - Medium-Low: Size reduction is required to increase surface area of bulk solids. Process concept appears similar to other nonthermal processes with high acid stream filtration, recovery of nitric acid and acid recycle, and solids management, etc. The process will probably require backup for destruction of halogenated hazardous organic compounds. Solutions require extensive recycle to minimize secondary waste. Metal containing streams will require stabilization. A fractionation process is required to remove $\mathrm{HCl}$ from the nitric acid to decrease the corrosiveness of the solution and prevent damage to system components. Phosphoric acid will be an advantage only if the final form selected is a phosphate and all residues can be incorporated in phosphate waste form.

Operation under elevated pressure and temperature with corrosive and erosive process solutions will likely result in leaks. Presence of insulation will hinder decontamination and slow repair and maintenance operations.

\section{Environmental Health and Safety}

\section{A-12.3.5 Emissions}

Ranking - Medium: Cleaned offgas will contain $\mathrm{CO}, \mathrm{CO}_{2}$, trace $\mathrm{HCl}$. Significant quantities of $\mathrm{CO}$ may be released if the oxidation process is not well controlled. Treated waste will contain higher molecular weight organics and some plastic constituents. Inorganic process solids and contaminated acid after separation from recycle loop will be sent to final waste form. Acid digestion will probably require backup for destruction of halogenated hazardous organic compounds. Solutions may require extensive recycle. Metal containing streams will require stabilization. Phosphoric acid will be an advantage only if the final form selected is a phosphate and all residues can be incorporated in phosphate waste form. The process has not been demonstrated to destroy all RCRA organics. Treated wastes may still contain organics. A backup polishing process may be required for some wastes. There is no indication of what the process does with inorganic reactive species. 


\section{A-12.3.6 Worker Health and Safety}

Ranking - Medium: Process exhibits hazards typical of industrial equipment after operation is stopped. Operations involve high temperature pressurized acid systems with some possibility of excursions from oxidation of highly reactive waste. The system requires handling common industrial chemicals for make up and effluent management. No high voltage or high amperage, and no hydrogen generation. Back pressure into feed preparation system is possible. Thermal excursion from too rapid feeding of reactive organics may lead to increased vessel pressure caused by a rapid temperature increase in the enclosed vessel. Reaction rate excursion may occur due to too rapid feeding of easily oxidized organic. Excess reactivity leading to increase in temperature may be partially quenched by the evaporation of nitric acid which becomes much less soluble at the top of the process temperature range. Operating temperature range is elevated to $>200^{\circ} \mathrm{C}$ with a working pressure of $10-15$ psig. Working fluid is high concentration of phosphoric acid (a dehydrating acid when in contact with cellulosic and similar organic materials) and a low concentration of nitric acid; the combination of acids, temperature, and pressure have been shown to be quite aggressive towards some materials. Sudden breach of primary containment during operation would present considerable hazard to exposed personnel. However, process when fed at the design/planned rate appears to be stable.

\section{A-12.4 References}

1. J. R. Smith, "Air-Nitric Acid Destructive Oxidation of Organic Wastes," WSRC-MS93-169, Westinghouse Savannah River Corporation, Aiken, SC.

2. R. A. Pierce, J. R. Smith, and W.G. Ramsey, "Nitric-Phosphoric Acid Oxidation," Westinghouse Savannah River Corporation, Aiken, SC. 


\section{A-13 SILVER MEDIATED ELECTROCHEMICAL OXIDATION (MEO)}

\section{A-13.1 Technology Description}

In Mediated Electrochemical Oxidation (MEO) an electrochemical cell is used to generate an oxidant species at the anode in an acidic solution. Balancing electrochemical reactions at the cathode must either decompose water or another chemical species in solution. MEO is typically operated in nitric acid solution; in that case, the species decomposed at the cathode is nitric acid.

MEO has been tested with a number of different electrochemical oxidants including $\mathrm{Ag}(\mathrm{II})$, $\mathrm{Co}(\mathrm{III}), \mathrm{Ce}$ (IV), and Fe(III). Aqueous media tested for the cobalt system included nitric and sulfuric acids. The oxidant is generated in the electrochemical cell; the solution is pumped from the electrochemical cell into the primary reactor. After reaction, electrolyte is recycled from the reactors back to the electrochemical cell for regeneration of the oxidant. In continuous feed mode, the waste feed rate is based on the destruction time required for the organic in the feed stream.

The MEO system operates at $50^{\circ}$ to $60^{\circ} \mathrm{C}\left(120^{\circ}\right.$ to $\left.140^{\circ} \mathrm{F}\right)$ and atmospheric pressure. The electrolytic cell cpnsists of a parallel set of chambers with Nafion membranes between the anode and the cathode chambers. Each cell contains approximately 60 pairs of electrodes. An electrolyte solution of nitric acid and silver nitrate is circulated through a set of cells in the MEO unit at rates up to 100 gallons per minute (gpm). Electric energy is applied to the anode and cathode. The metal is transformed in solution to a higher oxidation state. This oxidized metal acts as the primary active oxidizer in solution. The metal ion reacts either directly with the organic species, or with water to produce a reactive intermediate such as the hydroxyl radical $(\mathrm{OH} \cdot)$ that then reacts with the organic material. Eventually the organics are broken down into harmless constituents such as carbon dioxide and water. These reactions may occur any place in the circulating loop from the electrolytic cell to the primary reactor.

The extent of reaction depends on the time allowed for reaction with the active agents. A process conceptual design (LLNL System Design Study) is based on expected destruction of the organic by $90 \%$ on each pass through the primary reactor ${ }^{1}$. This destruction will decrease as the concentration decreases. However the current design provides for the solution to pass through the MEO reaction cells about 25 times. This is estimated to be sufficient to provide well over 99.99\% destruction of most organic compounds. Commercial scale operation has not been demonstrated.

Water formed in the oxidation of the organic compounds migrates through the membrane to the catholyte, reducing the nitric acid concentration below 6 molar $(M)$. Water must be removed continually to maintain the nitric acid concentration at $6 \mathrm{M}$ to avoid forming hydrogen. A slip stream of the catholyte is removed and processed for silver and acid recycling. A much smaller slip stream from the anolyte is combined with the catholyte stream for the removal of salts and to prevent buildup of inerts.

The combined electrolyte blowdown stream consists of water, nitric acid, silver nitrate, silver chloride, metals ions, unreacted waste, and miscellaneous inorganic ions, such as sulfate, chloride, and phosphate, which result from oxidation of the waste material. Most chloride resulting from waste destruction in the solution will combine with silver to produce the highly insoluble silver chloride. Recycle of silver and nitric acid is an economic concern as well as 
environmental. Silver is precious metal as well as a RCRA regulated toxic metal. A method for recovering silver from the silver chloride has been proposed by LLNL, but has not been demonstrated beyond the beaker scale.

\section{A-13.2 Advantages, Disadvantages, Issues}

\section{Advantages}

- This technology has had a good deal of development effort addressed to it and should be considered reasonably well developed. A pilot scale design concept has been prepared.

- MEO, silver based, as been shown to destroy a wide array of chemical compounds and some solid materials (primarily ion exchange resin and cellulosics) dissolved or suspended in an aqueous stream.

- Silver is claimed to be better kinetically than cerium, cobalt or iron. More work appears to have been done on the silver system than on the others.

- There should be no electrolytic production of hydrogen from the athode if the nitric acid concentration is maintained above $6 \mathrm{M}$.

- Has been demonstrated successfully in decontamination mode for hard plastics (PVC).

- The apparent disadvantage of precipitation of silver ions as $\mathrm{AgCl}$ produced from destruction of chlorocarbons may provide some simplicity in recovery and recycle of the metal back to solution. Silver recovery and recycle appears simpler than recovery of cobalt or cerium from the competing technologies. Loss of metal during recycle may be lower than for the other metals, although the other metals are neither expensive nor RCRA regulated.

\section{Disadvantages}

- The oxidant is short lived and cannot be stored. Precipitate of silver occurs in the presence of chloride ions.

- Silver is expensive and is a RCRA toxic metal. Use of silver ion requires recovery and recycle of metal for economic and environmental protection reasons. There may be a large investment in the silver inventory in the working cycle.

- Silver diffuses through the membrane and must be removed from the cathode solution.

- Reoxidation of NOx produced at the cathode back to nitrate is required for pollution control and for economics of the process.

- Does not dissolve "hard" plastics such as polyvinylchloride (PVC) or polyethylene, or dissolves them very slowly. 
- Successful operation depends on integrity of the membrane. Silver and acid appear to move through the membrane which may be degraded by corrosion and radiation effects.

- The system is somewhat complex with the requirement for acid recovery and silver metal recovery and recycle.

Issues

- The extent of organic destruction achieved in operation?

- A complete material balance and energy balance flow sheet including treatment of all side streams and secondary wastes needs to be produced. Verify the calculated behavior in actual experiments. Silver recovery cycle with small loss of silver at full scale operation needs to be demonstrated.

- Demonstration of the LLNL NOx/oxygen contactor for recovery of $\mathrm{HNO}_{3}$ at full scale operation is required.

\section{A-13.3 Evaluation}

\section{Performance}

\section{A-13.3.1 Range of Feed Material}

Ranking - Medium-Low: The Silver MEO process is developed for treatment of organic liquids. However, the process can treat aqueous-organic streams so long as the water does not excessively dilute the working fluid nitric acid concentration. MEO is based on original work dissolving suspended insoluble oxides and should handle sludges reasonably well if they are finely divided and suspended, slurried, or emulsified in the working fluid. This process is optimized for aqueous/organic systems. Some work reported has shown $94-98 \%$ destruction of soft combustible debris in a pilot scale unit.

\section{A-13.3.2 Treatment Effectiveness}

Ranking - Medium-Low: Accepts wastes dissolved or suspended in aqueous streams only. Does not effectively attack bulk hard organics such as plastic, PVC, etc.; however, MEO may be operated in a decontamination mode for those materials. The extent of reaction depends on the time allowed for reaction with the active agents. Further treatment of primary waste depends on the metals and other inorganic ion residues from the destruction of the organic compounds. An available design concept (LLNL) is based on expected destruction of the organic by $90 \%$ on each pass through the primary reactor. This will decrease as the concentration decreases. However the current design provides for the solution to pass through the MEO reaction cells about 25 times. This is estimated to be sufficient to provide well over $99.99 \%$ destruction of most organic compounds. Calculated and designed treatments are expected to achieve $99.99 \%$ destruction of most organic compounds. Measured reaction rates and extent of destruction for various organic material is shown in Table A-13.1. Some wastes may be incompletely destroyed and require a second stage organic destruction. 
Volume reduction is effectively $100 \%$ only for those liquid and soft combustible debris wastes destroyed by MEO. The working fluid in the process is loaded with RCRA regulated silver ions. This requires a carefully controlled recycle system and can yield RCRA regulated secondary waste.

Table A-13.1 Destruction of Materials in Silver Nitric Acid MEO Tests1.

\begin{tabular}{|c|c|c|c|c|c|}
\hline \multirow[t]{2}{*}{ Material } & \multirow{2}{*}{$\begin{array}{c}\text { Acid } \\
\text { Concentration } \\
\text { and } \\
\text { Temperature }\end{array}$} & \multicolumn{2}{|c|}{ Small Scale } & \multicolumn{2}{|c|}{ Bench Scale } \\
\hline & & $\begin{array}{c}\text { Rate } \\
\text { (g/s-amp) }\end{array}$ & $\begin{array}{c}\text { Extent of } \\
\text { Destruction }\end{array}$ & $\begin{array}{c}\text { Rate } \\
\text { (g/s-amp) }\end{array}$ & $\begin{array}{c}\text { Extent of } \\
\text { Destruction }\end{array}$ \\
\hline Trimsol & $8 \mathrm{M}-70^{\circ} \mathrm{C}$ & $2.61 \mathrm{E}-5$ & 90.60 & $2.84 \mathrm{E}-5$ & 96.29 \\
\hline Trimsol & $12 \mathrm{M}-70^{\circ} \mathrm{C}$ & $2.63 E-5$ & 95.41 & not tested & \\
\hline Cellulose & $8 \mathrm{M}-70^{\circ} \mathrm{C}$ & $5.93 \mathrm{E}-5$ & 98.47 & $5.05 \mathrm{E}-5$ & 98.99 \\
\hline Cellulose & $10 \mathrm{M}-70^{\circ} \mathrm{C}$ & $5.30 \mathrm{E}-5$ & 84.69 & $5.20 \mathrm{E}-5$ & 99.27 \\
\hline Wipe 1 & $8 \mathrm{M}-70^{\circ} \mathrm{C}$ & $5.76 \mathrm{E}-5$ & 98.07 & not tested & \\
\hline Wipe 1 & $10 \mathrm{M}-70^{\circ} \mathrm{C}$ & $3.94 \mathrm{E}-5$ & 94.02 & not tested & \\
\hline Wipe 2 & $8 \mathrm{M}-70^{\circ} \mathrm{C}$ & $5.91 \mathrm{E}-5$ & 97.65 & not tested & \\
\hline Wipe 2 & $10 \mathrm{M}-70^{\circ} \mathrm{C}$ & $5.69 \mathrm{E}-5$ & 96.74 & $5.06 \mathrm{E}-5$ & 99.97 \\
\hline Cloth & $10 \mathrm{M}-70^{\circ} \mathrm{C}$ & $5.79 \mathrm{E}-5$ & 95.95 & $3.08 \mathrm{E}-5$ & 99.97 \\
\hline Biomass & $10 \mathrm{M}-70^{\circ} \mathrm{C}$ & $4.61 \mathrm{E}-5$ & 96.37 & not tested & \\
\hline Latex & $10 \mathrm{M}-70^{\circ} \mathrm{C}$ & $2.62 E-5$ & 94.84 & not tested & \\
\hline Tyvek & $10 \mathrm{M}-70^{\circ} \mathrm{C}$ & $1.53 \mathrm{E}-5$ & 97.74 & not tested & \\
\hline polyethylene & $10 \mathrm{M}-70^{\circ} \mathrm{C}$ & $1.14 \mathrm{E}-5$ & 98.10 & not tested & \\
\hline $\begin{array}{l}\text { Polyvinyl } \\
\text { chloride }\end{array}$ & $8 \mathrm{M}-50^{\circ} \mathrm{C}$ & $4.24 \mathrm{E}-6$ & 20.80 & not tested & \\
\hline
\end{tabular}

Destruction rate or treatment capacity based on the bench scale data provided in this table and scaled to a 1 cubic meter equivalent reactor gives a destruction rate of $11.68 \mathrm{Kg} / \mathrm{hr}-\mathrm{M}^{3}$.

\section{Readiness for Deployment}

\section{A-13.3.3 Development and Understanding}

Ranking - High Minus: This technology has been studied extensively. Design concepts have been prepared. Commercial sector indicates readiness to design, build, and license the technology. However, process for recovery of silver from $\mathrm{AgCl}$ has not been demonstrated past the beaker level.

\section{A-13.3.4 System Complexity}

Ranking - Medium-Low: For the applicable waste streams, primarily organic liquids, introduction into the process is a minor matter. Application to solids would require greater preparation including size reduction and a demonstration of a method to feed the solids to the reaction loop. System should be straight forward to install and operate; however, it will be more complex than some of the other organic destruction systems due to acid recycle and metal recycle. The working fluid in the process is loaded with RCRA regulated silver ions. This requires a carefully controlled recycle system and will require extra effort, and when treating 
chlorinated hydrocarbons silver chloride is precipitated and will require recovery. Separation of heavy metal and radionuclide residues from the working solution without loss of silver will be moderately difficult. Nitric acid must be recovered from the nitrous acid in the offgas. Some wastes may be incompletely destroyed and require a second stage destruction.

\section{Environmental Health and Safety}

\section{A-13.3.5 Emissions}

Ranking - High-Medium: Off-gas and aqueous effluent streams should be quite clean comprised mainly of $\mathrm{CO}_{2}$, water vapor, and perhaps some VOCs. Activated carbon treatment should render off-gas suitable for discharge. Hazardous materials are either destroyed, recycled, or retained for stabilization. Built in recycle of oxidant metal and nitric acid is required. Some wastes may be incompletely destroyed and require a second stage destruction. Treated waste residue may require stabilization depending on metals and other inorganics present; separation of these residues from the working solution without loss of silver will be moderately difficult. The working fluid in the process is loaded with RCRA regulated silver ions. This requires a carefully controlled recycle system and will require extra effort.

\section{A-13.3.6 Worker Health and Safety}

Ranking - High-Medium: As "designed" the system should not be particularly hazardous for maintenance. Operations involve strong nitric acid solution and very high amperage electrolytic cells for plant scale equipment. Nitration of organics to form unstable reactive or explosive compounds is a possibility. Sudden loss of primary containment during operations would present a substantial hazard to exposed personnel. The system may be subject to process excursions which will require corrective action by operators or control systems.

The MEO system operates at $50^{\circ}$ to $60^{\circ} \mathrm{C}\left(120^{\circ}\right.$ to $\left.140^{\circ} \mathrm{F}\right)$ at atmospheric pressure so that the system should be stable. However, excess temperature leads to system overheat and vaporization of nitric acid from both parts of the electrolytic system. This is not self correcting.

Excess current will lead to destruction of $\mathrm{HNO}_{3}$ producing too much $\mathrm{NO}_{\mathbf{x}}$ in the offgas overwhelming the contactor. Not self correcting.

Excess waste feed (concentration too high for set conditions of feed to bleed) will lead to too high organic concentration in the bleed stream for treatment and discard. Not self correcting.

Depleted acid $\angle 2 \mathrm{M}$ will lead to destruction of water with release of $\mathrm{H}_{2}$ along with $\mathrm{NO}_{\mathrm{X}}$ in the cathode offgas creating a potentially explosive mixture. Not self correcting.

\section{A-13.4 References}

1. Z. Chiba, P. R. Lewis, L. C. Murguia, "Mediated Electrochemical Oxidation Treatment for Rocky Flats Combustible Low-Level Mixed Waste, FY 1994 Final Report," UCRL-ID-118679, Lawrence Livermore National Laboratory, Livermore, CA, September 1994. 


\section{A-14. CERIUM MEDIATED ELECTROCHEMICAL OXIDATION (MEO)}

\section{A-14.1 Technology Description}

In Mediated Electrochemical Oxidation (MEO) an electrochemical cell is used to generate an oxidant species at the anode in an acidic solution. Balancing electrochemical reactions at the cathode must either decompose water or another species in solution. MEO is typically operated in nitric acid solution; in that case, the species decomposed at the cathode is nitric acid.

MEO has been tested with a number of different electrochemical oxidants including $\mathrm{Ag}(\mathrm{II})$, $\mathrm{Co}(\mathrm{III}), \mathrm{Ce}$ (IV), and Fe(III). The aqueous media for cerium is nitric acid. As with the silver based process, the oxidant solution is pumped from the electrochemical cell into the primary reactor. After reaction, electrolyte is recycled from the reactors back to the electrochemical cell for regeneration of the oxidant. The waste feed rate is based on the destruction time required for the organic in the feed stream.

The MEO system operates at $50^{\circ} \mathrm{C}$ to $60^{\circ} \mathrm{C}\left(120^{\circ} \mathrm{F}\right.$ to $\left.140^{\circ} \mathrm{F}\right)$ and atmospheric pressure. The electrolytic cell consists of a parallel set of chambers with Nafion membranes between the anode and the cathode chambers. Each cell contains approximately 60 pairs of electrodes. An electrolyte solution of nitric acid and ceric nitrate is circulated through a set of cells in the MEO unit. The ceric ion is oxidized in solution from III to IV oxidation state. This oxidized metal acts as the primary active oxidizer in solution. The metal ion reacts either directly with the organic species, or with water to produce a reactive intermediate such as the hydroxyl radical (OH·) that then reacts with the organic material. Eventually the organics are broken down into harmless constituents such as carbon dioxide and water. These reaction may occur any place in the circulating loop from the electrolytic cell to the primary reactor.

Extent of reaction depends on the time allowed for reaction with the active agents. The process design (EOS Pilot System) is based on expected destruction of most organic material by $99.99 \%$.

Water formed in the oxidation of the organic compounds migrates through the membrane to the catholyte, reducing the nitric acid concentration below 6 molar (M). Water must be removed continually to maintain the nitric acid concentration at $6 \mathrm{M}$ to avoid forming hydrogen. A slip stream of the catholyte is removed and processed for acid recycling; $\mathrm{Ce}(\mathrm{III})$ and $\mathrm{Ce}$ (IV) ions do not migrate through the membrane. A much smaller slip stream from the anolyte is combined with the catholyte stream for the removal of salts and to prevent buildup of inerts. The combined electrolyte blowdown stream consists of water, nitric acid, ceric nitrate, metal ions, unreacted waste, miscellaneous inorganic ions, such as sulfate, chloride, and phosphate, which result from oxidation of the waste material. Chloride resulting from waste destruction in the solution will remain in solution to be dealt with in the recycle loop.

Recycle of cerium and acid may be an economic and an environmental concern. Discard of cerium may be costly and increase waste disposal requirements. Cerium is not a RCRA regulated toxic metal. 


\section{A-14.2 Advantages, Disadvantages, Issues}

\section{Advantages}

- This technology has had a good deal of development effort addressed to it and should be considered reasonably well developed.

- A pilot system has been built.

- $\quad$ MEO, cerium based, as been shown to destroy a wide array of chemical compounds and some solid materials (primarily ion exchange resin and cellulosics) dissolved or suspended in aqueous stream.

- Cerium, is claimed to be kinetically equivalent to silver for organic destruction.

- Cerium does not migrate through the membrane to the cathode side.

- Cerium is not a hazardous metal

- Parasitic reactions with water do not occur with cerium.

- Lower reaction potential reduces material corrosion and significantly increases material lifetime.

- There should be no electrolytic production of hydrogen from the cathode if nitric acid concentration maintained above $6 \mathrm{M}$.

- Does not precipitate chloride produced from destruction of chlorocarbons .

- Cerium claimed not to produce perchlorate ion.

\section{Disadvantages}

- The oxidant is short lived, cannot be stored.

- Recovery and recycle of metal may be desirable for economic and waste minimization reasons. Recycle chemistry may be more complex than for silver .

- Cerium may not react as fast or lead to as extensive destruction as does silver.

- Reoxidation of $\mathrm{NO}_{\mathrm{x}}$ produced at the cathode back to nitrate is required for pollution control and for economics of the process.

- Does not dissolve "hard" plastics such as polyvinylchloride (PVC) or polyethylene, or dissolves them very slowly.

- Successful operation depends on integrity of the membrane. Acid appears to move through the membrane which may be degraded by corrosion and radiation effects. 
- The system is somewhat complex with the requirement for acid recovery and cerium metal recycle.

Issues

- Verify the calculated behavior in actual experiments and demonstration the metal recovery cycle at full scale.

- Demonstrate the $\mathrm{NO}_{\mathrm{X}}$ reoxidation at full scale operation.

- Demonstrate small loss of cerium at full scale operation.

- Will high levels of destruction be achieved in operation?

A-14.3

Evaluation

Performance

\section{A-14.3.1 Range of Feed Material}

Ranking - Medium-Low: The Cerium MEO process is developed for treatment of organic liquids. However, the process can treat aqueous-organic streams so long as the water does not excessively dilute the working fluid nitric acid concentration. This process is based on original work dissolving suspended insoluble oxides and should handle sludges reasonably well if they are finely divided and suspended, slurried, or emulsified in the working fluid. This process is optimized for aqueous/organic systems and has limited applicability to combustible debris. Like silver MEO, it is not expected to treat hard debris effectively.

\section{A-14.3.2 Treatment Effectiveness}

Ranking - High-Medium: MEO accepts wastes dissolved or suspended in aqueous streams. It does not effectively attack bulk hard organics such as plastic, PVC, etc.; however, MEO could be operated in a decontamination mode for those materials. The extent of reaction depends on the time allowed for reaction with the active agents. Further treatment of primary waste depends on the metals and other inorganic ion residues from the destruction of the organic compounds. An available design concept for solver MEO (LLNL) is based on expected destruction of the organic by $90 \%$ on each pass through the primary reactor. This destruction efficiency per pass will decrease as the concentration decreases. However, that design provides for the solution to pass through the MEO reaction cells about 25 times. This is estimated to be sufficient to provide well over $99.99 \%$ destruction of most organic compounds. Calculated and designed treatments are expected to achieve $99.99 \%$ destruction of most organic compounds. Some wastes may be incompletely destroyed and require a second stage organic destruction. A similar design should be appropriate for cerium MEO.

Destruction rate or treatment capacity based on the pilot scale design and data provided by EOSystems, and scaling to a 1 cubic meter equivalent reactor, gives a destruction rate of about $70-100 \mathrm{Kg} / \mathrm{hr}_{\text {-cubic meter }}{ }^{1}$.

Volume reduction is effectively $100 \%$ only for those liquid and soft combustible debris wastes destroyed by MEO. The working fluid in the process is loaded with cerium ions which, 
although unregulated, may require recovery to limit secondary waste generation. This requires a carefully controlled recycle system.

\section{Readiness for Deployment}

\section{A-14.3.3 Development and Understanding}

Ranking - High Minus: This technology has been studied extensively. Design concepts have been prepared. Commercial sector indicates readiness to design, build, and license the technology. Separation of $\mathrm{HCl}$ from nitric acid has not been demonstrated.

\section{A-14.3.4 System Complexity}

Ranking - Medium-Low: For the applicable waste streams, primarily organic liquids, introduction into the process is a minor matter. Application to solids would require greater preparation including size reduction and a demonstration of a method to feed the solids to the reaction loop. System should be straight forward to install and operate; however, it will be more complex than some of the other organic destruction systems due to acid recycle and metal recycle. The working fluid in the process uses cerium which is not a RCRA regulated metal so that a recycle system is not necessary; however reclaiming cerium may be economically desirable to minimize the cost of replacing cerium and the amount of radioactive waste sent to disposal. Separation of heavy metal and radionuclide residues from the working solution without loss of cerium will be moderately difficult. When treating chlorinated hydrocarbons hydrochloric acid is produced and will require separation from the nitric acid to prevent excessive corrosion of the electrodes. Nitric acid must be recovered from the nitrous acid in the offgas. Some wastes may be incompletely destroyed and require a second stage destruction.

Some wastes may be incompletely destroyed and require a second stage destruction. Treated waste residue may require stabilization depending on metals and other inorganics present; separation of these residues from the working solution will be moderately difficult.

\section{Environmental Health and Safety}

\section{A-14.3.5 Emissions}

Ranking - High-Medium: Off-gas and aqueous effluent streams should be quite clean comprised mainly of $\mathrm{CO}_{2}$, water vapor, and perhaps some VOCs. Activated carbon treatment should be sufficient to render off-gas suitable for discharge. Built in recycle of oxidant metal and nitric acid may be desirable. Some wastes may be incompletely destroyed and require a second stage destruction. Treated waste residue may require stabilization depending on metals and other inorganics present; separation of these residues from the working solution will be moderately difficult. The working fluid in the process uses cerium which is not a RCRA regulated metal. Although a recycle system may be economically desirable, it is not necessary.

\section{A-14.3.6 Worker Health and Safety}

Ranking - High-Medium: As "designed" the system should not be particularly hazardous for maintenance. Operation with radioactive materials, strong nitric acid solution, and very high amperage electrolytic cells for plant scale equipment. Nitration of organics to form unstable reactive or explosive compounds is a possibility. Sudden loss of primary containment during 
operations would present a substantial hazard to exposed personnel. The system may be subject to process excursions which will require corrective action by operators or control systems. For example:

The MEO system operates at $50^{\circ}$ to $60^{\circ} \mathrm{C}\left(120^{\circ}\right.$ to $\left.140^{\circ} \mathrm{F}\right)$ at atmospheric pressure so that the system should be stable. However, excess temperature leads to system overheat and vaporization of nitric acid from both parts of the electrolytic system which is not self correcting.

Excess current will lead to destruction of $\mathrm{HNO}_{3}$ producing too much $\mathrm{NO}_{\mathbf{x}}$ in the offgas overwhelming the contactor. Not self correcting.

Excess waste feed (concentration too high for set conditions of feed to bleed) will lead to too high organic concentration in the bleed stream for treatment and discard. Not self correcting.

Depleted acid $<2 \mathrm{M}$ will lead to destruction of water to release $\mathrm{H}_{2}$ along with $\mathrm{NO}_{\mathrm{X}}$ in the cathode offgas creating a potentially explosive mixture. Not self correcting.

\section{A-14.4 References}

1. N. Nelson, G. A. Steward and W. Lawrence, "Mediated Electrochemical Oxidation for Chemical Destruction in Chem Demil Applications with Closed Loop Operation," Workshop on Advances in Alternative Demilitarization Technologies, Reston, VA, September 25-27, 1995. 


\section{A-15 COBALT MEDIATED ELECTROCHEMICAL OXIDATION (MEO)}

\section{A-15.1 Technology Description}

In Mediated Electrochemical Oxidation (MEO) an electrochemical cell is used to generate an oxidant species at the anode in an acidic solution. Balancing electrochemical reactions at the cathode must either decompose water or another species in solution. MEO is typically operated in nitric acid solution; in that case, the species decomposed at the cathode is nitric acid. If sulfuric acid is used then water is decomposed.

MEO has been tested with a number of different electrochemical oxidants including $\mathrm{Ag}(\mathrm{II})$, $\mathrm{Co}(\mathrm{III}), \mathrm{Ce}$ (IV), and $\mathrm{Fe}(\mathrm{III})$. Aqueous media tested for the cobalt system included nitric and sulfuric acids. The oxidant is generated in the electrochemical cell; the solution is pumped from the electrochemical cell into the primary reactor. After reaction, the electrolyte is recycled from the reactors back to the electrochemical cell for regeneration of the oxidant. The waste feed rate is based on the destruction time required for the organic in the feed stream.

The MEO system operates at $50^{\circ}$ to $60^{\circ} \mathrm{C}\left(120^{\circ}\right.$ to $\left.140^{\circ} \mathrm{F}\right)$ and atmospheric pressure. The electrolytic cell consists of a parallel set of chambers with Nafion membranes between the anode and the cathode chambers. Each cell contains approximately 60 pairs of electrojes. An electrolyte solution of nitric acid and cobalt nitrate is circulated through a set of cells in the MEO unit at rates up to 100 gallons per minute (gpm). Cobalt is oxidized in solution from II to III. This oxidized metal acts as the primary active oxidizer in solution. The metal ion reacts either directly with the organic species, or with water to produce a reactive intermediate such as the hydroxyl radical $(\mathrm{OH} \cdot)$ that then reacts with the organic material. Eventually the organics are broken down into harmless constituents such as carbon dioxide and water. These reaction may occur any place in the circulating loop from the electrolytic cell to the primary reactor.

Cobalt can also be operated in a sulfuric acid medium 1,2 . In this case no membrane separation is required. Hydrogen is generated at the cathode to balance the anode oxidation of cobalt II to III rather than disintegration of the acid at the cathode. The extent of reaction depends on the time allowed for reaction with the active agents and the number of passes of the solution through the reaction chamber.

Water formed in the oxidation of the organic compounds migrates through the membrane to the catholyte, reducing the nitric acid concentration below 6 molar (M). Water must be removed continually to maintain the nitric acid concentration at $6 \mathrm{M}$ to avoid forming hydrogen. A slip stream of the catholyte is removed and processed for cobalt and acid recycling. A much smaller slip stream from the anolyte is combined with the catholyte stream for the removal of salts and to prevent buildup of inerts. The combined electrolyte blowdown stream consists of water, nitric acid, cobalt nitrate or sulfate, cobalt chloride, metals ions, unreacted waste, and miscellaneous inorganic ions, such as sulfate, chloride, and phosphate, which result from oxidation of the waste material.

Recycle of cobalt and acid may be an economic concern as well as environmental. Discard of cobalt may be costly and increase waste disposal requirements. 


\section{A-15.2 Advantages, Disadvantages, Issues}

\section{Advantages}

- The cobalt based technology has much less development and efficiency data than does Ag-MEO. The results available have to be considered preliminary. A pilot scale design concept has been prepared.

- MEO, cobalt based, has been tested and is reported to destroy a wide array of chemical compounds and some solid materials (primarily ion exchange resin and cellulosics) dissolved or suspended in an aqueous stream. The results of these tests are currently held as company proprietary. Only limited data are available in the open literature.

- For the cobalt/nitric acid MEO there should be no electrolytic production of hydrogen from the cathode if nitric acid concentration maintained above $6 \mathrm{M}$.

- For cobalt/sulfuric acid MEO the cell will work without a membrane. The acid will not be decomposed in the electrolytic cell therefore acid regeneration will not be required.

- Cobalt is not precipitated by chloride ions produced from destruction of chlorocarbons.

- Cobalt is not a hazardous metal.

\section{Disadvantages}

- Recycle of both nitric acid and cobalt required for operation in the nitric acid system. Use of metal ion may require recovery and recycle of metal for economic and environmental reasons.

- Use of cobalt also requires recovery and recycle of metal to avoid excess wastes generation.

- Cobalt-nitric acid process does not appear to be as effective as is either silver-nitric or cerium-nitric acid.

- Few data are available on performance with solid materials. Verbal report that the system does not perform nearly as well as either silver or cerium nitric acid systems.

- Has shown limited destruction of few chemical compounds dissolved or suspended in aqueous stream.

- Little data are provided on cobalt sulfuric acid.

Issues

- Verify the calculated behavior in actual experiments and demonstrate the metal recovery cycle at full scale. 
- Demonstrate the nitric acid regeneration at full scale operation.

- What levels of destruction will be achieved in operation?

\section{A-15.3 Evaluation}

\section{Performance}

\section{A-15-3.1 Range of Feed Material}

Ranking-Medium-Low: The Cobalt MEO process is developed for treatment of organic liquids. However, the process can treat aqueous-organic streams so long as the water does not excessively dilute the working fluid nitric acid concentration. This process is based on original work dissolving suspended insoluble oxides and should handle sludges reasonably well if they are finely divided and suspended, slurried, or emulsified in the working fluid. While this process is optimized for aqueous/organic systems, fairly successful destruction of cellulose has been shown; however, the cobalt MEO process probably will not handle any other combustible solids.

\section{A-15.3.2 Treatment Effectiveness}

Ranking - Medium-Low: The cobalt MEO process accepts wastes dissolved or suspended in aqueous streams, but it does not effectively attack bulk hard organics such as plastic, PVC, etc.; however, the process could be operated in a decontamination mode for those materials. The extent of reaction depends on the time allowed for reaction with the active agents. Further treatment of primary waste depends on the metals and other inorganic ion residues from the destruction of the organic compounds. Reported destruction of regulated organics has been in the 80 to $90 \%$ range. Measured destruction percentages of various organics are shown in Table A15.1. Most wastes appear to be incompletely destroyed and require a second stage organic destruction.

Volume reduction could be effectively $80-90 \%$ only for those liquid and soft combustible debris wastes destroyed by MEO. This process does not have a regulated metal in the working fluid system. The nitric acid based system will have $\mathrm{NO}_{x}$ recombination to deal with. The sulfuric acid system will have hydrogen off-gas recombination requirement.

\section{Readiness for Deployment}

\section{A-15.3.3 Level of Development and Understanding}

Ranking - Low: System should be straight forward to install and operate based on design and experience with other MEO technologies. Basic process chemistry has had very limited investigation. Design concepts could be prepared based on other MEO process technologies. Commercial sector has indicated no interest in this technology.

\section{A-15.3.4 System Complexity}

Ranking-Medium to Low: For the applicable waste streams, primarily organic liquids, introduction to the process is a minor matter. Application to solids would require greater preparation including size reduction and a demonstration of a method to feed to the reaction loop. The low reactivity of cobalt would require extensive size reduction. Some wastes may be 
incompletely destroyed and require a second stage destruction. The system is moderately complex because of the acid and metal recycle loops and the further processing required for the treated waste to separate inorganics from the working fluid.

Table A-15.1 Materials Destruction with Cobalt MEO1.

\begin{tabular}{|c|c|c|}
\hline Chemical Compound & Feed Concentration & Percent Destruction \\
\hline Ethylene glycol & $0.110 \mathrm{M}$ & 100 \\
\hline 1,3 -dichloro-2-propanol & $0.065 \mathrm{M}$ & $80-90^{*}$ \\
\hline 2-chloro-1-propanol & $0.074 \mathrm{M}$ & $80-90^{*}$ \\
\hline Isopropanol (in $\mathrm{H} 2 \mathrm{SO} 4$ ) & $0.082 \mathrm{M}$ & $80-90^{*}$ \\
\hline Trimsol (in 4M H2SO4@70²) & $3.080 \mathrm{~g} / \mathrm{L}$ & 8.80 \\
\hline Trimsol (in 6M H2SO4@70 & $3.219 \mathrm{~g} / \mathrm{L}$ & 13.66 \\
\hline cellulose (in 4M H2SO4@70 0 ) & $2.95 \mathrm{~g} / \mathrm{L}$ & 99.92 \\
\hline cellulose (in 6M H2SO4@70 & $2.96 \mathrm{~g} / \mathrm{L}$ & 99.77 \\
\hline
\end{tabular}

*low numbers are assumed to be due to volatility loss

The working fluid in the process uses cobalt which is not a RCRA regulated metal so that a recycle system is not necessary; however reclaiming cobalt may be economically desirable to minimize the cost of replacing cobalt and the amount of radioactive waste sent to disposal. Treated waste residue may require stabilization depending on metals and other inorganics present; separation of these residues from the working solution without loss of cobalt will be moderately complicated. The nitric acid based system will have to deal with $\mathrm{NO}_{\mathbf{X}}$ recombination, recovery of nitric m nitrous acid, and separation of $\mathrm{HCl}$ from nitric acid. The sulfuric acid system will have the hydrogen offgas recombination requirement

\section{Environmental Health and Safety}

\section{A-15.3.5 Emissions}

Ranking - High-Medium: Off-gas and aqueous effluent streams should be quite clean comprised mainly of $\mathrm{CO}_{2}$, water vapor, and perhaps some VOCs. Activated carbon treatment should be sufficient to render off-gas suitable for discharge. Built in recycle of oxidant metal and nitric acid may be desirable. Some wastes may be incompletely destroyed and require a second stage destruction. Treated waste residue may require stabilization depending on metals and other inorganics present; separation of these residues from the working solution will be moderately difficult. The working fluid in the process uses cobalt which is not a RCRA regulated metal. Although a recycle system may be economically desirable, it is not necessary.

\section{A-15.3.6 Worker Health and Safety}

Ranking - High-Medium: As "designed" the system should not be particularly hazardous for maintenance. Operation with radioactive materials, strong nitric acid solution, and very high amperage electrolytic cells for plant scale equipment. Nitration of organics to form unstable reactive or explosive compounds is a possibility. Sudden loss of primary containment during operations would present a substantial hazard to exposed personnel. The system may be subject to process excursions which will require corrective action by operators or control systems. For example: 
The MEO system operates at $50^{\circ}$ to $60^{\circ} \mathrm{C}\left(120^{\circ}\right.$ to $\left.140^{\circ} \mathrm{F}\right)$ at atmospheric pressure so that the system should be stable. However, excess temperature leads to system overheat and vaporization of nitric acid from both parts of the electrolytic system which is not self correcting.

Excess current will lead to destruction of $\mathrm{HNO}_{3}$ producing too much $\mathrm{NO}_{\mathrm{X}}$ in the offgas overwhelming the contactor. Not self correcting.

Excess waste feed (concentration too high for set conditions of feed to bleed) will lead to too high organic concentration in the bleed stream for treatment and discard. Not self correcting.

Depleted acid $\angle 2 \mathrm{M}$ will lead to destruction of water to release $\mathrm{H}_{2}$ along with $\mathrm{NO}_{\mathrm{x}}$ in the cathode offgas creating a potentially explosive mixture. Not self correcting.

\section{A-15.4 References}

1. J. C. Farmer, F. T. Wang, P. R. Lewis, and L. Summers, "Electrochemical Treatment of Mixed and Hazardous Wastes: Oxidation of Ethylene Glycol by Cobalt(III) and Iron (III)", UCRL-JC-109134 Lawrence Livermore National Laboratory, Livermore, CA, December 1991

2. Z. Chiba, P. R. Lewis, L. C. Murguia, "Mediated Electrochemical Oxidation Treatment for Rocky Flats Combustible Low-Level Mixed Waste", FY 1994 Final Report, UCRL-D-118679, Lawrence Livermore National Laboratory, Livermore, CA, September 1994. 
Direct Chemical Oxidation (DCO) is an aqueous process for oxidative destruction of solid and liquid organic wastes. The proposed process is based on existing commercial processes that have been used at industrial scale for many years. Acidified peroxydisulfate is used routinely in laboratories and commercial total organic carbon analyzers for quantification of carbon by destructive oxidation. The process uses electrolysis cells to produce ammonium peroxydisulfate at $\mathrm{T}<30^{\circ} \mathrm{C}$ from recycled ammonium sulfate in slightly acidic solutions. Acidified ammonium peroxydisulfate is among the strongest known chemical oxidant compounds. The chemical reaction in the process is:

$$
\left(\mathrm{NH}_{4}\right)_{2} \mathrm{~S}_{2} \mathrm{O}_{8}+2 \mathrm{H}^{+}+2 \mathrm{e}^{-}=2\left(\mathrm{NH}_{4}\right) \mathrm{HSO}_{4}
$$

Oxidation potential for the electrode reaction

$$
\mathrm{S}_{2} \mathrm{O}_{8}^{-2}+2 \mathrm{e}^{-}=2 \mathrm{SO}_{4}^{-2}
$$

is $\mathrm{E}^{\circ}=2.05$ volts. This is high enough to oxidize most oxidizable chemical compounds.

The initial step, production of sulfate free radicals by decomposition of peroxydisulfate:

$$
\mathrm{S}_{2} \mathrm{O}_{8}^{-2}=2 \mathrm{SO}_{4}^{-}
$$

is slow unless promoted by a catalyst $(\mathrm{Pt})$.

The oxidation process using the acidified ammonium peroxydisulfate operates at ambient pressure and temperatures from 80 to $100{ }^{\circ} \mathrm{C}$. The used oxidant may be separated from the treated waste stream and recycled to the electrolysis cell for regeneration of the ammonium sulfate reduction product. Reaction in the electrolysis cell achieves about an $80 \%$ equilibrium conversion of ammonium sulfate to ammonium peroxydisulfate.

Regeneration of bisulfate from the reduced sulfate at the anode is accompanied by release of hydrogen at the cathode. Recycle of the reduced ammonium bisulfate to peroxydisulfate is based on commercially successful processes.

Tests to date have included chemical and biological warfare agents, high explosives, ion exchange resins, waste surrogates, kerosene, triethylamine, TBP, and oxalic acid. Materials known to be oxidized by the oxidant include numerous chemical compounds, polyethylene, polyvinyl chloride, cellulose, char in incinerator ash, and metal carbides. Destruction of fully halogenated organic compounds has not been tested; these may not be destroyed in a straight oxidation process. Perfluorinated polymers are unreactive; perchlorinated compounds also may be expected to be non reactive. 


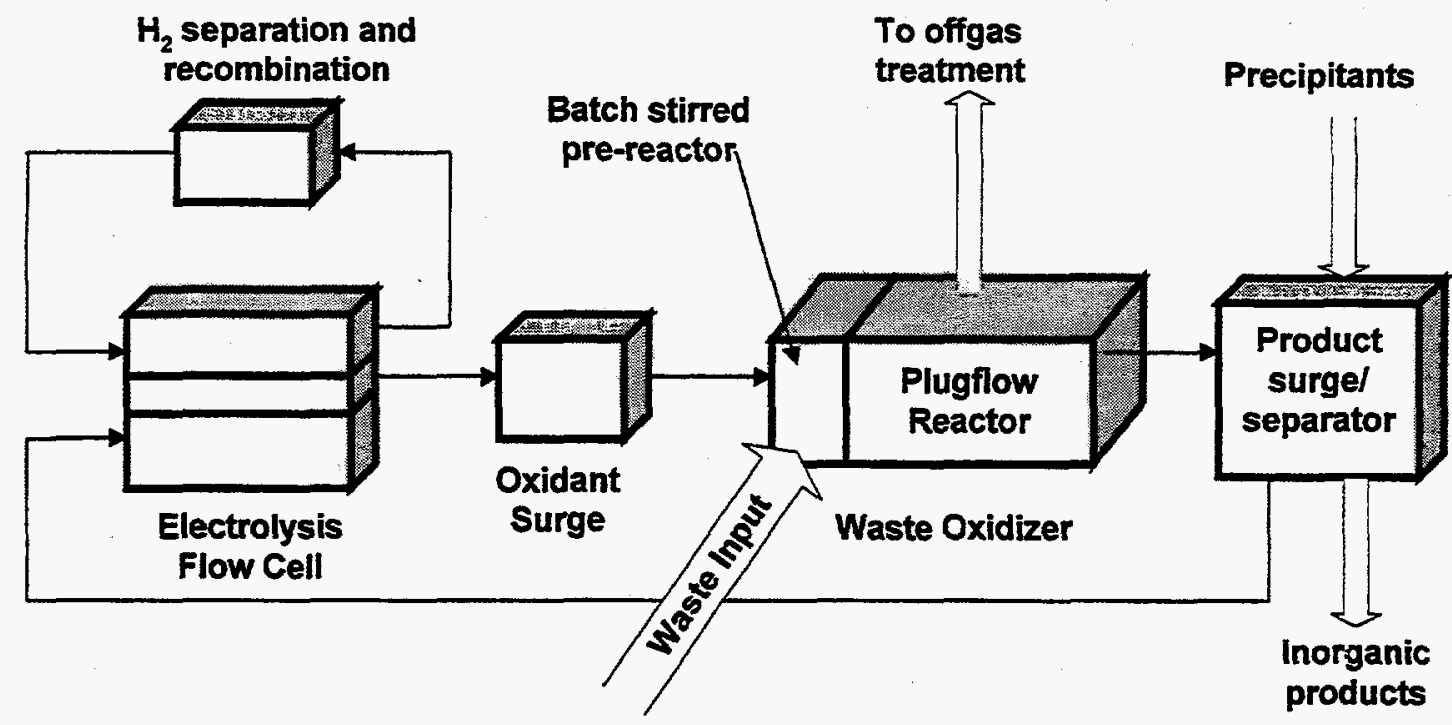

Figure A-16.1 Process Flow for the Direct Oxidation Process

A-16.2 Advantages, Disadvantages, Issues

\section{Advantages}

- This is not strictly an in-situ electrochemical process as are the MEO technologies; the oxidant is stable for a long period of time such that the recycle process can be decoupled from the oxidation reactor.

- The process is based on industrial process with many years experience.

- The oxidation process has been used at the 1000 ton/year rate for treatment of petroleum recovery wastes.

- If developed as planned, the process will recycle all of the reactants creating only hydrogen as a side stream to be managed.

- The oxidation/destruction process potentially is applicable to a wide variety of materials.

- Common materials of construction can be used to contain the process.

- Does not use catalysts.

- The process appears to proceed in the presence of significant quantities of inert material.

- Oxidant may not be easily decomposed in side reactions with inert materials.

- Process does not add chlorides. 


\section{Disadvantages}

- Largely untested.

- No experimental results on real world surrogates for DOE Mixed Wastes.

- Involves electrolysis which is always a complicating factor.

- May not treat full halogenated chemical compounds.

- Complete process has not been detailed even at the bench scale.

- Continuous process operations need to be demonstrated.

- Separation of process solution from inorganic residues and oxidized compounds (precipitated as salts) so the ammonium sulfate solution, can be recycled is not yet demonstrated.

- Very large quantities of hydrogen will be generated in the reoxidation of sulfate to peroxydisulfate.

- Limited to acceptance of liquid materials or solids that have be significantly reduced in size.

Issues

- Operation of the hydrogen "recombiner" needs to be shown fail safe.

- Extent of loss of primary oxidant in recycle, i.e. amount of secondary waste generated.

- Process is only at the beaker scale; bench scale work remains to be done.

- Separation of oxidation residues from recycle solution.

- Continuous process operations need to be demonstrated.

\section{A-16.3 Evaluation}

\section{Performance}

\section{A-16.3.1 Range of Feed Material}

Ranking - High-Medium: The process is developed for treatment of organic liquids. DCO could treat aqueous-organic waste water streams as long as the water does not excessively dilute the oxidant concentration. Process should handle sludges well if they are finely divided and suspended, slurried, or emulsified in the working fluid. Although this process is optimized for organic liquid and solid systems, initial work has shown fairly successful destruction of organic combustible solids. Aggressive dissolution of actinides suggests the process might work in a leaching-decontamination mode for insoluble debris. 


\section{A-16.3. 2 Treatment Effectiveness}

Ranking - Medium: This process has been shown effective for most tested wastes. However, there are no data at process scale, and the process has not been shown to treat all kinds of DOE wastes of particular interest. Extensive destruction of concentrated wastes has not been shown. The percent destruction and destruction rate observed for several organic compounds is shown in Table A-16.1.

Secondary waste is primarily the hydrogen generated by electrooxidation of sulfate to peroxydisulfate. The primary process oxidant is to be fully recycled, but the treated waste stream will require separation of inorganic residues from the oxidant to be recycled. Treated process effluent should be very low in organic contaminants but some materials may require secondary treatment

Table A-16.1 Destruction Observed For Some Chemical Materials of Interest 1

\begin{tabular}{||l|c|c|c|}
\hline \multicolumn{1}{|c|}{ Compound } & $\begin{array}{c}\text { Feed } \\
\text { Concentration }\end{array}$ & $\begin{array}{c}\text { Percent } \\
\text { Destruction }\end{array}$ & $\begin{array}{c}\text { Destruction Rate } \\
\text { (kg/M3-day) }\end{array}$ \\
\hline Batch Reactor & & & 186 \\
\hline Kerosene & $9.6 \mathrm{~g} / \mathrm{L}$ & 99.97 & 205 \\
\hline Triethylamine & $0.96 \mathrm{~g} / \mathrm{L}$ & 98.8 & 760 \\
\hline $2,4,6$-TNT & $(0.003 \mathrm{M})$ & 99.9 & 3 \\
\hline Polyvinyl Chloride* & Pieces and powder & 50 & \\
\hline Ethylene Glycol & $0.80 \mathrm{~g} / \mathrm{L}$ & & 432 \\
\hline Plug Flow Reactor & & & 99.93 \\
\hline Ethylene Glycol & $6.2 \mathrm{~g} / \mathrm{L}$ & & \\
\hline
\end{tabular}

*In preliminary tests polyvinyl chloride was not oxidized. After thermal degradation to release

$\sim 1 \% \quad$ of $\mathrm{Cl}$ as $\mathrm{HCl}$, charred material reacted to about $50 \%$ destruction.

\# These experiments were run under reflux.

The process concept is based on operating a plug flow reactor in which the oxidant is introduced at approximately 2 equivalents per liter. This concentration is fixed by the practical limit on the peroxydisulfate output of the electrolytic cell. The liquid organic is added to the plug flow reactor over a period of time up to approximately $1 / 2$ the equivalent of the oxidant or 1 equivalent per liter. Batch stirred reactor experiments were conducted at "high" concentrations of the organic reductant, in the range of 0.05 to 0.5 equivalents per liter. Many exploratory experiments were run at micromolar concentration of the reductant.

Estimates of throughput are based on "... A digester supplied with peroxydisulfate to maintain an average concentration of $3 \mathrm{~N}$ should sustain organic destruction rates of 0.05 equivalents per liter per minute at $80 \%$ coulomb efficiency. For organic compounds having a typical equivalent weight of $3 \mathrm{~g}$-carbon/equiv, a $1 \mathrm{M}^{3}$ batch reactor should be capable of oxidizing about $200 \mathrm{Kg}$ (as carbon) in one day $2 . "$ 
Table A-16.2 Comparison of Characteristics of Some Reductant Materials 2

\begin{tabular}{|l|c|c|c|c|c|}
\hline Chemical Material & MW & eq/mol & g/eq & $\begin{array}{c}\text { "High } \\
\text { Concentration" } \\
(\mathbf{g} / \mathbf{L})\end{array}$ & $\begin{array}{c}\text { Concentration after } \\
\text { 99.9\% Destruction } \\
\text { (g/ L) }\end{array}$ \\
\hline \hline Kerosene & 170 & 84 & 2.02 & $0.10-1.01$ & $0.00010-.0010$ \\
\hline Triethylamine & 101.19 & 36 & 2.81 & $0.14-1.41$ & $0.00014-.0014$ \\
\hline Ethylene Glycol & 62.07 & 10 & 6.21 & $0.31-3.10$ & $0.00031-.0031$ \\
\hline nitromethane & 61.04 & 8 & 7.63 & $0.38-3.82$ & $0.00038-.0038$ \\
\hline sucrose & 342.29 & 48 & 7.13 & $0.36-3.57$ & $0.00036-.0036$ \\
\hline 1,4-dioxane & 88.11 & 20 & 4.41 & $0.22-2.20$ & $0.00022-.0022$ \\
\hline
\end{tabular}

Readiness for Deployment

\section{A-16.3.3 Level of Development and Understanding}

Ranking - Low Plus: Process is at a very early pre-pilot stage of development. The proposed process rates a low because although the process steps are based on well understood commercial processes, applicability to compounds of interest to DOE has yet to be determined. Management of treated waste, especially residue separation, also remains to be demonstrated. Process equipment and operations of a complete integrated system is at an early stage or very low level of development.

This system's components are not fully defined. The electrolytic cell is still in evolutionary design based on commercial equipment and laboratory experience. The process could be moved into a higher rating if the reliance on the commercial experience proves justified.

\section{A-16.3.4 System Complexity}

Ranking - Low: Solid wastes will require size reduction for addition to batch reactor vessel and to allow access of oxidant solution to the organic contaminants. Treated waste stream will require separation of inorganic residues which has not been demonstrated. Complexity of the final system is not defined. Recycle loop for regeneration of peroxidysulfate and separation of residues is fairly complex. Requirement for capture and oxidation of significant quantities of hydrogen also adds complications.

\section{Environmental Health and Safety}

\section{A-16.3.5 Emissions}

Ranking - High-Medium: Only potential gaseous emission are carbon dioxide, hydrogen and process solution components depending on their vapor pressure at scrubber conditions. Activated carbon treatment should be sufficient to render the off-gas suitable for discharge. Following precipitation of inorganics, ammonium sulfate solution will contain inorganics at solubility limit; in recycle this should be at steady state after the first precipitation. Inorganic byproducts of reaction will be solidified if required. Some loss of sulfate through this route should be expected. Treated waste streams will require separation of inorganic residues. These may require stabilization if regulated inorganics are present. Separation of residues has not been 
demonstrated. Secondary waste is primarily the hydrogen generated by electrooxidation of sulfate to peroxydisulfate. The primary process solution is to be fully recycled.

\section{A-16.3.6 Worker Health and Safety}

Ranking - High: No particular hazardous or unique conditions during maintenance operations. Operation with radioactive materials, very high amperage electrolytic cells for plant scale equipment, and hydrogen production. However, operations personnel should see no impact of the high amperage. Other than the issue with hydrogen management it is not clear that there are significant excursion conditions. Reaction rates and temperature may be controlled by limiting the rates of oxidant and/or organic feed.

\section{A-16.4 References}

1. John Cooper, verbal communication LLNL, July 26,1996

2. J. F. Cooper, et al., "Demonstration of Omnivorous Non-Thermal Mixed Waste Treatment: Direct Chemical Oxidation using Peroxydisulfate," UCRL-ID-123193, Lawrence Livermore National Laboratory, Livermore, CA, February 1996

3. J. F. Cooper, et al., "Destruction of Organic Wastes by Ammonium Peroxydisulfate with Electrolytic Regeneration of the Oxidant," Paper Submitted to Environmental Science and Technology, published in Workshop on Advances in Alternative Demilitarization Technologies, Reston, VA, September 25-27, 1995. 


\section{A-17 NEUTRALIZATION/HYDROLYSIS-BIODEGRADATION}

\section{A-17.1 Technology Description}

The purpose of neutralization-hydrolysis is to significantly reduce toxicity of chemical warfare agents or to eliminate the explosive nature of high explosives. The objectives of the exploratory work on chemical agents was to identify reactions that can detoxify chemical warfare agents, that are simple, and for which the reactants are stable, cheap, and of relatively low molecular weight. The processes tested only act to destroy the acute toxicity of the agents by hydrolysis or splitting the agent into at least two chemical compounds 1,2 . Hydrolysis of high explosives provides a similar "deactivation". The resulting hydrolysis products from chemical agents still may be RCRA hazardous and require further degradation.

Aqueous base hydrolysis using sodium hydroxide or calcium hydroxide is the simplest and least expensive treatment approach. These systems would be easy to build and operate. Reaction rates are easily accelerated by heating. Costs for the system would be increased because of the requirement for careful containment of the chemical agents (similar to requirements for alpha radionuclide control).

"Post treatment of neutralized product is usually required before their final disposition in the natural environment." This post treatment, to complete destruction of the organic products of hydrolysis, could be any of the aqueous based destruction processes being evaluated by this study.

Biodegradation has been studied also for the degradation of $\mathrm{HD}$ and $\mathrm{VX}$ hydrolysis products. Detailed information on the biodegradation work was not available 2 .

\section{A-17.2 Advantages, Disadvantages, Issues}

\section{Advantages}

- Hydrolysis is accomplished quickly in aqueous caustic solution.

- Hydrolysis of high explosives may yield a non-RCRA waste. If the degradationhydrolysis products are not RCRA hazardous, this very simple process has the advantage of simplicity and easy implementation in conventional equipment.

- The process will eliminate the extreme high toxicity of chemical agents in a simple, carefully controlled environment. Any RCRA regulated secondary products can then be treated in an appropriate more aggressive treatment process.

\section{Disadvantages}

- For many target materials secondary treatment of the hydrolysis products will be required.

- Biodegradation has been determined not to be of particular interest for treatment of DOE MLLW because of the variability of the waste feed stream. 
- By comparison the working solutions in many of the aqueous based organic destruction systems will hydrolyze the active agent and proceed to destroy the organic hydrolysis products.

- The simple one step hydrolysis may adequately destroy the reactivity of high explosives.

- The target compounds are mostly insoluble or only slightly soluble in aqueous or highly caustic solutions.

Issues

- Extent of reaction for both hydrolysis and biodegradation.

- Hydrolysis of RCRA hazardous constituents would not be expected to have any advantage over better developed technologies for organic destruction in DOE MLLW applications.

- Prevention of loss of hydrolysis products (VOC) by evaporation has not been demonstrated.

- Status of the process understanding.

- An operational process has not been defined.

\section{A-17.3 Evaluation}

Evaluations are based on extrapolation of reported effectiveness of neutralization and hydrolysis for treatment of waste containing high explosives to treatment of DOE mixed wastes.

\section{Performance}

\section{A-17.3.1 Range of Feed Material}

Ranking - Low: Hydrolysis operates only in aqueous-organic waste water streams; for explosive residues in aqueous streams, this should be very effective. The process would require that organic wastes be suspended or emulsified in aqueous solution. Sludges and soils would also require suspension in solution for this process to attack the organic materials. Neutralization/hydrolysis would not significantly degrade most combustible debris wastes nor would it be expected to treat organics in non combustible debris.

\section{A-17.3.2 Treatment Effectiveness}

Ranking - Medium: The hydrolysis step works well on explosives but may be only the first step of the degradation process. Hydrolysis will work only on a limited set of chemical structures. Most regulated organics are not susceptible so this process is most likely not applicable to DOE wastes. There is partial to complete destruction of organics in an aqueous stream depending on the target waste component, and further treatment of the primary waste will be required for many RCRA and TSCA regulated materials. Volume reduction is low and there should be no secondary regulated waste generated 


\section{Readiness for Deployment}

\section{A-17.3.3 Level of Development and Understanding}

Ranking - Medium-Low: The technology rests on a large amount of industrial experience and implementation should be straightforward when the process parameters are defined. However, work is only preliminary and no process concepts have been presented. No tests have been performed on a range of compounds of interest to DOE.

\section{A-17.3.4 System Complexity}

Ranking - High-Medium: The hydrolysis process is very simple but the waste must be prepared for suspension and fed to the aqueous system. Hydrolysis products may require further RCRA organic destruction.

\section{Environmental Health and Safety}

\section{A-17.3.5 Emissions}

Ranking - High: The simple well contained aqueous system should produce little or no gaseous effluents. A minimally treated primary waste and secondary waste comprised of hydrolysis products will be produced that will require substantial further treatment.

\section{A-17.3.6 Worker Health and Safety}

Ranking - High: There would be very little hazard to maintenance workers. Process is simple and is based on industrial experience. Due to process simplicity and limited solubilities of high explosives and other organics, the reaction should be easily controlled. Hydrolysis operates from room temperature to moderate temperatures and atmospheric pressure.

\section{A-17.4 References}

1. Yu-Chu Yang, "Neutralization Reaction for Chemical Warfare Agents," Workshop on Advances in Alternative Demilitarization Technologies, Reston, VA, September 25$27,1995$.

2. S. P. Harvey and J. P. Early, "Hydrolysis and Biodegradation of HD/ Hydrolysis and Biodegradation of VX," Workshop on Advances in Alternative Demilitarization Technologies, Reston, VA, September 25-27, 1995. 


\section{A-18 ELECTROCHEMICAL PEROXIDATION (ECP)}

\section{A-18.1 Technology Description}

Electrochemical Peroxidation is an advanced oxidation process capable of destroying organic compounds in water and adsorbed onto solids in aqueous slurries 1,2 . The process generates ferrous ions by dissolution of (sacrificial) steel electrodes during an initial "charging" period. Test operations were at temperatures of $15^{\circ} \mathrm{C}$ to $70^{\circ} \mathrm{C}, \mathrm{pH}$ of 2 is achieved by addition of sulfuric acid. A current of about $1 / 2$ amp per $\mathrm{cm}^{2}$ (500 milliamp to $20 \mathrm{amp}$ ) is applied to the electrodes for a period of 2-5 minutes during which the current polarity was reversed every 5-10 seconds depending on size of the experiments. After this initial "charging" (the experimenters term for generation of ferrous ions), $\mathrm{H}_{2} \mathrm{O}_{2}$ was added to give solutions of 0.0125 to 0.6 parts per thousand to create a solution that is described as "Fenton-like". Reaction times after addition of peroxide was typically 5 minutes.

Ferrous ions generated in solution by dissolution of the electrodes, react with peroxide to generate free radicals resulting in nearly instantaneous degradation of polychlorinated biphenyls (PCB) and volatile organic compounds; various organic dyes were used in the preliminary experimental work. While a variety of degradation mechanisms are probably operational the most significant appears to be the Fenton reagent reaction between iron dissolved from the electrodes and hydrogen peroxide. The in-situ electro-generation of ferrous ions, however, appears to produce additional reactive species that enhance the process effectiveness over the use of straight Fenton's reagent. These species have not been characterized but are speculated to include hydrated electrons and free radical species.

Contaminated water and water with suspended sludge from an underground storage tank were tested in bench scale (500 milliliters) and pilot scale (200 liter drum) experiments. All experiments have been batch operations.

Destruction achieved in these experiments ranged from 68 to $97 \%$ for PCBs, and 95 to $99+\%$ destruction for VOCs. The reported tests have been batch mode only at the liter and 55 gallon drum scale and do not constitute a fully developed process. The experiments can be rated as exploratory at best with no attempts made to optimize treatment or to fully explore process operating parameters. A continuous or plug flow process has not been suggested but probably could be made to work.

\section{A-18.2 Advantages, Disadvantages, Issues}

\section{Advantages}

- Ferrous ions are introduced without a corresponding anion, usually sulfate, which would increase the generation of secondary waste.

- Appears to have reactivity advantages over conventional Fenton's reagent.

\section{Disadvantages}

- Not fully developed, uses sulfuric acid to set $\mathrm{pH}$. 
- May not be strong enough to destroy perhalogenated organics.

- Mechanisms and active agents are not identified.

Issues

- Status of the process understanding. An operational process has not been defined.

- Batch operation may be acceptable; a plug flow reactor concept probably could be developed.

- Transient reactive species appear to be generated that are better oxidizers than the $\mathrm{Fe}$ (III) or hydroxyl radicals. Between these efforts and the initial results from MIOX there may be an area of unexplored electrochemistry that is worth some attention.

- Extent of degradation of secondary organics has not been evaluated. It is not clear that the reported experiments would have prevented the escape of volatile chemicals being tested or of degradation products.

- The electrochemistry is not yet understood. This overlooks a potentially important question of generation of hydrogen (reduction of $\mathrm{H}^{+}$at the cathode) to electrochemically balance the oxidation of iron to ferrous at the anode. This would produce one mole of hydrogen per mole of ferrous ion generated. Process shares this question with DCO and MIOX.

\section{A-18.3 Evaluation}

\section{Performance}

\section{A-18.3.1 Range of Feed Material}

Ranking - Medium-Low: Electrochemical peroxidation is developed primarily for treatment of aqueous-organic waste water streams. ECP is similar to other Fenton's reagent processes with ferrous ions generated in this case by direct electrodissolution of iron electrodes into the solution. Very little process information is available. The process will also treat organic liquids diluted or dispersed into aqueous solutions. This process also might handle some organic sludges if the organic can be suspended or dissolves into the working fluid. It would be difficult to apply this process to inorganic sludge, soils, and debris.

\section{A-18.3.2 Treatment Effectiveness}

Ranking - Medium-Low: The data available are very preliminary. Destruction of organics is reported at $>95 \%$. Efforts have been directed towards CERCLA wastes with no reported efforts to date to optimize the treatment of RCRA organic contaminants. The process will be applicable only to aqueous systems and wastes suspendable in aqueous systems. ECP process will not change the status of regulated inorganic constituents; treatment of oxidants, or materials such as $\mathrm{H}_{2} \mathrm{~S}$ or cyanide is probable but not defined. Some RCRA organics will require further treatment.

Eventually the iron dissolved in the process probably will be removed by precipitation. "Hydrous ferric iron phases form as a by product of ECP treatment by the oxidation of ferrous 
iron via Fenton's Reagent. Iron hydroxides and sesquioxides (precipitates) can adsorb and immobilize a variety of metals 1 ."

Table A-18.1 Chemical Materials Tested In ECP

\begin{tabular}{|c|c|c|c|c|c|}
\hline Chemical Material & $\begin{array}{l}\text { Conc. in } \\
\text { Water } \\
\text { (ppm) }\end{array}$ & $\begin{array}{c}\text { Percent } \\
\text { Destruction }\end{array}$ & $\begin{array}{l}\text { Conc. in } \\
\text { Slurries } \\
\text { (ppm) }\end{array}$ & $\begin{array}{c}\text { Percent } \\
\text { Destruction }\end{array}$ & Seale \\
\hline PCB sediments & & & 65 & 80 & $0.5 \mathrm{~L}$ \\
\hline PCB & 19.8 & 97 & 99.0 & 68 & $0.5 \mathrm{~L}$ \\
\hline acetone & 74 & $>95$ & $*$ & $>95^{*}$ & $0.5 \mathrm{~L}$ \\
\hline chloroethane & 2150 & $>95$ & * & $>95^{*}$ & $0.5 \mathrm{~L}$ \\
\hline dichloromethane & 130 & $>95$ & $\bar{*}$ & $>95^{*}$ & $0.5 \mathrm{~L}$ \\
\hline 1,1-dichloroethane & 185 & $>95$ & $*$ & $>95^{*}$ & $0.5 \mathrm{~L}$ \\
\hline$\overline{\mathrm{BTX}} * *$ & $\sim 40$ & $\begin{array}{l}\text { nd after } \\
\text { treatment }\end{array}$ & $\sim 40$ & $\begin{array}{l}\text { nd after } \\
\text { treatment }\end{array}$ & $0.5 \mathrm{~L}$ \\
\hline Organic dye*** & 50 & decolorized & & & $0.5 \mathrm{~L}$ \\
\hline $\begin{array}{l}\text { Pulp waste water } \\
\text { BOD } \\
\text { COD } \\
\text { organic dye }\end{array}$ & $\begin{array}{c}1300 \\
3143 \\
200\end{array}$ & $\begin{array}{c}70 \\
77 \\
\text { decolorized }\end{array}$ & & & $1.0 \mathrm{~L}$ \\
\hline$\overline{\mathrm{PCB}}$ & $\begin{array}{l}200 \\
200\end{array}$ & $\begin{array}{l}87.9 \\
85.2\end{array}$ & & & $200 \mathrm{~L}$ \\
\hline
\end{tabular}

* slurry is described as organic rich; authors imply $>95 \%$ destruction without specifying beginning or ending concentrations.

** benzene, toluene, xylenes, MTBE, and 7 others were initially present. All were nondetectable after 3 successive 2 minute treatments.

*** methylene blue, resazurin, and fluorescein

\section{Readiness for Deployment}

\section{A-18.3.3 Level of Development and Understanding}

Ranking - Low Plus: The process is at the exploratory stage. Movement from exploratory to application could be quite quick using the knowledge in industry of application of Fenton's Reagent. However, tests have yet to be completed on a range of compounds of interest to DOE. If electrochemical generation of ferrous ions is proven to have a definite advantage its adaptation to aqueous system treatments should be achieved readily. The electrode system will need definition and the process is not yet defined; but probably will not be very different from conventional Wet Oxidation equipment.

\section{A-18.3.4 System Complexity}

Ranking - Medium: This is adds the complication of electrochemical operation to what has been strictly aqueous chemistry. However, the system will not have to provide for preparation and addition of ferrous sulfate salt or solution. A method of replacement or addition of the 
sacrificial electrode will be required. This may require opening or access to the radioactive equipment internals.

Eventually the iron dissolved in the process probably will be removed by precipitation. If regulated metals are present, this residue/precipitate will require a larger volume of secondary waste requiring stabilization and disposal. However, the hydrous ferric iron phases (iron hydroxides and sesquioxides) formed as a byproduct of ECP treatment by the oxidation of ferrous iron via Fenton's Reagent, can adsorb and immobilize a variety of metals 1 .

\section{Environmental Health and Safety}

\section{A-18.3.5 Emissions}

Ranking - High-Medium: This is a well contained system and there should be no difficulty in controlling effluents. Gaseous effluents will be comprised of cover gas (air?) containing carbon dioxide, water vapor, and perhaps some hydrogen from electrolysis of water and VOCs from the waste. Activated carbon treatment followed by catalytic recombination of hydrogen should render the off-gas suitable for discharge. Treated waste may contain unreacted RCRA organics requiring further cleanup. Destruction of organics could produce non-regulated secondary waste for some organics; some other organics will require further treatment. Process will not change the status of regulated inorganic constituents; treatment of oxidants, or materials such as $\mathrm{H}_{2} \mathrm{~S}$ or cyanide is probable but not defined. Eventually the iron dissolved in the process probably will be removed by precipitation. If regulated metals are present, this residue/precipitate will require stabilization and disposal.

\section{A-18.3.6 Worker Health and Safety}

Ranking - High-Medium: No unusual operating conditions and no unusual hazards for maintenance personnel. When the process is shut down it is benign. Hydrogen may be generated by electrolysis of aqueous solutions. Inadvertent hydrogen accumulation may present explosion hazards. Process operates near ambient conditions. Aqueous process solution is relatively benign exhibiting low toxicity and reactivity, and has high thermal inertia so excursions are unlikely. Reaction rate is controlled by electro-dissolution of iron electrodes so excursions would be very slow. Excessive generation of $\mathrm{Fe}^{3+}$ leads to precipitation from solution not an accelerated reaction.

\section{A-18.4 References}

1. J. R. Chiarenzelli, R.J. Scrudato, M. P. Fabrizio, and M. L. Wunderlich, "Degradation of PCBs and VOCs in Subsurface Storage Tank Water and Slurry," Proceedings of the Second International Symposium on Environmental Applications of Advanced Oxidation Technologies, February 28 -March 1, 1996

2. R. J. Scrudato and J. R. Chiarenzelli, "Destruction of Organic Contaminants by Electrochemical Peroxidation (ECP)," to be presented at the Third International Conference on Advanced Oxidation Technologies for Water and Air Remediation, October 26-29, 1996 


\section{A-19 X-RAY/GAMMAY RAY DESTRUCTION}

\section{A-19.1 Technology Description}

Energetic secondary electrons are formed when ionizing radiation is deposited in waste media. These energetic secondary electrons:

1. Cause homolytic cleavage of chemical bonds generating highly reactive free radicals which promote reaction and oxidation of chemical species.

2. Generate localized concentrations of aqueous electrons which can reduce chemical species,

3. Cause heterolytic cleavage of chemical bonds leading to ionization, partial decomposition, and reaction of some waste compounds.

Bremsstrahlung $\mathrm{X}$-rays are generated using an electron accelerator to direct an energetic (several $\mathrm{MeV}$ ) pulsed beam of electrons at a high atomic number (tantalum foil) converter. Gamma photons may be produced by a radioactive source such as Co-60 or spent nuclear fuel.

Ability of this technology to completely mineralize waste constituents depends on a) the nature and mix of waste compounds, b) their concentrations in the target media, c) the characteristics of the target media, and d) delivered radiation dose and dose rate.

Technologies are in the exploratory development stage. Pulse Sciences, Inc. is continuing development of X-ray destruction technology under EPA's SITE program 1,2. LLNL and INEL are jointly investigating the decomposition of chlorinated hydrocarbons using bremsstrahlung radiation produced by electron accelerators and gamma photons produced by a Co-60 source in spent reactor fuel 3,4 .

\section{A-19.2 Advantages, Disadvantages, and Issues}

\section{Advantages}

1. May allow processing of certain wastes (solids, slurries, and sludges) in relatively large vented containers thus reducing requirements for materials handling and sorting.

2. Is accomplished at near-ambient temperatures and pressures.

3. Is easily regulated and simple to control.

\section{Disadvantages}

1. Cannot reliably and predictably process a wide range of waste types and compositions. Dose and dose rates required for a certain $\mathrm{DE}$ are extremely dependent on waste type and composition.

2. May require extensive sampling and analysis capability to characterize process products and extent of waste destruction. 
3. Will require shielding, monitoring, and safety provisions associated with high energy radiation sources.

\section{Issues}

Little information is available concerning chemical intermediates and residuals formed during irradiation of multicomponent or heterogeneous wastes at moderate to high (tens to thousands of PPM) contaminant concentrations. Likewise, the irradiation behavior of more complex, refractory, and higher molecular weight organic contaminants has not been investigated.

Irradiation only supplies activation energy to initiate free-radical and other chemical reactions. Other measures must be taken to ensure that the stoichiometry requirements of the desired reactions are satisfied. If sufficient oxidants are not supplied, mineralization of organic waste components will be impossible even if they are subjected to extreme irradiation.

\section{A-19.3 Evaluation}

\section{Performance}

\section{A-19.3.1 Range of Feed Material}

Ranking - Low: Although it is unlikely that X-ray/gamma ray destruction will be a suitable stand alone technology for preparing any mixed wastes for ultimate disposal, tests to date show the best performance on relatively dilute organic contamination in aqueous waste. Concentration or pure organic wastes could be treated but require extremely high exposures plus addition of oxidants to satisfy reaction stoichiometry requirements. Destruction efficiencies are poor and decomposition products are poorly characterized. These technologies do not provide enough energy to significantly degrade most solid matrix materials. Some aqueous phase reactions may be expected in the interstitial regions of sludge matrices, but destruction efficiencies will likely be poor and very difficult to measure. Energy available from X-rays and gamma rays cannot significantly alter the nature of most debris wastes with reasonable exposures.

\section{A-19.3.2 Treatment Effectiveness}

Ranking - Medium-Low: X-ray/gamma ray treatment of regulated wastes addresses destruction of toxic or hazardous organic molecules in the waste matrix. Treatment effectiveness is not well characterized for the majority of mixed wastes. Experimental results to date are summarized as follows:

- At X-ray doses from 1 to $2 \mathrm{kGy}$, in aqueous media, olefinic VOCs e.g. trichloroethylene, perchloroethylene, etc. can be reduced from an initial concentration of a few tens of parts per million (ppm) to below one part per billion (ppb). However, at doses of about $2 \mathrm{kGy}$, compounds without a carbon-carbon double bond e.g. carbon tetrachloride, trichloroethane, etc. only show about a ten fold reduction from initial concentrations of 0.2 to $0.6 \mathrm{ppm}$.

- Media containing free radical scavengers e.g. carbonate and bicarbonate ions, etc. require much higher (five fold) doses for comparable reductions in contaminant concentration. Likewise, treatment carried out in non-aqueous media is less effective. 
A dose of $120 \mathrm{kGy}$ ( $9 \mathrm{MeV} \mathrm{X}$-ray or $0.7 \mathrm{MeV}$ gamma ray) is needed to reduce the $\mathrm{PCB}$ concentration in transformer oil from 50ppm to a few $\mathrm{ppm}$.

- Solid and liquid organophosphoric compounds (insecticides, nerve agents) appear to require very high doses ( $>600 \mathrm{kGy})$ for significant reductions in concentration.

It is likely that post treatment will be required to complete the destruction of regulated organic constituents before ultimate disposal of wastes which have undergone X-ray/gamma ray treatment. No secondary wastes are generated from recycle or support processes.

\section{Readiness for Deployment}

\section{A-19.3.3 Level of Development \& Understanding}

Ranking - Medium: Technology has been demonstrated on selected dilute aqueous wastes in EPA's SITE program. Dose/response data have been collected for individual species in distilled water, and for some mixtures in contaminated groundwater. Data are highly empirical and do not allow prediction of dose/response characteristics for the types of media and variety of contaminants associated with DOE's mixed wastes.

\section{A-19.3.4 System Complexity}

Ranking - High Minus: Minimum waste pretreatment is required. Some wastes may be treated "as retrieved" in vented containers (55-gal drums, burial boxes), but it is likely that extensive sampling and analyses will be required to verify adequacy of treatment for many constituents. Systems using gamma sources should be quite simple to build, operate, and maintain. Electron accelerators and converters for generating X-rays are well demonstrated technology and should be relatively simple to operate and maintain. However, it is likely that the electron accelerator will require trained technicians for operation and maintenance and some wastes may be incompletely destroyed and require a second stage destruction..

$\mathrm{X}$-ray/gamma ray treatment technology is well adapted for remote use with the most complex and maintenance intensive equipment can be located outside the contaminated process area.

\section{Environmental Health and Safety}

\section{A-19.3.5 Emissions}

Ranking - High: Emissions from X-ray/gamma ray treatment will be minor for both routine operations and under excursion or accident conditions. Gaseous effluents will be comprised of cover gas (air) containing carbon dioxide, water vapor, and possibly VOCs contained in the waste feed or from decomposition of POCs. Activated carbon treatment should render the offgas suitable for discharge. No secondary wastes are generated. Liquid phase residuals will contain oxidation and decomposition products of POCs which will require post treatment. It is likely that mixed wastes which have undergone $\mathrm{X}$-ray/gamma ray treatment will still be regarded as mixed wastes unless subjected to a rigorous delisting process. Non-volatile radionuclides will remain with the original waste matrix as will most of the solid and aqueous phase materials. Only the toxicity and hazard associated with the POCs will be somewhat reduced. Extensive post-treatment will be required to reduce the volume and stabilize most wastes. 


\section{A-19.3.6 Worker Health and Safety}

Ranking - High: Non-routine maintenance in contaminated areas will be lower than average. Extensive sampling and analyses will most likely provide the major exposure risk for operating personnel. The major consequence of any conceivable process excursion is likely to be inadequate irradiation of the target waste. Process excursions do not pose significant environmental health and safety concerns. Since the process operates at near ambient temperature and pressure and on generally non-reactive media containing little chemical potential energy, it will exhibit benign, stable operating conditions.

\section{A-19.4 References}

1. EPA/540/R-93/526, Superfund Innovative Technology Evaluation Program, Technology Profiles, Sixth Edition, U. S. Environmental Protection Agency, Washington DC, pp. 326-327, November 1993.

2. V. L. Bailey, et al., "X-Ray Treatment of Organically Contaminated Aqueous Solution," Fifth Forum on Innovative Hazardous Waste Treatment Technologies, U. S. Environmental Protection Agency, Chicago, IL, May 3-5, 1994.

3. S. M. Mathews, et al., "High-Energy Irradiation of Chlorinated Hydrocarbons," Journal of Radioanalytical and Nuclear Chemistry, Vol. 161, pp. 253-264, 1992.

4. S. M. Mathews, A. J. Boegel and J. A. Loftis, "Radiolytic Decomposition of Environmental Contaminants and Site Remediation Using an Electron Accelerator," Remediation. pp. 459-481, Autumn 1993. 


\section{A-20 SUPERCRITICAL WATER OXIDATION (SCWO)}

\section{A-20.1 Technology Description}

Supercritical Water Oxidation (SCWO) refers to oxidation of waste components in a fluid phase, in the presence of high concentrations of water, and at temperatures and pressures above the critical point of water: $374{ }^{\circ} \mathrm{C}$ and $22 \mathrm{MPa}$. Above its critical point water behaves as a nonpolar fluid in which organic materials are easily dissolved and inorganic oxides and salts are virtually insoluble at temperatures above $450^{\circ} \mathrm{C}$. Since supercritical water is miscible in all proportions with oxygen, oxidation reaction rates are limited by reaction kinetics rather than by mass transfer, and high conversions are possible with relatively short residence times ${ }^{1}$. Complex organic molecules are readily broken down or reformed into smaller partially oxygenated species. Further oxidation of these simpler compounds is rate limiting. Significant quantities of char and coke may be produced if many organic materials are brought too slowly to supercritical conditions.

Supercritical water provides a medium which allows relatively rapid oxidation of waste constituents without generation of objectionable offgas. In general, metals are converted to their oxides or (if stoichiometry permits) possibly salts and are precipitated from the supercritical fluid. Acid forming anions either form insoluble salts, which are precipitated, or soluble acids which remain with the supercritical fluid. Nitrogen may be separated as nitrogen gas with some $\mathrm{N}_{2}$ O. Very little $\left(<1 \mathrm{mg} / \mathrm{m}^{3}\right) \mathrm{NO}_{\mathrm{x}}$ is formed.

A small (5 gpm) commercial SCWO unit built by EcoWaste Technologies at the Austin Research Laboratory of Huntsman Chemical, Inc. has been in operation since 19942. The facility processes unchlorinated hydrocarbon petrochemical wastes in aqueous solution.

Several laboratory (25-50 gpd) and pilot (300-1000gpd) scale R\&D units have been built and operated by universities, research institutes, private companies, and Federal agencies $1,2,3,4$.

\section{A-20.2 Advantages, Disadvantages, and Issues}

\section{Advantages}

1. SCWO treatment promises rapid, efficient oxidation of organic materials in aqueous media without generation of PICs, particulate, $\mathrm{NO}_{\mathrm{x}}$ and $\mathrm{SO}_{\mathrm{x}}$.

2. SCWO may provide an efficient means of separating dissolved heavy metals and fission products from dilute aqueous waste solutions.

3. SCWO may offer operation as a totally enclosed facility with no uncontrolled releases to the environment.

\section{Disadvantages}

1. Pressure and temperature requirements may dictate maximum equipment size and severely limit throughput for individual SCWO processing trains. 
2. SCWO systems are generally limited to processing solutions and slurries containing from $2 \%$ to $25 \%$ organics with particulate not exceeding 100 microns in diameter.

3. Solids generated during SCWO processing will likely require substantial additional treatment and stabilization prior to ultimate disposal.

\section{Issues}

Corrosion management and solids handling are the two primary unresolved technical issues for SCWO technology3. To some extent these issues are related. Buffers and bases added to control $\mathrm{pH}$ often result in formation and deposition of sticky solid salts which can interfere with system fluid dynamics and eventually plug process equipment. Examination of some SCWO components has also shown enhanced corrosion at or near the sites of solids deposition. One system has shown enhanced corrosion in the preheater and cooldown sections where the fluid passes through the subcritical/supercritical transition point.

Corrosion is increased by extremes and fluctuations in temperature, pressure, $\mathrm{pH}$, oxidizing/reducing conditions, solution ionic strength, and solids deposition. Corrosion problems are likely to be exacerbated in SCWO systems which treat heterogeneous and poorly characterized DOE mixed wastes.

Efforts to resolve the corrosion issue focus on management of fluid $\mathrm{pH}$ either by addition of caustic and buffers (usually bicarbonates) or by limiting the concentration of acid precursors in the waste feed. Another approach to corrosion management includes use of "exotic" metal liners, super alloys, and ceramic components, to minimize the need for $\mathrm{pH}$ control. Despite these efforts, corrosion management remains a serious unresolved issue for SCWO.

Most metal oxides and salts readily precipitate from supercritical water solutions. Many of these precipitates are sticky and adhere to the walls of process equipment impairing performance and leading to premature process shutdown. Efforts to control solids deposition focus on minimizing generation of solids and developing reactor configurations which are resistant to solids deposition. Generation of solids can be reduced by foregoing addition of neutralizing and buffering chemicals -- and accepting increased corrosion -- or limiting the concentration of inorganic species in the feed. Considerable effort is being devoted to design of novel vessel reactors (transpiring wall, cooled base, annular nozzle feed) incorporating hydrodynamic designs which are either tolerant of solids deposition or prevent solids from depositing in critical locations.

\section{A-20.3 Evaluation}

\section{Performance}

\section{A-20.3.1 Range of Feed Material}

Ranking - Medium-Low: SCWO is best suited to treating relatively dilute organic materials in aqueous media. Concentrated or pure organic liquid wastes must be diluted or slowly fed into a supercritical water recycle stream in order to prevent temperature excursions beyond the limitations of process equipment. 
Solids, sludges, and soils fed to the SCWO process must be reduced to below $100 \mu \mathrm{m}$ particle size to pass through the high-pressure feed pumps. Such a high solids loading would greatly increase the erosion problems in the process. It would not be practical to reduce debris to the size required for treatment with this technology.

\section{A-20.3.2 Treatment Effectiveness}

Ranking - High: Treatment effectiveness is likely to be excellent for POCs in aqueous media. Results of bench- and pilot-scale tests show high destruction efficiency (DE) for most test materials (solvents, pesticides, propellants, preservatives, coolants, etc.) at moderate residence times in the SCWO reactor. In general DEs on the order of $99.9 \%$ can be achieved at $400^{\circ} \mathrm{C}$ to $500^{\circ} \mathrm{C}$ with $1-$ to 5 -minute residence times; $99.99 \%$ at $500^{\circ} \mathrm{C}$ to $550^{\circ} \mathrm{C}$ with about 1 minute; and $99.999 \%$ at $550^{\circ} \mathrm{C}$ to $600^{\circ} \mathrm{C}$ with less than 1 minute. It has also been reported that $99.9999 \% \mathrm{DE}$ is achievable at $600^{\circ} \mathrm{C}$ to $650^{\circ} \mathrm{C}$ with a residence time of seconds 5 . The process achieves high destruction efficiency for treated organics and there should be no post-treatment required.

SCWO treatment of regulated wastes has the potential to completely destroy hazardous POCs and substantially separate toxic metals, actinides and fission products from dilute aqueous solution in a single process, and achieve high volume reduction. Separation efficiencies for toxic metals, actinides, and fission products are not well characterized for the majority of mixed wastes; however, it is understood that inorganic solids are not dissolved in the working fluid. SCWO produces no secondary wastes from processing operations.

\section{Readiness for Deployment}

\section{A-20.3.3 Level of Development and Understanding}

Ranking - Medium: SCWO is an emerging technology with limited commercial application and all major elements of the technology have been demonstrated in non-radioactive service. However, problems with corrosion and solids deposition remain unresolved for many wastes of interest to DOE. Anticipated additional commercial applications tend to be waste specific and are supported by extensive laboratory and pilot plant process feasibility and demonstration tests. SCWO treatment performance for new or unusual waste types and compositions cannot be predicted without extensive laboratory and pilot testing. Equipment performance limitations and operating envelopes are not well established.

\section{A-20.3.4 System Complexity}

Ranking - Medium: Together with required ancillary and support systems the SCWO process train will be a moderately complex system. In many cases substantial waste feed characterization and pretreatment will be required because process performance is not easily predicted for different wastes. Concentrated wastes will require dilution or filtration, and solid wastes will require intensive size reduction. Maintenance to unplug nozzles and/or tubing may be required to remove precipitated salts. Key components must be constructed to pressure vessel codes and specifications out of high-alloy or exotic materials. Extensive inspections and acceptance testing will be required Provisions must be made for recycle of inadequately treated waste. 
Secondary containment, ventilation, and offgas treatment systems must be furnished to contain potential emissions from a sudden loss of primary (process equipment) containment. Containment and treatment of these emissions -- comprised primarily of steam, radioactive and hazardous aerosols and waste liquids, plus condensable and non-condensable gasses - will substantially increase the complexity and cost of support facilities. Pressure vessels and heat exchangers operating at high pressure and exposed to corrosive/erosive process solutions and subject to leaking, and solids deposition will likely require periodic "heel-out" and inspection. Presence of insulation will hinder decontamination and slow repair and maintenance operations.

\section{Environmental Health and Safety}

\section{A-20.3.5 Emissions}

Ranking - High-Medium: Routine emissions from SCWO treatment systems will include process offgas containing $\mathrm{CO}_{2}, \mathrm{H}_{2} \mathrm{O}, \mathrm{N}_{2}$ and perhaps some $\mathrm{N}_{2} \mathrm{O}$. During process excursions, some volatile waste POCs and/or reformed POC products (methane, methanol, formic acid, formaldehyde, etc.) may distribute to the offgas. As with all high-pressure processes, equipment failure may lead to rapid and energetic release of large quantities of contaminated material. Gaseous effluents from SCWO will likely require only GAC adsorption and HEPA filtration prior to discharge. Depending on the effectiveness of solids precipitation and separation during processing, cooled process solutions may require only degassing, filtration, and ion exchange polishing before discharge. Separated solids will require drying and appropriate stabilization prior to final disposal.

\section{A-20.3.6 Worker Health and Safety}

Ranking - Medium-Low: Non routine maintenance in contaminated areas is expected to be much higher than average. Frequent "heel-out" and inspection of equipment is likely to be required. "Weeping" at seals and gaskets will contribute to contamination of enclosures and containments. Extensive sampling and analyses will most likely provide a major exposure risk for operating personnel. Process conditions will likely require secondary containment and other provisions to protect operating personnel. The process is quite sensitive to heating value of the feed material. Normal operation is with excess oxidizer. Reaction kinetics are relatively rapid and temperature transients from credible feed excursions may be severe. Since the process operates at high temperature and pressure and normally with excess oxidizer, active control measures will be required to maintain process conditions within permitted equipment limitations. Wastes having heating values above about $4,100 \mathrm{~kJ} / \mathrm{kg}$ will require removal of excess process heat or will have to be diluted. Use of excess oxygen to ensure adequate DEs will require good feed monitoring and control to prevent process temperature excursions. SCWO reactions are rapid enough to be considered adiabatic, and the allowable temperature rise $\left(200^{\circ} \mathrm{C}\right.$ to $\left.300^{\circ} \mathrm{C}\right)$ imposed by equipment limitations is rather small. Control functions will be rather complex, involving heating, pressurizing, and mixing multiple feed streams and managing one or more recycle streams. Control time constants will be relatively short and the consequences of control failure my be severe.

\section{A-20.4 References}

1. R. Oldenborg, et al., "Evaluation of IPM Selection Criteria for Hydrothermal Processing," Los Alamos National Laboratory, Los Alamos, NM, June 9, 1993. 
2. J. Griffith, "Update on Supercritical Water Oxidation (SCWO)," letter dated October $5,1994$.

3. J. A. Bettinger, P. E. Ferland and E. D. Ferland, "Demonstration of the MODAR Supercritical Water Oxidation Process," Proceedings of the Waste Management '94 Conference, Tucson, AXZ, February-March 1994.

4. C. M. Barnes, et al., "Identification of Technical Constraints for Treatment of DOE Mixed Waste by Supercritical Water Oxidation," EGG-WTD-10768, Idaho National Engineering Laboratory, EG\&G Idaho, Inc., Idaho Falls, ID, October 1993.

5. M. Modell, "Supercritical Water," in Standard Handbook of Hazardous Waste Treatment and Disposal, H. M. Freeman, editor, McGraw-Hill Book Company, New York, NY, 1989. 


\section{A-21 STEAM REFORMING}

\section{A-21.1 Technology Description}

Steam is reacted at elevated temperature $\left(300^{\circ} \mathrm{C}\right.$ to $\left.1200^{\circ} \mathrm{C}\right)$ with organic waste constituents to yield synthesis gas comprised primarily of $\mathrm{CO}, \mathrm{CO}_{2}, \mathrm{H}_{2}, \mathrm{H}_{2} \mathrm{O}$, and $\mathrm{CH}_{4}$. Methane is usually a minor constituent in the absence of high pressure or catalysts. Halogenated organics will generate offgas containing halogen acids, and if nitrates and sulfates are present in the waste, the offgas may contain some $\mathrm{SO}_{\mathrm{X}}$ and $\mathrm{NO}$. Steam reforming is usually accomplished in two stages:

1. Waste is pyrolized and volatilized by exposure to steam or a mixture of steam and synthesis gas at temperatures between about $300^{\circ} \mathrm{C}$ and $800^{\circ} \mathrm{C}$. Pyrolysis residues include coke or char together with non-volatile inorganic ash materials.

2. Volatile species generated in the first stage are further reacted with steam at temperatures up to $1200^{\circ} \mathrm{C}$ to produce synthesis gas.

For waste treatment applications, acid gases (mainly $\mathrm{HCl}$ ) are scrubbed or adsorbed from the synthesis gas which is then burned to produce $\mathrm{CO}_{2}$ and $\mathrm{H}_{2} \mathrm{O}$ for release to the environment. Thermodynamic equilibrium data for major steam reforming reactions are presented in Figure 1.

For several decades, steam reforming technology has been applied commercially and worldwide for the production of synthesis gas from coal. Only recently, however, has the technology been modified for application to waste management. Two companies, Synthetica Technologies 1 and ThermoChem, Inc. 2,3 , have developed systems which may find application to treatment of DOE mixed wastes.

The Synthetica Detoxifier $\AA$ is a two step process. In the first step, organics are pyrolized and volatilized by high temperature $\left(300{ }^{\circ} \mathrm{C}\right.$ to $\left.600^{\circ} \mathrm{C}\right)$ steam and synthesis gas in one of four different feed systems:

- Drum feed evaporator for contained wastes,

- Moving bed evaporator for liquids or slurries, halogenated hydrocarbons, and nitrate wastes,

- Heated shredder for debris wastes, and

- Heated screw for contaminated soils. 


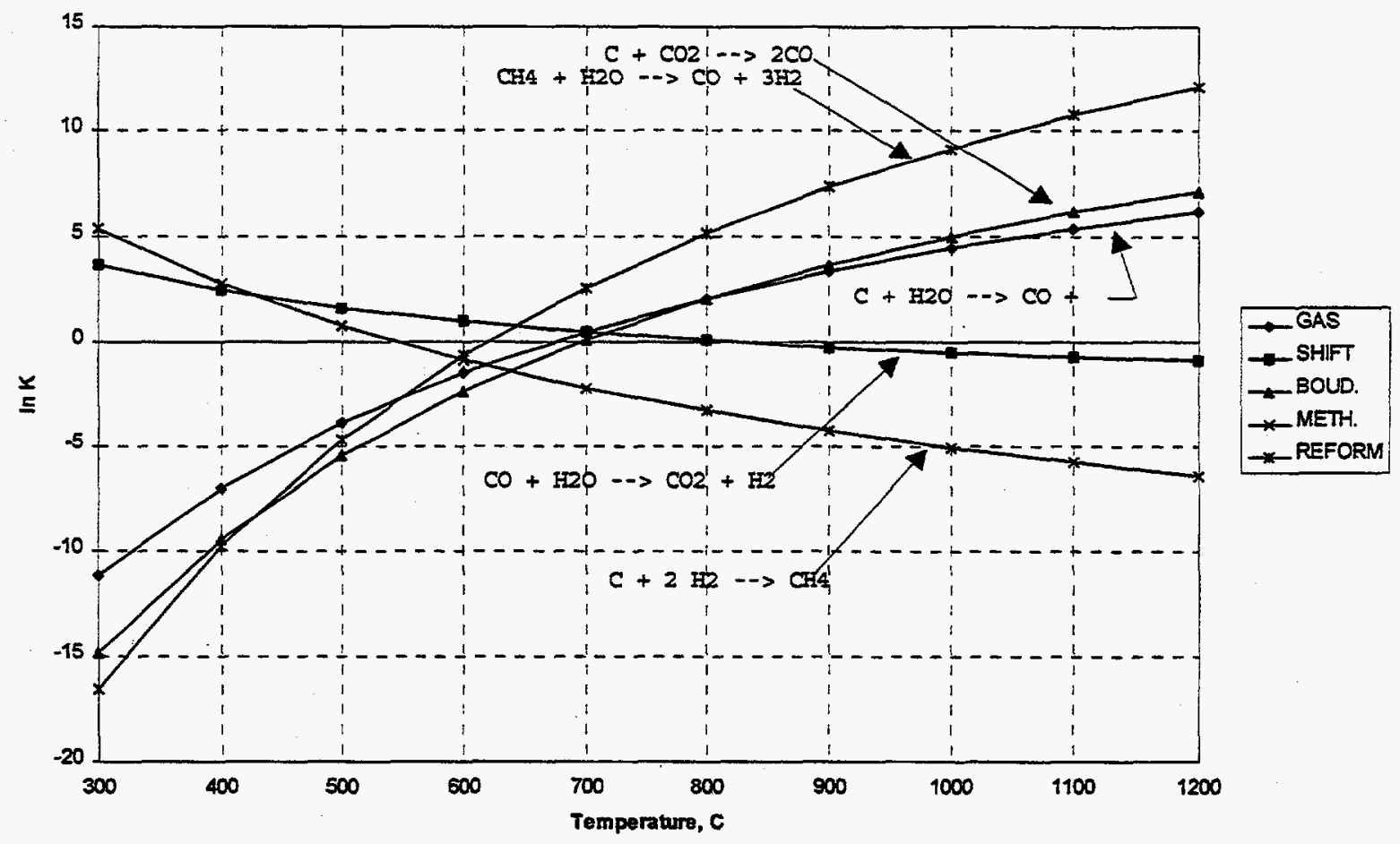

Figure A-21.1. Thermodynamic Equilibrium Data for Selected Steam Reforming Reactions.

Volatilized organic materials and partially reformed gasses from the selected waste feed evaporator then are mixed with excess superheated steam and are fed to a high-temperature, electrically heated, steam reforming reactor (Detoxifier) which is operated at a temperature above $1100{ }^{\circ} \mathrm{C}$. Hot Detoxifier offgas is cooled and passed through GAC and chemical adsorption beds to remove trace organics, metals, and acid gasses. A small bleed stream is burned in a catalytic oxidizer to yield $\mathrm{CO}_{2}$ and water vapor. The balance of the gas is reheated and returned to the selected waste feed evaporator to continue the process. Synthetica has demonstrated processing of solvent and oil contaminated rags, paper, and protective clothing at a rate of approximately one 200-liter drum per 8-hour shift. Measured volume and mass reductions were about $99.7 \%$ and $98 \%$ respectively.

The process is energy intensive. A one ton per day system for treating military chemical agents requires a $335 \mathrm{~kW}$ electrically fired Detoxifier.

ThermoChem is developing a two reactor system for treating hazardous or mixed wastes. First, waste is reacted with steam in an indirectly heated fluidized bed operating at temperatures from about $650^{\circ} \mathrm{C}$ to $900^{\circ} \mathrm{C}$ depending on the feedstock. Liquid and slurry wastes are sprayed on the surface the bed, and solid wastes are reduced to about minus $7-\mathrm{mm}$ ring size before being screw fed to the fluidized bed. Off-gas from the fluidized bed reactor is filtered and passed to an electrically heated secondary reactor where the reforming reactions are completed at higher 
temperature. Off-gas from the secondary reforming reactor is quenched using an ejector venturi scrubber where steam is condensed, and acid gasses and particulate are removed. Scrubbed synthesis gas is then burned in a thermal oxidizer and the resulting offgas is again cooled and scrubbed in a spray or packed tower before being released to the environment. System residues include spent fluidized bed material, scrubber sludges and contaminated char.

\section{A-21.2 Advantages, Disadvantages and Issues}

\section{Advantages}

1. Steam reforming promises reaction of POCs and removal of chlorine prior to oxidation or combustion of reformed waste components. Dioxins and other chlorinated PICs should not be formed, or if formed should be destroyed in the secondary reactor or the thermal oxidizer.

2. The process is relatively "omnivorous" if the various waste feed evaporators can be made to work reliably.

\section{Disadvantages}

1. The process requires handling large volumes of hydrogen and other fuel gasses at high temperature.

2. The process requires a minimum of three (waste feed evaporator or fluidized bed, second stage reformer, catalytic or thermal oxidizer) reactors operating at elevated temperature plus associated heat exchangers, wet scrubbers, and solids residue (dry particulate, scrubber sludge, fluidized bed fines, etc.) separation and handling systems.

3. "Waste evaporator" technologies using heated screws, shredders, or moving beds are not well demonstrated, and are mechanically complex.

\section{Issues}

The Synthetica process uses a recycle stream from the Detoxifier 8 to initiate steam reforming and accomplish pyrolysis in the selected waste heat evaporator. It is not clear from their literature how the steam is generated and where and how much steam is introduced into the hot gas fed to the waste heat evaporator. However, examination of Figure 1 shows that steam reforming of methane and reaction of char are not favored at typical operating conditions $\left(300^{\circ} \mathrm{C}\right.$ to $600^{\circ} \mathrm{C}$ ) for the waste feed evaporators.

Low temperature and low partial pressure of steam make it unlikely that significant reforming can be accomplished in the waste feed evaporators proposed by Synthetica.

Synthetica reports high-temperature reactor emissions comprised of $80 \% \mathrm{CO}_{2}, 15 \% \mathrm{H}_{2} \mathrm{O}$, $1.4 \% \mathrm{H}_{2}$, and $0.2 \% \mathrm{CO}$ when processing a waste mixture of $66 \%$ acetone, $32 \%$ xylene, and $1 \%$ each of 1,1,1-TCE and 1,2-DCB. These results indicate that the high-temperature steam reformer is acting as an incinerator. Steam reforming reactions produce substantial quantities of hydrogen and carbon monoxide. (See Figure 1) At Detoxifier ${ }^{\circledR}$ operating temperatures formation of $\mathrm{CO}$ and $\mathrm{H}_{2}$ are favored unless oxygen is introduced to promote combustion yielding $\mathrm{CO}_{2}$. 
High-temperature electrically heated reforming reactors have exhibited severe corrosion during processing of halogenated hydrocarbons due to formation of $\mathrm{HCl}$.

\section{A-21.3 Evaluation}

\section{Performance}

\section{A-21.3.1 Range of Feed Material}

Ranking - High: Concentrated or pure organic liquids present no special problems for treatment by steam reforming. Aqueous wastes provide the possibility for autogenous steam generation in the first stage (waste feed evaporator, fluidized bed) reformer. Solids sludges and soil may present challenging feed and first stage contacting problems, but it is likely that these problems can be addressed successfully using minor modifications of existing technologies. Depending on the feed and first stage contacting method used, generation and handling of particle fines may require addition or modification of process equipment.

Steam reforming technology should be nearly as flexible as incineration for destruction and volume reduction of combustible debris waste matrices and treatment of hazardous organic constituents. If organic contaminants in non combustible debris can be accessed by the process steam, these should be treated by the process as well.

\section{A-21.3.2 Treatment Effectiveness}

Ranking - High: Destruction of organic species by steam reforming has been demonstrated to be quite effective. Table -21.1 summarizes DREs reported by Synthetica for a number of waste compounds. In addition, steam reforming supplies sufficient energy to decompose most organic waste matrix materials and expose hazardous compounds for treatment.

Table A-21.1: Summary of Typical DRE Results for Synthetica Steam Reforming1

\begin{tabular}{|l|c|c|}
\hline \multicolumn{1}{|c|}{ COMPOUND } & TEMPERATURE ( $\left.{ }^{\circ} \mathbf{C}\right)$ & DRE (\%) \\
\hline Acetone & 1190 & 99.9995 \\
\hline Carbon Tetrachloride & 1150 & 99.9952 \\
\hline Chloroform & 1150 & 99.9992 \\
\hline Dichlorobenzene & 1120 & 99.9904 \\
\hline Isopropanol & 1150 & $>99.9994$ \\
\hline Methanol & 1150 & $>99.9996$ \\
\hline Methylene Chloride & 1150 & 99.9978 \\
\hline Methyl Isobutyl Keytone & 980 & $>99.99$ \\
\hline 1,1,1-Trichloroethane & 1090 & 99.9916 \\
\hline Xylene & 1110 & 99.9926 \\
\hline
\end{tabular}

Most combustible solids and debris will exhibit volume reduction comparable to that provided by incineration. Treated residues from steam reforming will be dry solids which are amenable to simple stabilization prior to final disposal. The Synthetica process generates solid sorbents (GAC, Selexsorb) which may be regulated secondary wastes. The ThermoChem fluidized bed will require final disposition as a regulated solid waste. In addition, wet scrubber sludges from the proposed ThermoChem system may require disposal as regulated waste. 


\section{Readiness for Deployment}

\section{A-21.3.3 Level of Development and Understanding}

Ranking - High: Steam reforming technology has been commercialized for treatment of biomass and has been pilot demonstrated for treatment of hazardous wastes. Thermochem has installed waste treatment facilities to treat paper pulp mill waste, and is planning on demonstrating a complete mixed waste treatment process near the end of 1996.

\section{A-21.3.4 System Complexity}

Ranking - Medium-Low: The amount of pretreatment required to treat wastes using steam reforming depends on the design of the system and the waste matrix. Synthetica has demonstrated treatment of bulk wastes in 200 liter steel drums but has not resolved the issue regarding corrosion due to $\mathrm{HCl}$ produced when treating chlorinated hydrocarbons. ThermoChem's fluidized bed requires solids to be reduced to about minus 6-mm ring size. Technologies are available for all pre-treatment requirements anticipated for steam reforming.

Steam reforming systems for treatment of mixed wastes will be relatively complex. The proposed ThermoChem system is comprised of approximately ten unit operations which must be integrated and operated in a continuous process train. Support and auxiliary equipment includes high-power electrical utilities, steam generators and superheaters, process cooling water loops, chemical makeup and adjustment systems for wet scrubbers, and provisions for scrubber sludge separation and stabilization. A thermal oxidizer will be required to treat the combustible gas produced by the steam reformer. Feeding solid wastes to the fluidized bed may be an additional complexity.

Systems handling large quantities of hydrogen and carbon monoxide will be difficult to adapt to radioactive service. Secondary containment needed to prevent spread of radionuclides in the event of a breach in primary containment may provide sites for accumulation of explosive or poisonous gas mixtures. If the primary containment (process equipment) is operated under negative pressure with respect to the secondary containment, air inleakage would be a significant hazard.

\section{Environmental Health and Safety}

\section{A-21.3.5 Emissions}

Ranking - Medium: Steam is reacted at elevated temperature $\left(300^{\circ} \mathrm{C}\right.$ to $\left.1200^{\circ} \mathrm{C}\right)$ with organic waste constituents to yield synthesis gas comprised primarily of $\mathrm{CO}, \mathrm{CO}_{2}, \mathrm{H}_{2}, \mathrm{H}_{2} \mathrm{O}$, and $\mathrm{CH}_{4}$. Methane is usually a minor constituent in the absence of high pressure or catalysts. Halogenated organics will generate offgas containing halogen acids, and if nitrates and sulfates are present in the waste, the offgas may contain some $\mathrm{SO}_{\mathrm{x}}$ and $\mathrm{NO}_{\mathrm{x}}$. At a minimum, reformer gas will require scrubbing to remove acid gasses followed by afterburning in a thermal or catalytic oxidizer prior to release to the environment. Significant chemical and thermal energy is contained in superheated steam and reformer product gas. Releases will be correspondingly more frequent and difficult to mitigate. With the possible exception of wet scrubber sludge, treated residues from steam reforming will be dry solids which are amenable to simple stabilization prior to final disposal. The Synthetica process generates solid sorbents (GAC, Selexsorb) which 
may be regulated wastes. The ThermoChem fluidized bed will require final disposition as a regulated solid waste. In addition, wet scrubber sludges from the proposed ThermoChem system may require disposal as regulated waste.

\section{A-21.3.6 Worker Health and Safety}

Ranking - Medium-Low: Steam reforming systems will be relatively complex, heavily insulated, housed in multiple large containments, and will feature multiple utility and I\&C connections. Ensuring acceptable risk to maintenance workers will require correspondingly more effort. Steam reforming is a "high energy" technology which handles large quantities of hot, reactive, and poisonous gasses. High voltage, high power electric service is required to run the second stage reformer. These features tend to degrade operational worker health and safety. Steam reforming reactions are endothermic. Although considerable energy is contained in the process streams, typical excursions tend to be self limiting. Operation is stable over a very large range of operating conditions. Time constant for major control parameters are long and the system exhibits a large negative thermal coefficient of reactivity. Runaway steam reforming reactions are not possible. Since proposed systems will operate near ambient pressure, sudden and catastrophic containment failures will be unlikely.

\section{A-21.4 References}

1. T. Galloway and S. S. Depetris, "Destroying LLW and Hazardous Waste On-Site with the Synthetica Steam Reformer," Proceedings of the Waste Management '94 Conference, Tucson, AZ, March-February 1994.

2. B. Aghamohammadi, "Test Report for Sandia National Laboratory," MTCI Project No. 10075, March 1995.

3. Anon, "Steam Reforming of Municipal Wastewater Sludge," Phase I Final Report for the Environmental Protection Agency, MTCI 20049-PI-F, Manufacturing and Technology Conversion International, Inc., Columbia, MD. 


\section{A-22 CHEMCHAR}

\section{A-22.1 Technology Description}

Waste constituents undergo pyrolysis, partial combustion, steam reforming, and gasification in the vicinity of a moving high-temperature $\left(1200^{\circ} \mathrm{C}\right)$ reaction zone inside a shaft furnace packed with a mixture of waste and triple reverse bum (TRB) char 1,2 .

TRB char is a low grade of activated carbon produced from sub-bituminous coal using a reactor similar to the ChemChar waste treatment reactor. The char provides a porous, highly adsorptive media which binds or supports waste constituents in the reactor, but allows adequate passage of reaction and product gasses. Char is comprised of carbon particles ranging from about 0.5 to $1.0 \mathrm{~mm}$ diameter which can adsorb up to their own mass of liquids or sludges without significant deterioration in handling (dry, granular) properties.

For batch operation, waste is mixed with char and charged to a vertical shaft furnace. Oxygen and, depending on the waste characteristics, steam are fed at the top of the furnace and the charge is ignited at the lower end. After ignition the hot reaction zone moves upward through the charge and counter to the flow of the gas stream. During its passage the hot reaction zone consumes about $10 \%$ of the solid charge. Waste is subjected to oxidation, pyrolysis, gasification, and steam reforming as the hot reaction zone passes. Combustible product (synthesis) gas is comprised primarily of $\mathrm{CO}, \mathrm{H}_{2}, \mathrm{H}_{2} \mathrm{O}, \mathrm{CO}_{2}, \mathrm{CH}_{4}$, and perhaps some other low molecular weight hydrocarbons. Dehydrohalogenation produces halogen acids which may be sorbed to some extent on the hot char residual. Use of caustic impregnated or naturally alkaline char will enhance retention of acid gas. Laboratory tests indicate that char may be used several times before its structure is so impaired or it is so loaded with ash materials that it must be replaced. Spent char may be forward burned (incinerated) to produce a substantially volume reduced ash or slag.

In principle, the ChemChar process may be operated in a continuous feed mode with the char/waste feed and burned char discharge so regulated as to provide a stationary hot reaction zone.

For application to mixed waste treatment, the synthesis gas produced by the Chemchar process would be cooled to remove condensable components, and would be filtered through a bed of fresh char before being burned in a catalytic or thermal oxidizer. Off-gas condensate, and loaded char filter material would be mixed (together with fresh waste) into a quantity of fresh or recycle char for feed to the ChemChar reactor, thus continuing the process.

Development is in the advanced laboratory and early pilot stage. The process has been patented and Mirage Systems in Sunnyvale, CA has an exclusive license to develop and market the technology. Development is continuing using a $100-\mathrm{mm}$ diameter, continuous feed, adiabatic reactor.

\section{A-22.2 Advantages, Disadvantages and Issues}

\section{Advantages}


1. ChemChar technology promises efficient, complete destruction of POCs without generation of undesirable PICs such as dioxins and dibenzofuran.

2. Application of the technology to mixed waste treatment is relatively simple in concept and provides a high degree of internal waste recycle.

3. The process requires no supplementary energy.

\section{Disadvantages}

1. The process periodically produces a contaminated char bed which must be incinerated in place or removed for stabilization and disposal.

2. The process requires mixing waste with TRB char which must be purchased or produced from coal in the waste treatment facility.

\section{Issues}

Scale-up is a key issue for the ChemChar process. Downflow shaft furnaces are extremely vulnerable to local temperature excursions, clinkering, "rat-hole" formation and poor gas distribution. These problems typically increase with increasing scale of the furnace and with reduced homogeneity of the charge. Management of pressure drop across a deep bed is likely to be a problem. As shown in Figure 1, for a given bed depth pressure drop increases dramatically as particles shrink and provide greater aerodynamic surface per unit bed volume. Bed pressure drop will also increase with temperature due both to increased viscosity of the gas stream and increased superficial velocity from expansion.

Design and materials of construction for a full-scale mixed waste gasification reactor are other major issues. The reactor lining will be subjected to high temperatures, very high rates of temperature change, multiple temperature cycles, alternating strongly oxidizing and strongly reducing conditions, and both acid and alkaline environments. Some of the materials problems may be partially addressed through use of a continuous reactor with a stationary reaction zone. However, mechanical design and scale-up problems will also be significant for continuous operation. Synchronized and reliable feed and discharge may be difficult to achieve especially if bed agglomeration or clinker formation occurs. Likewise, managing solids flow and wall effects in a moving bed reactor may be difficult with variable or inhomogeneous feed mixes. 


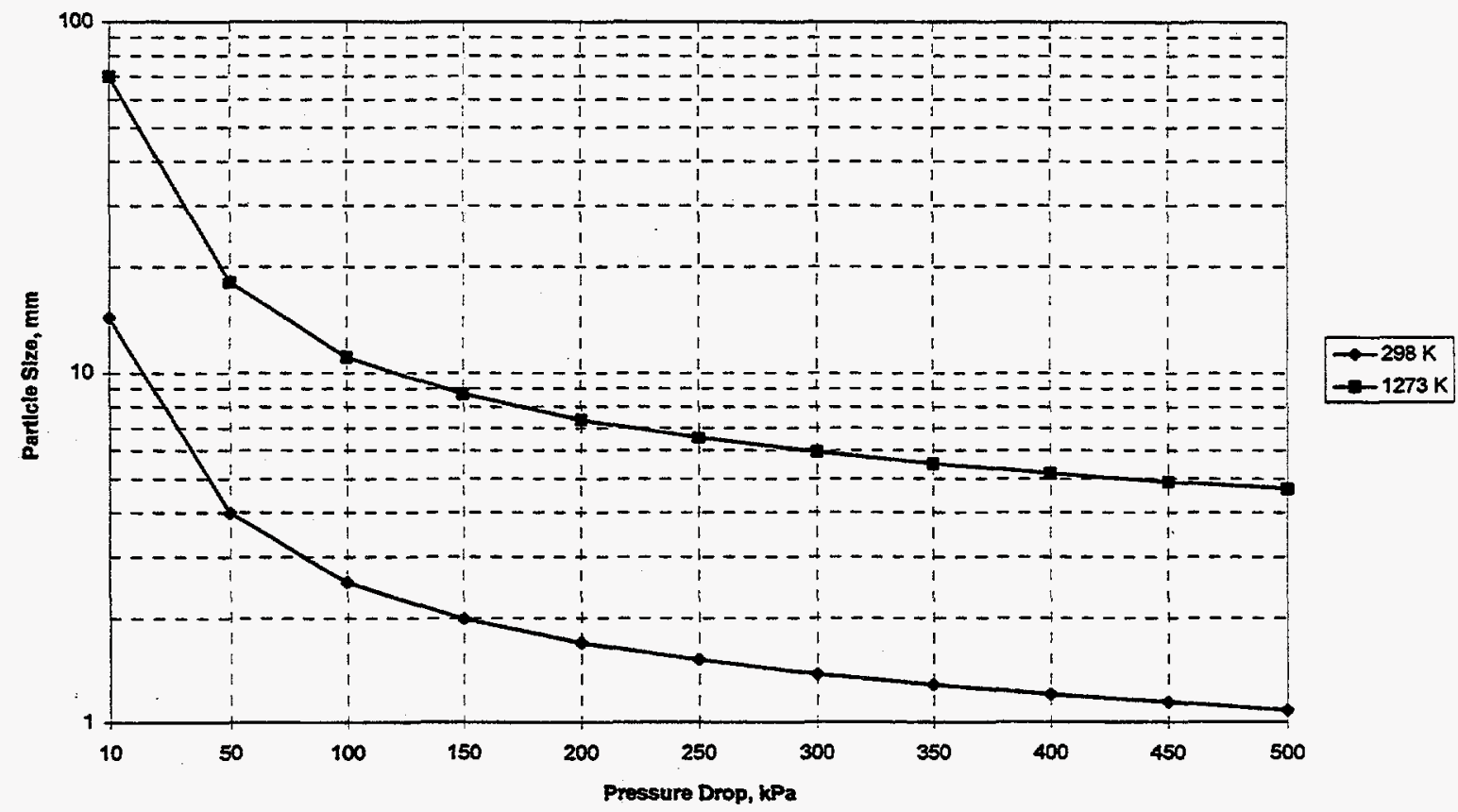

Figure A-22.1. Influence of Particle Size and Gas Temperature on Bed Pressure Drop.

\section{A-22.3 Evaluation}

\section{Performance}

\section{A-22.3.1 Range of Feed Material}

Ranking - Medium-Low: Concentrated or pure organic liquid wastes are excellent candidates for ChemChar processing. They are readily adsorbed by the TRB char to yield a homogeneous, tractable, furnace charge. Organic contaminated aqueous wastes may be suitable for filtration through TRB char to remove most contaminants. Following polishing by GAC or ion-exchange the aqueous fraction may be suitable for discharge, and the loaded char and polishing materials would be appropriate for ChemChar processing. Processing of sludge and soils wastes will depend on development of techniques to ensure acceptable handling characteristics are retained when these wastes are mixed with TRB char Addition of solvents or use of very low waste/char ratios may be required. Waste/char blends must be gas permeable and free flowing both before and after gasification. This condition will be difficult or impossible to achieve with many stabilized wastes and soils.

Appropriate size reduction and blending of debris wastes would be required to ensure waste/char mixes are suitable for ChemChar processing. This task would seem to be a very difficult and unlikely to succeed for managing combustible wastes, and impossible for non combustible waste matrices. 


\section{A-22.3.2 Treatment Effectiveness}

Ranking - High-Medium: Very high temperatures and strong reducing conditions ensure high destruction efficiencies for waste POCs. Laboratory scale tests with hydrocarbons, hexachlorobenzene, and PCBs showed destruction efficiencies of $99.99 \%$ in the ChemChar reactor. Secondary combustion of the offgas yielded overall destruction efficiencies of 99.9999\%.

A combustion driven primary process along with the secondary combustion chamber makes ChemChar process technically equivalent to an incinerator. Volume reduction of original waste fed to the ChemChar process will be very high for those wastes readily handled by the process. Organic matrix materials will be consumed by the combustion and gasification reactions and POCs will be destroyed.

Regulated secondary waste will be generated from pretreatment and disposal of the spent char. The quantity will depend on how many time the char can be reworked and the allowable waste-to-char feed ratio. The number of times char can be recycled will be governed by deterioration in its structural and adsorptive properties. Processing of halogenated organic sludges may require low waste to char ratios while processing of pure hydrocarbons may allow relatively high waste to char ratios. Data are not currently available.

There should be no post treatment required. Original waste POCs should be completely destroyed by the ChemChar process. Spent char containing carbon fines, salts, toxic metals, radionuclides and ash materials will require disposal by other means.

\section{Readiness for Deployment}

\section{A-22.3.3 Level of Development and Understanding}

Ranking - Medium-Low: The scientific basis of the technology is well demonstrated and tests have been performed on several difficult to treat contaminants of interest to DOE.. However, only laboratory and bench-scale equipment have been used for development to date, and scale-up has yet to be addressed and problems should be anticipated. Systems for waste characterization, waste/char mixing, transport, and feeding and spent char discharge and characterization have yet to be developed.

\section{A-22.3.4 System Complexity}

Ranking - Low: Although the core technology is quite simple, the integrated processing system will be quite complex. Production of a homogeneous waste/char mix is a critical prerequisite for the ChemChar process and material handling may make this process quite complex. Debris waste will require size reduction (magnitude as yet undetermined) before being mixed with the char. These various waste/char mixes must then be further blended with recycle char, offgas filter char, and offgas condensate before being charged to the gasification reactor.

These mixing and blending operations will require surge storage, characterization, materials transport, and blending systems for each component. The process also requires a steam generator/superheater plus an offgas cooler/condenser and secondary oxidizer. A solids cooler will also be required for burned, contaminated char. If forward burning of spent char is implemented, the system will require addition of an incinerator type offgas treatment system. 
Systems handling large quantities of synthesis gas at high temperature will be difficult to adapt to radioactive service. Secondary containment needed to prevent spread of radionuclides in the event of a breach in primary containment may provide sites for accumulation of explosive or poisonous gas mixtures. Bed agglomeration or sintering would present a major problem and must be anticipated for this type of furnace. Recovery will require furnace cooling, direct personnel access, and application of mechanical force to bed and furnace components.

\section{Environmental Health and Safety}

\section{A-22.3.5 Emissions}

Ranking - Medium-Low: Combustible product (synthesis) gas is comprised primarily of $\mathrm{CO}, \mathrm{H}_{2}, \mathrm{H}_{2} \mathrm{O}, \mathrm{CO}_{2}, \mathrm{CH}_{4}$, and perhaps some other low molecular weight hydrocarbons. Dehydrohalogenation produces halogen acids which may be sorbed to some extent on the hot char residual. At a minimum, synthesis gas must be cooled and scrubbed to remove acid gasses before being afterburned in a thermal or catalytic oxidizer. Significant thermal and chemical energy are associated with the ChemChar reactions and product gas. The primary containment (reactor) is subjected to severe operating conditions. Accidents could cause significant releases of hazardous and radioactive materials. Original waste POCs should be completely destroyed by the ChemChar process. Spent char containing carbon fines, salts, toxic metals, radionuclides and ash materials will require disposal by other means. Generation of regulated secondary waste will depend on the allowable waste to char ratio in the feed and the number of times char may be recycled before requiring disposal. Allowable waste to char feed ratio will be determined by mixing and handling properties and the need for burned char to adsorb acid species and other contaminants in the product gas. The number of times char can be recycled will be governed by deterioration in its structural and adsorptive properties. Processing of halogenated organic sludges may require low waste to char ratios while processing of pure hydrocarbons may allow relatively high waste to char ratios. Data are not currently available.

\section{A-22.3.6 Worker Health and Safety}

Ranking - Medium-Low: ChemChar systems will be relatively complex, heavily insulated, housed in multiple large containments, and will require multiple utility and I\&C connections. It is probable that a full scale ChemChar reactor will require significant non-routine maintenance and repair. Ensuring acceptable risk to maintenance workers will require correspondingly more effort. ChemChar is a "high energy" technology which produces and requires handling of large quantities of hot, reactive, and poisonous gasses. Extensive handling and transport of hot, dusty, contaminated materials is required. These features mitigate against operational worker health and safety. It may be very difficult to detect significant excursions during operation of a fullscale reactor. Local hot spots can occur undetected and cause agglomeration and sintering sufficient to form clinkers which cannot easily be discharged from the reactor. Even if hot spots are detected, control response is limited to changing the partial pressure of oxygen delivered to the entire bed. Direct control of local temperature is impossible. If "rat holing" occurs in the burned char section of the bed, its ability to adsorb contaminants may be compromised leading to "break through" of contamination and loading of the offgas treatment system beyond its design capability. Overall control parameters are relatively stable and exhibit long time constants. Runaway reactions in the gasification reactor are impossible except in the unlikely event of loss of control of oxygen feed leading to uncontrolled combustion. Since pressure drop across a deep bed may be rather high (See Figure 1) operation of part of the reactor at pressure substantially 
above ambient is likely. The combined effects of temperature, pressure, and corrosion substantially increase the risk of sudden catastrophic failure (burn through) of the reactor vessel accompanied by partial ejection of reactor inventory to the containment.

\section{A-22.4 References}

1. L. L. Kinner, et al., "Reverse-Burn Gasification of Hazardous Wastes: Application to Treatment of Refractory Organic Waste, Contaminated Soil, Sewage, Sludge, Mixed Radioactive Wastes and Spent Activated Carbon," Hazardous Waste Conference, Boulder, CO, June 1992.

2. L. L. Kinner, et al., "Reverse-Burn Gasification for Treatment of Hazardous Wastes: Contaminated Soil, Mixed Wastes and Spent Activated Carbon Regeneration," Environmental Science and Technology, Vol. 27, pp. 482-488, 1993. 


\section{A-23 ECO LOGIC HYDROGEN REDUCTION}

\section{A-23.1 Technology Description}

Vaporized organic wastes are mixed with hydrogen rich ( $>50 \%$ dry basis) gas at high temperature $\left(850^{\circ} \mathrm{C}\right.$ to $\left.950^{\circ} \mathrm{C}\right)$ in an electrically heated reactor to accomplish nearly complete hydrogenolysis of the waste components 1 . Hydrogenolysis reaction products are comprised primarily of light hydrocarbons (primarily methane and ethylene), plus some $\mathrm{H}_{2} \mathrm{O}, \mathrm{CO}, \mathrm{CO}_{2}$, and acid halogens formed depending on the oxygen, moisture, and halogen content of the waste stream.

"Seed" hydrogen is required for process startup. During steady-state operation, a fired steam reformer is used to generate hydrogen from a portion of the hydrogenolysis product stream:

$$
\mathrm{CH}_{4}+\mathrm{H}_{2} \mathrm{O} \Leftrightarrow \mathrm{CO}+3 \mathrm{H}_{2}
$$

Moisture in the waste stream or added steam may also form some hydrogen via the water shift reaction:

$$
\mathrm{CO}+\mathrm{H}_{2} \mathrm{O} \Leftrightarrow \mathrm{CO}_{2}+\mathrm{H}_{2}
$$

Product gas from the hydrogenolysis reactor is quenched and cleaned in a multistage wet scrubber which employs:

- packed bed caustic scrubbing to remove acid gas,

- neutral oil scrubbing to remove residual higher molecular weight hydrocarbons (primarily benzene and naphthalene), and

- $\quad$ scrubbing with monoethanolamine (MEA) to remove carbon dioxide.

Hydrocarbons are stripped from the neutral oil and routed to the steam reformer for destruction. Carbon dioxide is stripped from the MEA and discharged to the atmosphere. Removal of the carbon dioxide is necessary to help drive the reforming and water shift reactions, and to produce a high BTU product gas suitable for firing the process boiler, steam reformer, and gas heaters.

Gases exiting the scrubber are primarily hydrogen (60\%), light hydrocarbons (30\%), carbon dioxide $(8 \%)$, carbon monoxide $(2 \%)$ and traces of higher molecular weight or aromatic hydrocarbons, e.g., benzene and naphthalene. Gas in excess of that necessary for recirculation to the process is compressed, stored, and analyzed in preparation for use in firing process equipment. A co-fired (propane/process gas) boiler generates process steam for the steam reformer and liquid waste evaporator and also serves as an incinerator for excess process gas.

Since the hydrogenolysis reactions must be completed in the gas phase, a number of techniques and systems must be employed to desorb or vaporize waste principle organic contaminants (POCs) and transport them to the high temperature reactor: 
- Aqueous wastes are vaporized in a steam heated evaporator and are fed directly to the hydrogenolysis reactor.

- Concentrated organic liquids and evaporator bottoms are injected via atomizing nozzles to the hydrogenolysis reactor.

- Organic constituents in an homogeneous solid waste matrix may be desorbed or vaporized in a thermal reduction mill (hot ball mill) or thermal desorption unit (molten tin bath).

- Larger or monolithic solids may be treated in an insulated autoclave like chamber called a sequencing batch vaporizer (SBV).

Recirculated product gas is used to purge these "head-end" systems and transport the desorbed, vaporized, or partially reacted contaminants to the high temperature hydrogenolysis reactor. Purge gas is heated in gas fired or electric heaters for feed to the head-end systems. The SBV chambers are also provided with supplementary electrical heaters.

Eco Logic has commercialized the technology and has built systems having a design capacity of 150 tons/day for contaminated soils and other solids, 60 tons/day for watery wastes, and 30 tons/day for concentrated (100\%) PCB liquids.

\section{A-23.2 Advantages, Disadvantages and Issues}

\section{Advantages}

1. The Eco Logic process offers the possibility of closed loop operation with no uncontrolled emissions.

2. The process provides complete destruction of POCs without formation of undesirable PICs such as dioxins and dibenzofuran.

\section{Disadvantages}

1. The process uses and produces large quantities of reactive and combustible gasses.

2. The process can only treat organics in the gas phase.

\section{Issues}

The key issue in applying Eco Logic hydrogen reduction technology to mixed wastes is performance of the head-end systems needed to ensure that hazardous organic wastes are quantitatively rendered into the gas phase for transport and treatment in the high temperature hydrogenolysis reactor. Vaporization or direct injection of liquid wastes is straightforward, simple, and easily accomplished. However, treatment of organic contaminants in slurries, sludges, and solid matrices poses significant problems.

Head-end processing techniques tried to date have been bottlenecks for the integrated process. Basically, these techniques involve thermal desorption carried out in a reducing atmosphere of heated, recirculated, process gas. These systems must operate at typical thermal 
desorption temperatures $\left(150^{\circ} \mathrm{C}\right.$ to $\left.350^{\circ} \mathrm{C}\right)$ or greater, and must provide for effective, intimate contact of waste materials and process gas, plus they must manage feed and discharge of waste matrix materials while preventing leakage or mixing of ambient air and process gas. Heat transfer and molecular diffusion control thermal desorption rates for many waste matrices. As a result, the thermal desorption processes are relatively slow and limits the overall Eco Logic process throughput.

\section{A-23.3 Evaluation}

\section{Performance}

\section{A-23.3.1 Range of Feed Material}

Ranking - Medium: Organic contaminated aqueous wastes are easily processed by vaporization or atomization and direct injection into the hydrogenolysis reactor. Concentrated or pure organic liquid wastes are easily processed by vaporization or atomization and direct injection into the hydrogenolysis reactor. Some filterable slurries, granular solids, and tractable caked and friable sludges containing organic wastes having relatively high vapor pressures may also be suitable for treatment by the process.

Significant hydrogenolysis does not occur at the relatively low temperatures existing in Eco Logic's head-end thermal desorption systems. Typical combustible debris wastes will be degraded too slowly for practical application. Only debris wastes exhibiting easily desorbed or surface contamination will be good candidates for processing with this technology.

\section{A-23.3.2 Treatment Effectiveness}

Ranking - High: POCs are completely destroyed by the process $1,2,3$. Data from large scale (several tons/day) demonstration tests have shown overall process DREs for PAHs and PCBs to exceed $99.9999 \%$ based on total organic feed and constituents measured in the stack emissions. Tests on wastewater containing about $3,700 \mathrm{ppm}$ perchloroethane yielded a DRE of $99.99 \%$. Desorption data taken from tests using $15,240 \mathrm{ppm}$ hexachlorobenzene (HCB) and $650 \mathrm{ppm}$ octachlorodibenzo-p-dioxin (OCDD) in soil showed desorption efficiencies of $99.99 \%$ and $99.8 \%$ respectively. Aqueous and organic liquid wastes are completely destroyed in the hydrogenolysis reactor.

Volume reduction of solid or debris wastes will be limited by the extent to which head-end processes can separate hazardous components from matrix materials. The combustible debris fraction will not be particularly attacked by this process. There should be no regulated secondary waste produced. The process features a high degree of internal waste recycle and has no waste generating side streams.

\section{Readiness for Deployment}

\section{A-23.3.3 Level of Development and Understanding}

Ranking - High: The process is offered commercially as an integrated transportable (7-10 trailers) system for on-site hazardous waste treatment. Although all of the components have been demonstrated in an integrated hazardous waste treatment system, the process may be difficult to implement in radioactive service. 


\section{A-23.3.4 System Complexity}

Ranking - Low: The integrated Eco Logic hydrogen reduction facility is exceedingly complex. Although relatively simple pretreatment and feeding technologies (filtration, vaporization, atomization) exist for aqueous and organic liquid wastes. Better head-end pretreatment systems must be developed for the process to be effective in treating solid and debris wastes. The flowsheet indicates four fuel fired process heaters (boiler, steam reformer, recirculation gas heater, thermal reduction mill); three high power electric loads (hydrogenolysis reactor, SBV gas heater, SBV chamber heaters); and a multitude of materials handling, processing, and offgas cleanup unit operations performing in mixed batch and continuous modes. Support and auxiliary equipment includes high-power electrical utilities; steam generators and superheaters; process cooling water loops; chemical makeup and adjustment systems for organic and aqueous liquid scrubbers; gas adsorption, stripping, compression and storage systems; and provisions for scrubber sludge separation and stabilization.

Systems handling large quantities of hydrogen and methane will be difficult to adapt to radioactive service. Secondary containment is needed to prevent spread of radionuclides in the event of a breach in primary containment and may provide sites for accumulation of explosive gas mixtures. If the primary containment (process equipment) is operated under negative pressure with respect to the secondary containment, air inleakage would be a significant hazard.

\section{Environmental Health and Safety}

\section{A-23.3.5 Emissions}

Ranking - Medium: . Hydrogenolysis reaction products are comprised primarily of light hydrocarbons (primarily methane and ethylene), plus some $\mathrm{H}_{2} \mathrm{O}, \mathrm{CO}, \mathrm{CO}_{2}$, and acid halogens formed depending on the oxygen, moisture, and halogen content of the waste stream. Significant chemical and thermal energy is contained in Eco Logic process and product gasses. Releases will be correspondingly more frequent and difficult to mitigate. The process features a high degree of internal waste recycle and has no waste generating side streams.

\section{A-23.3.6 Worker Health and Safety}

Ranking - Medium-Low: Eco Logic processing systems will be relatively complex, heavily insulated, housed in multiple large containments, and will feature multiple utility and I\&C connections. Ensuring acceptable risk to maintenance workers will require correspondingly more effort. Hydrogenolysis, thermal desorption, and steam reforming are "high energy" technologies which handle large quantities of hot, reactive, and possibly poisonous gasses. Process equipment is subject to corrosion, erosion and hydrogen embrittlement. High voltage, high power (1.5 MW, 3-phase, 1000 amps) electric service is required to run several unit operations. These features mitigate against operational worker health and safety. Hydrogenolysis, thermal desorption and steam reforming reactions are endothermic. Although considerable energy is contained in the process streams, typical excursions tend to be self limiting. Operation is stable over a very large range of operating conditions. Time constants for major control parameters are long and the system exhibits a large negative thermal coefficient of reactivity. Runaway hydrogenolysis or steam reforming reactions are not possible. Since 
proposed systems will operate near ambient pressure, and presuming adequate inspection and maintenance, sudden and catastrophic containment failures will be unlikely.

\section{A-23.4 References}

1. Eco Logic, "The Eco Logic Process: A Gas Phase Reduction Process for PCB Destruction," Company Literature, ELI Eco Logic International, Inc., Rockwood, Ontario, Canada.

2. G. M. Evans, "Chemical Reduction of PCBs," EPA Tech Trends, EPA/542/N-93/005, May 1993.

3. EPA/540/MR-93/522, "Gas Phase Chemical Reduction; Eco Logic International, Inc.," U. S. EPA Demonstration Bulletin, September 1993. 


\section{Appendix B}

\section{Formation Of Dioxins And Furans In Waste Treatment Systems}

\section{B.1 Formation Conditions for Chlorinated Dibenzo Dioxins and Chlorinated Dibenzo Furans in the Offgas from Thermal Treatment Units.}

Detailed mechanisms have not been fully established in the published literature; however, the necessary steps are reasonably clear. There are three principal sources of dioxin/furan emissions 1 :

1. They can be present in the waste feed and pass through the combustion process without being destroyed,

2. They can be formed in the combustion process as products of incomplete combustion (PICs), and

3. They can be formed de novo in cooler areas downstream of the combustion products from elements and compounds that act as precursors.

\section{Combustion}

Exemplary combustion practices will (1) maximize the destruction of dioxins/furans in the feed, (2) minimize formation of dioxins/furans as PICs, and (3) minimize the formation of compounds that behave as precursor compounds to dioxin/furan formation. The approach to good combustion practice is adequate time ( $>2$ seconds) at high enough temperature $\left(>870^{\circ} \mathrm{C}\right)$, with high turbulence to assure mixing, and sufficient excess oxygen to insure complete oxidation of all organic material. A well designed thermal oxidation system (incinerator and secondary combustor) and air pollution control system can minimize or avoid the production and or release of dioxins or furans by proper reaction chamber design that promotes complete mixing with oxygen, adequate residence time, and reaction of every molecule at sufficiently high temperature.

\section{De Novo Svnthesis}

Dioxin/furan production by de novo synthesis requires four conditions ${ }^{1}$ :

1. Organic precursors, primarily aromatic hydrocarbons, present in the gas stream,

2. A source of chlorine $\left(\mathrm{Cl}_{2}\right)$, such as $\mathrm{HCl}$, in the gas stream.

3. A source of free oxygen $\left(\mathrm{O}_{2}\right)$ in the gas phase. 
4. Significant quantities of metal-containing particulates and adequate reaction time within the required temperature range during off-gas cooling for the appropriate sequence of reactions to occur.

If these conditions are met, dioxins can be formed de novo in those offgas streams that are cooled slowly through the $350^{\circ} \mathrm{C}$ to $250^{\circ} \mathrm{C}$ range, or in those offgas streams in which particulates are held up in this temperature range 2 . Gas streams that are quenched rapidly through this range produce less or no detected dioxins or furans.

Precursors: The presence of aromatics or partially oxygenated aromatics is characteristic of the offgas from combustion processes. Flame chemistry produces ethylene radicals that combine to form benzene and higher level fused-ring aromatics such as naphthalene, anthracene, phenanthrene, etc. These can then become partially oxygenated to produce phenol-like compounds. Benzene and higher fused-ring aromatics (polycyclic aromatic hydrocarbons or PAHs) are common PICs at the 0.1 to $1 \mathrm{ppb}$ level.

Additional precursors may form if all organic components are not exposed to combustion temperatures for a sufficient period of time, or if there is insufficient turbulence to provide adequate fuel/air mixing. Such conditions may occur during upset conditions caused by variations in the waste input rate or composition.

A Source of Chlorine: Chlorine as $\mathrm{Cl}_{2}$ is an effective chlorinating agent for addition of chlorine atoms to aromatic hydrocarbons. The current thought is that metals in the particulates, primarily bivalent copper $\left(\mathrm{Cu}^{+2}\right)$ and possibly others such as iron or zinc, catalyze the formation of $\mathrm{Cl}_{2}$ from $\mathrm{HCl}$. The metal-catalyzed reaction is the basis of a historical industrial $\mathrm{Cl}_{2}$ production process, the Deacon process. The $\mathrm{Cl}_{2}$ formed can then easily chlorinate any organic compound by hydrogen abstraction. If some of these organic compounds (precursors) are aromatics, or partially oxygenated aromatics, all the ingredients for dioxin/furan formation exist. Few reactions are required to achieve picogram $/ \mathrm{m}^{3}$ quantities of dioxin/furan congeners.

A Source of Oxygen: Increasing concentrations of free oxygen $\left(\mathrm{O}_{2}\right)$ from 0 to $10 \%$ have been shown to increase the production of dioxins and furans via the Deacon reaction to produce free chlorine $\left(\mathrm{Cl}_{2}\right)$ from $\mathrm{HCl}$ (i.e., $2 \mathrm{HCl}+1 / 2 \mathrm{O}_{2} \Leftrightarrow \mathrm{Cl}_{2}+\mathrm{H}_{2} \mathrm{O}$ ) 3, 4, 5. Free $\mathrm{O}_{2}$ appears critical to the formation of dioxins or furans, and there is an indication that the absence of $\mathrm{O}_{2}$ promotes the decomposition of dioxins and furans via a dechlorination/hydrogenation reaction 5 .

Particulates and Reaction Time: Particulates provide a reaction surface for the chlorination of organic precursors and for combination reactions among undestroyed organics that may escape combustion and pass on to the APC system. Even in well designed combustion systems, turbulence and excess air required to insure mixing and exposure to oxygen, contribute to high particulate content of the offgas and significant offgas volumes. An example of "particulate surface" that has been shown to be quite effective is the fireside surface of boiler tubes in steam generating facilities, especially municipal solid waste incinerators. Here, the particulate material from the combustion process has been deposited on the tubes in a manner to create a porous surface with a very large surface area for reaction.

The most important aspect of the particulate (or flyash) involvement is holdup at temperatures in the $250^{\circ} \mathrm{C}$ to $350^{\circ} \mathrm{C}$ range. The holdup is important because de novo synthesis reaction times are of the order of minutes. This holdup in the correct temperature range occurs on 
waste heat boiler tubes in municipal incinerators (as described above) or in hot electrostatic precipitators or high temperature $\left(>200^{\circ} \mathrm{C}\right)$ baghouses in other combustion systems. Because the holdup at temperature is important, waste combustion systems that rapidly quench offgas from combustion temperatures $\left(870\right.$ to $\left.1,200^{\circ} \mathrm{C}\right)$ to saturation temperature of about $80^{\circ} \mathrm{C}$ are low dioxin/furan emission systems.

\section{B.2 Dioxin and Furan Production in Thermal Non-Incinerator and Condensed Phase Processes}

Thermal non-incinerator processes include pyrolysis, destructive distillation in the presence of limited oxygen, and wet air oxidation. Reactions in these systems occur at elevated temperatures with a limited availability of oxygen so that partial degradation or partially oxygenated fragments can be formed readily as part of the destruction process. Oxygen may also be provided by steam added to the reaction process (e.g., steam reforming). Under these conditions it is possible to produce dioxin/furan precursors; however, free $\mathrm{O}_{2}$ in the gas phase appears critical to the formation of dioxins and furans. The limited amount of steam or oxygen added produces a very low net offgas product, and the relatively quiescent mode of operation produces few particulates in the offgas. In some non-incinerator processes the offgas is as much as an order-of-magnitude less than the gas from an excess air combustion process. There has been little or no testing of effluents for dioxins or furans reported in these non incinerator processes; however, the low offgas volume lends itself to removal of particulates and $\mathrm{HCl}$ prior to secondary thermal oxidation of the combustible offgas or cooling of the hot offgas thereby minimizing the potential for dioxin/furan formation.

Formation of dioxins and furans has also been observed in aqueous systems under conditions of aggressive chlorination in the presence of aromatic hydrocarbons. Examples include bleaching of wood pulp with chlorine, and use of hypochlorite for disinfection of water containing phenol. Dioxins may also form under slow aqueous phase destruction of aromatic organo chlorides where free radical recombination is probable. Although dioxins and furans are known to be formed in some aqueous phase systems they have not been reported as being present in the results for the alternative technologies included in this survey. For some of the technologies it is known that analyses for dioxins and furans have not been made. 


\section{References}

1. P. Acharya, S. G. DeCicco and R. G. Novak, "Factors that can Influence and Control the Emissions of Dioxins and Furans from Hazardous Waste Incinerators," Journal of the Air and Waste Management Association, Vol. 41, No. 12, pp. 1605-1615, December 1991.

2. L. Waterland, personal communication, December $18,1996$.

3. L. Stieglitz, et al., "On the de novo synthesis of PCDD/PCDF on Flyash of Municipal Waste Incinerators," Chemosphere, Vol. 18, Nos. 1-6, pp. 1219-1226, 1989.

4. B. K. Gullet, P. M. Lemieux, and J. E. Dunn, "Role of Combustion and Sorbent Parameters in Prevention of Polychlorinated Dibenzo-p-dioxin and Polychlorinated Dibenzofuran Formation During Waste Combustion," Environmental Science Technology, Vol. 28, pp. 107-118, 1994.

5. H. Hagenmaier, et al., Environmental Science Technology, Vol. 21, pp. 1080-1084, 1987. 


\section{Appendix C}

\section{Definitions Of Thermal And Nonthermal Systems}

\section{Regulatory Setting for Thermal Treatment}

RCRA regulations define thermal treatment ( 40 CFR 260.10) as follows:

"Thermal treatment means the treatment of hazardous waste in a device which uses elevated temperatures as a primary means to change the chemical, physical, or biological character or composition of the hazardous waste. Examples of thermal treatment processes are, incineration, molten salt, pyrolysis, calcination, wet air oxidation, and microwave discharge. (See also "incinerator" and "open burning".)"

"Incinerator means any enclosed device that:

1) Uses controlled flame combustion and neither meets the criteria for classification as a boiler, sludge dryer, or carbon regeneration unit, nor is listed as an industrial furnace: or

2) Meets the definition of infrared incinerator or plasma arc incinerator."

"Infrared incinerator means any enclosed device that uses electric powered resistance heaters as a source of radiant heat followed by an afterburner using controlled flame combustion which is not listed as an industrial furnace."

"Plasma arc incinerator means any enclosed device using a high intensity electrical discharge or arc as a source of heat followed by an afterburner using controlled flame combustion which is not listed as an industrial furnace."

In the alternative treatment standards for debris, Debris Rule, some clarification and sorting of technologies is presented. (40 CFR 268.45, Table 1) as follows:

"B. Destruction Technologies:

3) Thermal Destruction: Treatment in an incinerator operating in accordance with Subpart $O$ of Parts 264 or 265 of this chapter, a boiler or industrial furnace operating in accordance with Subpart X, Part 264 of this chapter, or Subpart P, Part 265 of this chapter, but excluding for purposes of these debris treatment standards Thermal Desorption units."

"A. Extraction Technologies

3. Thermal extraction

b) Thermal Desorption: Heating in an enclosed chamber under either oxidizing or nonoxidizing atmospheres at sufficient temperature and residence time to vaporize hazardous contaminants from contaminated surfaces and surface 
pores and to remove the contaminants for the heating chamber in a gaseous exhaust gas."

Thermal treatment units (TTUs) include processes for separation of materials or thermal extraction, (e.g. thermal desorption) and for organic destruction (e.g. any of the many types of incinerators and boilers, microwave discharge, pyrolysis, and wet air oxidation). Thermal organic destruction technologies are divided into incinerators and non-incinerators. While nothing in these combined definitions establish temperatures guidelines, flame operation ("controlled flame combustion") and pyrolysis imply high temperatures. Both of these sets of thermal organic destruction processes use elevated temperatures and free oxygen as the means of degradation/destruction of organics.

Thus we have TTUs categorized as:

- Materials separation (e.g., thermal desorption);

- Organic destruction: incinerator - plasma arc, controlled air, rotary kiln;

- Organic destruction: non-incinerator - pyrolysis, wet air oxidation, etc..

Although EPA's list of non-incinerator organic thermal destruction units do not include molten glass, molten metal, and steam reforming, they should also be included. However, in molten glass and molten metal systems organics are rapidly vaporized and organic destruction occurs primarily in the gas phase above the melt.

Elsewhere in the regulations, requirements are imposed on the operation of these technologies to provide for destruction of hazardous organic constituents.

\section{Proposed Definition of Non-Thermal Treatment}

A definition of non thermal treatment which parallels the definitions provided by EPA is:

Non-thermal treatment means the destruction of hazardous organic waste in a device which uses chemical or electrochemical oxidants other than oxygen or air as the primary means to change the chemical, physical, or biological character or composition of the hazardous waste. Moderate increases in temperature may be used to accelerate the rates of the organic destruction reactions but gas phase oxidation or pyrolytic degradation with or without combustion flames or plasma arcs is not included in these systems. Examples of non-thermal treatment processes are, electrochemical oxidation, aqueous phase UV photolysis, systems of oxidation of organic materials based on the use of Fenton's reagent, aqueous phase oxidation with strong inorganic oxidants. Examples of strong inorganic oxidants are nitric acid, permanganate, $\mathrm{Ag}^{2+}, \mathrm{Ce}^{2+}$, perchlorate, peroxy disulfate, and dichromate. 